SILVIA REGINA TRAVAGLIA CARDOSO

HISTÓRIA NATURAL DAS SERPENTES DA REGIÃO DE MUNHOZ, SUL DE MINAS GERAIS, SERRA DA MANTIQUEIRA

Tese apresentada ao Programa da Pós-

Graduação Interunidades em Biotecnologia

USP/Instituto Butantan/IPT, para obtenção

do Título de Doutor em Biotecnologia.

São Paulo

2011 
SILVIA REGINA TRAVAGLIA CARDOSO

\title{
HISTÓRIA NATURAL DAS SERPENTES DA REGIÃO DE MUNHOZ, SUL DE MINAS GERAIS, SERRA DA MANTIQUEIRA
}

\author{
Tese apresentada ao Programa da Pós- \\ Graduação Interunidades em Biotecnologia \\ USP/Instituto Butantan/IPT, para obtenção \\ do Título de Doutor em Biotecnologia. \\ Área de concentração: Biotecnologia \\ Orientador: Selma Maria de Almeida Santos \\ Versão Original
}

São Paulo

2011 
DADOS DE CATALOGAÇÃO NA PUBLICAÇÃO (CIP)

Serviço de Biblioteca e Informação Biomédica do

Instituto de Ciências Biomédicas da Universidade de São Paulo

(C) reprodução total

Travaglia-Cardoso, Silvia Regina.

História natural das serpentes da região de Munhoz, sul de Minas

Gerais, Serra da Mantiqueira. / Silvia Regina Travaglia Cardoso. --

São Paulo, 2011.

Orientador: Selma Maria de Almeida Santos.

Tese (Doutorado) - Universidade de São Paulo. Instituto de Ciências Biomédicas. Programa de Pós-Graduação Interunidades em

Biotecnologia USP/IPT/Instituto Butantan. Área de concentração:

Biotecnologia. Linha de pesquisa: Herpetologia.

Versão do título para o inglês: Natural history of the snakes from the Munhoz region, south of Minas Gerais, Serra da Mantiqueira.

Descritores: 1. História Natural 2. Diversidade 3 . Serra da Mantiqueira 4. Serpentes 5. Viperidae 6. Reprodução I. Santos, Selma Maria de Almeida II. Universidade de São Paulo. Instituto de Ciências Biomédicas. Programa de Pós-Graduação Interunidades em Biotecnologia USP/IPT/Instituto Butantan III. Título. 


\section{UNIVERSIDADE DE SÃO PAULO}

Programa de Pós-Graduação Interunidades em Biotecnologia

Universidade de São Paulo, Instituto Butantan, Instituto de Pesquisas Tecnológicas

Candidato(a): $\quad$ Silvia Regina Travaglia Cardoso.

Título da Tese: $\quad$ História natural das serpentes da região de Munhoz, sul de Minas Gerais, Serra da Mantiqueira.

Orientador(a): $\quad$ Selma Maria de Almeida Santos.

A Comissão Julgadora dos trabalhos de Defesa da Tese de Doutorado, em sessão pública realizada a considerou

\section{( ) Aprovado(a) ( ) Reprovado(a)}

\begin{tabular}{|c|c|}
\hline Examinador(a): & $\begin{array}{l}\text { Assinatura: } \\
\text { Nome: ........ } \\
\text { Instituição: }\end{array}$ \\
\hline Examinador(a): & $\begin{array}{l}\text { Assinatura: } \\
\text { Nome: ........ } \\
\text { Instituição: }\end{array}$ \\
\hline Examinador(a): & $\begin{array}{l}\text { Assinatura: } \\
\text { Nome: ........ } \\
\text { Instituição: }\end{array}$ \\
\hline Examinador(a): & $\begin{array}{l}\text { Assinatura: } \\
\text { Nome: ........ } \\
\text { Instituição: }\end{array}$ \\
\hline Presidente: & $\begin{array}{l}\text { Assinatura: } \\
\text { Nome: ........ } \\
\text { Instituição: }\end{array}$ \\
\hline
\end{tabular}




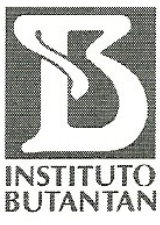

COMISSÃO DE ÉTICA NO USO DE ANIMAIS

INSTITUTO BUTANTAN

Av. Vital Brazil, 1500, CEP 05503-900, São Paulo, SP, Brazil

Telefone: (55) (011) 3726-7222 ramal 2106 - Fax: (55) (011) 3726-1505

\section{CERTIFICADO}

( $2^{a}$ VIA)

Certificamos que o Projeto intitulado "Estratégias reprodutivas e dieta de Bothrops neuwiedi (Wagler,1824) da Serra da Mantiqueira" protocolo $n^{\circ}$ 044/01, sob a responsabilidade de Silvia Regina Travaglia Cardoso, está de acordo com os Princípios Éticos na Experimentação Animal adotado pelo Colégio Brasileiro de Experimentação Animal (COBEA), e foi aprovado pela COMISSÃO DE ÉTICA NO USO DE ANIMAIS DO INSTITUTO BUTANTAN (CEUAIB) em reunião de $02 / 2002$

\begin{tabular}{|c|c|}
\hline $\begin{array}{c}\text { Vigência do Projeto: } \\
2002-2003\end{array}$ & $\mathbf{N}^{\circ}$ de animais/espécie \\
\hline Laboratório de Herpetologia & 90 serpentes Bothrops neuwiedi \\
\cline { 2 - 2 }
\end{tabular}

São Paulo, 30 de junho 2011.

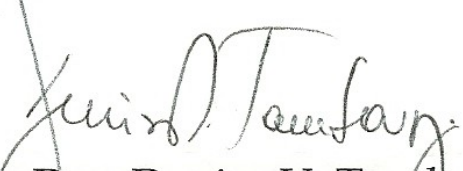

Dra. Denise V. Tambourgi Presidente da CEUAIB 
A meus queridos pais

\section{Maria Cecília e Wanderley,}

por tudo... 


\section{AGRADECIMENTOS}

À Selma Maria de Almeida Santos pela orientação, pelo incentivo, pela confiança em meu trabalho, e por dividir seu conhecimento sempre com alegria e entusiasmo. Obrigada pela amizade ao longo de todos esses anos de Instituto Butantan.

Ao Sr. Nelson Nomura, Sra. Laura Nomura, Celso Nomura, Fabio Nomura e demais membros da família Nomura, proprietários da Fazenda Santa Elisa, por permitir que esse trabalho fosse realizado em sua propriedade, por proporcionar todo o apoio logístico, pelo incentivo e por receber com muito carinho a mim e a meus amigos do Instituo Butantan. Agradecimento especial ao amigo Celso Nomura por todo o apoio, ajuda na coleta das serpentes, informações sobre a Fazenda Santa Elisa e pelo constante transporte das serpentes para São Paulo. Ao Sr. Antonio G. Laurentino pela coleta de inúmeras serpentes, pelo cuidado dispensado aos animais até o transporte para São Paulo, por recolher e acondicionar as serpentes mortas e atropeladas e por todo auxilio durante minha permanência na Fazenda Santa Elisa. A todos os funcionários e colaboradores da fazenda pela disponibilidade em não matar as serpentes e entregar os animais encontrados na sede da fazenda.

Ao grande amigo Celso Morato de Carvalho pelas críticas e sugestões, que foram de grande importância para este trabalho.

À Circe Cavalcanti de Albuquerque pela amizade e pelos inúmeros auxílios, sempre com alegria e boa vontade. Sua ajuda com as referências bibliográficas na fase final deste trabalho foi muito importante. Às amigas Danusa Camanduchy Maia e Patricia Marchioretto Rossi por assumirem com carinho minha rotina com as serpentes no Laboratório de Herpetologia. A vocês, meu muito obrigada.

Aos amigos e colegas pela imensa ajuda durante os trabalhos de campo: Adriana Rafael, Antonino Laurentino, Bruno Almoinha, Celso Nomura, Circe C. de Albuquerque, Elaine R. da Cunha, Fabio Nomura, João Paulo N. Pitam, Laura Narvaes, Patricia Abujanra, Paulo S. Garrubo e Selma M. de Almeida Santos. 
Aos amigos de tantos anos de Instituto Butantan, Marisa Maria Teixeira da Rocha, Maria de Fátima Domingues Furtado, Wilson Fernandes, Giuseppe Puorto, Mariza de Lima, Radenka Francisca Batistic, Eliana de O. Serapicos, Thelia R.F.J.Cinquini, Maria da Graça Salomão e Patricia Abujanra, que de inúmeras maneiras contribuíram para a realização deste trabalho.

Ao Claudio Augusto Rojas pela confecção das fotomicrografias.

Ao Miguel Trefaut U. Rodrigues pela identificação do lagarto ingerido pela serpente.

Aos amigos e colegas do Laboratório de Herpetologia do Instituto Butantan: Valdir, Kathleen, Sávio, Rosângela, Antonio, Solange, Marcelo, Kiko, Mirian, Lucia, Valério, Carlos, Luan, Cintia, Soma, João, Antonio Carlos, Vera, Helena, Claudio, Eladio, Amauri, Renato, Josianne, Rafael, Bruno, Mayara e demais funcionários e estagiários pelo agradável convívio diário.

À todos os colegas do grupo de reprodução do Laboratório de Ecologia e Evolução do Instituto Butantan.

Ao meu irmão Wanderley e a todos meus familiares por todo o carinho. Meu muito obrigada! 


\section{RESUMO}

TRAVAGLIA-CARDOSO S.R. História natural das serpentes da região de Munhoz, Sul de Minas Gerais, Serra da Mantiqueira [Tese (Doutorado em Biotecnologia)]. Instituto de Ciências Biomédicas, Universidade de São Paulo, São Paulo, 2011.

Pouco se sabe sobre a herpetofauna das regiões mais elevadas da Serra da Mantiqueira, uma das porções mais altas e acidentadas do território brasileiro. Este estudo foi desenvolvido em uma área ao sul de Minas Gerais, na Serra da Mantiqueira, região com predomínio das Florestas Ombrófilas Densas, Florestas Ombrófilas Mistas (Floresta de Araucárias) e Campos de Altitude. Foram estudados aspectos biológicos e ecológicos de uma comunidade de serpentes, caracterizando a riqueza, a abundância e o uso do ambiente, além da história natural das espécies, por meio da caracterização do ciclo e das estratégias reprodutivas, padrões de atividade, comportamento, dieta, e analises da morfometria de adultos e filhotes. Foram listadas 11 espécies de serpentes, e constatada a superioridade numérica de indivíduos da família Viperidae em relação à família Dipsadidae. As áreas abertas foram as mais freqüentadas pelos indivíduos, além de mostrar maior riqueza de espécies. Um percentual significativo das espécies encontradas apresenta a viviparidade como modo reprodutivo, fato incomum em comunidades de serpentes neotropicais. A altitude mostrou influenciar a distribuição e abundância das espécies. As três espécies mais abundantes foram os viperídeos B. neuwiedi, B. jararaca e C. durissus, e são apresentadas informações de sua história natural. As fêmeas são maiores e mais robustas do que os machos. Entre filhotes, o dimorfismo sexual não ocorre ou é restrito a uma variável morfométrica. Foi observado aumento na atividade das fêmeas nos períodos de primavera e verão, e dos machos no outono. As fêmeas parecem ser mais agressivas, exibindo um maior repertório de estratégias de defesa. As três espécies alimentam-se preferencialmente de pequenos mamíferos. A espermatogênese e a vitelogênese são sazonais, e machos e fêmeas estocam espermatozóides no trato genital a fim de harmonizarem seus ciclos. O nascimento dos filhotes ocorre no verão. A espécie $B$. jararaca é maior e mais robusta do que $B$. neuwiedi, e as fêmeas de $B$. jararaca produzem ninhadas maiores e mais pesadas.

Palavras-chave: História natural. Diversidade. Serra da Mantiqueira. Serpentes. Viperidae. Reprodução. 


\begin{abstract}
TRAVAGLIA-CARDOSO, S.R. Natural history of the snakes from the Munhoz region, south of Minas Gerais, Serra da Mantiqueira. 2011. Master thesis (Biotechnology) Instituto de Ciências Biomédicas, Universidade de São Paulo, São Paulo, 2011.

Little is known about the snakes population in the higher elevations of the Serra da Mantiqueira, one of the highest and most rugged portion in the Brazilian territory. This study was conducted in the Serra da Mantiqueira, south of Minas Gerais in an area dominated by Atlantic Forest, Araucaria Forest and altitude grasslands. The study show biological and ecological aspects within a community of snakes by analyzing the richness, the abundance, as how the environment was used and into the natural history of species though characterization of reproductive strategies, activity patterns, behavior, diet and morphometric analyses of young and adult snakes. Eleven species were found. The snakes was mostly found in open areas, and open areas also showed a greater richness of species. A significant percentage of the species reproduced by viviparity, a fact that is not so common among neotropical snakes. Altitude influenced the abundance and distribution of the species. The three dominant species of snakes was B. neuwiedi, B jararaca and $C$. durissus. Females are bigger and stronger then the males. Among the young, sexual dimorphism does not happen or it is restricted. Females also showed increased activity during the spring and summer, whiles males had increased activity levels during the autumn months. Females were more aggressive and showed a wider range in defense strategy. These three species feed primarily on small mammals. Spermatogenesis and vitellogenesis are seasonal, and males and females show sperm storage in the genital tract so their cycles are harmonized. B. jararaca is bigger and stronger than B. neuwiedi, and female $B$. jararaca have larger and heavier litters.
\end{abstract}

Key words: Natural History. Diversity. Serra da Mantiqueira. Snakes. Viperidae. Reproduction. 


\section{SUMÁRIO}

1 Cap. 1 - Composição faunística e história natural das serpentes da região de Munhoz, Sul de Minas Gerais, Serra da Mantiqueira

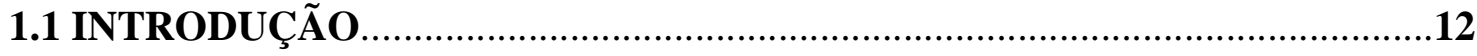

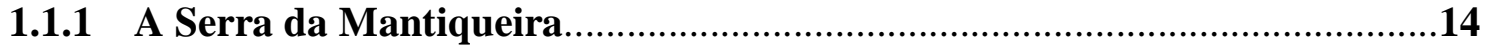

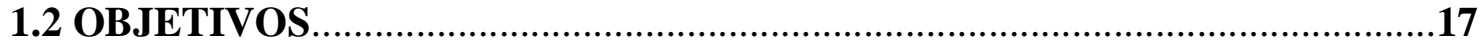

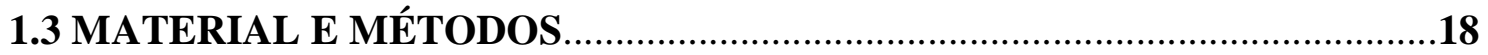

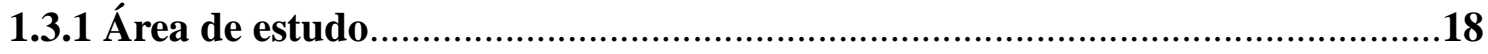

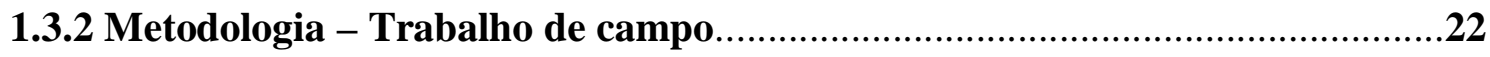

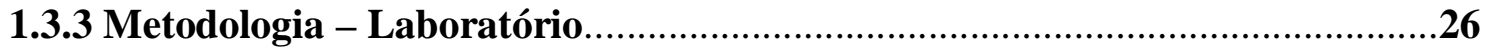

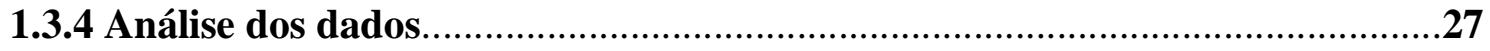

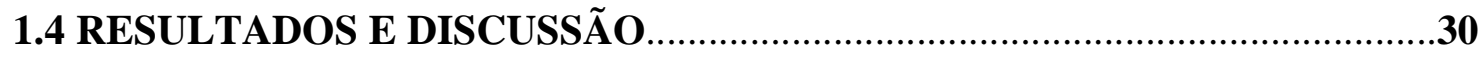

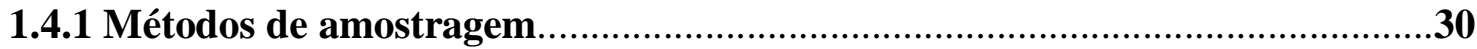

1.4.2 Comunidade de serpentes, Fazenda Santa Elisa, Munhoz, MG (Grupo 1)....33

1.4.3 História natural - Família Dipsadidae................................................51

1.4.4 Composição da comunidade de serpentes da região de Munhoz, Sul de

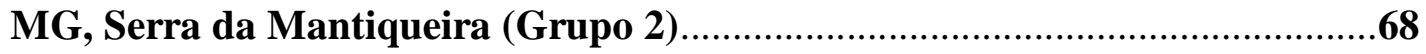

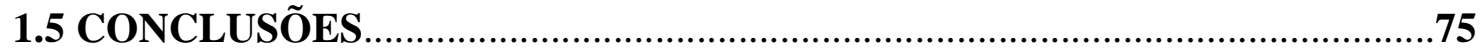

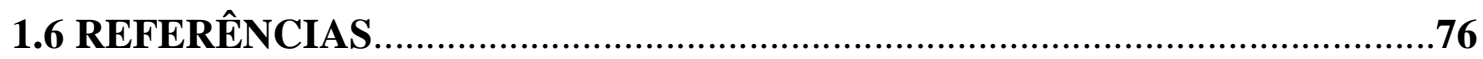

1.7 ANEXOS 


\section{CAPÍTULO 1}

COMPOSIÇÃO FAUNÍSTICA E HISTÓRIA NATURAL DAS SERPENTES DA REGIÃO DE MUNHOZ, SUL DE MINAS GERAIS, SERRA DA MANTIQUEIRA 


\subsection{INTRODUÇÃO}

Este estudo é sobre comunidades de serpentes, desenvolvido por meio de observações sobre a história natural das espécies e uso dos habitats disponíveis para os indivíduos. Uma forma clássica de focar comunidades é por meio da composição de espécies que integram as populações locais, das suas inter-relações ecológicas, e da distribuição das espécies dentro de uma formação vegetal ou, mais amplo ainda, abrangendo vários ambientes e ecossistemas (VANZOLINI, 1970; VANZOLINI e WILLIANS, 1970; POUGH et al., 2001). As comunidades e seus componentes são variáveis e dinâmicos, e apresentam variações dentro da área de distribuição das espécies, uso do espaço pelos indivíduos, e também nos aspectos reprodutivos e comportamentais (SAWAYA, 2004; BERNARDE e ABE, 2006). O clima e a altitude são dois fatores que podem influenciar estas variações (POUGH et al., 2001).

Entre os grupos de animais que constituem bons modelos para se entender comunidades, devido à riqueza de espécies e ampla distribuição geográfica, estão as serpentes, estudadas sob diferentes aspectos em várias partes do mundo (SEIGEL e FORD, 1987; POUGH et al., 2001). Estudos com serpentes, do ponto de vista ecológico, começaram a ter maior repercussão após a década de 60, principalmente nas Américas do Norte e Central, focando aspectos sobre concorrência entre as espécies e segregação do nicho, comportamento, reprodução e distribuição geográfica (FITCH, 1970; DUELLMAN, 1978; SEIGEL, 1984).

No Brasil, Vanzolini foi um dos primeiros herpetólogos a abordar os aspectos biológicos e ecológicos de serpentes, mais especificamente a diversidade das espécies relacionadas aos ambientes imediatos, em relato sobre os répteis da Cachoeira de Emas, na região de Pirassununga, em São Paulo (VANZOLINI, 1948).

Posteriormente, tivemos os relatos de Hoge (1952a,b) sobre distribuição geográfica de diversos grupos de serpentes; os estudos de Vitt e Vangilder (1983) sobre as serpentes de Exu, Pernambuco; e os relatos de Vanzolini, Ramos-Costa e Vitt (1980) sobre as serpentes da caatinga, com informações sobre dieta, ecologia, reprodução e distribuição 
geográfica. Ainda na caatinga, os trabalhos de Rodrigues (1992, 1993, 1996) sobre a ofidiofauna das dunas do rio São Francisco, na Bahia, foram fundamentais para o conhecimento da biologia e da distribuição da fauna de répteis fossoriais nos vários ambientes.

Na região amazônica foi realizado um longo estudo sobre as serpentes da região leste do Pará, o primeiro a abordar de forma ampla a distribuição das serpentes na Amazônia (CUNHA e NASCIMENTO, 1978). Ainda na região amazônica há os relatos sobre a história natural e ecologia das serpentes da Reserva Ducke, em Manaus, realizado por Martins (1994), e a história natural de uma comunidade de serpentes de Rondônia, um estudo realizado por Bernarde (2004).

As serpentes do Pantanal foram o objeto de estudo de Strüsmann e Sazima (1993), sendo relatados aspectos ecológicos e de história natural das espécies encontradas.

As serpentes do cerrado foram abordadas principalmente em dois estudos. O primeiro relata a ecologia comparada de espécies do cerrado do Brasil Central e região sudeste (NOGUEIRA, 2001); e o segundo foi realizado na região de Itirapina, São Paulo, fornecendo informações detalhadas sobre a ecologia e a história natural das espécies encontradas (SAWAYA, 2004).

Sobre as serpentes da Mata Atlântica há diversos trabalhos. Marques (1998) estudou a composição faunística e a história natural de serpentes da região da Juréia, fornecendo detalhes sobre a abundância, reprodução e dieta das espécies amostradas. Em outra região da Mata Atlântica, no Parque Estadual da Serra do Mar, Hartmann, Hartmann e Martins (2009), estudaram as relações ecológicas e a biologia das espécies da localidade. A composição e a diversidade dos Squamata em remanescentes da Floresta Estacional Semidecidual, no estado de São Paulo, foram recentemente relatadas por Pereira (2010). No contato entre a Mata Atlântica e a caatinga há os relatos de Carvalho, Vilar e Oliveira (2005), que estudaram a herpetofauna do Parque Nacional Serra de Itabaiana, Sergipe, uma região com fragmentos de mata e áreas abertas, cujos ambientes influenciam no uso dos habitats pelas serpentes. 
Outras regiões de Mata Atlântica que tem sido objeto de estudo sobre as serpentes são os ecossistemas litorâneos, com vários relatos sobre a diversidade de répteis do litoral de São Paulo. Por exemplo, a Ilha de São Sebastião (CENTENO, 2008), a Ilha Anchieta, em Ubatuba (CICCHI et al., 2009), e as serpentes de ilhas costeiras do estado de São Paulo (CICCHI et al., 2007). Estes estudos ampliaram o conhecimento sobre as comunidades de serpentes que habitam ilhas.

Apesar dos conhecimentos sobre a herpetofauna dos vários ecossistemas brasileiros terem avançado significativamente, ainda há muitas lacunas. Por exemplo, poucos trabalhos abordam as comunidades de serpentes nas áreas compreendidas pelas Florestas de Araucárias e ecossistemas associados a esta formação vegetal. Estudos sobre estas regiões se restringem ao Sul do Brasil, com os relatos da composição faunística e os padrões de distribuição das serpentes das Florestas de Araucárias (MORATO, 1995), a historia natural de uma comunidade de serpentes do Planalto das Araucárias (DI-BERNARDO, 1998), e os répteis da Floresta de Araucárias e ecossistemas associados do Parque Nacional de Aparados da Serra, Rio Grande do Sul (DEIQUES, 2009). Em relação aos enclaves das Florestas de Araucárias e ecossistemas associados que ocorrem nas regiões elevadas da Serra da Mantiqueira, principalmente em Minas Gerais, não temos informações relacionadas à fauna ofídica.

Dessa forma, este estudo descreve a composição faunística das serpentes, do ponto de vista da riqueza de espécies, o uso dos habitats disponíveis e a história natural das espécies de serpentes que ali vivem. Este trabalho pretende contribuir com conhecimentos sobre a distribuição das serpentes nos vários ambientes, além de auxiliar em futuros projetos relacionados à conservação das espécies que habitam as Florestas de Araucárias e ecossistemas associados. Este estudo foi desenvolvido em áreas de altitude da Serra da Mantiqueira, no sul de Minas Gerais. 


\subsubsection{A Serra da Mantiqueira - Sul de Minas Gerais}

A Serra da Mantiqueira integra o Domínio Tropical Atlântico, e compreende um maciço rochoso com grandes extensões onde a altitude varia entre 1.000 a 3.000 metros, ao longo das divisas dos estados de São Paulo, Rio de Janeiro e Minas Gerais (HUECK, 1972; AB `SABER, 2003). É uma das regiões mais altas do Brasil, sendo considerada a porção mais acidentada do território brasileiro, caracterizada principalmente por clima tropical úmido de altitude e domínio quase absoluto da Floresta Atlântica (AB'SABER e BERNARDES, 1958).

A variação da altitude é um dos principais parâmetros ambientais, capaz de influenciar o crescimento e alterar a composição florística e a fisionomia das formações vegetais (MEIRELES; SHEPHERD; KINOSHITA, 2008). A altitude, a precipitação e a temperatura, são os principais fatores associados às variações florestais do sudeste do Brasil (OLIVEIRA-FILHO e FONTES, 2000). As variações na altitude, além de atuar sobre as formações vegetais, influenciam também na composição, abundância e distribuição das espécies animais (MEIRELES; SHEPHERD; KINOSHITA, 2008; VASCONCELOS e D’ANGELO NETO, 2009; MALLET-RODRIGUES et al., 2010).

O sul de Minas Gerais apresenta interessantes variações fitofisionômicas decorrentes de condições diversas do clima, solos, altitude e relevo, mostrando uma floresta distinta, associada a climas mais frios e composta por espécies geograficamente restritas que cobrem as regiões elevadas da Mantiqueira e o maciço do Itatiaia (AZEVEDO, 1962; LEITÃO FILHO, 1982). Assim, nas áreas altas da Serra da Mantiqueira no sul de Minas Gerais predominam as Florestas Ombrófilas Densas Alto-Montanas e Florestas Ombrófilas Mistas Alto-Montanas (Floresta de Araucárias). Ocorrem nestas áreas afloramentos rochosos e Campos de Altitude, que atualmente representam a formação mais impactada e descaracterizada pela ação humana (MEIRELES; SHEPHERD; KINOSHITA, 2008). As florestas se expandem pelos grotões e vales situados entre 1100-1300 metros, deixando as plataformas mais elevadas cobertas pelos Campos de Altitude, entremeadas pelas Florestas 
de Araucárias, que diversificam e individualizam a paisagem das terras altas do sudeste (AB'SABER e BERNARDES, 1958).

As araucárias no Brasil estão presentes em fragmentos nas regiões mais altas da Serra da Mantiqueira em áreas que variam ao longo de sua distribuição. Em São Paulo (principalmente Campos do Jordão), Rio de Janeiro, Minas Gerais e Espírito Santo, as araucárias ocorrem entre 1200 e 2000m de altitude (HUECK, 1972; FURLAN e NUCCI, 1999; PARODI, 2002; AB`SABER, 2003). No sul do Brasil, onde é encontrada a maior porção contínua desta formação vegetal, a altitude varia entre 700-1000m, no Planalto sulriograndense (LEITE, 2002).

As áreas atualmente ocupadas pela Floresta de Araucária e ecossistemas associados constituem refúgios, e abrigam espécies animais restritas a altitudes elevadas da Serra da Mantiqueira, algumas raras e outras ameaçadas de extinção pela crescente degradação de seus habitats. Devido às alterações climáticas e ao alto nível de perturbação causada pela exploração de madeira, pecuária e introdução de espécies exóticas, como o Pinus (BAUERMANN e BEHLING, 2009), a tendência é que essas florestas fiquem cada vez mais confinadas em áreas menores. Atualmente, menos de $5 \%$ da área original coberta pela Floresta Ombrófila Mista ainda é coberta por remanescentes desse tipo florestal (BACKES, 2009). 


\subsection{MATERIAL E MÉTODOS}

\subsection{1 Área de estudo}

A região analisada neste estudo compreende o município de Munhoz $\left(22^{\circ} 36^{\prime} \mathrm{S}\right.$, $46^{\circ} 21^{\prime} \mathrm{W}$ ), Minas Gerais e cidades limítrofes. O município de Munhoz (1235m de altitude média) possui aproximadamente 6.500 habitantes (IBGE, 2009) e faz divisa com os municípios mineiros de Bueno Brandão (22 $26^{\circ} \mathrm{S}, 4^{\circ} 21^{\prime} \mathrm{W}$; 1182m), Itapeva ( $22^{\circ} 46^{\prime} \mathrm{S}$,

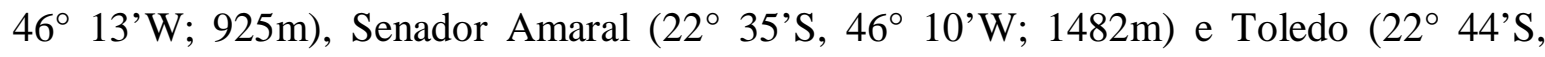

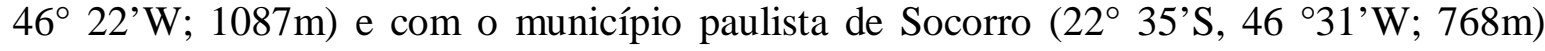
(Figura 1).
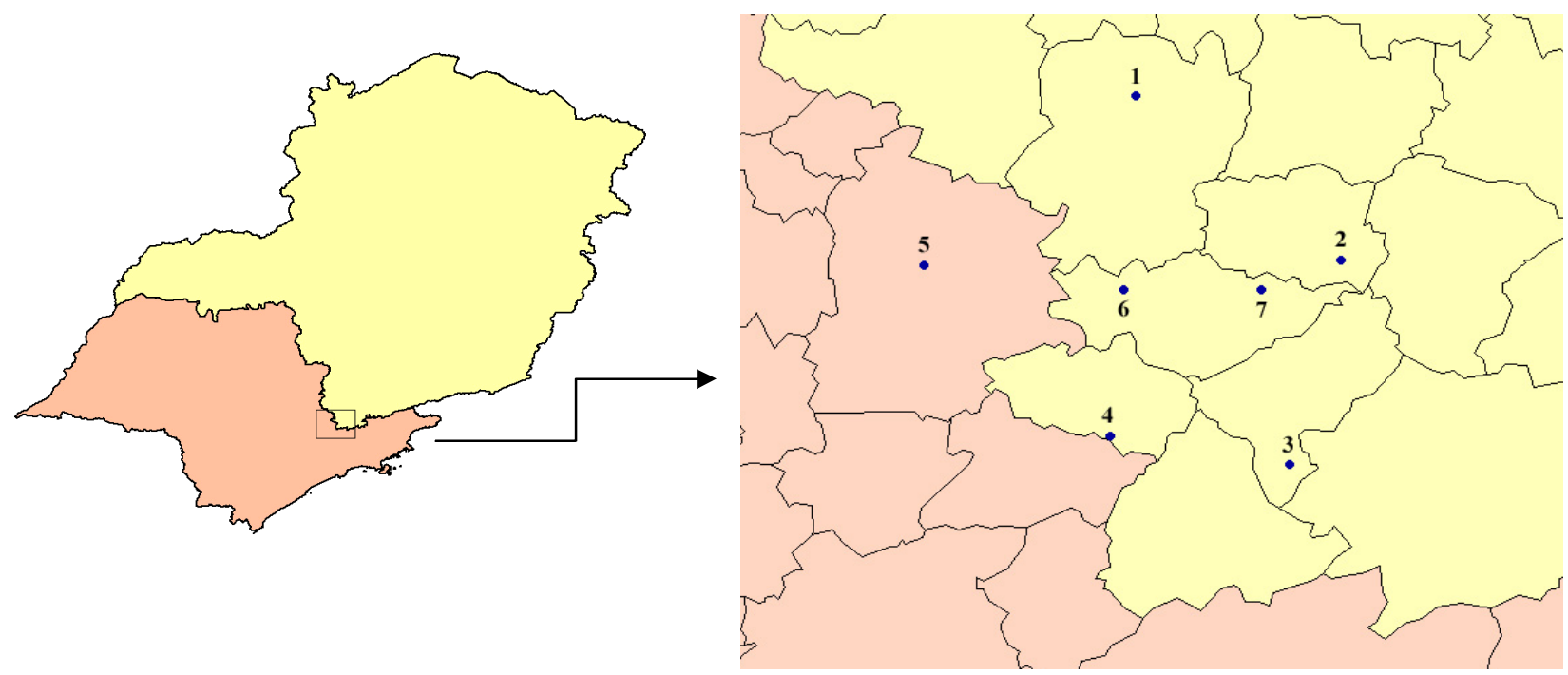

Figura 1: Àrea de estudo -1: Bueno Brandão (MG), 2: Senador Amaral (MG), 3: Itapeva (MG), 4: Toledo (MG), 5: Socorro (SP), 6: Munhoz (MG) e 7: Fazenda Santa Elisa (Munhoz,MG). 
Fazenda Santa Elisa: na Fazenda Santa Elisa foi realizado todo o trabalho de campo, e a maior parte da coleta de dados deste estudo. A Fazenda Santa Elisa ( $\left.22^{\circ} 36^{\prime} \mathrm{S}, 46^{\circ} 14^{\prime} \mathrm{W}\right)$ ocupa uma área de 300 alqueires $\left(7260 \mathrm{Km}^{2}\right.$ de área total) e está situada na zona rural da cidade de Munhoz (MG), distando aproximadamente $13 \mathrm{~km}$ do centro do município (Figura 2).

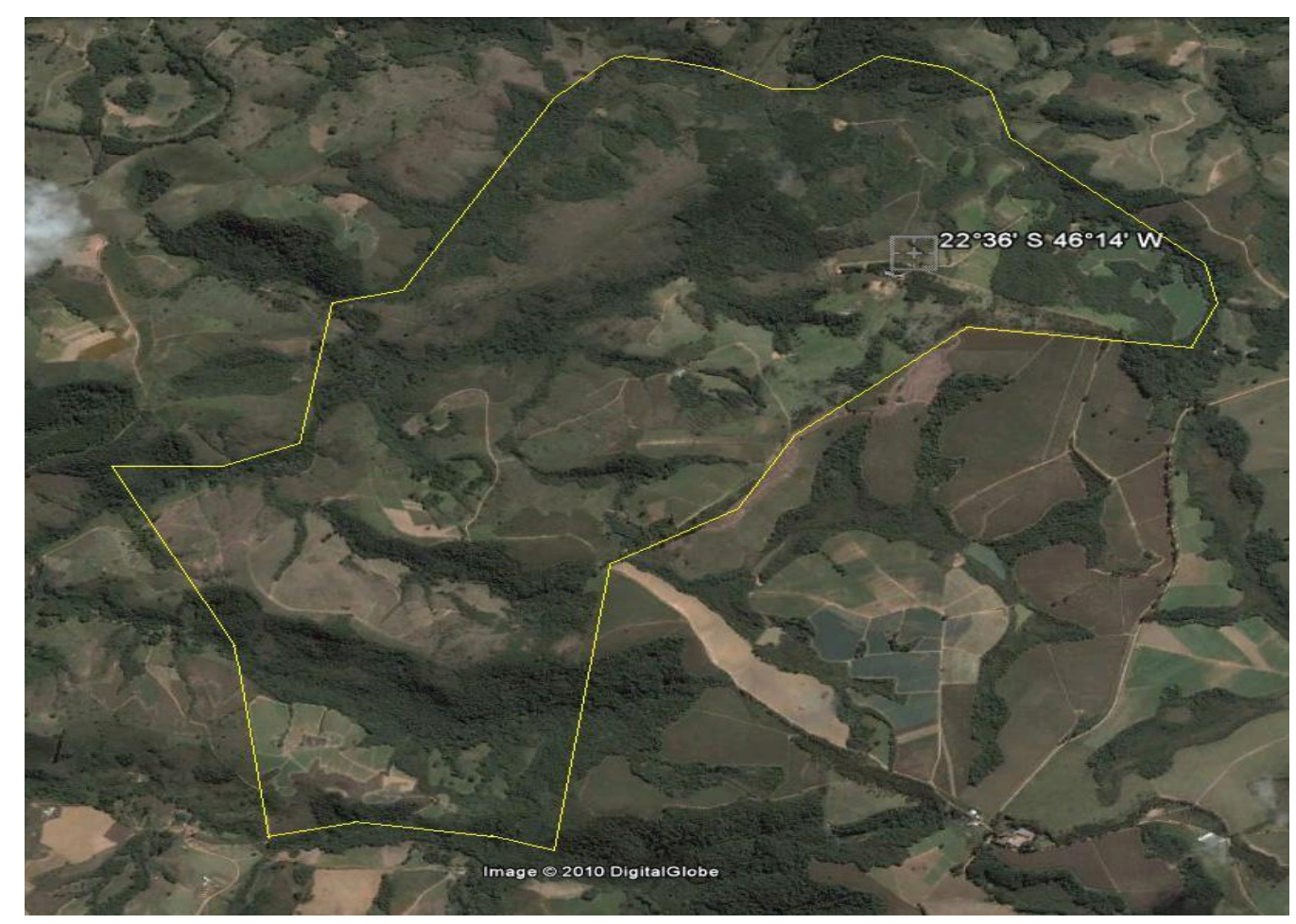

Figura 2: Fazenda Santa Elisa, Munhoz, Minas Gerais (perímetro em destaque).

No local a altitude varia de 1320 a aproximadamente $1640 \mathrm{~m}$, em uma região de relevo acidentado. O clima é classificado como tropical de altitude $(\mathrm{Cwb}$, segundo classificação climática de KÖPPEN-GEIGER, 1936), que ocorre principalmente nas regiões serranas do Espírito Santo, Rio de Janeiro e Serra da Mantiqueira. As chuvas são intensas no verão, verões brandos e inverno seco com possibilidade de geadas. As temperaturas médias variam de $15{ }^{\circ} \mathrm{C}$ a $25{ }^{\circ} \mathrm{C}$ durante o verão. No inverno as temperaturas médias variam de $5{ }^{\circ} \mathrm{C}$ a $18{ }^{\circ} \mathrm{C}$, e com a ocorrência de geadas as temperaturas chegam a ficar negativas. 
A água é um recurso abundante em toda a região. A área da Fazenda Santa Elisa é cortada pelo rio Correntinho (um dos formadores do Rio do Peixe, importante rio da região com nascente em Minas Gerais e que atravessa boa parte do estado de São Paulo), e também por três cachoeiras de grande porte, três açudes com criação de peixes e uma nascente de água mineral, não explorada comercialmente.

A extensão ocupada pela Fazenda Santa Elisa é diversa em relação às fisionomias vegetais. Ocorrem áreas preservadas de Mata Atlântica, Floresta de Araucária e Campos de Altitude, áreas alteradas como capoeiras em diferentes estágios de sucessão, e áreas utilizadas para agricultura e pecuária. A Fazenda Santa Elisa ocupa um dos pontos mais altos da cidade de Munhoz, e pode ser considerada uma "ilha de vegetação" em meio a grandes fazendas destinadas à agricultura, onde praticamente toda a vegetação original foi desmatada. Alguns corredores de mata presentes na região cortam toda a extensão da área, e a presença de espécies de grande e médio porte como o Puma concolor (suçuarana), Chrisocyon brachyurus (lobo-guará), Leopardus tigrinus (gato do mato), Speothos venaticus (cachorro do mato vinagre), Alouatta fusca (bugio), Agouti paca (paca), já foram registradas.

As diferentes fisionomias vegetais encontradas na Fazenda Santa Elisa são (segundo VELOSO; RANGEL FILHO; LIMA, 1991):

\section{Áreas Florestadas}

Floresta Ombrófila Densa Alto-Montana (Mata Atlântica): com predominância de jacarandá de minas (Jacarandá cuspidifolia), cedro rosa (Cedrella fissilis), araticum (Annona coriacea), caroba (Jacaranda caroba).

Floresta Ombrófila Mista Alto-Montana (Floresta de Araucária): Araucária angustifólia. Reflorestamento: Pinus sp e Eucalyptus sp. 


\section{Áreas Abertas}

Campos de Altitude: com predominância de gabiroba (Campomanesia pubescens), candeia (Eremanthus erythropappus), capim barba de bode (Aristida pallens) e macela do campo (Achyriocline satureioides).

Campos de Altitude com afloramentos rochosos.

Capoeiras (em diferentes estágios de sucessão): com predominância de aroeira pimenteira (Schinus terebinthifolius), capororoca (Rapanea sp), alecrim do campo (Baccharis dracunculifolia).

\section{Tratos Antrópicos}

Edificações: áreas da sede e demais edificações.

Pecuária: pastagens com predominância de Brachiaria sp.

Agricultura: plantio de batata (Solanum tuberosun), milho (Zea mays), mandioquinha (Arracacia xanthorrhiza), feijão (Phaseolus vulgaris) e morango (Fragaria vesca).

Imagens das diferentes fisionomias da vegetação e tratos antrópicos são mostradas no Anexo A. 


\subsubsection{Metodologia - Trabalho de Campo}

Período de Estudo: de janeiro a dezembro de 2002 foram realizadas coletas preliminares. A amostragem regular e continua das serpentes em campo foi realizada de janeiro de 2003 a dezembro de 2007. As viagens para coleta aconteciam a cada dois meses, e tinham a duração média de cinco dias. Durante os anos de 2008 e 2009 foram incorporadas serpentes coletadas por terceiros.

Métodos de Amostragem:

Procura visual: realizada durante o dia e a noite em diferentes transectos (e seus arredores) previamente escolhidos por atravessarem os diversos tipos de ambientes. Esses transectos foram percorridos a pé, em deslocamento lento, e abrigos naturais visualmente acessíveis (como cupinzeiros, formigueiros, pedras amontoadas, tocas) também foram investigados. Cada transecto era percorrido (ida e volta) duas vezes em cada viagem para coleta, em diferentes períodos.

TRANSECTO 1 - áreas da sede $\rightarrow$ campo de altitude $\rightarrow$ capoeiras $\rightarrow$ açude $1 \rightarrow$ reflorestamento $\rightarrow$ mata $\rightarrow$ cachoeira 1 (extensão de $3,2 \mathrm{Km}$; altitude variando de 1490 a $1320 \mathrm{~m})$.

TRANSECTO 2 - áreas da sede $\rightarrow$ pastagens/ curral $\rightarrow$ açudes 2 e $3 \rightarrow$ campo de altitude $\rightarrow$ campo de altitude com afloramentos rochosos $\rightarrow$ araucárias (extensão de 1,6 Km; altitude variando de 1490 a $1610 \mathrm{~m})$.

TRANSECTO 3 - áreas da sede $\rightarrow$ pastagens/ curral $\rightarrow$ açudes 2 e $3 \rightarrow$ campo de altitude $\rightarrow$ água mineral $\rightarrow$ capoeiras $\rightarrow$ mata $\rightarrow$ cachoeira 2 (extensão de 2,8 Km; altitude variando de 1490 a $1384 \mathrm{~m})$.

TRANSECTO 4 - áreas da sede $\rightarrow$ campo de altitude $\rightarrow$ araucárias (extensão de 1,2 Km; altitude variando de 1490 a $1545 \mathrm{~m})$. 
TRANSECTO 5 - áreas da sede $\rightarrow$ reflorestamento $\rightarrow$ mata (extensão de 1,4 Km; altitude variando de 1490 a 1370m)

TRANSECTO 6 - plantações

Procura de carro: estradas de acesso à Fazenda Santa Elisa, e estradas secundárias internas foram percorridas de carro a baixa velocidade (aproximadamente $30 \mathrm{~km} / \mathrm{hora}$ ). Procura realizada durante o dia e à noite. Encontros ocasionais ocorridos durante trajetos de automóvel foram incluídos neste item.

Coleta por terceiros: as coletas foram realizadas pelos moradores e funcionários da Fazenda Santa Elisa, e pelos trabalhadores rurais da região. As serpentes foram coletadas sempre que encontradas durante a rotina diária de trabalho dessas pessoas, e durante seu trajeto de ida e volta do trabalho, feito a pé ou a cavalo.

Coleta "de trator": utilizado apenas em três oportunidades, é um método de coleta não usual, principalmente em áreas protegidas como parques, florestas nacionais e áreas de proteção ambiental. Porém, frente à realidade deste trabalho, mostrou-se bastante eficaz. Como uma porcentagem da Fazenda Santa Elisa foi destinada à agricultura, este tipo de coleta consistiu em acompanhar de cima do trator o desmatamento de pequenas áreas de Campos de Altitude. Ao sentir a aproximação do trator as serpentes se afastavam rapidamente, evidenciando sua posição.

Armadilhas / Abrigos artificiais: não foram instaladas armadilhas de interceptação e queda para a coleta de serpentes. Porém, muitos abrigos artificiais já existentes no local (e que permaneceram no mesmo lugar durante todo o período deste trabalho) foram vistoriados constantemente: 
- sobreposição de grandes telhas de amianto (armadilha tipo "sanduíche")

- barcos de fibra de vidro emborcados ao redor dos açudes

- pilhas de espigas de milho estocadas para alimentar cavalos

- telas plásticas pretas com pequenos poros (tipo "sombrite") utilizadas durante todo o inverno para proteger das intempéries as culturas mais sensíveis (no caso plantação de morangos).

Acondicionamento e destino do material coletado:

Serpentes capturadas vivas: foram acondicionadas em caixas de madeira apropriadas para o transporte de serpentes. Algodão embebido em água era sempre colocado nas caixas, posteriormente armazenadas em local adequado.

Serpentes mortas: animais mortos por trabalhadores rurais ou encontrados atropelados foram acondicionados em baldes com tampa, contendo formol a 10\%, previamente distribuídos em alguns pontos da Fazenda Santa Elisa. Semanalmente os animais coletados por terceiros (vivos ou mortos) ou encontrados atropelados eram transportados para São Paulo. Esse procedimento evitou a morte de serpentes capturadas vivas e a perda de informações importantes.

Grande parte dos espécimes foi incorporada à Coleção de Serpentes do Instituto Butantan (IB) e alguns exemplares foram tombados na coleção de répteis do MZUSP (Anexo B). Parte dos exemplares de Bothropoides jararaca, Bothropoides neuwiedi e Crotalus durissus foram incorporados ao plantel de serpentes para produção de veneno ou plantel de serpentes para pesquisa do Laboratório de Herpetologia do Instituto Butantan. Alguns exemplares de Philodryas patagoniensis e de Oxyrhopus rhombifer também estão sendo mantidos no Laboratório de Herpetologia, tendo em vista que a secreção tóxica de algumas serpentes opistóglifas tem sido objeto de estudo no Instituto Butantan. 
Coleta de dados no campo:

No momento da captura foram registradas em fichas previamente preparadas as seguintes informações:

- data de coleta

- horário da coleta (no caso de coleta por terceiros, apenas se foi no período da manhã, tarde ou noite)

- local de coleta (ambiente e substrato ou abrigo onde a serpente se encontrava)

- condições climáticas (quando possível)

Quando possível também foi registrada a postura do animal no momento do encontro: atividade/ inatividade ou repouso (com base em DI-BERNARDO, 1998; OLIVEIRA e MARTINS, 2001). Foram consideradas ativas as serpentes que:

- estavam em deslocamento

- estavam expostas (em atividade de termorregulação), porém se mostravam atentas a qualquer aproximação

- estavam enrodilhadas com pescoço em "S", mas com a cabeça formando um ângulo maior ou igual a $20^{\circ}$ em relação ao substrato (o que indica que estão atentas)

Foram consideradas inativas (em repouso) as serpentes que:

- não demonstraram reação imediata com a aproximação do coletor

- estavam abrigadas

- estavam frouxamente esticadas ou enrodilhadas com a cabeça formando um ângulo menor que $20^{\circ}$ em relação ao substrato

O comportamento exibido pela serpente na hora da captura (desferir botes, fuga, tentar morder, descarga cloacal) também foi registrado. Vale ressaltar que os dados referentes à postura e comportamento da serpente no momento do encontro foram considerados apenas quando o animal foi capturado pela equipe de coletores (autora e colegas funcionários ou estagiários do Laboratório de Herpetologia), a fim de evitar interpretações equivocadas. 
Alguns indivíduos com exemplares já tombados na coleção do IB foram marcados (através de picoteamento das escamas ventrais) e soltos no local de captura após a coleta dos dados morfológicos e de dieta.

\subsubsection{Metodologia - Laboratório}

As serpentes foram eutanasiadas por anóxia com gás carbônico. Foram registrados para todos os espécimes:

- identificação da espécie

- dados morfométricos: comprimento rostro-cloacal (mm) (CRC) e comprimento da cauda (mm) (CC) (fita milimetrada com precisão de $1 \mathrm{~mm}$ ); comprimento da cabeça (mm) (CCA) (paquímetro digital com precisão de 0,1mm) e massa corporal (g) (balança digital com precisão de $1 \mathrm{~g}$ ).

- sexo

Dieta:

Espécimes que foram tombados na coleção foram dissecados através de incisão ventral ao longo dos dois terços posteriores do corpo (MARTINS e GORDO, 1993) para obtenção do conteúdo do trato gastrointestinal.

No caso das serpentes mantidas em cativeiro, foram aguardados 15 dias para que defecassem (caso houvesse alimento em seu tubo digestivo) antes de oferecer alimento aos animais. Grande parte das amostras de fezes obtidas foi proveniente das caixas de madeira onde as serpentes eram mantidas após sua captura até serem transportadas para o IB. Após a coleta, as fezes foram lavadas com água sucessivas vezes em peneiras de pequenos poros. Nesse processo foram separados os pêlos, dentes, ossos, escamas, penas e outros materiais que puderam auxiliar na identificação do item ingerido.

Conteúdos estomacais foram obtidos também através do regurgitamento espontâneo (ocorrido durante a captura ou transporte de serpentes recém alimentadas). Quando 
presentes foram medidos, pesados, fixados em formol a $10 \%$ e preservados em álcool a $70 \%$.

Reprodução:

A condição reprodutiva de cada exemplar foi determinada por meio do exame visual das gônadas, com a finalidade de diferenciar a faixa etária (jovens / adultos) através da maturidade sexual. Machos foram considerados adultos (maduros) quando apresentaram canais deferentes alargados, enovelados e opacos e testículos túrgidos (SHINE, 1977a; SHINE, 1980). As fêmeas foram consideradas adultas (maduras) quando apresentaram folículos em vitelogênese secundária, ovos ou embriões nos ovidutos, ou corpo lúteo nos ovários (SHINE, 1977b; SHINE, 1978).

Registros do Instituto Butantan (Recepção de Serpentes / Coleção de Serpentes):

Foi realizado o levantamento da entrada de serpentes no Setor de Recepção de Serpentes do Laboratório de Herpetologia do Instituto Butantan, durante o período de 1997 a 2010, da cidade de Munhoz (MG) e municípios limítrofes (Bueno Brandão, Itapeva, Senador Amaral e Toledo em MG; Socorro em SP). Além de serem limítrofes à área de estudo, essas cidades mineiras apresentam similaridade de cobertura vegetal, clima e altitude com a cidade de Munhoz. Apenas Itapeva (MG) e Socorro (SP) apresentam diferenças mais marcantes em relação aos fatores acima mencionados.

\subsubsection{Análise dos dados:}

Os dados foram agrupados em dois conjuntos de análises: o primeiro com as serpentes encontradas apenas dentro dos limites da Fazenda Santa Elisa, identificadas como "Grupo 1". A localidade Fazenda Santa Elisa pode ser considerada pouco alterada e bastante preservada em relação a seu entorno, com características vegetacionais peculiares e altitudes elevadas. 
Na segunda análise, identificada como "Grupo 2", ou grande região de estudo, estão as espécies coletadas na Fazenda Santa Elisa (Grupo 1), mais as espécies coletadas em Munhoz (fora dos limites da fazenda) e arredores, mais os registros da Recepção de Serpentes do IB de Munhoz e cidades limítrofes. Detalhes dos grupos 1 e 2 são mostrados a seguir:

\section{Grupo 1 - Serpentes da Fazenda Santa Elisa:}

Neste grupo foram abordadas apenas as serpentes coletadas dentro dos limites da Fazenda Santa Elisa. O Grupo 1 foi utilizado para as análises de riqueza, abundância, uso do ambiente e informações sobre a história natural dos espécimes coletados.

Para as análises de uso do ambiente, as serpentes foram agrupadas levando em consideração o tipo de fisionomia da vegetação dos locais de encontro, que foram divididos em:

- Áreas florestadas: Mata Atlântica, Floresta de Araucárias, Reflorestamento (Pinus sp e Eucalyptus sp).

- Áreas abertas: Campos de Altitude (incluindo afloramentos rochosos) e pastagens

- Capoeiras (em diferentes estágios de sucessão)

- Áreas cultivadas

- Edificações (áreas da sede e demais construções, com constante presença humana)

Na Fazenda Santa Elisa o gado é criado solto em grandes extensões de pastagens. Assim, as pastagens foram incluídas nas áreas abertas por representarem grandes extensões e por estarem cercadas pelos Campos de Altitude.

Devido ao maior número de coletas, e conseqüentemente maior número de informações disponíveis os exemplares de viperídeos serão analisados em detalhes no capítulo 2 deste trabalho. 


\section{Grupo 2 - Grande Região}

Neste grupo analisamos em conjunto as serpentes encontradas na Fazenda Santa Elisa (Grupo 1); as serpentes coletadas na cidade de Munhoz (MG) fora dos limites da fazenda; as serpentes preservadas na coleção do Colégio Municipal de Bueno Brandão $(\mathrm{MG})^{1}$; e os dados da Recepção de Serpentes do Laboratório de Herpetologia do Instituto Butantan (IB) durante o período de 1997 a 2010, da cidade de Munhoz e municípios limítrofes. Este grupo foi utilizado para as análises de composição faunística e distribuição altitudinal.

Quando os resultados foram analisados em relação às diferentes estações climáticas, os anos (de estudo) foram acumulados.

Este estudo foi aprovado pela Comissão de Ética no Uso de Animais do Instituto Butantan (CEUAIB), sob o número de protocolo 044/2001.

1- O Colégio Municipal de Bueno Brandão (MG) preserva em álcool as serpentes mortas pela população da região. 


\section{2 OBJETIVOS}

\section{Objetivos Gerais:}

Estudar aspectos biológicos e ecológicos de uma comunidade de serpentes da Serra da Mantiqueira.

\section{Objetivos Específicos:}

1) Descrever a riqueza e abundância das espécies da região.

2) Descrever o uso dos habitats pelas serpentes.

3) Descrever aspectos da história natural da ofidiofauna regional, por meio de informações sobre as atividades reprodutivas, dieta e atividade e comportamento no momento do encontro.

4) Verificar a influencia da altitude sobre a distribuição e abundância das espécies. 


\subsection{RESULTADOS E DISCUSSÃO}

\subsubsection{Métodos de amostragem}

Procura visual: foram percorridos, em diferentes horários, transectos que atravessam os diversos tipos de ambientes, incluindo a procura por serpentes sobre a vegetação e na beira dos cursos d'água. Coletas noturnas foram realizadas, embora as baixas temperaturas registradas no período noturno tenham restringido essa coleta em algumas épocas do ano, principalmente no inverno. A procura visual proporcionou o encontro de 49 exemplares $(25,3 \%$ do total).

Procura de carro: o método proporcionou o encontro de 27 exemplares (13,9\% do total). Os encontros aconteceram principalmente durante o trajeto de chegada e saída dos proprietários ou funcionários da Fazenda Santa Elisa e durante a procura em estradas internas.

Coleta por terceiros: foi o método pelo qual se obteve a maioria das serpentes coletadas. A movimentação de trabalhadores rurais nas áreas de plantações e de reflorestamento é grande, o que favorece o encontro. O método foi responsável por 54,6\% das espécies coletadas $(\mathrm{N}=106)$. Apenas duas pessoas, que se deslocam continuamente por toda a área da fazenda (o proprietário e o caseiro residente), foram os responsáveis pela coleta de 38 e 47 exemplares, respectivamente. Os demais espécimes encontrados por terceiros foram coletados pelos trabalhadores rurais, durante preparação de terrenos, plantio ou colheita das culturas existentes na Fazenda Santa Elisa.

Coleta de "trator": método viável apenas para áreas já destinadas ao desmatamento, a coleta de trator, apesar de realizada poucas vezes $(\mathrm{N}=3)$, possibilitou bons resultados, mas não pode ser considerado um método tradicional de coleta. Os animais ficam apenas com a opção de fuga, tornando fácil sua visualização. Nas três ocasiões em que foi possível acompanhar o desmatamento (sempre em áreas de Campo de Altitude), em cinco horas totais de trabalho, foram encontradas 11 serpentes (5,7\% do total), todas B. neuwiedi. 
Armadilhas/Abrigos artificiais: durante todo o período de estudo apenas uma serpente $(0,5 \%$ do total) foi encontrada nos abrigos artificiais. Um jovem de $B$. neuwiedi foi encontrado abrigado sob uma pilha de espigas de milho (local regularmente freqüentado por roedores). $\mathrm{O}$ fato de apenas uma serpente ter sido capturada nos abrigos artificiais talvez possa ser explicado pela grande quantidade de abrigos naturais existentes na área, como cupinzeiros, tocas, formigueiros abandonados e troncos de árvores caídos.

Dentre os diversos métodos de amostragem (procura visual, procura de carro, coleta por terceiros, coleta de "trator" e armadilhas/ abrigos artificiais), os métodos coleta por terceiros e procura visual foram os que apresentaram melhor desempenho (Figura 3).

O número de indivíduos amostrados por espécie pode estar vinculado aos métodos de amostragem empregados, e conciliar diferentes métodos é o ideal em levantamentos faunísticos (MARTINS, 1994). Método bastante eficiente neste estudo, as coletas por terceiros e os encontros ocasionais tem-se mostrado importante também em outros trabalhos, contribuindo com os estudos de composição faunística (SAWAYA, 2004; HARTMANN, 2005; PEREIRA, 2010). Os abrigos artificiais, apesar de não terem sido eficientes, mostram-se eficazes em outras localidades, principalmente em áreas abertas (DEIQUES et al., 2007). 


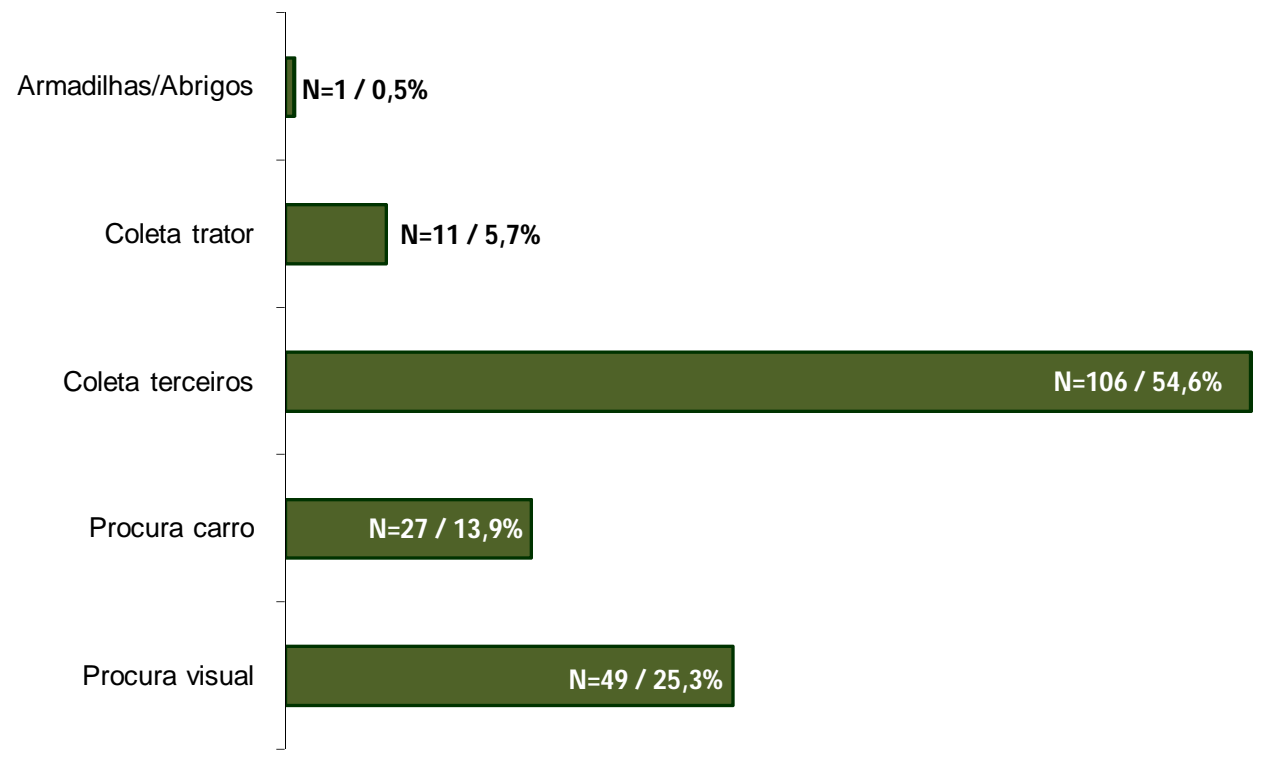

Figura 3: Número e percentual de serpentes coletadas na Fazenda Santa Elisa em relação aos diferentes métodos de amostragem durante o período de estudo. 


\subsubsection{Comunidade de Serpentes - Fazenda Santa Elisa, Munhoz, MG (Grupo 1)}

\section{Composição}

A composição da comunidade de serpentes é apresentada considerando-se a riqueza de espécies e suas freqüências relativas de encontro. Durante o período consecutivo de amostragem, e considerando as serpentes coletadas dentro dos limites da Fazenda Santa Elisa (Grupo 1), foram encontrados 194 indivíduos, representando 2 famílias, 9 gêneros e 11 espécies (Tabela 1, Figura 4).

Tabela 1: Espécies registradas na Fazenda Santa Elisa, Munhoz - MG, durante o período de estudo: número de indivíduos capturados $(\mathrm{N})$ e frequiência relativa de encontros (FR) (\%).

\begin{tabular}{ccc}
\hline \hline & N & FR (\%) \\
\hline FAMILIA DIPSADIDAE & & \\
SUBFAMILIA XENODONTINAE & & \\
TRIBO TACHYMENINI & 1 & 0,52 \\
Ptychophis flavovirgatus (Gomes, 1915) & 1 & 0,52 \\
Thamnodynastes strigatus (Gunther,1863) & 3 & 1,55 \\
Tomodon dorsatus(Duméril \& Bibron 1853) & & \\
TRIBO ECHINANTHERINI & 1 & 0,52 \\
Echinanthera bilineata (Fischer, 1885) & 4 & 2,06 \\
TRIBO PSEUDOBOINI & 10 & 5,15 \\
Oxyrhopus clathratus (Duméril, Bibron \& Duméril 1854) & & \\
Oxyrhopus rhombifer (Duméril, Bibron \& Duméril 1854) & 7 & 3,61 \\
TRIBO PHILODRYADINI & 3 & 1,55 \\
Philodryas patagoniensis (Girard 1858) & 3 & \\
TRIBO XENODONTINI & 26 & 13,4 \\
Xenodon merremii (Wagler, 1824) & 124 & 63,9 \\
Bothropoides jararaca (Wied, 1824) & 14 & 7,22 \\
\hline Bothropoides neuwiedi (Wagler, 1824) & $\mathbf{1 9 4}$ & $\mathbf{1 0 0}$ \\
\hline Crotalus durissus (Linnaeus, 1758)
\end{tabular}




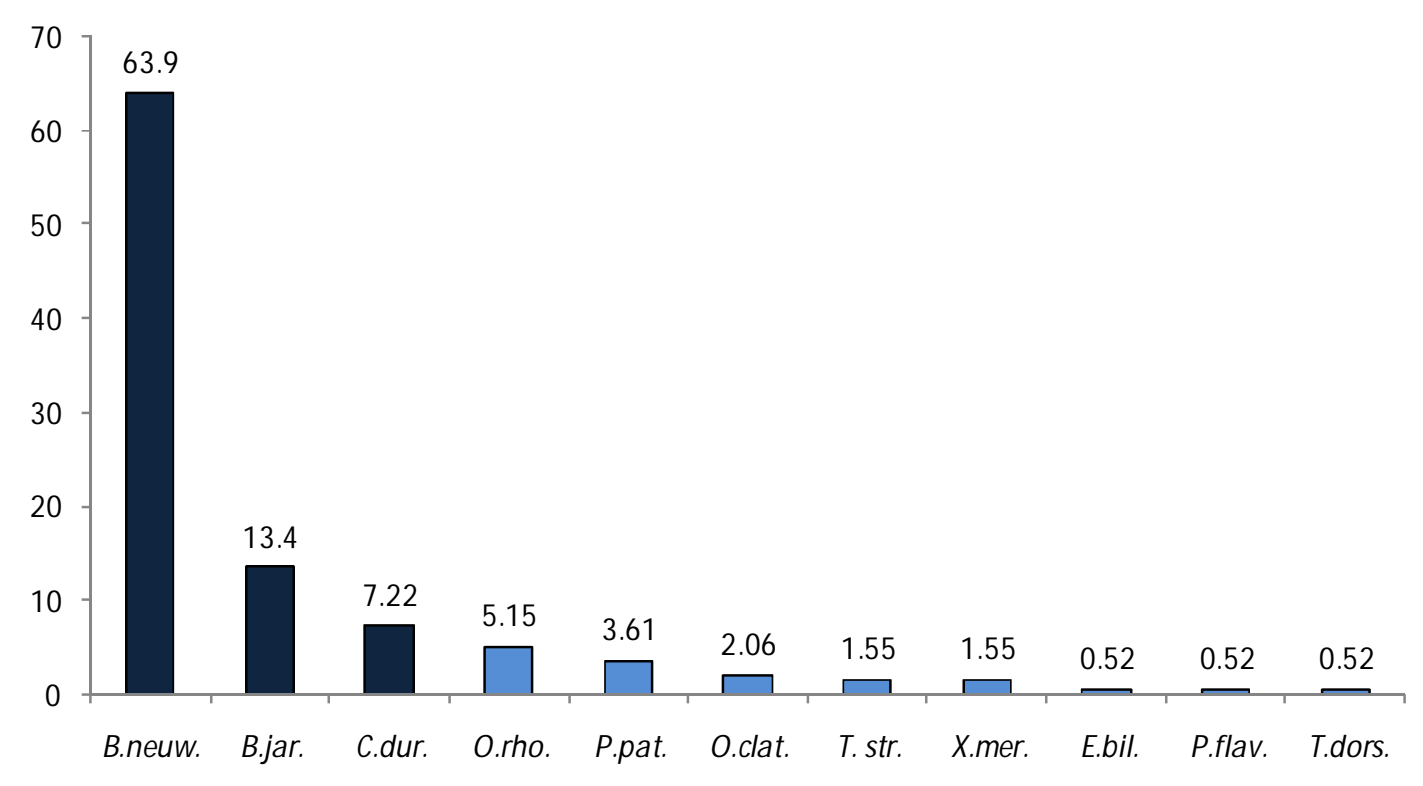

Figura 4: Freqüência relativa das espécies coletadas durante o período de estudo.
B. neuw = B. neuwiedi $; \quad$ B.jar. $=B$. jararaca $;$ C. dur. $=$
C. durissus;
O. rho. $=$ O. rhombifer; P.pat.$=$ P. patagoniensis $; \quad$ O. clat $=$ O. clathratus $;$ T. str. $=$ T. strigatus; $X$. mer. $=X$. merremii; E. bil. $=$ E bilineata $;$. flav $=P$. flavovirgatus; $T$. dors. $=T$. dorsatus.

Ao analisar separadamente as serpentes encontradas apenas dentro dos limites da Fazenda Santa Elisa (Grupo 1), foram obtidas informações referentes a uma localidade restrita, com atributos ecológicos diferenciados dos arredores. Segundo Vanzolini, RamosCosta e Vitt (1980), a lista das espécies que ocorrem em uma determinada localidade ou área bem delimitada é um dado de grande importância.

Desde a aquisição da área da fazenda (no ano de 1995) os proprietários entregam todas as serpentes encontradas ao IB. O levantamento da entrada de serpentes da Fazenda Santa Elisa baseado nos livros de registro da Recepção de Serpentes do IB durante um período de 13 anos (1997-2010) mostrou que apenas duas espécies de serpentes já haviam sido registradas na localidade e não foram capturadas durante o período de coletas deste trabalho: Rhinocerophis fonsecai e Atractus zebrinus. 
A espécie $R$. fonsecai (Anexo D; Figura 5) é o quarto viperídeo listado para a Fazenda Santa Elisa, com a captura de dois indivíduos há 11 anos (em 2000). Depois desses encontros, nenhum exemplar da espécie foi coletado ou morto. Antigos funcionários da fazenda afirmam que a "jararaca gorda e preta" não é encontrada há muito tempo. Sabese que a população de $R$. fonsecai encontra-se em declínio, inclusive aparece com o status de vulnerável na lista de répteis do livro Fauna Ameaçada de Extinção no Estado de São Paulo (GOVERNO DO ESTADO DE SP, 2009). Nos últimos 13 anos, o IB recebeu 59 exemplares da espécie. Desse total, apenas nove procediam de Minas Gerais (2 de Munhoz (Fazenda Santa Elisa), 2 de Alagoa e 5 de Itamonte), e os demais eram todos de São Paulo (1 de Cunha, 1 de São José do Barreiro e 48 de Campos do Jordão). Campos do Jordão é uma cidade turística, atualmente com parte de seu território protegido, e onde se encontra a porção mais significativa de Florestas de Araucárias do sudeste do Brasil (HUECK, 1972). Talvez por esse motivo a espécie ainda seja encontrada na região. No ano passado (2010) foram registradas apenas 4 entradas de $R$. fonsecai no IB, sendo 2 de Campos do Jordão.

Quanto à ausência de A. zebrinus na amostragem, podemos concluir que não é uma espécie abundante no local, pois apenas dois exemplares foram registrados durante o período de 1997 a 2010 (um coletado na Fazenda Santa Elisa e um na cidade de Itapeva, MG). Além disso, a menor frequiência de espécies de hábitos fossórios pode estar relacionada à dificuldade de encontro, já que passam a maior parte do tempo sob a terra ou a vegetação. Talvez o uso de armadilhas de interceptação e queda auxiliasse na coleta de espécies fossórias. Porém, mesmo durante os trabalhos de limpeza das áreas destinadas à agricultura, onde tratores revolvem a terra e a vegetação, a espécie não foi encontrada. $\mathrm{O}$ único réptil de hábitos fossórios coletado foi um exemplar de Amphisbaena mertensi, encontrado sob pedras próximas a área da sede da fazenda.

Nenhum representante da família Elapidae foi encontrado nos limites da Fazenda Santa Elisa e nem em nenhuma das cidades mineiras analisadas neste trabalho. O gênero Micrurus, entretanto, é bem distribuído no Sudeste brasileiro (CAMPBELL e LAMAR, 2004), e possíveis erros na metodologia poderiam ser questionados, como a ausência de armadilhas de interceptação e queda. Porém, a não amostragem do gênero também no 
levantamento de dados da Recepção de Serpentes do IB nos últimos 13 anos nos leva a crer em ausência do gênero na área de estudo.

A literatura traz informações referentes à riqueza de algumas comunidades de serpentes. Estudos realizados na Amazônia mostram uma grande riqueza de espécies: foram listadas para a Reserva Ducke (Manaus) 50 espécies (MARTINS, 1994), e em Rondônia (Município de Espigão do Oeste) 56 espécies foram encontradas (BERNARDE, 2004). Na Mata Atlântica, dentro dos limites da Estação Ecológica da Juréia-Itatins, foram listadas 24 espécies (MARQUES, 1998). No Cerrado, mais precisamente na Estação Ecológica de Itirapina e região, foram registradas 35 espécies (SAWAYA, 2004).

Neste estudo, na área da Fazenda Santa Elisa, foram encontrados 194 exemplares, representando 2 famílias, 9 gêneros e 11 espécies.

Sob condições climáticas e vegetacionais semelhantes a este estudo (porém em baixas altitudes) Di-Bernardo (1998), estudando a comunidade de serpentes do CPCN Pró Mata (RS), obteve uma amostragem muito semelhante a aqui apresentada: 168 encontros, representando 2 famílias, 9 gêneros e 17 espécies. Em outro estudo, realizado no Parque Nacional de Aparados da Serra (RS) durante cinco anos, área cujas formações florestais predominantes são também a Floresta de Araucária, a Mata Atlântica e os Campos de Altitude, os autores registraram 124 encontros de serpentes, totalizando 22 espécies (DEIQUES, 2009).

A riqueza de espécies deste estudo parece ser baixa quando comparada a outras comunidades brasileiras estudadas. Mas, em geral, a riqueza de espécies aumenta em latitudes mais baixas (MARTINS e SANO, 2009). Quanto mais baixas as latitudes, mais altas as temperaturas, o que pode afetar diretamente a fauna de serpentes, seus padrões de atividade e seu metabolismo (LILLYWHITE, 1987; VITT, 1987; SHINE, 1992). Isso parece se confirmar quando observamos que as comunidades de serpentes da Amazônia (latitudes mais baixas) apresentam maior riqueza quando comparadas a outras comunidades brasileiras (MARTINS, 1994; BERNARDE, 2004). Além disso, a riqueza de espécies também pode diminuir em localidades mais restritas (MARQUES, 1998). 
A antropização é outro fator que pode afetar a diversidade e a abundância de espécies. Analisando a herpetofauna do Parque Nacional Serra de Itabaiana (SE), localidade que apresenta temperaturas elevadas e diversidade de habitats, foram registradas apenas 14 espécies de serpentes, com baixo número de indivíduos (CARVALHO; VILAR; OLIVEIRA, 2005).

Durante o período de coletas, o número de espécies se estabilizou após 27 meses (Figura 5), tendo permanecido o mesmo até o final do período de coletas, em 2007, e continuando o mesmo até o final de 2009, período em que foram incorporadas apenas serpentes coletadas por terceiros. Dessa maneira, foi concluído que a riqueza de espécies é baixa na região, provavelmente devido às características climáticas da localidade.

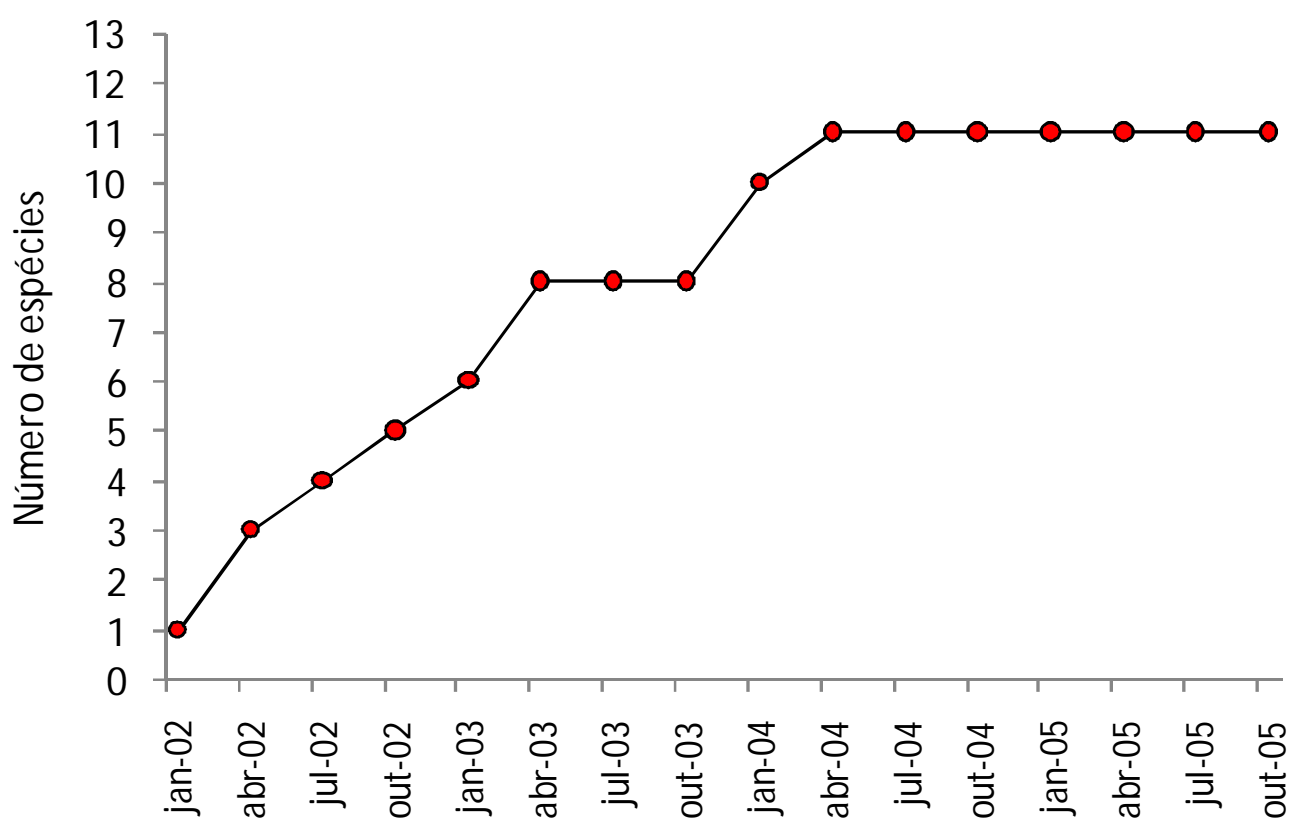

Figura 5: Número cumulativo de espécies amostradas na Fazenda Santa Elisa durante o período de coletas deste estudo. 


\begin{abstract}
Abundância
A família Viperidae, representada por dois gêneros (Bothropoides e Crotalus) é a dominante, contribuindo com 84,5\% (N=164) do total de indivíduos coletados. A família Dipsadidae, representada por sete gêneros, contribuiu com 15,5\% (N=30) do total. Foram encontrados aproximadamente 6 viperideos para cada dipsadideo (Tabela 2, Figura 6).

Marques (1998) observa que existe uma maior dificuldade de coleta para serpentes como colubrídeos e dipsadídeos, pois algumas espécies são extremamente ágeis, enquanto os viperídeos são geralmente mais lentos, com capacidade limitada de fuga. Essa afirmação vem de encontro aos resultados obtidos, pois dos 30 dipsadídeos encontrados na Fazenda Santa Elisa apenas cinco foram coletados por terceiros. Ainda neste estudo quatro outros exemplares (três $X$. merremii e um $P$. patagoniensis) foram observados, mas fugiram com a aproximação dos coletores. Porém, apesar das fugas e possíveis insucessos na coleta de outros indivíduos, o número de viperídeos na área de estudo é extremamente superior ao de dipsadídeos.
\end{abstract}

Quando analisado o número de indivíduos coletados por espécie, B.neuwiedi é a mais freqüente, mostrando clara dominância na área, representada por 63,9\% (N=124) do total de serpentes coletadas. A segunda serpente mais abundante foi B. jararaca, com 13,4\% $(\mathrm{N}=26)$, e a terceira $C$. durissus, com 7,2\% (N=14). O percentual de cada espécie dentro da familia Viperidae pode ser observado na figura 7.

Considerando apenas os viperídeos, B.neuwiedi é significativamente mais freqüente na área de estudo $\left(\chi^{2}=135.6, \mathrm{p}<0.001\right.$, g.l. $\left.=2\right)$, sendo pelo menos 5 vezes mais freqüente do que $B$. jararaca e pelo menos 9 vezes mais freqüente do que $C$. durissus. A espécie B. jararaca é pelo menos 2 vezes mais freqüente do que $C$. durissus.

Na familia Dipsadidae as espécies mais abundantes foram O. rhombifer $(5,21 \%)$, seguida por $P$. patagoniensis $(3,65 \%)$. O número total de coletas e a freqüência relativa representada pelas espécies podem ser observados na tabela 1. 


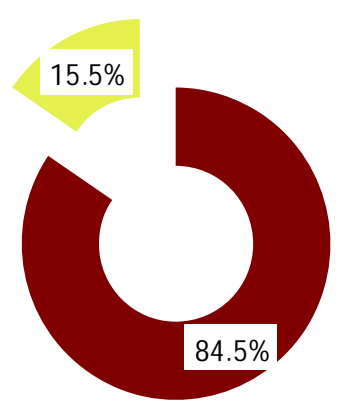

Figura 6: Encontros (\%) de viperídeos e dipsadídeos na Fazenda Santa Elisa, Munhoz, MG.

Bothropoides neuwiedi Bothropoides jararaca Crotalus durissus

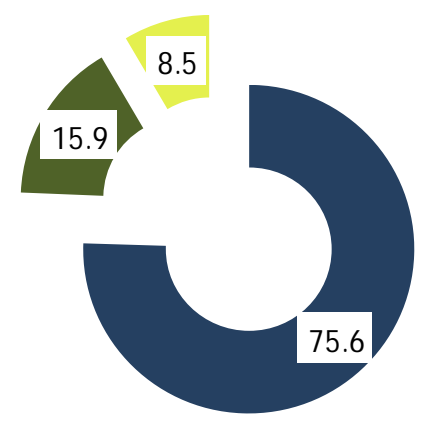

Figura 7: Encontros (\%) das espécies de viperídeos na Fazenda Santa Elisa, Munhoz, MG.

Comparando os resultados obtidos com os outros estudos realizados nas áreas de Florestas de Araucária e ecossistemas associados, mais uma vez a superioridade numérica dos viperideos diferencia a região de estudo. Na amostragem obtida no CPCN Pró Mata (RS) 92\% das serpentes coletadas foram dipsadídeos e apenas 5\% viperídeos. As duas espécies dominantes foram $P$. patagoniensis, representando $27 \%$ do total, seguida por Liophis jaegeri com 25,5 \% (DI-BERNARDO, 1998). No Parque Nacional de Aparados da Serra (RS), a espécie mais abundante, Liophis jaegeri, correspondeu a $39,5 \%$ do total de serpentes coletadas (DEIQUES, 2009). Representantes da família Elapidae também não foram amostrados nos dois estudos acima mencionados, mais 
uma vez sugerindo ausência da espécie nas localidades com as características climáticas e vegetacionais apresentadas.

A abundância de indivíduos da família Viperidae em relação às outras famílias de serpentes foi encontrada em algumas comunidades brasileiras. Porém, apesar de mais abundantes, a frequiência relativa de encontros da espécie dominante foi mais baixa do que neste estudo. Na Mata Atlântica as espécies mais freqüentes foram B. jararacussu $(17,5 \%)$, seguida por B. jararaca (16,5\%) (MARQUES, 1998). Na Amazônia a mais freqüente foi B. atrox (MARTINS, 1994), e no Cerrado C. durissus $(13,1 \%)$ (SAWAYA, 2004). Considerando algumas comunidades estudadas, geralmente as três espécies de serpentes mais freqüentes, juntas, não ultrapassam $50 \%$ do total de indivíduos coletados (STRÜSSMANN e SAZIMA, 1993; MARTINS, 1994; MARQUES, 1998; SAWAYA, 2004).

Neste estudo, apenas B. neuwiedi, com 124 exemplares coletados, atinge 63,9\% do total. Os números aqui obtidos se assemelham aos de Sazima (1992), que na Reserva de Santa Genebra (Campinas, SP) encontrou 121 serpentes, das quais 77 indivíduos $(63 \%)$ eram B. jararaca.

Vanzolini (1981) e Sazima (1992) apresentam como uma das possíveis explicações para a grande freqüência de viperídeos e sua abundância anormal em algumas áreas o fato das regiões naturais em questão estarem cercadas por áreas bastante alteradas pela ação antrópica, funcionando como um "refúgio" para essas populações. Além disso, a oferta do alimento mais freqüente na dieta dos viperídeos (pequenos roedores) pode ser maior nesses ambientes antropizados.

Considerando a dominância dos viperídeos, foi analisado o porquê da abundância de $B$. neuwiedi e sua superioridade numérica em relação à segunda espécie mais freqüente, B. jararaca, sendo que ambas pertencem ao mesmo gênero. Geralmente B. jararaca costuma ser abundante em suas áreas de ocorrência, sendo encontrada em diferentes tipos de ambientes (SAZIMA, 1988; PUORTO; SAZIMA; LAPORTAFERREIRA, 1991; SAZIMA, 1992).

Foram descartados problemas relacionados à disponibilidade de alimento, pois as informações de dieta deste estudo mostraram que ambas se alimentam preferencialmente de roedores, e a maioria das serpentes coletadas (de ambas as 
espécies) apresentavam alimento no trato gastrointestinal (ver capitulo 2). Talvez existam problemas na disponibilidade de alimento para os filhotes, mas isso provavelmente afetaria mais as $B$. neuwiedi (que se alimentam preferencialmente de roedores desde filhotes) do que as $B$. jararaca, espécie que apresenta variação ontogenética na dieta, e quando jovens se alimentam freqüentemente de anuros e lagartos (VANZOLINI, 1948; SAZIMA, 1992; MARTINS; MARQUES; SAZIMA, 2002), presas abundantes na Fazenda Santa Elisa principalmente durante o período de recrutamento dos filhotes.

A predação poderia estar afetando mais a serpente $B$. jararaca, mas possivelmente as duas espécies sofrem a mesma pressão de predação, pois os filhotes nascem com tamanho similar. Talvez a espécie $B$. neuwiedi, que freqüenta preferencialmente áreas abertas, seja encontrada mais facilmente do que B. jararaca, que além das áreas abertas freqüenta também áreas de mata, mas isso não explica a grande diferença numérica entre as espécies.

Os resultados de reprodução deste trabalho (ver capitulo 2) mostram que a fecundidade é similar entre as duas espécies, apesar de $B$. jararaca produzir maior número de filhotes. Além disso, os indivíduos (de ambos os sexos) de B. jararaca atingem maior comprimento de corpo do que $B$. neuwiedi.

Considerando todos esses fatores, possivelmente adaptações fisiológicas diversas podem estar favorecendo a serpente $B$. neuwiedi nessa localidade de altitude e temperaturas baixas. Provavelmente um complexo de fatores esteja contribuindo para a dominância de B. neuwiedi na área de estudo.

\section{Atividade Sazonal}

A época de encontro pode refletir a atividade das serpentes. A freqüência de serpentes da família Dipsadidae foi significativamente maior na primavera e no verão $\left(\chi^{2}=11,06, p<0.05\right.$, g.l. $\left.=3\right)$, e os viperídeos foram significativamente mais freqüentes na primavera, verão e outono $\left(\chi^{2}=27,95, \mathrm{p}<0.001\right.$, g.1. $\left.=3\right)$ (Tabela 3$)$. 
A atividade sazonal das serpentes pode ser influenciada por fatores abióticos como temperatura e pluviosidade (GIBBONS e SEMLITSCH, 1987) e por fatores bióticos como época reprodutiva e disponibilidade de presas (MARQUES, 1998). Em áreas de clima tropical, o pico de atividade das serpentes está geralmente relacionado ao período de chuvas, pois as temperaturas se mantêm praticamente constantes ao longo do ano. Em regiões onde o regime de chuvas não é estritamente sazonal, a atividade das serpentes parece estar mais estreitamente relacionada às temperaturas, que sofrem alterações mais bruscas. As baixas temperaturas podem limitar a atividade das serpentes, reduzindo sua taxa metabólica (GIBBONS e SEMLITSCH, 1987; LILLYWHITE, 1987), e parece ser esse o motivo para o pequeno número de indivíduos coletados nos meses de inverno.

Tabela 3: Frequiência de serpentes coletadas durante o período de estudo.

\begin{tabular}{ccccc}
\hline & PRIMAVERA & VERÃO & OUTONO & INVERNO \\
\hline Viperídeos & $31,1 \%$ & $32,9 \%$ & $28,7 \%$ & $7,3 \%$ \\
Dipsadídeos & $36,7 \%$ & $43,3 \%$ & $10 \%$ & $10 \%$ \\
\hline
\end{tabular}

Devido ao número pequeno de dipsadídeos, não foi possível definir padrões específicos de atividade. Dessa forma, analisando as espécies em conjunto foi observado um pico de encontros de fêmeas na primavera, época de vitelogênese secundária e de postura de ovos para algumas das espécies encontradas, como $P$. patagoniensis e O. rhombifer (ver reprodução dos espécimes nas informações de história natural). Pico de encontro de machos no verão pode estar associado à maior atividade nos períodos de temperaturas mais elevadas (Figura 8). 


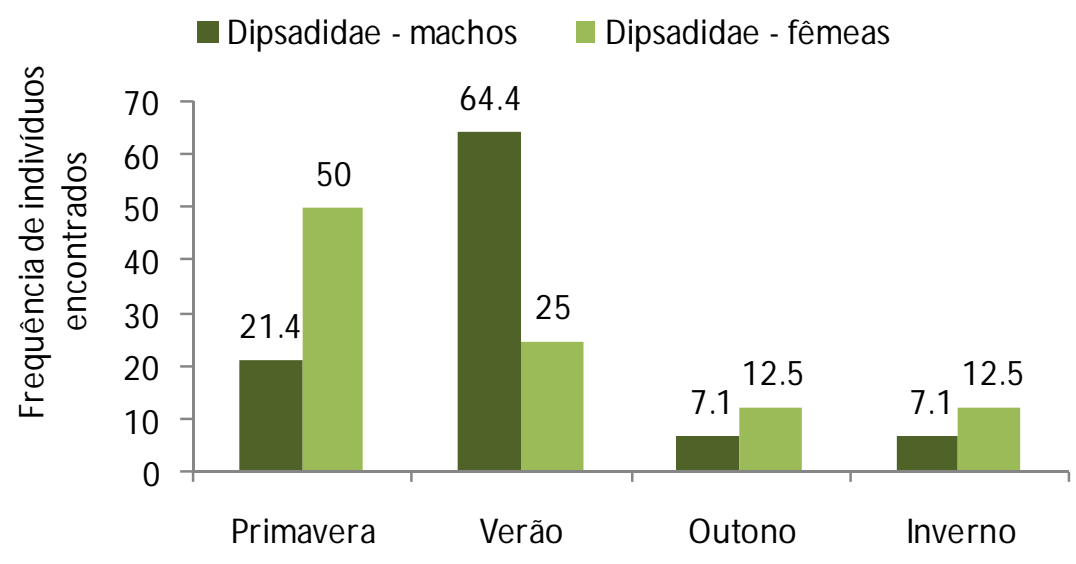

Figura 8: Sazonalidade no encontro de serpentes da família Dipsadidae.

Os viperídeos mostraram um pico de atividade das fêmeas na primavera e no verão, explicado pela época da vitelogênese secundária e gestação nas espécies analisadas (ALMEIDA-SANTOS e SALOMÃO, 2002). Grande número de machos no outono pode refletir o período de acasalamento, quando os machos estão mais ativos à procura de fêmeas (ALMEIDA-SANTOS e SALOMÃO, 2002). O número significativo de encontros de ambos os sexos no verão pode refletir a época de recrutamento dos filhotes e a maior atividade devido às temperaturas mais elevadas. Baixo número de coletas no inverno corresponde ao período de menor atividade das serpentes, devido às possíveis restrições da temperatura (Figura 9). Os viperídeos serão analisados em detalhes no capitulo 2.

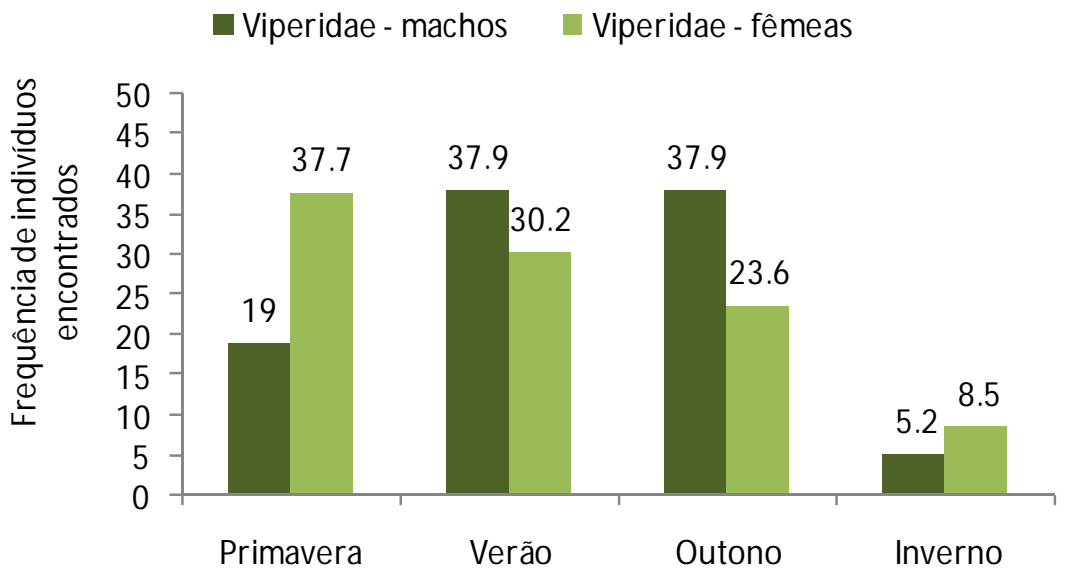

Figura 9: Sazonalidade no encontro de serpentes da família Viperidae. 


\section{Uso do Ambiente}

Os ambientes foram divididos em áreas abertas, áreas florestadas, capoeiras, áreas cultivadas e edificações (vide metodologia). A análise da abundância dos espécimes $(\mathrm{N}$ total $=194)$ em relação ao tipo de fisionomia vegetal onde foram coletadas mostrou que o número de indivíduos encontrados nas áreas abertas foi significativamente maior do que os coletados nas outras fisionomias vegetais $\left(\chi^{2}=163.9, \mathrm{p}<0.001\right.$, g.1. $\left.=4\right)$. Nas áreas abertas foram capturadas 107 serpentes, um número significativo de exemplares foi encontrado nas capoeiras $(\mathrm{N}=37)$, seguido pelas áreas florestadas e áreas cultivadas (ambos com 21 encontros), e poucos registros nas edificações $(\mathrm{N}=8)$ (Tabela 4).

A riqueza de espécies também foi maior nas fisionomias abertas, porém a análise estatística mostrou que essa diferença não é significativa $\left(\chi^{2}=6.6\right.$, n.s., g.l. $\left.=4\right)$. Das 11 espécies coletadas, 9 estão representadas nas áreas abertas, seguidas pelas áreas florestadas, com 7 espécies. Poucas espécies foram registradas nas capoeiras $(\mathrm{N}=4)$, áreas cultivadas $(\mathrm{N}=3)$ e edificações $(\mathrm{N}=3)$ (Tabela 4). A maior abundância nas áreas abertas não está relacionada à riqueza de espécies, e sim a maior freqüência de algumas espécies, principalmente $B$. neuwiedi e $C$. durissus.

Tabela 4: Número de espécies $(\mathrm{N})$ e abundância relativa; número de indivíduos $(\mathrm{N})$ e abundância relativa das serpentes coletadas nas diferentes fisionomias vegetais.

\begin{tabular}{lcc}
\hline & Espécies (N) / \% & Indivíduos (N) / \% \\
\hline Áreas abertas & $9(81,8 \%)$ & $107(55,2 \%)$ \\
Áreas florestadas & $7(63,6 \%)$ & $21(10,8 \%)$ \\
Capoeiras & $4(36,4 \%)$ & $37(19,1 \%)$ \\
Áreas cultivadas & $3(27,3 \%)$ & $21(10,8 \%)$ \\
Edificações & $3(27,3 \%)$ & $8(4,1 \%)$ \\
\hline
\end{tabular}

As espécies de viperídeos, que juntas somam $84,5 \%$ do total coletado, proporcionam uma análise mais precisa sobre a preferência de habitat (Figura 10), abordada no capítulo 2 deste trabalho. 
Tabela 5: Números absolutos e freqüência das serpentes coletadas nos diferentes tipos de fisionomias vegetais e área de edificações na Fazenda Santa Elisa durante o período de estudo.

\begin{tabular}{|c|c|c|c|c|c|}
\hline & Abertas & Florestadas & Capoeiras & Cultivadas & Edificações \\
\hline B. jararaca & $8(30,8 \%)$ & $5(19,2 \%)$ & $10(38,5 \%)$ & $2(7,7 \%)$ & $1(3,8 \%)$ \\
\hline B.neuwiedi & $70(56,5 \%)$ & $7(5,6 \%)$ & $24(19,4 \%)$ & $17(13,7 \%)$ & $6(4,8 \%)$ \\
\hline C. durissus & $14(100 \%)$ & & & & \\
\hline O. rhombifer & $4(40 \%)$ & $2(20 \%)$ & $2(20 \%)$ & $2(20 \%)$ & \\
\hline P. patagoniensis & $5(71,4 \%)$ & $1(14,3 \%)$ & $1(14,3 \%)$ & & \\
\hline O. clathratus & $1(25 \%)$ & $2(50 \%)$ & & & $1(25 \%)$ \\
\hline T. strigatus & $3(100 \%)$ & & & & \\
\hline X. merremii & & $3(100 \%)$ & & & \\
\hline E. bilineata & $1(100 \%)$ & & & & \\
\hline P. flavovirgatus & $1(100 \%)$ & & & & \\
\hline T. dorsatus & & $1(100 \%)$ & & & \\
\hline Total $(\mathbf{N})$ & 107 & 21 & 37 & 21 & 8 \\
\hline
\end{tabular}

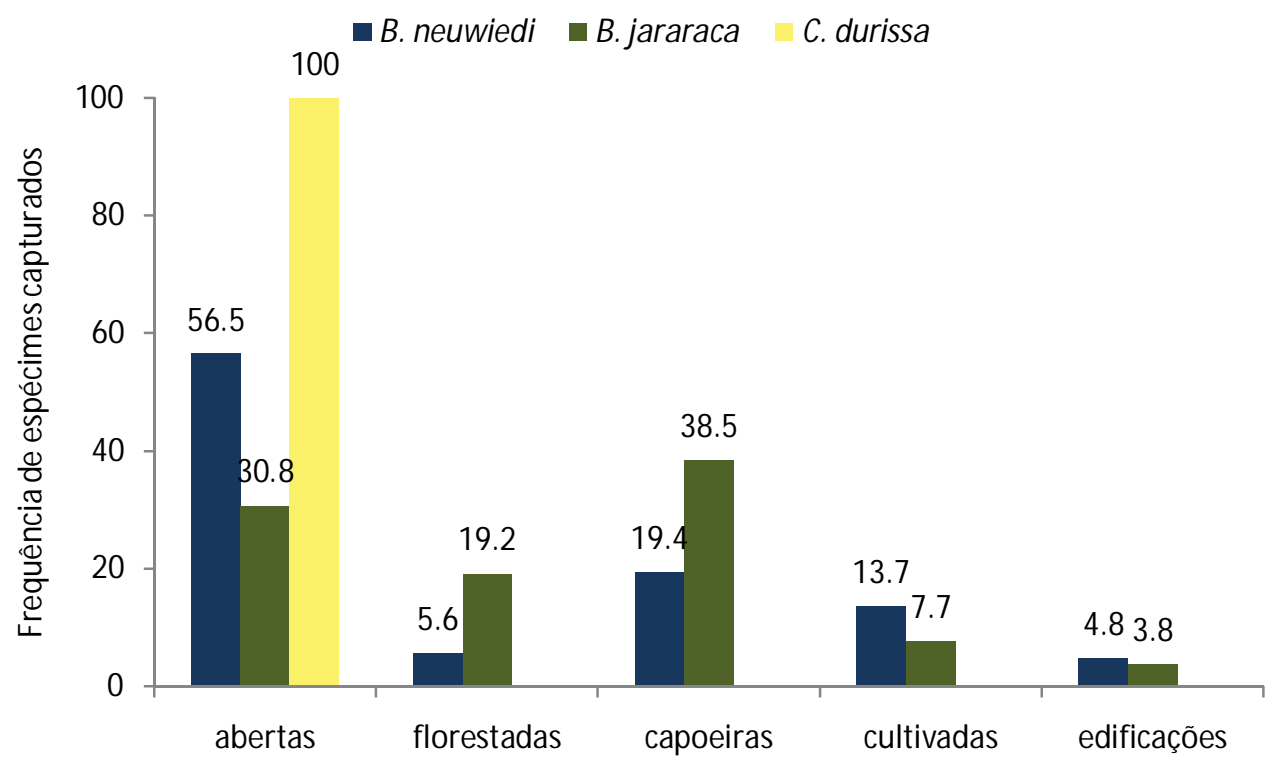

Figura 10: Freqüência de encontro de viperídeos nas diferentes fisionomias vegetais e área de edificações na Fazenda Santa Elisa durante o período de estudo. 
As espécies da família Dipsadidae também foram analisadas em relação ao local de coleta. Devido ao pequeno número de encontros por espécie, são apresentadas informações pontuais, sem a intenção de estabelecer padrões. Detalhes são mostrados no Anexo E. Seguem comentários sobre as serpentes coletadas nas diferentes fisionomias de vegetação analisadas:

\section{Áreas Abertas}

\section{(Campos de Altitude; Campos de Altitude com Afloramentos Rochosos; Pastagens)}

Espécies amostradas: B. jararaca $(\mathrm{N}=8)$, B. neuwiedi $(\mathrm{N}=70)$, C. durissus $(\mathrm{N}=14)$, $O$. rhombifer $(\mathrm{N}=4), P$. patagoniensis $(\mathrm{N}=5)$, O. clathratus $(\mathrm{N}=1), T$. strigatus $(\mathrm{N}=3)$, E. bilineata $(\mathrm{N}=1), P$. flavovirgatus $(\mathrm{N}=1)$

Nas áreas abertas foi encontrada a maior riqueza ( $\mathrm{N}=9$ espécies) e também a maior abundância ( $\mathrm{N}=107$ espécimes) de serpentes. Apenas as espécies X. merremii e T. dorsatus não foram registradas nesse ambiente. As espécies com maior número de indivíduos amostrados nas áreas abertas foram B. neuwiedi, C. durissus, O. rhombifer, P. patagoniensis e T. strigatus.

Como era esperado, todas as $C$. durissus foram encontradas nos Campos de Altitude. Observamos que dos 14 espécimes encontrados, cinco $(35,7 \%)$ estavam dentro de cupinzeiros: duas fêmeas na primavera, uma fêmea (prenhe) e dois machos no verão. $\mathrm{Na}$ Fazenda Santa Elisa os cupinzeiros são bastante freqüentes nos Campos de Altitude, e podem ser utilizados como abrigo por várias espécies de animais, provavelmente para proteção das baixas temperaturas e também de predadores (GRAVES e DUVALL, 1995). Além disso, o uso de cupinzeiros por fêmeas prenhes da espécie $C$. durissus parece ser usual (TRAVAGLIA-CARDOSO e ALMEIDA-SANTOS, 2007).

Dos cinco exemplares de $P$. patagoniensis coletados nas áreas abertas, três estavam em deslocamento nas pastagens, mostrando freqüentar áreas alteradas. Nas pastagens, durante a época de produção de sementes do capim Brachiaria, os roedores são encontrados com freqüência (Celso Nomura, comunicação pessoal ${ }^{1}$ ).

\footnotetext{
${ }^{1}$ Nomura, Celso. São Paulo, 2010.
} 
Todos os T. strigatus estavam na beira de um dos açudes, e todos os O. rhombifer nos Campos de Altitude.

Nenhuma serpente foi capturada nos Campos de Altitude com afloramentos rochosos, um dos pontos mais altos da FSE, com altitude variando entre 1400 a 1640m. Mas foi observado que as serpentes freqüentam o local. Uma ecdise de $B$. neuwiedi (exemplar adulto) foi encontrada presa a um pequeno pé de juá (Zizyphus joazeiro) durante a primavera, e o encontro com um exemplar adulto de B. jararaca também ocorreu no local (durante o verão), porém a serpente não foi capturada (Celso Nomura, comunicação pessoal ${ }^{2}$ ).

\section{Áreas Florestadas}

\section{(Mata Atlântica, Floresta de Araucárias, Reflorestamentos)}

Espécies amostradas: B. jararaca $(\mathrm{N}=5)$, B. neuwiedi $(\mathrm{N}=7)$, O. rhombifer $(\mathrm{N}=2)$, P. patagoniensis $(\mathrm{N}=1)$, O. clathratus $(\mathrm{N}=2)$, X.merremii $(\mathrm{N}=3)$, T. dorsatus $(\mathrm{N}=1)$

Segundo ambiente com maior riqueza ( $N=7$ espécies), e o terceiro em abundância ( $\mathrm{N}=21$ indivíduos). Nas áreas florestadas não foram encontradas as espécies C. durissus, E. bilineata e P.flavovirgatus.

Na Floresta de Araucárias foi registrado o encontro de B. jararaca, O. rhombifer, $O$. clathratus e $X$. merremii. Nos reflorestamentos foram encontradas as mesmas espécies, além de B. neuwiedi. Apenas B. jararaca e T. dorsatus foram observadas em fragmentos de Mata Atlântica. Talvez a vegetação mais fechada das áreas florestadas dificulte a visualização das serpentes, contribuindo para um número mais baixo de encontros.

\footnotetext{
${ }^{2}$ Nomura, Celso. São Paulo, 2010.
} 


\section{Capoeiras}

Espécies amostradas: B. jararaca $(\mathrm{N}=10)$, B. neuwiedi $(\mathrm{N}=24)$, O. rhombifer $(\mathrm{N}=2)$, P. patagoniensis $(\mathrm{N}=1)$

Ambiente que pode ser considerado como intermediário entre áreas abertas e florestadas, na Fazenda Santa Elisa as capoeiras são encontradas em diversos estágios de regeneração. Mostrou baixa riqueza, sendo freqüentado por poucas espécies $(\mathrm{N}=4)$. Porém, foi o segundo habitat mais freqüentado pelas serpentes ( $N=37$ indivíduos), devido à freqüência das espécies $B$. neuwiedi e $B$. jararaca.

\section{Áreas cultivadas}

Espécies amostradas: B. jararaca $(\mathrm{N}=2)$; B.neuwiedi $(\mathrm{N}=17)$; O. rhombifer $(\mathrm{N}=2)$

Ambiente com poucas espécies registradas, a abundância de B. neuwiedi contribuiu para que o número de coletas não fosse baixo. Na Fazenda Santa Elisa as áreas utilizadas para cultivo são pequenas se comparadas às de fazendas dedicadas apenas à agricultura. Todas essas áreas eram originalmente cobertas pelos Campos de Altitude, e conseqüentemente permanecem cercadas por esse tipo de vegetação. Quase todas as serpentes encontradas nas áreas cultivadas estavam abrigadas sob as folhas nas plantações de batata $(\mathrm{N}=12)$, mandioquinha $(\mathrm{N}=7)$, e dentro de uma abóbora $(\mathrm{N}=1)$. Apenas uma B. jararaca estava em locomoção na plantação de milho $(\mathrm{N}=1)$. Geralmente muitas serpentes são encontradas nas áreas de cultivo devido à abundância de roedores (Celso Nomura, comunicação pessoal ${ }^{3}$ ). Um fato interessante foi o encontro de uma fêmea adulta de $B$. neuwiedi, coletada enquanto repousava dentro de uma abóbora moranga imediatamente após a ingestão de um roedor. Parte da abóbora estava visivelmente roída, e concluímos que o roedor estava se alimentando da abóbora quando foi surpreendido pela serpente, que após a ingestão da presa aproveitou o espaço interno da abóbora para repousar.

\footnotetext{
${ }^{3}$ Nomura, Celso. São Paulo, 2010.
} 


\section{Edificações}

Espécies amostradas: B.neuwiedi $(\mathrm{N}=6) ; B$. jararaca $(\mathrm{N}=1) ;$ O. clathratus $(\mathrm{N}=1)$

Foram poucas as serpentes encontradas nas edificações, talvez devido à constante movimentação de pessoas. O exemplar de O. clathratus e todos os exemplares de B. neuwiedi encontrados nas edificações eram jovens. Apenas o espécime de B. jararaca era uma fêmea adulta, encontrada dentro de um depósito de materiais agrícolas e de ração, local freqüentado por roedores.

\section{Modo Reprodutivo}

Das 11 espécies registradas para a Fazenda Santa Elisa, seis (54,6\%) são vivíparas (Tabela 6). Maior percentual de viviparidade em relação à oviparidade não é freqüente em comunidades de serpentes neotropicais (SHINE, 1985). O termo oviparidade referese às fêmeas que retém os ovos nos ovidutos (úteros) por um curto período de tempo após a ovulação e aquelas que retém os ovos por um tempo um pouco maior, até que parte do desenvolvimento embrionário de complete (SHINE, 1983; 1985). O termo viviparidade refere-se às fêmeas que retém os ovos nos ovidutos (úteros) até o completo desenvolvimento dos embriões, ou seja, o filhote nasce totalmente desenvolvido (SHINE, 1983; 1985).

A viviparidade entre os répteis provavelmente evoluiu em resposta aos climas frios, e grande parte das espécies vivíparas ocorre em regiões mais frias, com latitudes e altitudes mais elevadas (TINKLE e GIBBONS, 1977; SHINE, 1985; SEIGEL e FORD, 1987). Nas regiões mais frias das zonas temperadas a porcentagem de espécies vivíparas é maior que a de ovíparas, e nos climas mais quentes a proporção de oviparidade aumenta, superando a viviparidade (FITCH, 1970). Apenas aproximadamente $20 \%$ das espécies de serpentes conhecidas são vivíparas (SHINE, 1985). 
Tabela 6: Modo reprodutivo das serpentes encontradas na área de estudo.

\begin{tabular}{lccc}
\hline & FAMILIA & VIVÍPARA & OVÍPARA \\
\hline B. jararaca & Viperidae & $\mathrm{X}$ & \\
B. neuwiedi & Viperidae & $\mathrm{X}$ & \\
C. durissus & Viperidae & $\mathrm{X}$ & \\
O. rhombifer & Dipsadidae & & $\mathrm{X}$ \\
$P$. patagoniensis & Dipsadidae & & $\mathrm{X}$ \\
O. clathratus & Dipsadidae & & $\mathrm{X}$ \\
$T$. strigatus & Dipsadidae & $\mathrm{X}$ & \\
$X$. merremii & Dipsadidae & & $\mathrm{X}$ \\
E. bilineata & Dipsadidae & & $\mathrm{X}$ \\
$P$. flavovirgatus & Dipsadidae & $\mathrm{X}$ & \\
$T$. dorsatus & Dipsadidae & $\mathrm{X}$ & \\
\hline
\end{tabular}

O modo reprodutivo vivíparo é vantajoso para as espécies que habitam regiões frias, pois as baixas temperaturas são prejudiciais ao desenvolvimento dos embriões. A viviparidade possibilita que estes se desenvolvam em temperaturas adequadas, devido à possibilidade das fêmeas regularem suas atividades para termorregulação (TINKLE e GIBBONS, 1977).

Além da temperatura, outro fator que deve ser levado em consideração é a linhagem dos grupos. Com exceção do gênero Lachesis, todos os viperídeos brasileiros são vivíparos. Todos os dipsadídeos vivíparos encontrados neste estudo pertencem a Tribo Thachymenini, grupo exclusivamente vivíparo.

Análises do modo reprodutivo de serpentes de outras comunidades brasileiras mostram que a porcentagem de espécies vivíparas parece estar diretamente relacionada aos fatores climáticos. Na Amazônia o percentual de viviparidade foi de 16,5\% (MARTINS, 1994), em Ilhéus (BA), 19\%, na Mata Atlântica (Juréia, SP) de 23,5\% (MARQUES, 1998) e no Planalto das Araucárias (RS) de 29,4\% (DI-BERNARDO, 1998). A proporção de viviparidade encontrada neste estudo $(54,6 \%)$ corrobora a idéia de que em regiões mais frias a proporção de espécies vivíparas é maior. 


\subsubsection{História natural - Família Dipsadidae}

São apresentados os aspectos observados sobre a história natural das serpentes coletadas da família Dipsadidae, obtidos exclusivamente durante o período deste estudo. Informações complementares obtidas da literatura são utilizadas para auxiliar na discussão das informações apresentadas. Os viperídeos, devido à maior amostragem e quantidade de informações, são analisados no capítulo 2 deste trabalho.

\section{Uso do substrato, atividade e defesa}

\section{Echinantera bilineata (Anexo C, Figura 4)}

Um macho (CRC $370 \mathrm{~mm}$ ), coletado em área de reflorestamento por Pinus, estava em aparente inatividade, aproximadamente às 14 horas, durante o verão (março).

Espécie pouco freqüente possui hábitos terrícolas e atividade basicamente diurna (HARTMANN, 2005). A espécie geralmente mostra baixa freqüência de encontros (DIBERNARDO, 1998; DEIQUES, 2009).

\section{Oxyrhopus clathratus (Anexo C, Figura 5)}

Na Floresta de Araucárias foram capturados dois exemplares: um macho (CRC $340 \mathrm{~mm}$ ) no inverno (julho) enrodilhado sob uma pedra, aproximadamente às 16:00 horas, e uma fêmea (CRC 296mm) na primavera (dezembro), abrigada sob uma pilha de galhos secos de Araucária angustifólia, por volta de 17:20 horas.

Outras duas fêmeas foram capturadas em diferentes áreas: a primeira (CRC 295 $\mathrm{mm}$ ) foi encontrada em área de Campos de Altitude, na primavera (dezembro), e a outra (CRC 289 mm) no verão (fevereiro), coletada próximo à sede da FSE.

Apesar do número de encontros não permitir analisar preferências, os exemplares foram encontrados em diferentes tipos de habitats. Dos quatro exemplares amostrados, dois estavam abrigados e inativos (no final de tarde), e dos outros dois não possuímos 
maiores informações. Nenhum exemplar apresentou repertório defensivo no momento da captura.

\section{Oxyrhopus rhombifer (Anexo C, Figura 6)}

Espécie mais abundante entre os dipsadídeos, com 10 indivíduos encontrados (5 machos e 5 fêmeas).

Um macho (CRC $430 \mathrm{~mm}$ ) estava em locomoção, às 8:00 horas, em área de reflorestamento por Pinus, na primavera (dezembro).

Dois exemplares jovens foram capturados abrigados sob folhas de batata, durante o verão (ambos em fevereiro): um macho (CRC $400 \mathrm{~mm}$ ) foi coletado às 10:30 horas e outro macho (CRC $385 \mathrm{~mm}$ ) foi coletado na mesma plantação e no mesmo dia, por volta de 14:30 horas.

Outros dois machos foram coletados no verão, nos Campos de Altitude: o primeiro em deslocamento lento, no mês de fevereiro (CRC $440 \mathrm{~mm}$ ) capturado às 17:40 horas. O segundo, um macho jovem (CRC $380 \mathrm{~mm}$ ) coletado em janeiro, também estava em locomoção, aproximadamente às 16:00 horas.

Duas fêmeas reprodutivas foram encontradas: a primeira (CRC $530 \mathrm{~mm}$ ) por volta de 17:00 horas, no inverno (julho), na borda da Floresta de Araucárias, em deslocamento sobre amontoados de pedras. Assim que manipulada, exibiu comportamento de esconder a cabeça (Anexo D; Figura 1). A segunda fêmea (CRC 680 $\mathrm{mm}$ ) foi coletada na primavera (novembro) nos Campos de Altitude.

Mais uma fêmea (CRC $475 \mathrm{~mm}$ ) estava na borda de uma área de capoeira, no verão (janeiro), exposta ao sol no período da manhã (aproximadamente 9:20 horas), em aparente atividade de termorregulação. A serpente havia se alimentado recentemente, pois regurgitou um roedor pouco digerido no momento da captura. Quando percebeu a aproximação, tentou a fuga (Anexo D; Figura 2).

Outra fêmea (CRC $540 \mathrm{~mm}$ ) foi coletada no inverno (julho), na Floresta de Araucárias, e de outra fêmea sabemos apenas que foi encontrada nos Campos de Altitude, na primavera. 
Poucas informações são registradas para a espécie $O$. rhombifer, que é considerada de hábitos terrícolas e atividade predominantemente noturna (DIBERNARDO, 1998; SAWAYA, 2004), mas pode ser encontrada em atividade durante o dia (neste estudo quatro indivíduos foram coletados em locomoção, um pela manhã e três no final da tarde).

A serpente $O$. rhombifer parece ocupar tanto áreas abertas quanto fechadas, em vários tipos de habitats. Também foi registrada na borda de Florestas de Araucárias em outras localidades (DEIQUES, 2009). Foi mais freqüente no verão $(\mathrm{N}=5)$, embora tenha sido amostrada em todas as estações climáticas, com exceção do outono. Resultado semelhante foi obtido em estudo no cerrado, região de Itirapina (SP), onde a espécie foi considerada comum e ativa durante todo o ano (SAWAYA, 2004). Ao serem capturadas não apresentaram repertório defensivo.

\section{Philodryas patagoniensis (Anexo C, Figura 7)}

A espécie parece ser relativamente abundante no local, com registro de sete encontros (4 machos ; 3 fêmeas). Foi coletada ao longo do ano, a maioria em áreas abertas.

Dos sete espécimes capturados, três estavam em área forrada por pastagem, todos em deslocamento: uma fêmea adulta (CRC $910 \mathrm{~mm}$ ) coletada na primavera (novembro), no período da tarde (entre 15:00 e 16:00 horas), um macho (CRC $437 \mathrm{~mm}$ ) coletado na primavera por volta de 6:30 horas, e outro macho (CRC $685 \mathrm{~mm}$ ) coletado no outono (junho), às 7: 20 horas.

Outra fêmea (CRC $250 \mathrm{~mm}$ ) foi coletada no verão (março), às 7:30 horas, em estrada que corta uma área de capoeira. A serpente estava bebendo água em uma poça, e tentou fugir ao perceber a aproximação (Anexo D; Figura 3).

Mais uma fêmea adulta (CRC $1080 \mathrm{~mm}$ ) foi coletada no verão (fevereiro) em repouso, na área de reflorestamento com Eucalyptus.

Dois machos foram encontrados nos Campos de Altitude: um adulto (CRC 680 mm) na primavera (novembro) em locomoção, e um macho filhote (CRC $285 \mathrm{~mm}$ ) coletado por volta de 16:15 horas, no verão, enrodilhado sob pedras. 
P. patagoniensis é uma serpente ágil (um exemplar fugiu ao ser localizado nas proximidades de uma das residências), todos os indivíduos tentavam fugir ao perceber a aproximação, e quando capturados apresentaram as táticas defensivas típicas da espécie, como descarga cloacal $(\mathrm{N}=5)$ e mordidas $(\mathrm{N}=3)$ (MARQUES e SAZIMA, 2004). É uma espécie que apresenta dentição opistóglifa e possui glândula de Duvernoy, e quando manipuladas costumam morder com freqüência, inclusive causando um número considerável de acidentes humanos (MEDEIROS et al., 2010).

Espécie de ocorrência apenas na América do Sul foi o segundo dipsadídeo mais freqüente na área de estudo. A espécie é considerada sempre abundante nas áreas em que ocorre (LEMA, 2002). P. patagoniensis mostrou preferência pelas áreas abertas, corroborando com os dados da literatura (LEMA, 1973; THOMAS, 1976; DIBERNARDO, 1998), apesar de também ser encontrada em áreas de mata (PETERS e OREJAS-MIRANDA, 1986). Parece não se incomodar com ambientes perturbados, e possuem hábitos terrícolas e semi-arborícolas (MARQUES; ETEROVIC; SAZIMA, 2001; SAZIMA e HADDAD, 1992). Neste estudo todos os exemplares foram encontrados no chão, e a maioria estava em atividade. Possuem atividade predominantemente diurna, sendo freqüentemente encontradas nas horas mais quentes do dia (FOWLER e SALOMÃO, 1994). Porém, dos sete exemplares encontrados, três foram coletados entre $06 \mathrm{~h} 30 \mathrm{~min}$ e $07 \mathrm{~h} 30 \mathrm{~min}$, e dois por volta de $16 \mathrm{~h} 00 \mathrm{~min}$, quando a temperatura é relativamente baixa, mesmo durante o verão.

\section{Ptycophis flavovirgatus (Anexo C, Figura 1)}

Apenas um macho (CRC $280 \mathrm{~mm}$ ) foi coletado às 11:10 horas, no verão (fevereiro) em região de Campos de Altitude (1486 m, área com predominância de capim barba de bode), com temperatura de $18{ }^{\circ} \mathrm{C}$. A serpente estava enrodilhada e não apresentou comportamento defensivo na hora da captura.

Existem poucas informações disponíveis na literatura sobre a espécie, que também é rara em coleções zoológicas. Apresenta distribuição disjunta pelas áreas montanhosas do sudeste e sul do Brasil (SCARTOZZONI e MARQUES, 2004), ocorrendo principalmente nas áreas abertas associadas às Florestas de Araucárias (PORTO e CARAMASCHI,1988; DEIQUES, 2009). 
Possui atividade diurna e hábitos aquáticos, sendo geralmente encontrada em ambientes lóticos de pequena profundidade (PORTO e CARAMASCHI,1988; LEMA e DEIQUES, 1992; DI-BERNARDO, 1998; LEMA, 2002). Apesar de estar sempre associada à água, o exemplar encontrado estava a uma distância de 480m da água disponível mais próxima. Este é o primeiro registro para a localidade, e talvez o recorde altitudinal para a espécie.

\section{Thamnodynastes strigatus (Anexo C, Figura 2)}

Espécie com três indivíduos coletados (2 machos e 1 fêmea), todos foram capturados à noite, na beira de um dos açudes (localizado na transição entre Campos de Altitude e pastagem).

A fêmea, adulta (CRC $360 \mathrm{~mm}$ ), foi coletada no mês de abril (outono), às 20:10 horas, em locomoção na beira de açude, em noite relativamente fria, com temperatura no momento da coleta de $14{ }^{\circ} \mathrm{C}$.

Os dois machos foram capturados praticamente na mesma hora, no mês de fevereiro. Um adulto (CRC $470 \mathrm{~mm}$ ) por volta de 23:00 horas se locomovendo próximo à beira do açude, e alguns minutos depois um filhote (CRC $185 \mathrm{~mm}$ ) abrigado sob uma folha, a poucos metros do outro macho.

Espécie de hábitos predominantemente noturnos (STRÜSSMANN e SAZIMA, 1993; MARQUES; ETEROVIC; SAZIMA, 2001), ocorre nas regiões sul e sudeste do Brasil, e seus registros são associados principalmente ao Domínio Tropical Atlântico (PETERS e OREJAS-MIRANDA, 1986). O filhote estava abrigado em aparente inatividade, porém os dois exemplares adultos estavam ativos, provavelmente forrageando na beira do açude. Observações semelhantes foram feitas por Di-Bernardo (1998), que encontrou exemplares de T. strigatus em locais muito próximos à água (dois inclusive dentro da água). Os anuros constituem parte importante de sua dieta e hilídeos e bufonídeos são abundantes na beira dos açudes na área de estudo.

Os dois adultos utilizaram seu repertório defensivo no momento da captura, com achatamento dorso-ventral do corpo, triangulação da cabeça e mordidas. 


\section{Tomodon dorsatus (Anexo C, Figura 3)}

Apenas um fêmea (CRC $470 \mathrm{~mm}$ ) foi coletada, na primavera (novembro). A serpente estava repousando sobre a vegetação, na borda de um fragmento de Mata Atlântica, na beira da nascente de água mineral. Ocupava um galho exposto ao sol, a uma altura de 1.20 m do solo, às 11:20 horas (Anexo D; Figura 4). Mesmo em aparente atividade de termorregulação estava ativa, tentando fugir e se defendendo através de mordidas e achatamento do terço anterior do corpo, comportamentos típicos da espécie quando molestada.

Associada à Floresta Atlântica, a espécie possui atividade predominantemente diurna, embora possa ser encontrada durante a noite (DEIQUES, 2009). Seus hábitos são descritos como predominantemente terrícolas (DI-BERNARDO, 1998), mas parece ser comum o encontro de indivíduos sobre a vegetação (MARQUES, 1998).

\section{Xenodon merremii (Anexo C, Figura 8)}

Durante este estudo foram capturadas três fêmeas.

Uma fêmea (CRC $740 \mathrm{~mm}$ ) foi coletada na primavera, em locomoção (18:10 horas), próxima a um açude, em área de reflorestamento por Pinus. Ao ser capturado o animal exibiu comportamento defensivo típico da espécie, achatando e erguendo o terço dianteiro do corpo e desferindo botes, o que a torna uma serpente conhecida e temida pelos trabalhadores rurais da região.

As outras duas foram encontradas na Floresta de Araucárias: a primeira (CRC $620 \mathrm{~mm}$ ) na primavera (dezembro) na borda da mata, aproximadamente às 10:00 horas, tomando sol sobre uma grande pedra, em local com altitude de $1525 \mathrm{~m}$. A segunda, um filhote (CRC $230 \mathrm{~mm}$ ) foi encontrada enrodilhada, abrigada sob um tronco de árvore caído, no outono (maio) por volta de 16:00 horas.

Serpente associada principalmente a áreas abertas (VANZOLINI, 1948; VITT, 1983; JORDÃO, 1996; CARVALHO; VILAR; OLIVEIRA, 2005), os três exemplares foram encontrados nas áreas florestadas, corroborando os registros de Lema (1994) para as áreas florestadas por Araucárias do Rio Grande do Sul. Possui atividade basicamente diurna e hábitos terrícolas (VITT, 1983; CARVALHO; VILAR; OLIVEIRA, 2005), e 
padrão de coloração extremamente variável (VANZOLINI; RAMOS-COSTA; VITT, 1980). É uma espécie de baixa ocorrência em outras localidades (SAWAYA, 2004), mas parece não ser rara na área de estudo. Foram capturados três exemplares, mas segundo relatos confiáveis outros dois conseguiram fugir antes de serem coletados (estavam abrigados sob pilha de galhos secos de araucária), e um terceiro fugiu do recipiente em que havia sido colocado após a captura.

Um resumo sobre os dados biométricos, atividade e substrato utilizado no momento do encontro são mostrados no anexo F.

\section{Reprodução}

\section{Echinantera bilineata (ovípara)}

O único espécime, um macho, foi classificado como imaturo. São poucas as informações disponíveis na literatura sobre a reprodução da espécie. Temos o registro de uma postura com 6 ovos no mês de outubro (fêmea procedente de Mairiporã-SP), com o nascimento de 2 filhotes em janeiro (CRC $160 \mathrm{~mm}$, massa 2g; CRC $145 \mathrm{~mm}$, massa 2,2g).

\section{Oxyrhopus clathratus (ovípara)}

Foram obtidos quatro registros, todos jovens (1 macho; 3 fêmeas), não trazendo maiores informações sobre o ciclo reprodutivo da espécie, que é também pouco conhecido.

Fêmeas procedentes do Vale do Ribeira (SP) e litoral norte do Paraná apresentaram ovos em novembro e nascimento dos filhotes na estação chuvosa (MARQUES, 1998). Uma fêmea procedente de São Bernardo do Campo (SP) fez a postura de 10 ovos no final da primavera, e o nascimento dos filhotes ocorreu no final do verão. O CRC dos recém nascidos variou de 220 a $240 \mathrm{~mm}$, e a massa corporal de 4,8 a 5,4g (dados não publicados, Lab. de Herpetologia). 


\section{Oxyrhopus rhombifer (ovípara)}

Um macho coletado no verão (CRC $440 \mathrm{~mm}$; massa 20g) apresentava características morfológicas de reprodutivo, com testículos desenvolvidos e ductos deferentes hipertrofiados, enovelados e de coloração opaca.

Uma fêmea (CRC $530 \mathrm{~mm}$ ) capturada no inverno apresentava 11 folículos em vitelogênese secundária (comprimento do maior folículo $9 \mathrm{~mm}$ ). Outra fêmea (CRC 680 $\mathrm{mm}$ ) coletada na primavera apresentava 22 folículos em vitelogênese primária (comprimento do maior folículo $0,4 \mathrm{~mm}$ ), porém com presença de corpo lúteo nos ovários (3 no ovário direito; 2 no esquerdo), indicando que já havia ovulado e feito a postura dos ovos recentemente, portanto classificada como sexualmente madura. Uma terceira fêmea (CRC $540 \mathrm{~mm}$ ) coletada no inverno era imatura, com ovidutos finos e translúcidos, e folículos não vitelogênicos.

A literatura não apresenta muitas informações sobre o ciclo reprodutivo da espécie, e os registros obtidos (fêmea com folículos vitelogênicos no início do inverno; fêmea com corpo lúteo nos ovários no final da primavera; macho reprodutivo no final do verão) indicam que o período de cópula é no outono, com postura de ovos na primavera e nascimentos no verão.

\section{Philodryas patagoniensis (ovípara)}

Dois machos (CRC $680 \mathrm{~mm}$ coletado na primavera; CRC $685 \mathrm{~mm}$ coletado no outono) apresentaram características de reprodutivos, com os testículos desenvolvidos e os ductos deferentes enovelados e opacos.

Duas fêmeas fizeram postura de ovos poucos dias após serem coletadas: uma fêmea (CRC 910 mm; massa após postura: 185 g) coletada na primavera estava prenhe e após sete dias fez a postura de 11 ovos (massa da postura 105g), que foram incubados em laboratório. Seu RCM foi de 0,57. Os filhotes (N=9) nasceram no verão (fevereiro), com CRC entre 180 a $250 \mathrm{~mm}$, e massa entre 4,5 e 7,6g.

Uma segunda fêmea (CRC $1080 \mathrm{~mm}$; massa após postura 190g) foi coletada no verão. A serpente estava visivelmente mais lenta para os padrões da espécie, e após 14 dias fez a postura de 15 ovos (massa da postura 114g; maior ovo com $35 \mathrm{~mm}$ de 
comprimento) que também foram incubados em laboratório. Seu RCM foi de 0,6. Os filhotes $(\mathrm{N}=11)$ nasceram no outono (maio), com CRC entre 190 a $250 \mathrm{~mm}$, e massa entre 5,0 e $8,5 \mathrm{~g}$.

Registros referentes a 24 posturas de ovos de $P$. patagoniensis procedentes de diversas cidades paulistas (Laboratório de Herpetologia, dados não publicados), mostram que todas as posturas foram feitas na primavera (com predominância do mês de outubro), o número de ovos variou de 10 a 25, e o nascimento dos filhotes ocorreu no verão (com predominância do mês de janeiro). Vitelogênese secundária do meio do inverno até a primavera, postura de ovos na primavera e eclosões dos ovos no verão vem de encontro aos registros da literatura para a espécie em diferentes localidades (FOWLER; SALOMÃO; JORDÃO, 1998).

Os resultados mostram macho reprodutivo no outono e postura de ovos na primavera, o que sugere período de acasalamento no outono/inverno, com posturas de ovos na primavera e nascimentos no verão, corroborando com a literatura e os dados acima citados. Porém, foi capturada uma fêmea que fez a postura de ovos no verão e os nascimentos ocorreram no outono. Essa divergência sugere indícios de duas épocas reprodutivas para a espécie na localidade estudada.

\section{Ptycophis flavovirgatus (vivípara)}

Espécie com ciclo reprodutivo sazonal, os nascimentos ocorrem principalmente no início da estação chuvosa. O número de embriões observados em espécimes de coleções variou de 5 a 10 (SCARTOZZONI e MARQUES, 2004), além do registro de uma ninhada com 11 filhotes (PORTO e CARAMASCHI,1988).

\section{Thamnodynastes strigatus (vivípara)}

Um macho coletado no verão (CRC $470 \mathrm{~mm}$ ) foi classificado como reprodutivo. Uma fêmea (CRC $360 \mathrm{~mm}$ ) coletada no outono apresentava 8 folículos em vitelogênese secundária (comprimento do maior folículo $12 \mathrm{~mm}$ ). 
Para exemplares da espécie procedentes da grande São Paulo (N=3) temos registros de nascimentos de ninhadas do meio para o final da primavera, com o CRC dos filhotes variando de 130 a $150 \mathrm{~mm}$ (Laboratório de Herpetologia, dados não publicados).

\section{Tomodon dorsatus (vivípara)}

Folículos em vitelogênese secundária (10 folículos, cinco em cada oviduto, comprimento do maior folículo $17 \mathrm{~mm}$ ) foram registrados em novembro (CRC 470 $\mathrm{mm})$. Serpente com ciclo reprodutivo sazonal, a vitelogênese secundária ocorre na estação chuvosa (outubro a maio) e o nascimento dos filhotes entre junho a outubro, com predominância no mês de agosto (BIZERRA; MARQUES; SAZIMA, 2005; TRAVAGLIA-CARDOSO e MAIA, 2010).

\section{Xenodon merremii (ovípara)}

A literatura relata para a espécie posturas com 6 a 8 ovos (AMARAL, 1977), 5 a 29 (VANZOLINI; RAMOS-COSTA; VITT, 1980), 7 a 35 (PONTES e DIBERNARDO, 1988). Durante este estudo foram coletados dentro de um cupinzeiro 71 ovos de X. merremii, sendo: ovos já eclodidos $(\mathrm{N}=55)$, não eclodidos incubados no laboratório $(\mathrm{N}=14)$ e atrésicos $(\mathrm{N}=2)$. Alguns dos ovos já eclodidos estavam unidos aos não eclodidos. Devido ao grande número de ovos e a aparência da casca de alguns já eclodidos (casca bastante seca, aparentando eclosão há algum tempo) esse ninho foi relatado como provável postura comunal (TRAVAGLIA-CARDOSO, 2007). Dos ovos eclodidos no laboratório, o CRC dos filhotes variou de 190 a $220 \mathrm{~mm}$, e a massa de 6 a 8g. Um filhote foi encontrado a poucos metros do local do encontro dos ovos, no mesmo dia. Talvez esse filhote fosse proveniente do ninho, pois sua biometria foi compatível com a biometria dos filhotes nascidos no laboratório.

No mesmo cupinzeiro, porém na parede oposta, havia uma aranha caranguejeira (Vitalius sp.) e pedaços de ecdise de lagarto do gênero Tupinambis. Essas informações podem indicar a importância dos cupinzeiros como abrigo para diferentes espécies, principalmente em áreas de clima frio. 


\section{Dieta}

\section{Echinantera bilineata}

O único exemplar encontrado não apresentava indícios de alimento no trato gastrointestinal. Alimentam-se de anuros e pequenos lagartos (MARQUES e SAZIMA, 2004; HARTMANN, 2005), mas são poucas as informações disponíveis para a espécie.

\section{Oxyrhopus clathratus}

Uma fêmea coletada no verão (CRC $289 \mathrm{~mm}$ ) havia ingerido um pequeno roedor, evidenciado através de dentes e pelos em suas fezes. Alimenta-se de roedores e pequenos lagartos (MARQUES e SAZIMA, 2004; DEIQUES, 2009).

\section{Oxyrhopus rhombifer}

Alimenta-se principalmente de pequenos mamíferos, anfíbios e lagartos (SAWAYA, 2004, DEIQUES, 2009). Dos 10 exemplares obtidos neste estudo, três haviam ingerido pequenos mamíferos.

Uma fêmea (CRC $475 \mathrm{~mm}$ ) capturada no verão regurgitou um roedor no momento da captura (massa da presa: 17,3g; razão da massa da presa/ massa da serpente = 0,51). Outra fêmea (CRC $530 \mathrm{~mm}$ ) e um macho (CRC $430 \mathrm{~mm}$ ) haviam ingerido pequenos roedores, evidenciados através de pelos e dentes nas fezes.

\section{Philodryas patagoniensis}

Espécie que caça ativamente é generalista e alimenta-se de aves, lagartos, pequenos mamíferos e outras serpentes (AMARAL, 1977; LEMA; ARAUJO; AZEVEDO, 1983; DI-BERNARDO, 1998), inclusive com registro de ingestão de serpente peçonhenta (PERRONI e TRAVAGLIA-CARDOSO, 2007). Dos sete espécimes capturados três estavam com alimento no trato gastrointestinal. Dois machos 
haviam ingerido pequenos roedores (CRC $680 \mathrm{~mm}$; CRC $285 \mathrm{~mm}$ ), e uma fêmea (CRC $910 \mathrm{~mm}$ ) que fez postura de ovos logo após a coleta havia ingerido roedor e lagarto, evidenciados através da presença de pêlos, dentes, unhas (roedor) e escamas (lagarto) em suas fezes.

\section{Ptycophis flavovirgatus}

Sabe-se pouco a respeito dos hábitos alimentares da espécie. Em cativeiro, alguns exemplares ingeriram anuros (gênero Hyla) e pedaços de peixe (LEMA e DEIQUES, 1992). Experimentos posteriores relatam que outros exemplares mantidos em cativeiro recusaram anuros como alimento, o que leva os autores a sugerir hábitos ictiófagos para a espécie (LEMA, 2002). O exame do sistema digestório dos espécimes tombados na coleção de serpentes do Instituto Butantan não revelou indícios da dieta, porém estudos preliminares da dentição da espécie também sugerem hábitos ictiófagos (R. Scartozzoni, comunicação pessoal ${ }^{3}$ ).

\section{Thamnodynastes strigatus}

Espécie anurófaga, mas podem ingerir ocasionalmente pequenos roedores, peixes e lagartos (BERNARDE et al., 2000; RUFFATO; DI-BERNARDO; MASCHIO, 2003). Caçam ativamente, o que pode facilitar o encontro com as presas menos usuais como peixes e lagartos (BERNARDE et al., 2000). Os dois adultos capturados neste estudo aparentavam estar procurando alimento na beira do açude. Foram encontrados pelos nas fezes do macho (CRC $470 \mathrm{~mm}$; massa 45g), evidenciando a ingestão de um pequeno roedor.

\footnotetext{
${ }^{3}$ Scartozzoni, Rodrigo, São Paulo, 2010.
} 


\section{Tomodon dorsatus}

Serpente especialista alimenta-se apenas de moluscos, que procura ativamente (BIZERRA; MARQUES; SAZIMA, 2005).

\section{Xenodon merremii}

Alimenta-se exclusivamente de anuros, principalmente bufonídeos (VANZOLINI; RAMOS-COSTA; VITT, 1980; VITT, 1983; JORDÃO, 1996). Na área de estudo, a espécie provavelmente não encontra dificuldades em conseguir sua principal presa, abundantes nas proximidades dos açudes e da nascente de água mineral. Não obtivemos nenhum registro alimentar da espécie.

Um resumo da dieta, atividade e substrato predominantemente utilizado pelas espécies pode ser observado na tabela 7. 
Tabela 7: Informações da história natural das serpentes coletadas na área de estudo:

Dieta - Itens alimentares consumidos pelas serpentes. Os itens em destaque e negritados são os mais freqüentes na dieta; os outros são itens eventuais ou que as serpentes ingerem em alguma fase de sua vida. $\mathrm{MOL}=$ moluscos; $\mathrm{PE}=$ peixes; $\mathrm{ANU}=$ anuros; $\mathrm{LAG}=$ lagartos; $\mathrm{SER}=$ serpentes; $\mathrm{AV}=$ aves; $\mathrm{MAM}=$ mamíferos.

Atividade - período (predominante) de atividade. NOT = noturno; DIU = diurno.

Substrato - substrato mais utilizado. TER= terrícola; $\mathrm{S} . \mathrm{ARB}=$ semi arborícola.

Informações complementadas com dados de literatura. Os viperídeos foram incluídos nesta tabela.

$?=$ informação provável, porém não confirmada.

\section{DIETA}

ATIV.

SUBST.

\begin{tabular}{|c|c|c|c|c|c|c|c|c|c|}
\hline & MOL & PE & ANU & LAG & SER & $\mathbf{A V}$ & MAM & & \\
\hline P. flavovirgatus & & $?$ & & & & & & DIU. & TER. \\
\hline T. strigatus & & $\mathrm{x}$ & $\mathbf{X}$ & $\mathrm{x}$ & $\mathrm{x}$ & & $\mathrm{x}$ & NOT. & TER/S. ARB \\
\hline T. dorsatus & $\mathbf{X}$ & & & & & & & DIU. & TER. \\
\hline E. bilineata & & & $\mathbf{X}$ & $\mathrm{x}$ & & & & DIU. & TER. \\
\hline O. clathratus & & & & $\mathrm{x}$ & & & $\mathbf{X}$ & NOT. & TER. \\
\hline O. rhombifer & & & $\mathrm{x}$ & $\mathrm{x}$ & & & $\mathbf{X}$ & NOT. & TER. \\
\hline P. patagoniensis & & & $\mathrm{x}$ & $\mathrm{x}$ & $\mathrm{x}$ & $\mathrm{x}$ & $\mathrm{x}$ & DIU. & TER/S. ARB. \\
\hline X. merremii & & & $\mathbf{X}$ & & & & & DIU. & TER. \\
\hline B. jararaca & & & $\mathrm{x}$ & $\mathrm{x}$ & & $\mathrm{x}$ & $\mathbf{X}$ & NOT. & TER. \\
\hline B. neuwiedi & & & & $\mathrm{x}$ & & $\mathrm{x}$ & $\mathbf{X}$ & NOT. & TER. \\
\hline C. durissus & & & & $\mathrm{x}$ & & & $\mathbf{X}$ & NOT. & TER. \\
\hline
\end{tabular}




\section{Predação}

Três eventos de predação foram observados durante o período de estudo.

No primeiro, observado em julho de 2006, uma siriema (Cariama cristata) predou um jovem de P. patagoniensis (comprimento do corpo estimado em $400 \mathrm{~mm}$ ), em área de transição entre Campos de Altitude e uma plantação de batatas. O evento ocorreu às 09:45 horas e a siriema pareceu não se incomodar com a proximidade dos observadores.

O segundo foi observado no mês de julho de 2008, entre 20 e 21 horas. Uma coruja suindara (Tyto alba) capturou uma serpente há poucos metros das edificações da Fazenda Santa Elisa, em área gramada. Havia um ninho de suindara no forro do telhado de um dos alojamentos, com três filhotes e um adulto possivelmente cuidando da prole. Uma segunda coruja adulta saiu de uma araucária nas proximidades, onde estava pousada, voou por aproximadamente $7 \mathrm{~m}$, capturou a serpente (provavelmente um filhote, não foi possível identificar a espécie) e entrou no ninho.

Na terceira predação observada, em dezembro de 2008, às 10:20 horas, uma siriema (Cariama cristata) predou um filhote de $P$. patagoniensis (comprimento do corpo estimado em $200 \mathrm{~mm}$ ) em área de pasto coberto por Brachiaria.

Em maio de 2004 foi coletada (Campos de Altitude) uma fêmea jovem de B. neuwiedi (CRC $350 \mathrm{~mm}$; massa 40g) que apresentava na lateral direita do corpo duas costelas quebradas já calcificadas e uma cicatriz ao redor das calcificações em forma de meia lua. Provavelmente a serpente havia sofrido um ataque predatório mal sucedido.

São diversos os predadores de serpentes observados freqüentemente na FSE. As siriemas (Cariama cristata) são abundantes, principalmente nas áreas de pasto, ao redor das plantações e nos Campos de Altitude, e parecem ser predadores eficientes na região. Também são abundantes as aves de rapina, principalmente as corujas suindara (Tyto alba), as corujas buraqueira (Athene cunicularia), e o gavião carrapateiro (Milvago chimachima). Com menor freqüência são observados o falcão de coleira (Falco femoralis) e o carcará (Caracara plancus). Outros possíveis predadores de 
serpentes que freqüentam a área, porém observados com pouca freqüência, são os gatos do mato (Leopardus tigrinus) e o lobo-guará (Chrisocyon brachyurus).

As aves de rapina são consideradas eficientes predadores de serpentes. Várias predações por Athene cunicularia são relatadas, algumas tendo como presas espécies peçonhentas: Sawaya, et al. (2003a) relatou a predação de um adulto de $O$. rhombifer na Estação Ecológica de Itirapina (SP); Valdujo e Nogueira (2000) relatam a predação de B. pauloensis (GO), e Martins, et al. (2003) relatam três eventos de predação de B. alternatus (também na Estação Ecológica de Itirapina, SP), onde em dois dos eventos as presas eram machos jovens, que tiveram partes de seu corpo devorado, e no terceiro evento uma fêmea de maior porte sobreviveu ao ataque. Ainda na Estação Ecológica de Itirapina foi relatada a predação de um adulto de Chironius flavolineatus por gavião (Buteo albicaudatus) (SAWAYA et al., 2003b). Tozetti, et al. (2004) relata a predação de Oxyrhopus guibei por um lobo-guará (Chrysocyon brachyurus). Todos esses eventos descritos na literatura ocorreram em áreas de cerrado.

Provavelmente a predação de serpentes peçonhentas adultas (se ocorrer) ocorre em pequeno número, e talvez nem sempre o ataque seja bem sucedido. Este fator também pode contribuir para a abundância de viperídeos na Fazenda Santa Elisa. 


\section{Família Dipsadidae - Considerações Gerais}

Entre as oito espécies de dipsadídeos registradas para a FSE, seis são terrícolas e duas terrícolas e semi-arborícolas. Cinco espécies possuem hábitos predominantemente diurnos, e três noturnos. Com relação ao modo reprodutivo, cinco são ovíparas e três vivíparas.

Quanto à dieta, os itens alimentares consumidos são bastante variados. Duas espécies são especialistas: uma ingere exclusivamente moluscos (T. dorsatus) e uma é batracófaga (X. merremii). A espécie $P$. patagoniensis é generalista, consumindo vários ítens alimentares. Outras espécies também são generalistas, porém mostram preferência por um ítem alimentar. T. strigatus e E. bilineata consumem predominantemente anfíbios, mas incluem outros itens na dieta. As espécies $O$. rhombifer e $O$. clathratus ingerem principalmente mamíferos, mas os lagartos são parte importante em sua dieta. Pouco se sabe sobre $P$. flavovirgatus, porém observações de cativeiro indicam hábitos piscívoros.

Apesar de ser uma área antropizada, os anfíbios e répteis são parte importante da dieta de algumas espécies de dipsadídeos da comunidade, e sob o ponto de vista da conservação, a comunidade herpetológica da localidade deve ser entendida de forma integrada. As diferentes fisionomias da vegetação são essenciais para a conservação da diversidade das serpentes e manutenção de suas populações. 


\subsubsection{Composição da comunidade de serpentes da região de Munhoz, sul de Minas Gerais, Serra da Mantiqueira (Grupo 2)}

Considerando a grande região analisada neste estudo, o Grupo 2 (serpentes registradas para a Fazenda Santa Elisa, mais serpentes coletas na cidade de Munhoz fora dos limites da fazenda, mais levantamento da entrada de serpentes no IB da cidade de Munhoz e municípios limítrofes, mais serpentes da coleção do Colégio Municipal de Bueno Brandão) foram registrados representantes de 4 famílias, 20 gêneros e 28 espécies (Tabela 8).

As características climáticas e altitudinais da região analisada neste grupo são menos homogêneas, e a riqueza de espécies observada foi maior em relação ao Grupo 1 (Fazenda Santa Elisa). O número de famílias dobrou (de 2 para 4). O número de gêneros (de 9 para 20) e de espécies (de 11 para 28) ficou mais representativo considerando a comunidade como um todo (Figura 11).

A familia Colubridae, antes não amostrada, é representada pelas espécies Chironius bicarinatus e Simophis rhinostoma, e a família Elapidae, também anteriormente não amostrada, passa a ser representada por Micrurus frontalis.

Duas espécies registradas na grande região não ocorreram na Fazenda Santa Elisa, mas foram encontradas nas proximidades: Apostolepis assimilis e Phalotris reticulatus. A ausência dessas espécies de hábitos predominantemente fossórios nos limites da fazenda pode estar relacionada aos métodos de coleta empregados, além da dificuldade de encontro. A baixa amostragem de espécies de hábitos fossórios parece ser comum em estudos de comunidades de serpentes (DI-BERNARDO, 1998; MARTINS, 1994; MARQUES, 1998).

As espécies Oxirhopus guibei e Sibynomorphus mikani, consideradas comuns em áreas alteradas (SAWAYA, 2004), não foram observadas na Fazenda Santa Elisa, mas foram encontradas na cidade de Munhoz (MG), porém em regiões de menor altitude.

Chironius bicarinatus, espécie relativamente comum na Mata Atlântica (porém mais abundante nas áreas mais baixas) (MARQUES, 1998), parece ser rara na região analisada (nenhum registro da espécie nos dados da Recepção e da Coleção de 
Serpentes do IB). Apenas um indivíduo foi encontrado logo após ser atropelado, em abril, em local com altitude próxima a 1200 m (uma fêmea apresentava folículos em vitelogênese secundária).

Entre os municípios que fazem parte da grande área de estudo (Grupo 2), Socorro (SP) é o mais distinto, com diferenças em relação à altitude, clima e vegetação. Cidade mais desenvolvida e com maior número de habitantes, a ação antrópica pode ter interferido com maior intensidade. O comércio é a principal fonte de renda da população, ao contrário das cidades mineiras analisadas, onde a agricultura continua sendo a principal fonte de renda (IBGE, 2009). Mas apesar de Socorro (SP) ser a mais antropizada e urbanizada das cidades analisadas, das 28 espécies listadas para o Grupo 2 (grande região), 5 espécies ocorreram exclusivamente na cidade de Socorro: M. frontalis, S. rhinostoma, Dipsas indica, Philodryas olfersii e Liophis miliaris. Portanto, se analisarmos o Grupo 2 excluindo a cidade de Socorro (SP), observamos a exclusão de uma família (Elapidae), dois gêneros (Simophis e Dipsas) e cinco espécies de serpentes (Figura 11). Provavelmente os fatores altitudinais e climáticos estejam afetando mais fortemente a distribuição das espécies do que a antropização.

Apesar de presente, apenas dois exemplares de Micrurus frontalis foram registrados. A espécie é bem distribuída no Sudeste brasileiro, porém a maioria dos exemplares é encontrada até aproximadamente os $700 \mathrm{~m}$ de altitude (CAMPBELL e LAMAR, 2004). Os resultados sugerem que a espécie é ausente das áreas mais altas e frias da Serra da Mantiqueira. As espécies L. miliaris, D. indica e P. olfersii são encontradas freqüentemente em áreas associadas à Floresta Atlântica (dados da recepção de serpentes do Instituto Butantan), mas provavelmente não habitam as áreas mais altas da Serra da Mantiqueira. S. rhinostoma parece ser freqüente em áreas perturbadas (SAWAYA, 2004).

A espécie $B$. neuwiedi é a dominante em toda a região de estudo ao sul de Minas Gerais. Porém quando as áreas mais baixas (Socorro, SP) entram na análise, a serpente mais abundante passa a ser Crotalus durissus. A espécie $C$. durissus é associada a áreas abertas (CAMPBELL e LAMAR, 2004), e nos últimos anos tem colonizado áreas antes florestadas, agora degradadas pela ação antrópica. A fragmentação dos habitats florestados favorece a entrada e permanência da espécie nessas áreas alteradas, o que tem aumentado sua incidência em algumas regiões (BASTOS; ARAUJO; SILVA, 2005; 
TOZETTI e MARTINS, 2008). Apenas para comparação, o levantamento de dados da Recepção de Serpentes do IB realizado nos últimos 13 anos registrou para a cidade de Socorro apenas 1 exemplar de B. neuwiedi, 8 de $B$. jararaca e 352 de $C$. durissus. Mais uma vez os resultados sugerem que a abundância das espécies está relacionada às características vegetacionais, altitudinais e climáticas favoráveis.

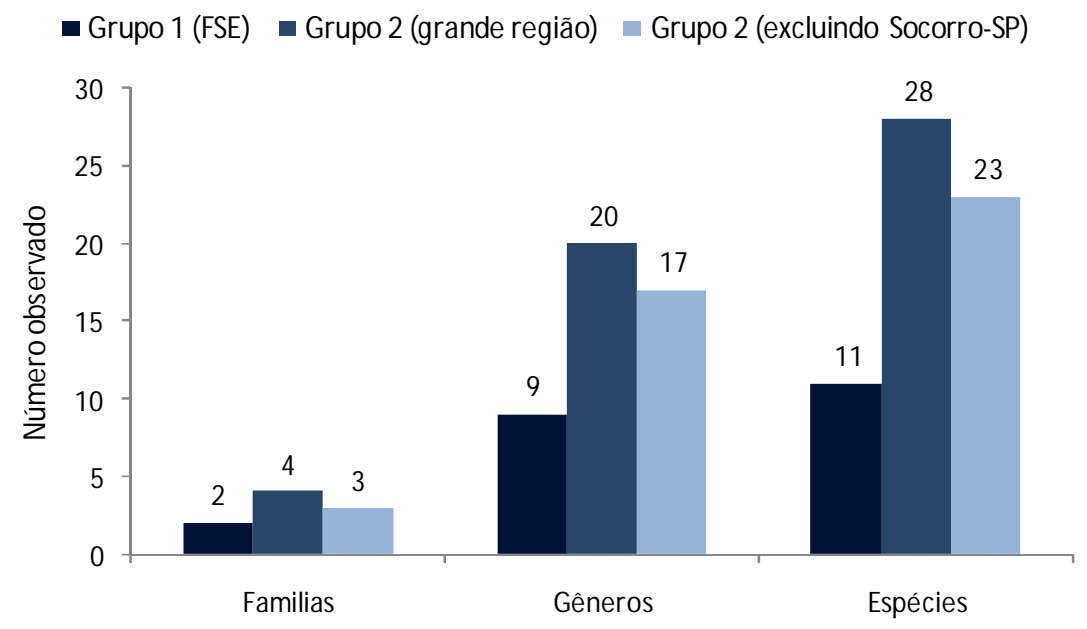

Figura 11: Número de famílias, gêneros e espécies amostradas no Grupo 1 (Fazenda Santa Elisa) e no Grupo 2 (grande região). 
Tabela 8: Grupo 2 - Espécies registradas na área de estudo (Fazenda Santa Elisa) e grande região durante o período de janeiro de 1997 a junho de 2010.

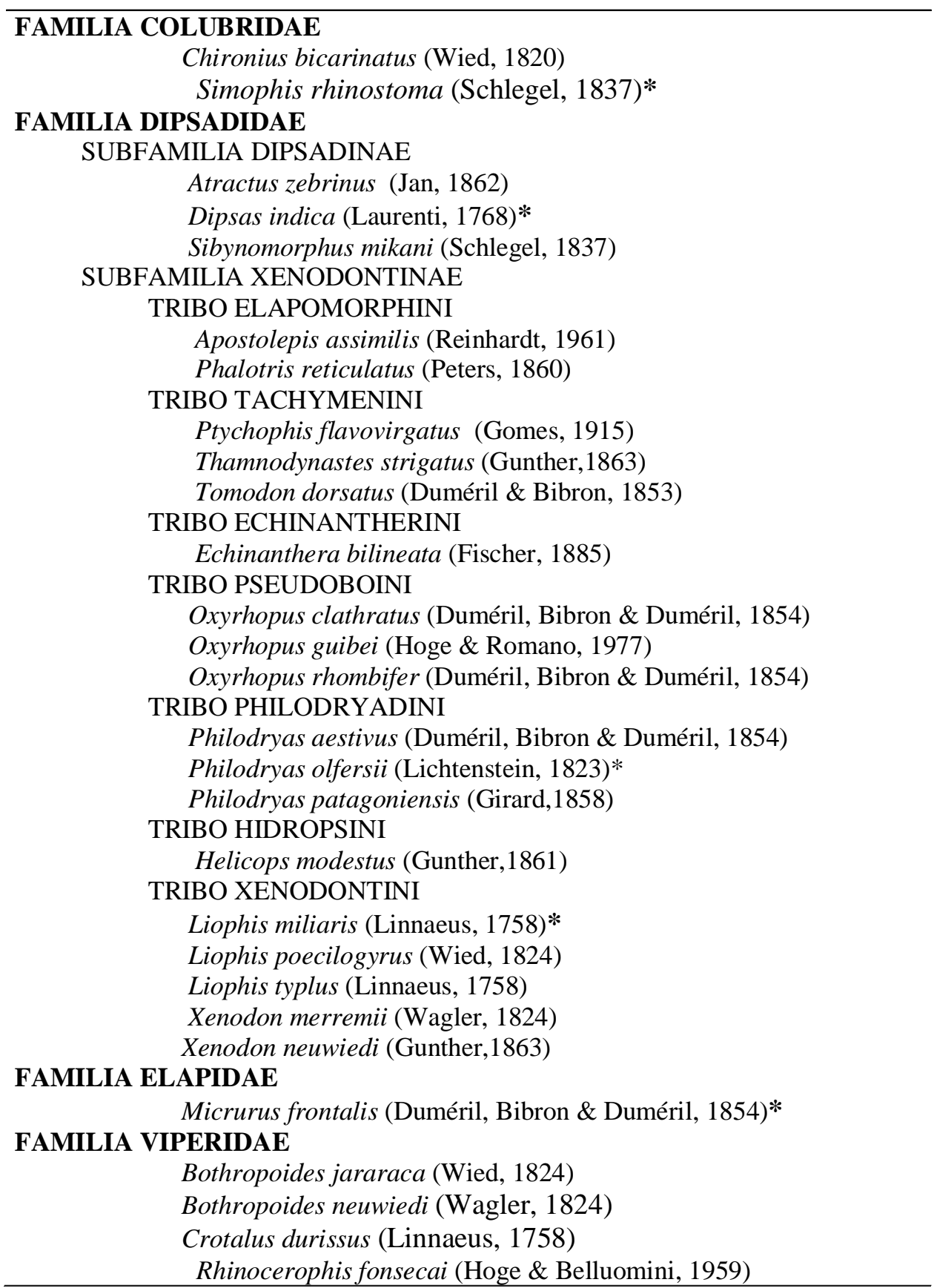

\footnotetext{
* serpentes registradas apenas para a cidade de Socorro (SP).
} 


\section{Distribuição Altitudinal}

Dos elementos climáticos, a temperatura é o que promove efeitos diretos e mais significativos sobre os processos fisiológicos que ocorrem em plantas e animais (FRITZSONS; MANTOVANI; AGUIAR, 2008). A temperatura do ar decresce com a elevação da altitude numa proporção de aproximadamente entre $1{ }^{\circ} \mathrm{C} / 100 \mathrm{~m}$ ou $1{ }^{\circ} \mathrm{C} /$ 180 m (dependendo da saturação do ar) (DURY, 1972). Nos trópicos, as diferenças de temperatura em pequenas distâncias são principalmente decorrentes da variação da altitude e nebulosidade e não tanto da latitude. A relação direta da altitude com a temperatura é especialmente importante para as regiões tropicais e subtropicais, onde uma diferença altitudinal de poucas centenas de metros provoca alterações no clima, solo, vegetação e, conseqüentemente, na adaptação das espécies animais e vegetais a essas variáveis (FRITZSONS; MANTOVANI; AGUIAR, 2008).

A distribuição das espécies em regiões montanhosas geralmente varia de acordo com as diferenças altitudinais (MALLET-RODRIGUES et al., 2010). Assim como outros grupos animais, a composição da herpetofauna pode sofrer alterações significativas com a altitude. Os fatores climáticos que variam em função da latitude, em especial a temperatura, podem influenciar o número de espécies que habitam determinadas localidades (VITT, 1987; SHINE, 1992), sendo que as baixas temperaturas funcionam como fator limitante na atividade das serpentes (LILLYWHITE, 1987).

Neste estudo, devido ao maior número de coletas, os viperídeos permitem análises mais precisas relacionadas à sua distribuição altitudinal. B. neuwiedi, ocupando todos os tipos de ambientes, foi encontrada em todas as cotas altitudinais, sendo mais abundante acima dos $1000 \mathrm{~m}$. Uma ecdise da espécie foi encontrada nos afloramentos rochosos, um dos pontos mais altos da localidade estudada $(1520 \mathrm{~m})$. A literatura relata para a espécie distribuição vertical geralmente até os $1000 \mathrm{~m}$ de altitude (CAMPBELL e LAMAR, 2004). B. jararaca também foi encontrada em todo o gradiente altitudinal da área de estudo, com um exemplar coletado aos $1488 \mathrm{~m}$, porém a espécie não mostra abundância na localidade. Segundo Campbell e Lamar (2004), B. jararaca habita desde o nível do mar até aproximadamente $1.000 \mathrm{~m}$ de altitude. 
Na área de estudo, a distribuição de $C$. durissus parece estar limitada a um limite altitudinal. Nenhum exemplar foi encontrado acima dos $1400 \mathrm{~m}$ de altitude, e a espécie não é abundante na área de estudo. Porém nas regiões mais baixas (Socorro, SP) passa a ser a espécie mais freqüente. Geralmente encontrada abaixo dos $1000 \mathrm{~m}$ de altitude nas regiões tropicais e subtropicais (CAMPBELL e LAMAR, 2004), existem registros de encontro da espécie a $2040 \mathrm{~m}$ na Colômbia, $2500 \mathrm{~m}$ na Venezuela, $2300 \mathrm{~m}$ no Peru e uma população isolada a aproximadamente $2000 \mathrm{~m}$ de altitude nos Andes (ver CAMPBELL e LAMAR, 2004).

Rhinocerophis fonsecai não é encontrada na área de estudo desde o ano 2000, mas os últimos espécimes capturados estavam acima dos $1400 \mathrm{~m}$. Micrurus frontalis foi registrada apenas abaixo dos $1000 \mathrm{~m}$, com apenas dois exemplares.

Quanto aos dipsadídeos não podemos definir padrões de distribuição, mas vale ressaltar que as espécies $P$. flavovirgatus e $X$. merremii foram coletadas apenas nas áreas mais altas. As espécies O.clathratus e O. rhombifer parecem ocupar todas as faixas altitudinais, porém são mais freqüentes acima dos $1000 \mathrm{~m}$.

Considerando as espécies listadas para a grande região de estudo, o número de espécies diminui conforme aumenta a altitude (Figura 12).

A amostragem das espécies listadas neste estudo em relação à altitude do local de coleta pode ser observada na tabela 9 .

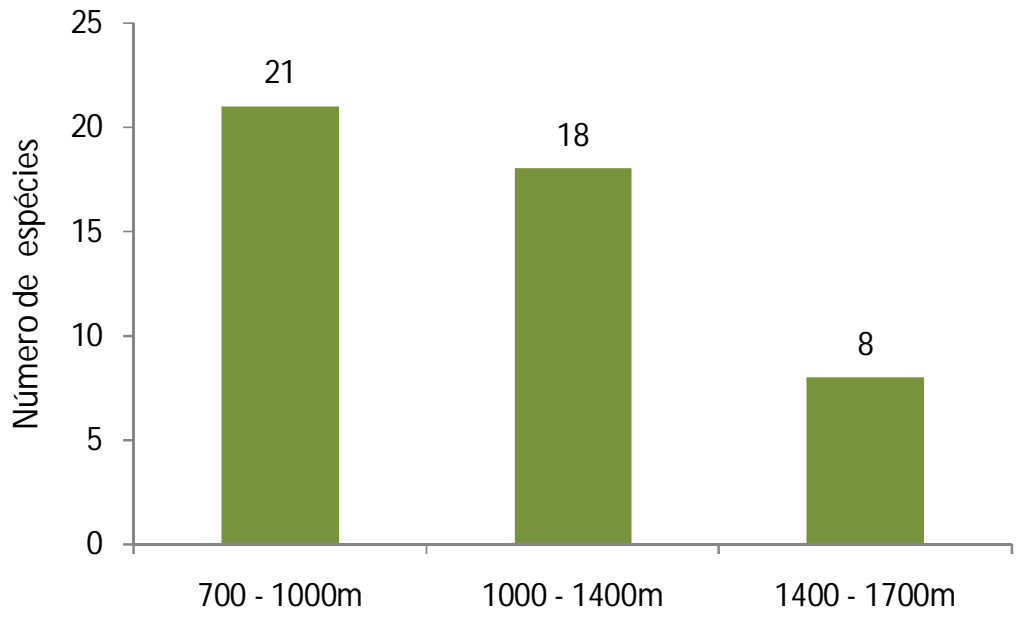

Figura 12: Grupo 2 - Número de espécies amostradas em relação à altitude dos locais de coleta. 
Tabela 9: Presença (X) das espécies amostradas (coletas deste estudo e levantamento da Recepção de Serpentes do Instituto Butantan da grande região durante o período de 1997 a 2010) em relação à altitude do local de coleta. $X=$ pouco freqüente - até 10 exemplares registrados; $\mathrm{XX}=$ freqüente - de 10 a 30 exemplares registrados; $\mathrm{XXX}=$ abundante - mais de 30 exemplares registrados.

\begin{tabular}{|c|c|c|c|}
\hline & $700-1000 \mathrm{~m}$ & $1000-1400 \mathrm{~m}$ & $>1400 \mathrm{~m}$ \\
\hline Chironius bicarinatus & $\mathrm{X}$ & $\mathrm{X}$ & \\
\hline Simophis rhinostoma & $\mathrm{X}$ & & \\
\hline Atractus zebrinus & $\mathrm{X}$ & $\mathrm{X}$ & \\
\hline Dipsas indica & $\mathrm{X}$ & & \\
\hline Sibynomorphus mikani & $\mathrm{XX}$ & $\mathrm{X}$ & \\
\hline Apostolepis assimilis & XX & $\mathrm{X}$ & \\
\hline Phalotris reticulatus & & $\mathrm{X}$ & \\
\hline Ptycophis flavovirgatus & & & $\mathrm{X}$ \\
\hline Thamnodynastes strigatus & $\mathrm{XX}$ & $\mathrm{X}$ & \\
\hline Tomodon dorsatus & $\mathrm{X}$ & $\mathrm{X}$ & \\
\hline Echinantera bilineata & & $\mathrm{X}$ & \\
\hline Oxyrhopus clathratus & $\mathrm{X}$ & $\mathrm{X}$ & $\mathrm{X}$ \\
\hline Oxyrhopus guibei & $\mathrm{XXX}$ & $\mathrm{X}$ & \\
\hline Oxyrhopus rhombifer & $\mathrm{X}$ & $\mathrm{XX}$ & $\mathrm{XX}$ \\
\hline Philodryas aestivus & & $\mathrm{X}$ & \\
\hline Philodryas olfersii & $\mathrm{X}$ & & \\
\hline Philodryas patagoniensis & $\mathrm{X}$ & $\mathrm{X}$ & $\mathrm{X}$ \\
\hline Helicops modestus & $\mathrm{X}$ & & \\
\hline Liophis miliaris & $\mathrm{X}$ & & \\
\hline Liophis poecilogyrus & $\mathrm{X}$ & & \\
\hline Liophis typlus & & $\mathrm{X}$ & \\
\hline Xenodon merremii & & & $\mathrm{X}$ \\
\hline Xenodon neuwiedi & $\mathrm{X}$ & $\mathrm{X}$ & \\
\hline Micrurus frontalsi & $\mathrm{X}$ & & \\
\hline Bothropoides jararaca & $\mathrm{XX}$ & $\mathrm{XX}$ & $\mathrm{XX}$ \\
\hline Bothropoides neuwiedi & $\mathrm{X}$ & $\mathrm{XXX}$ & XXX \\
\hline Crotalus durissus & $\mathrm{XXX}$ & $\mathrm{X}$ & \\
\hline Rhinocerophis fonsecai & & & $\mathrm{X}$ \\
\hline
\end{tabular}




\subsection{CONCLUSÕES}

1) A riqueza de espécies da área de estudo Fazenda Santa Elisa é menor do que a encontrada em outras comunidades brasileiras analisadas, devido às características climáticas e altitudinais da região.

2) A família Viperidae é a dominante na área de estudo Fazenda Santa Eliza, representada pelas espécies Bothropoides jararaca, Bothropoides neuwiedi e Crotalus durissus, as três espécies mais freqüentes na região. Bothropoides neuwiedi é a espécie mais freqüente, representada por $64,6 \%$ do total de indivíduos coletados.

3) Nas áreas abertas foi encontrado o maior número de indivíduos. A riqueza de espécies também foi maior nas áreas abertas, com o registro de 9 espécies, seguido pelas áreas florestadas, com o registro de 7 espécies.

4) A comunidade analisada (Fazenda Santa Elisa) apresentou porcentagem significativa de espécies vivíparas (54,6\%). Provavelmente os altos índices de viviparidade estão associados ao clima frio e as altitudes elevadas da região.

5) A distribuição e abundância das espécies na região são influenciadas pela altitude e, conseqüentemente, pelas características climáticas. Quando analisada a "grande região de estudo", representada pela área da Fazenda Santa Elisa e região ao entorno, as características climáticas e altitudinais passam a ser menos homogêneas. A riqueza de espécies sobe de 11 para 28, e as famílias Colubridae e Elapidae passam a ser representadas. Nas áreas de menor altitude, a espécie Crotalus durissus passa a ser a mais freqüente.

6) As Florestas de Araucárias e ecossistemas associados são importantes para a biodiversidade da ofidiofauna, pois abrigam espécies de serpentes raras e pouco freqüientes. 


\section{REFERÊNCIAS}

AB'SABER, A. N. Os domínios de natureza no Brasil: potencialidades paisagísticas. São Paulo: Ateliê Editorial, 2003. 159p.

AB'SABER, A. N.; BERNARDES, N. Vale do Paraíba, Serra da Mantiqueira e arredores de São Paulo. Rio de Janeiro: União Geográfica Nacional, Comissão Nacional do Brasil, 1958. $304 \mathrm{p}$.

ALMEIDA-SANTOS, S. M; SALOMÃO, M. G. Reproduction in neotropical pitvipers, with emphasis on species of the genus Bothrops. In: SCHUETT, G. W.; HÖGGREN, M.; DOUGLAS, M. E.; GREENE, H. W. (Ed.). Biology of the vipers. Utah: Eagle Mountain Publishing, 2002. p. 445-462.

AMARAL, A. Serpentes do Brasil: iconografia colorida. São Paulo: Melhoramentos, 1977. 248p.

AZEVEDO, L. G. Tipos de vegetação do Sul de Minas e campos da Mantiqueira (Brasil). An. Acad. Bras. Cienc., v. 34, n. 2, p. 225-234, 1962.

BACKES, A. Distribuição geográfica atual da Floresta com Araucária: condicionamento climático. In: FONSECA, C. R.; SOUZA, A. F.; LEAL-ZANCHET, A. M.; DUTRA, T. L.; BACKES, A.; GANADE, G. (Ed.). Floresta com araucária: ecologia, conservação e desenvolvimento sustentável. Ribeirão Preto: Holos Editora, 2009. p. 39-44.

BASTOS, E. G. M.; ARAUJO, A. F. B.; SILVA, H. R. Records of the rattlesnakes Crotalus durissus terrificus (Laurenti) (Serpentes, Viperidae) in the state of Rio de Janeiro, Brazil: a possible case of invasion facilitated by deforestation. Rev. Bras.Zool., v. 22, n. 3, p. 812-815, 2005. 
BAUERMANN, S. G.; BEHLING, H. Dinâmica paleovegetacional da floresta com araucária a partir do pleistoceno: o que mostra a palinologia. In: FONSECA, C. R.; SOUZA, A. F.; LEAL-ZANCHET, A. M.; DUTRA, T. L.; BACKES, A.; GANADE, G. (Ed.). Floresta com araucária: ecologia, conservação e desenvolvimento sustentável. Ribeirão Preto: Holos Editora, 2009. p. 35-38.

BERNARDE, P. S. Composição faunística, ecologia e história natural de serpentes de uma região no sudeste da Amazônia, Rondônia, Brasil. 139 f. Tese (Doutorado em Zoologia) - Instituto de Ciências Biológicas, Universidade Estadual Paulista, Rio Claro, 2004.

BERNARDE, P. S.; ABE, A. S.A snake community at Espigão do Oeste, Rondônia, southwestern Amazon, Brazil. South Am. J. Herpetol., v. 1, n. 2, p. 102-113, 2006.

BERNARDE, P. S.; MOURA-LEITE, J. C.; MACHADO, R. A.; KOKOBUM, M. N. C. Diet of the colubrid snake Thamnodynastes strigatus (Gunther, 1858) from Paraná state, Brazil, with field notes on anuran predation. Rev. Bras. Biol., v. 60, n. 4, p. 695-699, 2000.

BIZERRA, A.; MARQUES, O. A. V.; SAZIMA, I. Reproduction and feeding of the colubrid snake Tomodon dorsatus from south-eastern Brazil. Amphib-reptil., v. 26, n. 1, p. 33-38, 2005.

CAMPBELL, J. A.; LAMAR, W. W.The venomous reptiles of the western hemisphere. Ithaca, NY: Comstock Publishing, Cornell University Press, 2004. 870p.

CARVALHO, C. M.; VILAR, J. C.; OLIVEIRA, F. F. Répteis e anfíbios. In: CARVALHO, C. M.; VILAR, J. C. (Ed.). Parque Nacional Serra de Itabaiana: levantamento da biota. Aracaju: Ibama, 2005. p. 39-61.

CENTENO, F. C. Diversidade e uso do ambiente pelos anfíbios e répteis da Ilha deSão Sebastião, Ilhabela, SP. 138 f. Dissertação (Mestrado em Biotecnologia) - Instituto de Ciências Biomédicas, Universidade de São Paulo, São Paulo, 2008. 
CICCHI, P. J. P.; SENA, M. A.; PICCININI-SEALE, D. M.; DUARTE, M. R. Snakes from coastal islands of State of São Paulo, Southeastern Brazil. Biota Neotrop., v. 7, n. 2, p. $227-$ $240,2007$.

CICCHI, P. J. P.; SERAFIM, H.; SENA, M. A.; CENTENO, F. C.; JIM, J. Herpetofauna em uma área de Floresta Atlântica na Ilha Anchieta, município de Ubatuba, sudeste do Brasil. Biota Neotrop., v. 9, n. 2, p. 201-212, 2009.

CUNHA, O. R.; NASCIMENTO, F. P. Ofídios da Amazônia. X. As cobras da região leste do Pará. Publ. Avulsas Mus. Paraense Emílio Goeldi, n. 32, p. 1-218, 1978.

DEIQUES, C. H. Répteis da floresta com araucária. In: FONSECA, C. R.; SOUZA, A. F.; LEAL-ZANCHET, A. M.; DUTRA, T. L.; BACKES, A.; GANADE, G. (Ed.). Floresta com araucária: ecologia, conservação e desenvolvimento sustentável. Ribeirão Preto: Holos Editora, 2009. p. 185-190.

DEIQUES, C. H.; STAHNKE, L. F.; REINKE, M.; SCHMITT, P. Guia ilustrado dos anfíbios e répteis do Parque Nacional de Aparados da Serra, Rio Grande do Sul - Santa Catarina, Brasil. Pelotas: Editora USEB, 2007. 120p.

DI-BERNARDO, M. História natural de uma comunidade de serpentes da borda oriental do planalto das araucárias, Rio Grande do Sul, Brasil. 123 f. Tese (Doutorado em Zoologia) - Instituto de Biociências, Universidade Estadual Paulista, Rio Claro, 1998.

DUELLMAN, W. E. The biology of an equatorial herpetofauna in Amazonian Ecuador.Misc.

Publ. Mus. Nat. Hist., n. 65, p. 1-352, 1978.

DURY, G. H. High temperature extremes in Australia.Ann. Assoc. Am. Geogr., v. 62, n. 3, p. $388-400,1972$.

FITCH, H. S. Reproductive cycles in lizards and snakes. Publ. Mus. Nat. Hist. Univ. Kansas, n. 52, p. 1-247, 1970.

FOWLER, I.; SALOMÃO, M. G. Activity patterns in the colubrid snake genus Philodryas and their relationship to reproduction and snakebite.Bull. Chicago Herp.Soc., v. 29, n. 10, p. 229-232, 1994. 
FOWLER, I.; SALOMÃO, M. G.; JORDÃO, R. S. A description of the female reproductive cycle in four species from the neotropical colubrid snake Philodryas (Colubridae, Xenodontinae). Snake,v. 28, n. 1-2, p. 71-78, 1998.

FRITZSONS, E.; MANTOVANI, L. E.; AGUIAR, A. V. Relação entre altitude e temperatura: uma contribuição ao zoneamento climático no estado do Paraná. REA, v. 10, n. 1, p. 49-64, 2008.

FURLAN, A. S.; NUCCI, J. C. A conservação das florestas tropicais. São Paulo: Atual Editora, 1999. 112p.

GIBBONS, J. W.; SEMLITSCH, R. D. Activity patterns. In: SEIGEL, R. A.; COLLINS, J. T.; NOVAK, S. S. (Ed.). Snakes: ecology and evolutionary biology. New York: MacMillan Publ. Co., 1987. p. 396-421.

GOVERNO DO ESTADO DE SÃO PAULO. Secretaria do Meio Ambiente. Fauna ameaçada de extinção noEstado de São Paulo - Vertebrados.BRESSAN, P. M.; KIERULFF, M. C. M.; SUGIEDA, A. M. (Coord.). São Paulo: Fundação Parque Zoológico de São Paulo, 2009. 648p.

GRAVES, B. M.; DUVALL, D. Aggregation of squamate reptiles associated with gestation, oviposition, and parturition. Herpetol. Monogrs., v. 9, n. 1995, p. 102-119, 1995.

HARTMANN, P. A. Historia natural e ecologia de duas taxocenoses de serpentes na Mata Atlântica. 117 f. Tese (Doutorado em Zoologia) - Instituto de Biociências, Universidade Estadual Paulista, Rio Claro, 2005.

HARTMANN, P. A.; HARTMANN, M. T.; MARTINS, M. Ecologia e história natural de uma taxocenose de serpentes do Núcleo Santa Virgínia do Parque estadual da Serra do Mar, no sudeste do Brasil. Biota Neotrop., v. 9, n. 3, p. 173-184, 2009.

HOGE, A. R. Notas herpetológicas. 1 contribuição ao conhecimento dos ofídios do Brasil Central. Mem. Inst. Butantan, v. 24, n. 2, p. 179-214, 1952a.

HOGE, A. R. Notas herpetológicas. 2 contribuição ao conhecimento dos ofídios do Brasil Central. Mem. Inst. Butantan, v. 24, n. 2, p. 214-224, 1952 b.

HUECK, K. As florestas da América do Sul. São Paulo: Editora UnB/Polígono, 1972. 466p. 
INSTITUTO BRASILEIRO DE GEOGRAFIA E ESTATÍSTICA - IBGE. Cidades, Minas

Gerais, Munhoz, estimativa da população 2009. Disponível em:

<http://www.ibge.gov.br/cidades> Acesso em: 02 set. 2010.

JORDÃO, R. S. Estudo comparativo da alimentação e da reprodução de Waglerophis merremii e Xenodon neuwiedii (Serpentes: Colubridae). 93 f. Dissertação (Mestrado em Zoologia) - Instituto de Biociências, Universidade de São Paulo, São Paulo, 1996.

KÖPPEN, W.; GEIGER, R. Classificação climática de Köppen-Geiger. 1936. Disponível em: <http://www.ambientebrasil.com.br/classificaçãoclimática > Acesso em: 10 set. 2010.

LEITÃO FILHO, H. F. Aspectos taxonômicos das florestas do Estado de São Paulo. Silvicultura, v. 16A, n. 1, p.197-206, 1982.

LEITE, P. F. Contribuição ao conhecimento fitoecológico do Sul do Brasil. Ciência e Ambiente. Santa Maria: Universidade Federal de Santa Maria (UFSM), v. 24, p. 51-73, 2002.

LEMA, T. As serpentes do estado do Rio Grande do Sul. Iheringia (Série Divulgação), n. 3, p. 19-33, 1973.

LEMA, T. Lista comentada dos répteis ocorrentes no Rio Grande do Sul, Brasil. Com. Mus. Cienc. Tecnol. , v. 7, p. 41-150, 1994.

LEMA, T. Os répteis do Rio Grande do Sul: atuais e fósseis - biogeografia - ofidismo. Porto Alegre: EDIPUCRS, 2002. 166 p.

LEMA, T.; DEIQUES, C. H. Contribuição ao conhecimento da "Cobra espada d'água", Ptycophis flavovirgatus Gomes, (Serpentes, Colubridae, Xenodontinae, Tachymenini). Com. Mus. Cienc. Tecnol., v. 5, n. 6, p. 55-83, 1992.

LEMA, T.; ARAUJO, M. L.; AZEVEDO, A. C. P. Contribuição ao conhecimento da alimentação e do modo alimentar de serpentes do Brasil. Com. Mus. Cienc. Tecnol., v. 26, p. 41-121, 1983. 
LILLYWHITE, H. B. Circulatory adaptations of snakes to gravity. Am. Zool., v. 27, n. 1, p. 81-95, 1987.

MALLET-RODRIGUES, F.; PARRINI, R.; PIMENTEL, L. M.; BESSA, R. Altitudinal distribution of birds in a mountainous region in southeastern Brazil. Zoologia, v. 27, n. 4, p. 503-522, 2010.

MARQUES, O. A. V. Composição faunística, história natural e ecologia de serpentes da Mata Atlântica, na região da estação ecológica Juréia-Itatins, São Paulo, SP. 135 f. Tese (Doutorado em Zoologia) - Instituto de Biociências, Universidade de São Paulo, São Paulo, 1998.

MARQUES, O. A. V.; SAZIMA, I. História natural dos répteis da estação ecológica JuréiaItatins. In: MARQUES, O. A. V; DULEBA, W. (Ed.). Estação ecológica Juréia-Itatins: ambiente físico, flora e fauna. Ribeirão Preto: Holos Editora, 2004. p. 257-277.

MARQUeS, O. A. V.; ETEROVIC, A.; SAZIMA, I. Serpentes da Mata Atlântica: guia ilustrado para a Serra do Mar. Ribeirão Preto: Holos Editora, 2001. 184p.

MARTINS, M. História natural e ecologia de uma taxocenose de serpentes de mata na região de Manaus, Amazônia Central, Brasil. 98 f. Tese (Doutorado em Ecologia) Instituto de Biologia, Universidade Estadual de Campinas, Campinas, 1994.

MARTINS, M.; GORDO, M. Bothrops atrox (Common Lancehead).Diet. Herpetol.Rev., v. 24, n. 4, p.151-152, 1993.

MARTINS, M.; SANO, P. T. Biodiversidade tropical. Coleção Paradidáticos (Série Evolução). São Paulo: Editora UNESP, 2009, v.1, 128p.

MARTINS, M.; MARQUES, O. A. V.; SAZIMA, I. Ecological and phylogenetic correlates of feeding habits in neotropical pitvipers of the genus Bothrops. In: SCHUETT, G. W.; HÖGGREN, M.; DOUGLAS, M. E.; GREENE, H. W. (Ed.). Biology of the vipers. Utah: Eagle Mountain Publishing, 2002. p. 307-328.

MARTINS, M.; SPINA, F.; MONTEIRO, C.; SAWAYA, R. J.; ARIEDI-JUNIOR, V. R.Bothropsalternatus(Urutu).Predation. Herpetol.Rev., v. 34, n. 2, p.147-148, 2003. 
MEDEIROS, C. R.; HESS, P. L.; NICOLETI, A. F.; SUEIRO, L. R.; DUARTE, M. R.; ALMEIDA-SANTOS, S. M.; FRANÇA, F. O. S. Bites by the colubrid snake Philodryas patagoniensis: a clinical and epidemiological study of 297 cases. Toxicon, v. 56, n.6, p. 1018-1024, 2010.

MEIRELES, L. D.; SHEPHERD, G. J.; KINOSHITA, L. S. Variações na composição florística e na estrutura fitossociológica de uma floresta ombrófila densa alto-montana na Serra da Mantiqueira, Monte Verde, MG. Rev. Bras. Bot.,v. 31, n. 4, p. 559-574, 2008.

MORATO, S. A. A. Padrões de distribuição da fauna de serpentes da floresta de araucária e ecossistemas associados na região sul do Brasil. 122 f. Dissertação (Mestrado em Zoologia) - Departamento de Zoologia, Universidade Federal do Paraná, Curitiba, 1995.

NOGUEIRA, C. C. Ecologia histórica de Bothrops spp. (Serpentes: Viperidae: Crotalinae) simpátricas no Cerrado. 69 f. Dissertação (Mestrado em Ecologia) - Instituto de Biociências, Universidade de São Paulo, São Paulo, 2001.

OLIVEIRA-FILHO, A. T.; FONTES, M. A. L. Patterns of floristic differentiation among Atlantic Forest in southeastern Brazil and the influence of climate. Biotropica, v. 32, p. 793 $810,2000$.

OLIVEIRA, M. E.; MARTINS, M. When and where to find a pitviper: activity patterns and habitat use of the lancehead, Bothrops atrox, in central Amazonia, Brazil. Herpetol. Nat. Hist., v. 8, n. 2, p. 101-110, 2001.

PARODI, L. R. Las regiones fitogeográficas argentinas. Ciência e Ambiente, v. 24, p. 25-34, 2002.

PEREIRA, D. N. Composição e diversidade de répteis Squamata em fragmentos florestais do noroeste do estado de São Paulo. 130 f. Dissertação (Mestrado em Biotecnologia) - Instituto de Ciências Biomédicas, Universidade de São Paulo, São Paulo, 2010.

PERRONI, L. P. G.; TRAVAGLIA-CARDOSO, S. R. Philodryas patagoniensis (Parelheira): venomous snake (Crotalid) as prey. Natural History Notes. Herpetol.Bull., n. 101, p. 37-39, 2007. 
PETERS, J. A.; OREJAS-MIRANDA, B. Catalogue of the Neotropical Squamata: Part I, Snakes. Revised edition (originally published 1970), addenda and corrigenda by Vanzolini, P. E.Washington, D.C.: SmithsonianInstitution, 1986. 347p.

PONTES, G. M. F.; DI-BERNARDO, M. Registros sobre aspectos reprodutivos de serpentes neotropicais (Serpentes, Colubridae e Elapidae). Com. Mus. Cienc. Tecnol., v. 1, n. 5, p. 123-149, 1988.

PORTO, M.; CARAMASCHI, U. Notes on the taxonomic status, biology, and distribution of Ptycophis flavovirgatus Gomes, 1915 (Ophidia, Colubridae).An. Acad. Bras. Cienc., v. 60, n. 4, p. 471-475, 1988.

POUGH, F. H.; ANDREWS, R. M.; CADLE, J. E.; CRUMP, M. L.; SAVITZKY, A. H.; WELLS, K. D. Herpetology. New Jersey: Prentice-Hall Inc., 2001. 612p.

PUORTO, G.; SAZIMA, I.; LAPORTA-FERREIRA, I. L. Serpentes na selva de pedra. Ciência Hoje, v. 13, n. 76, p. 66-67, 1991.

RODRIGUES, M. T. Herpetofauna das dunas interiores do Rio São Francisco, Bahia, Brasil. V. Duas novas espécies de Apostolepis (Ophidia, Colubridae). Mem. Inst. Butantan, v. 54, n. 2,p. 53-59, 1992.

RODRIGUES, M. T. Herpetofauna of paleoquaternary sand dunes of the middle São Francisco River: Bahia, Brazil.VI. Two New Species of Phimophis (Serpentes: Colubridae) with notes on the origin of psammophilic adaptations. Pap. Avulsos Zool., v. 38, n. 11, p. 187-198, 1993.

RODRIGUES, M.T. Lizards, snakes, and amphisbaenians from the quaternary sand dunes of the middle Rio São Francisco, Bahia, Brazil.J. Herpetol., v. 30, n. 4, p. 513-523, 1996.

RUFFATO, R.; DI-BERNARDO, M.; MASCHIO, G. F. Dieta de Thamnodynastes strigatus (Serpentes, Colubridae) no Sul do Brasil. Phyllomedusa, v. 2, n. 1, p. 27-34, 2003. 
SAWAYA, R. J. História natural e ecologia das serpentes de cerrado da região de Itirapina, SP. 145 f. Tese (Doutorado em Ecologia) - Instituto de Biologia, Universidade Estadual de Campinas, Campinas, 2004.

SAWAYA, R. J.; ARIEDI-JUNIOR, V. R.; MONTEIRO, C.; SPINA, F. Oxyrhopus rhombifer (false coral snake).Predation. Herpetol. Rev., v. 34, n. 2, p. 152-153, $2003 \mathrm{a}$.

SAWAYA, R. J.; SPINA, F., MONTEIRO, C.; OLIVEIRA, J. L.; BRASILEIRO, C. A. Chironius flavolineatus(NCN). Predation. Herpetol. Rev., v. 34, n. 4, p. 371-372, 2003 b.

SAZIMA, I. Um estudo de biologia comportamental da jararaca, Bothrops jararaca, com uso de marcas naturais. Mem. Inst. Butantan, v. 50, n. 3, p. 83-99, 1988.

SAZIMA, I. Natural history of the jararaca pitviper, Bothrops jararaca, in southeastern Brazil. In: CAMPBELL, J. A.; BRODIE JR, E. D. (Ed.).Biology of the pitvipers. Arlington: Selva Publ., 1992. p. 199-216.

SAZIMA, I.; HADDAD, C. F. B. Répteis da Serra do Japi: notas sobre história natural. In: MORELLATO, L. P. C. (Ed.). História natural da serra do Japi: ecologia e preservação de uma área florestal no sudeste do Brasil. Campinas: Ed. UNICAMP, 1992. p. 212-236.

SCARTOZZONI, R. R.; MARQUES, O. A. V. Sexual dimorphism, reproductive cycle, and fecundity of the water snake Ptycophis flavovirgatus (Serpentes, Colubridae).Phyllomedusa, v. 3, n. 1, p. 69-71, 2004.

SEIGEL, R. A. The foraging ecology and resource partioning patterns of two species of garter snakes. Ph. D. Thesis - University of Kansas, Lawrence, 1984.

SEIGEL, R. A.; FORD, N. B. Reproductive ecology. In: SEIGEL, R. A.; COLLINS, J. T.; NOVAK, S. S. (Ed.). Snakes: ecology andevolutionary biology. New York: MacMillan Publ. Co., 1987. p. 210-252.

SHINE, R. Reproduction in Australian Elapidsnakes. I. testicular cycles and mating seasons. Aust. J. Zool., v. 25, n. 4, p. 647-653, 1977 a. 
SHINE, R. Reproduction in Australian Elapid snakes. II. Female reproductive cycles. Aust. J. Zool., v. 25, n. 4, p. 655-666, 1977b.

SHINE, R. Grow rates and sexual maturation in six species of Australian elapid snakes. Herpetologica, v. 34, n. 1, p. 73-79, 1978.

SHINE, R. "Costs” of reproduction in reptiles. Oecologia, v. 46, n. 1, p. 92-100, 1980.

SHINE, R. Reptilian reproductive modes: the oviparity-viviparity continuum. Herpetologica.v. 39, p. 1-8.

SHINE, R. The evolution of viviparity in reptiles: an ecological analysis. In: GANS, C.; BILLETT, F. (Ed.). Biology of the reptilia. New York: John Wiley and Sons, 1985. v. 15 , p. $605-694$.

SHINE, R. Relative clutch mass and body shape in lizards and snakes: is reproductive investment constrained or optimized?. Evolution, v. 46, n. 3, p. 828-833, 1992.

STRÜSSMANN, C.; SAZIMA, I. The snake assemblage of the Pantanal at Poconé, western Brazil: faunal composition and ecological summary. Stud. Neotrop. Fauna Environ., v. 28, n. 3, p. 157-168, 1993.

THOMAS, R. A. A revision of the American colubrid snake genus Philodryas Wagler, 1830. Ph. D. Thesis - Graduate College of Texas, A \& M University, 1976.

TINKLE, D. W.; GIBBONS, J. W.The distribution and evolution of viviparity in reptiles. Misc. Publ. Mus. Zool. Univ. Mich., n. 154, p. 1-55, 1977.

TOZETTI, A. M.; MARTINS, M. Habitat use by the South-American rattlesnake (Crotalus durissus) in South-Eastern Brazil. J. Nat. Hist., v. 42, n. 19-20, p. 1435-1444, 2008. 
TOZETTI, A. M.; MARTINS, M.; MOTTA-JUNIOR, J. C.; SAWAYA, R. J. Oxyrhopus guibei (false coral snake).Predation. Herpetol. Rev., v. 35, n. 2, p. 179, 2004.

TRAVAGLIA-CARDOSO, S. R. Waglerophis merremii (Boipeva). Reproduction. Herpetol.Rev., v. 38, n. 4, p. 471, 2007.

TRAVAGLIA-CARDOSO, S. R.; ALMEIDA-SANTOS, S. M. Termites nests as brood-laying sites in Crotalus durissus. Resumos. IX Reunião Científica Anual do Instituto Butantan, São Paulo, 2007. 1 CD-ROM.

TRAVAGLIA-CARDOSO, S. R.; MAIA, D. C. Tomodon dorsatus (pampas snake). Reproduction. Herpetol.Bull., v. 111, p. 38, 2010.

VALDUJO, P. H.; NOGUEIRA, C. Bothrops neuwiedi pauloensis. Predation. Herpetol.Rev., v. 31, n.1, p. 45, 2000.

VANZOLINI, P. E. Notas sobre os ofídios e lagartos da Cachoeira de Emas, no município de Pirassununga, Estado de São Paulo. Rev. Bras. Biol., v. 8, n. 3, p. 377-400, 1948.

VANZOLINI, P. E. Zoologia sistemática, geografia e a origem das espécies. São Paulo, Instituto de Geografia da Universidade de São Paulo, 1970. n. 3,56p.

VANZOLINI, P. E. A Quase-Historical approach to the natural history of the differentiation of reptiles in tropical geographic isolates.Pap.Avulsos Zool., v. 34, n. 19, p. 189-204, 1981.

VANZOLINI, P. E.; WILLIAMS, E. E. South American anoles: the geographic differentiation and evolution of the Anolis chrysolepis species group (Sauria, Iguanidae). São Paulo: Arquivos de Zoologia, v. 19, n. 3-4, p. 125-298, 1970.

VANZOLINI, P. E.; RAMOS-COSTA, A. M. M.; VITT, L. J. Répteis das caatingas. Rio de Janeiro: Academia Brasileira de Ciências, 1980. 161p.

VASCONCELOS, M. F.; D'ANGELO NETO, S. First assessment of the avifauna of Araucaria forests and other habitats from extreme southern Minas Gerais, Serra da Mantiqueira, Brazil, with notes on biogeography and conservation. Pap. Avulsos Zool., v. 49, n. 3, p. 49-71, 2009. 
VELOSO, H. P.; RANGEL FILHO, A. L. R.; LIMA, J. C. A. Classificação da vegetação brasileira, adaptada a um sistema universal. Rio de Janeiro: IBGE, 1991. 123p.

VITT, L. J. Ecology of an anuran eating guild of terrestrial tropical snakes. Herpetologica, v. 39 , n. 1 , p. $52-66,1983$.

VITT, L. J. Communities. In: SEIGEL, R. A.; COLliNS, J. T.; NOVAK, S. S. (Ed.). Snakes: ecology and evolutionary biology. New York: MacMillan Publ. Co., 1987. p. 335-365.

VITT, L. J.; VANGILDER, L. D. Ecology of a snake community in northeastern Brazil.Amphib-reptil., v. 4, n. 2-4, p. 273-296, 1983. 


\section{ANEXO A - Diferentes fisionomias da vegetação de ocorrência na Fazenda Santa Elisa, Munhoz, MG.}

Fig. A 1 - Floresta Ombrófila Densa Alto-Montana

Fig. A 2 - Floresta Ombrófila Densa Alto-Montana

Fig. A 3 - Floresta Ombrófila Densa Alto-Montana

Fig. A 4 - Floresta Ombrófila Mista Alto-Montana

Fig. A 5 - Floresta Ombrófila Mista Alto-Montana

Fig. A 6 - Transição Reflorestamento / Campos de Altitude

Fig. A 7 - Reflorestamento

Fig. A 8 - Reflorestamento

Fig. A 9 - Campos de Altitude (verão)

Fig. A 10 - Campos de Altitude (inverno)

Fig. A 11 - Morro coberto por Campos de Altitude (presença de cupinzeiros)

Fig. A 12 - Campos de Altitude

Fig. A 13 - Campos de Altitude com afloramentos rochosos

Fig. A 14 - Campos de Altitude com afloramentos rochosos

Fig. A 15 - Capoeira (verão)

Fig. A 16 - Capoeira (inverno)

Fig. A 17 - Mosaico de vegetação (Capoeira / Campos de Altitude / Mata)

Fig. A 18 - Tratos antrópicos (edificações da Fazenda Santa Elisa / pastagens)

Fig. A 19 - Tratos antrópicos (canteiro de mudas - ao fundo, reflorestamento e Campos de Altitude) 

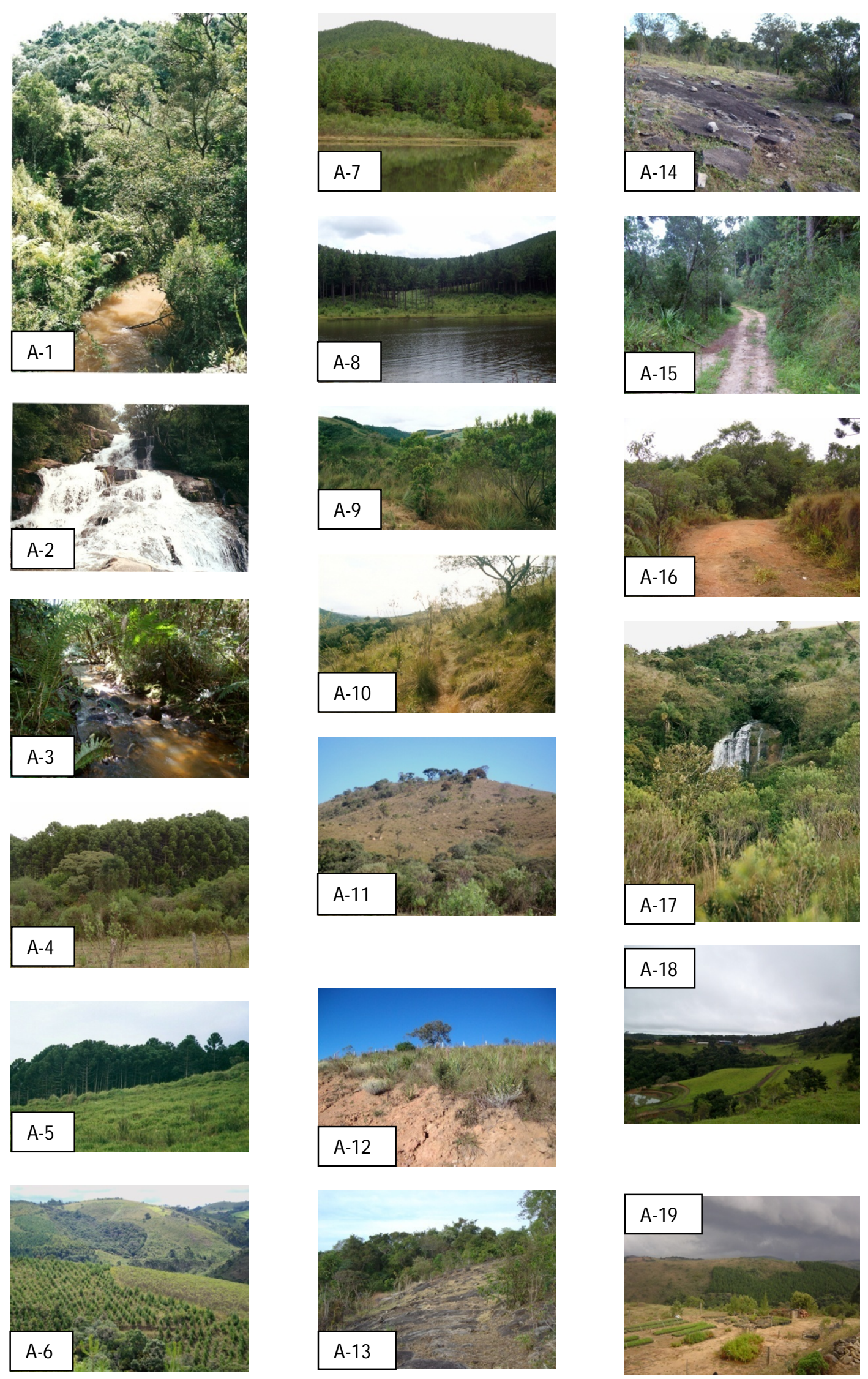


\section{ANEXO B - Contribuição deste estudo para coleções científicas.}

Bothropoides neuwiedi - Munhoz, Minas Gerais. Machos:

MZUSP: 12139; 12138; IB: 65628; 65909; 66440; 66441; 66758; 66942; 67186; $67598 ; 70583 ; 73187 ; 73186 ; 75351 ; 75352 ; 75505 ; 77838$.

Bothropoides neuwiedi - Munhoz, Minas Gerais. Fêmeas:

MZUSP: 12137; IB: 64716; 65629; 65630; 65908; 66653; 66319; 66320; 66321; $66322 ; 66442 ; 66757 ; 66840 ; 67196 ; 67362 ; 67782 ; 67863 ; 67956 ; 68862 ; 69846$; 70965; 70966; 73185; 75349; 75350; 75502; 75503; 75504; 77837; 77839.

Bothropoides jararaca: IB: 62417; 66318; 70123; 70130; 77836.

Crotalus durissus: IB 75508.

Oxyrhopus clathratus: IB 68663.

Oxyrhopus rhombifer: IB 66443; 66522; 66395; 69887; 70249.

Ptycophis flavovirgatus: IB 68662.

Philodryas patagoniensis: IB 67867; 70220; 70558.

Thamnodynastes strigatus: IB 68780; 70250.

Tomodon dorsatus: IB 69886.

Apostolepis assimilis: IB 69810; 69811.

Philodryas aestivus aestivus: IB 69808.

Amphisbaena mertensi: IBSP CRIB 0713.

Cercosaura quadrilineata: MZUSP 95283.

Ophiodes striatus: IBSP-CRIB 0714.

Rhinella ictérica: IBSP-CRIB 009.

Tupinanbis merianae: IBSP-CRIB 0721.

Tropidurus itambere: MZUSP 95284; 95285; 95286. 
ANEXO C - Espécies de serpentes coletadas na Fazenda Santa Elisa, Munhoz, MG. Família Dipsadidae.

Fig. C 1 - Ptycophis flavovirgatus (Foto: Marcelo Duarte)

Fig. C 2 - Thamnodynastes strigatus.

Fig. C 3 - Tomodon dorsatus.

Fig. C 4 -Echinanthera bilineata.

Fig. C 5 - Oxyrhopus clathratus (Foto: Giuseppe Puorto).

Fig. C 6 -Oxyrhopus rhombifer.

Fig. C 7 - Philodryas patagoniensis.

Fig. C 8 -Xenodon merremii. 


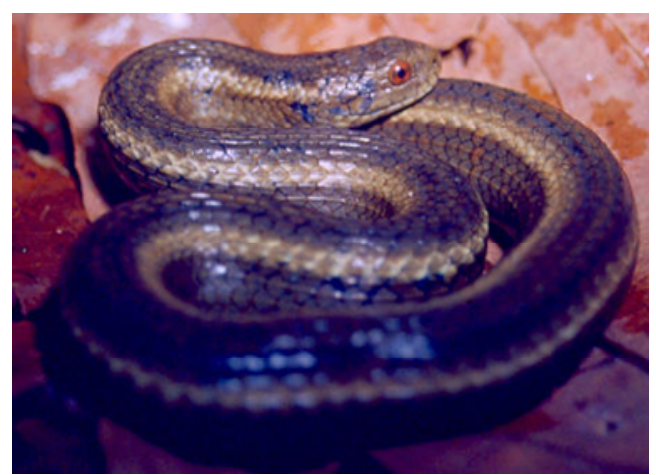

Fig.C 1: Ptycophis flavovirgatus

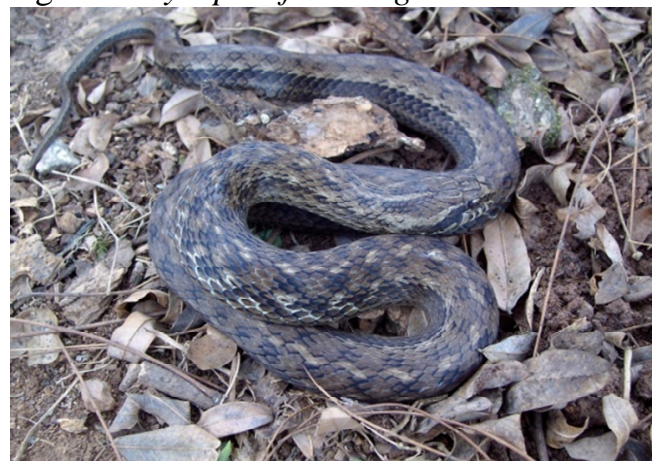

Fig.C 2: Thamnodynastes strigatus

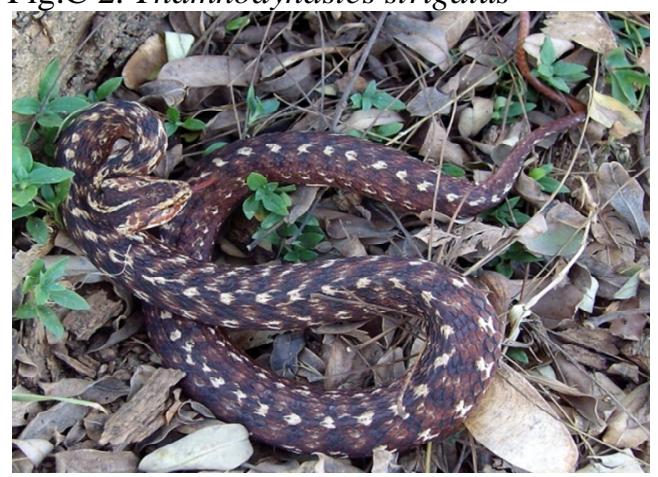

Fig.C 3: Tomodon dorsatus

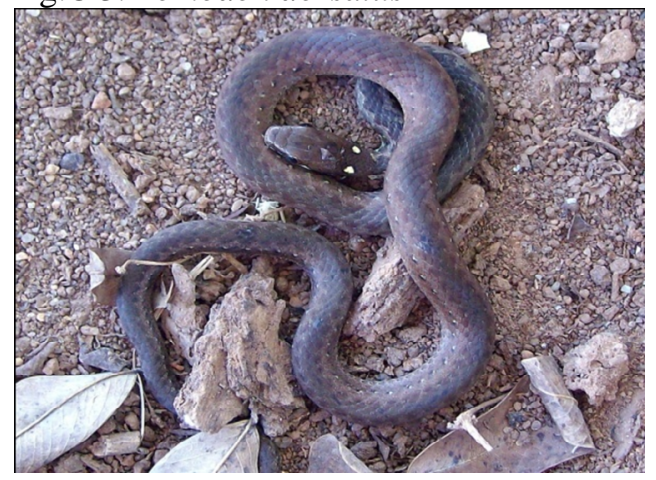

Fig.C 4: Echinanthera bilineata

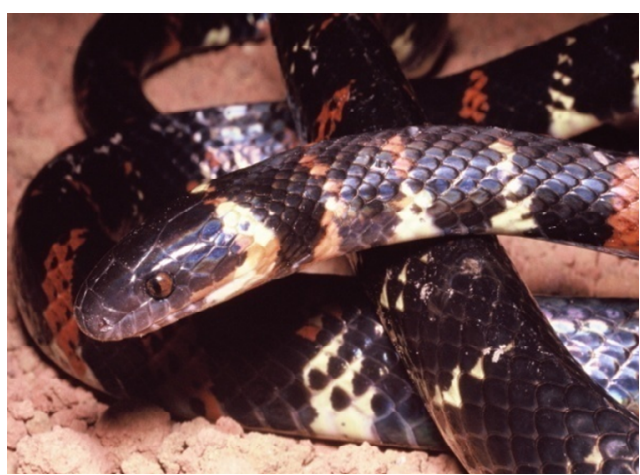

Fig.C 5: Oxyrhopus clathratus

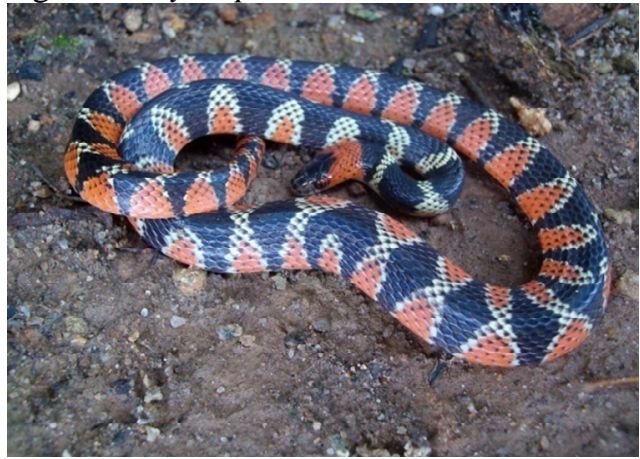

Fig.C 6: Oxyrhopus rhombifer

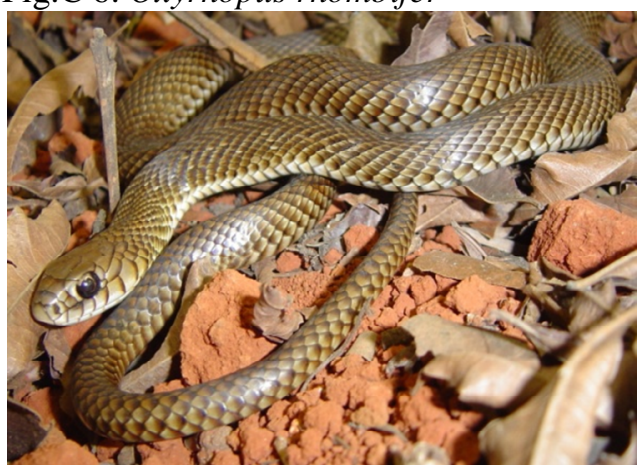

Fig.C 7: Philodryas patagoniensis

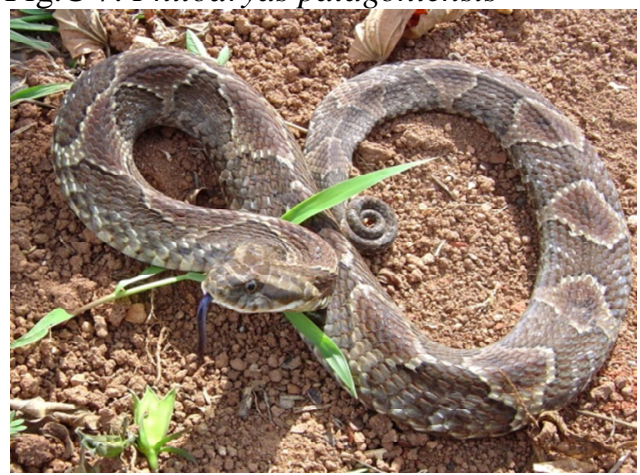

Fig.C 8: Xenodon merremii 


\section{ANEXO D - Serpentes da família Dipsadidae no momento do encontro, Fazenda Santa Elisa, Munhoz, MG (Figs. D 1 a D 4). \\ Rhinocerophis fonsecai (Fig. D 5).}

Fig. D 1 - Oxyrhopus rhombifer, exibindo comportamento de esconder a cabeça. Fêmea (CRC $530 \mathrm{~mm})$.

Fig. D 2 - Oxyrhopus rhombifer, em tentativa de fuga. Fêmea (CRC 475 mm).

Fig. D 3 - Philodryas patagoniensis, bebendo água. Estrada de terra que corta área de capoeira. Fêmea (CRC 250 mm).

Fig. D 4 - Tomodon dorsatus, exposta ao sol na borda de um fragmento de mata. Altura: $1.20 \mathrm{~m}$ do solo. Fêmea (CRC $470 \mathrm{~mm}$ ).

Fig. D 5 - Rhinocerophis fonsecai. 


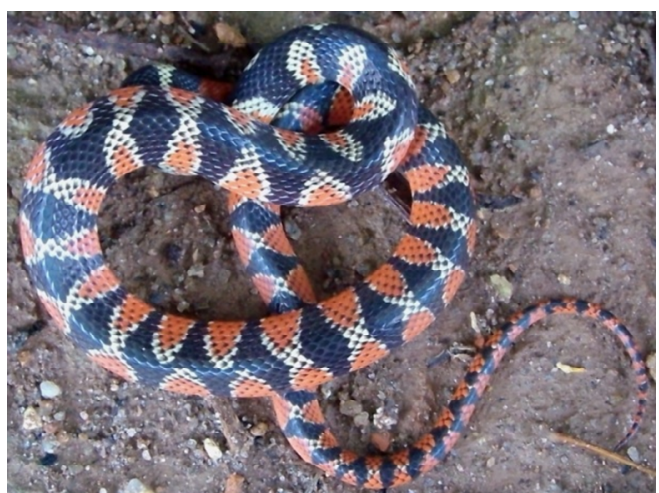

Fig. D 1: Oxyrhopus rhombifer.

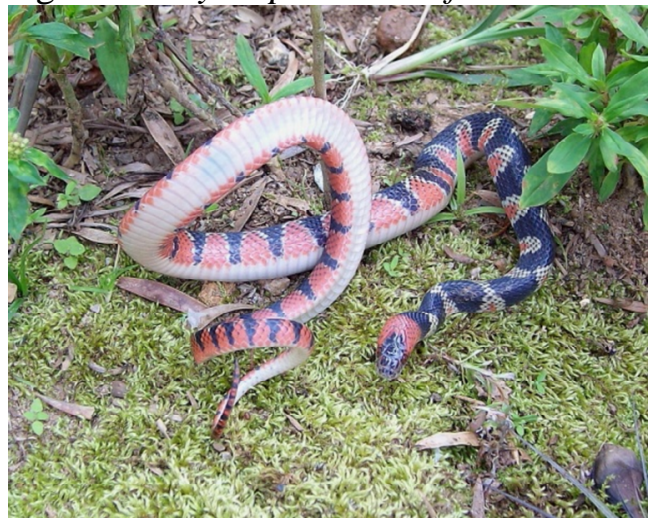

Fig. D 2: Oxyrhopus rhombifer.

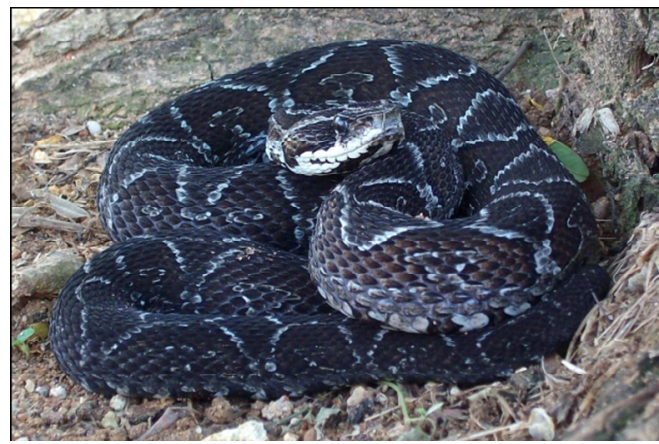

Fig. D 5: Rhinocerophis fonsecai.

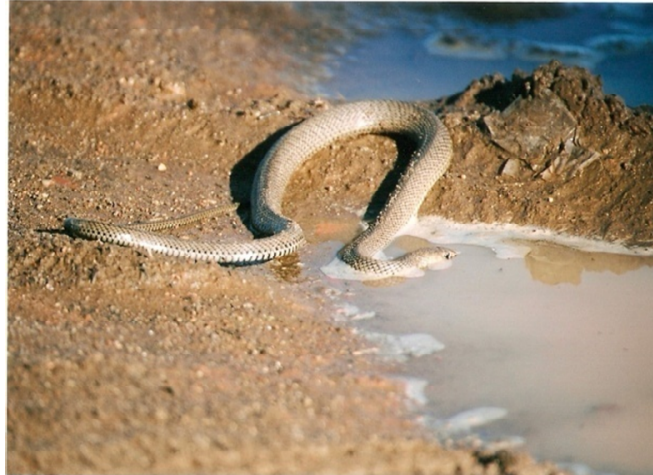

Fig. D 3: Philodryas patagoniensis.

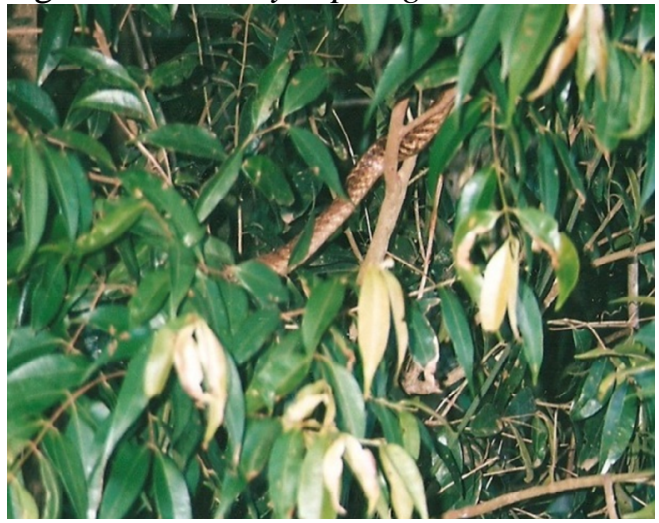

Fig. D 4: Tomodon dorsatus. 


\section{CAPÍTULO 2}

HISTÓRIA NATURAL DOS VIPERÍDEOS DA FAZENDA SANTA ELISA, MUNHOZ, SUL DE MINAS GERAIS, SERRA DA MANTIQUEIRA 


\section{SUMÁRIO}

2 Cap. 2 - História natural dos viperídeos da Fazenda Santa Elisa, Munhoz, Sul de Minas Gerais, Serra da Mantiqueira.

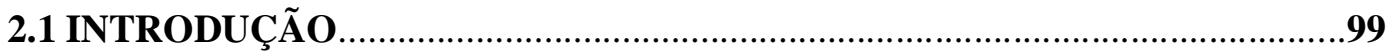

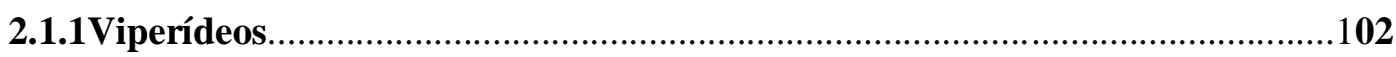

2.2 OBJETIVOS

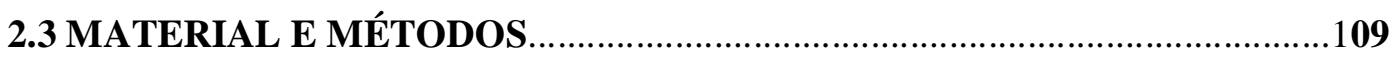

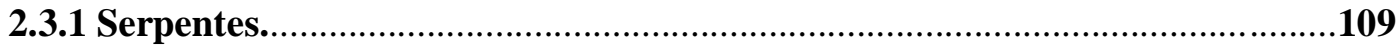

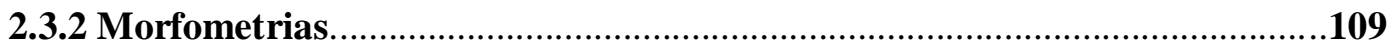

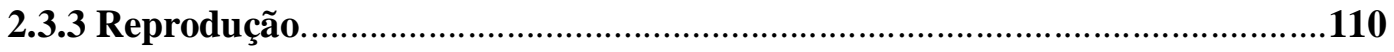

2.3.4 Dieta

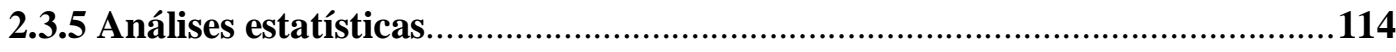

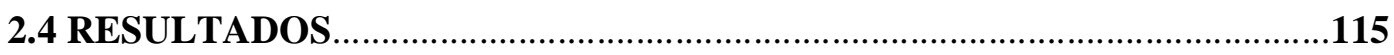

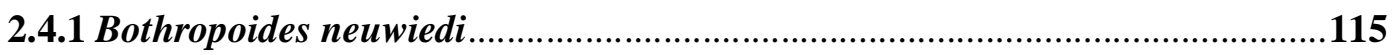

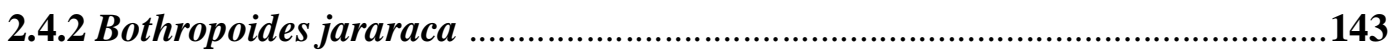

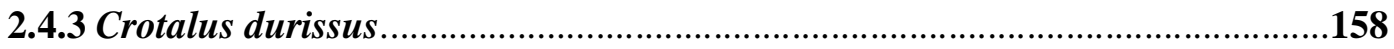

2.4.4 Bothropoides neuwiedi e Bothropoides jararaca - análises comparativas......166

2.5 DISCUSSÃO

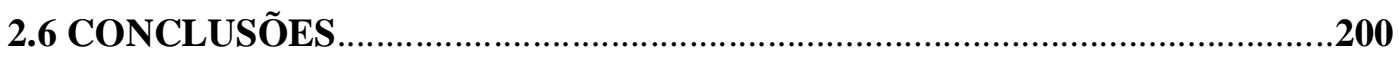

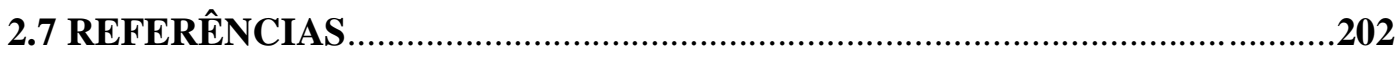

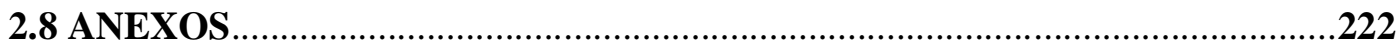




\subsection{INTRODUÇÃO}

A ecologia de comunidades aborda a história natural das espécies que ocorrem em uma localidade e seus padrões de distribuição, riqueza, abundância relativa e o uso de recursos do ambiente (POUGH et al., 2001).

As análises de uso do ambiente trazem informações sobre o habitat e período de atividade, sendo que as características de determinados ambientes podem influenciar nos comportamentos adotados pelas serpentes (VANZOLINI, 1948; STRÜSSMANN e SAZIMA, 1993; MARQUES, 1998). Fatores históricos como biogeografia, e fatores ecológicos como predação, competição, parasitismo e as condições ambientais também estão envolvidos na estruturação de uma comunidade (SAWAYA, 2004).

Quanto à história natural de serpentes neotropicais, as informações ainda são escassas quando comparadas as de espécies que habitam as regiões temperadas (PARKER e PLUMMER, 1987; SEIGEL e FORD, 1987; HENDERSON et al, 1995; DI-BERNARDO, 1998), porém nas duas últimas décadas este cenário vem mudando, e no Brasil uma série de estudos abordando a história natural de comunidades ou de espécies tem contribuído para aumentar o conhecimento sobre a ecologia das serpentes (STRÜSMANN e SAZIMA, 1993; MARTINS, 1994; MORATO, 1995; DIBERNARDO, 1998; DUARTE, 1999; NOGUEIRA， 2001; BERNARDE，2004; CARVALHO;VILLAR; OLIVEIRA, 2005; OLIVEIRA, 2008; TOZETTI e MARTINS, 2008; DEIQUES, 2009; HARTMANN; HARTMANN; MARTINS, 2009).

Dentre os diferentes aspectos que a história natural aborda, a reprodução e a alimentação são os mais estudados (MUSHINSKY, 1987; SEIGEL e FORD, 1987). Informações sobre reprodução e alimentação são essenciais para a compreensão dos processos adaptativos que promovem e mantém mecanismos de especiação e distribuição das espécies nos diferentes habitats e formações vegetais. As diferentes estratégias reprodutivas e alimentares variam entre as espécies e também entre populações da mesma espécie, podendo ser influenciadas por fatores bióticos e abióticos (STEARNS, 1980; SEIGEL e FITCH, 1984; DUNHAM e MILES, 1985; SEIGEL; FITCH; FORD, 1986; PARKER e PLUMMER, 1987; SHINE, 1988; PIANKA, 2000). Conhecer as variações regionais e populacionais das especializações reprodutivas e 
alimentares é fundamental para a compreensão da biologia das espécies ou comunidades de serpentes.

As serpentes apresentam grande diversidade nas estratégias reprodutivas, e grande parte do conhecimento acumulado sobre a reprodução de serpentes provém de estudos baseados em espécies que habitam regiões de clima temperado onde, em sua maioria, os ciclos reprodutivos são estritamente sazonais (ALDRIDGE, 1979; QUINN, 1979; SAINT- GIRONS, 1963, 1982; SEIGEL e FORD, 1987; SHINE et al., 1998).

Porém, nos últimos anos, a quantidade e principalmente a qualidade das informações referentes à biologia reprodutiva das serpentes neotropicais aumentou consideravelmente, através de estudos mais abrangentes que abordam diferentes aspectos da reprodução. Mais especificamente no Brasil, a biologia reprodutiva tem sido objeto de estudo de muitos pesquisadores (ver ALMEIDA-SANTOS e SALOMÃO, 2002; ver PIZZATTO; ALMEIDA-SANTOS; MARQUES, 2007).

São várias as abordagens possíveis nos estudos reprodutivos. Um dos aspectos mais estudados são os ciclos reprodutivos de machos e fêmeas, cuja freqüência e duração podem ser influenciadas por uma série de fatores, principalmente os ambientais (FITCH, 1970, 1982; LICHT, 1972; DUELMANN, 1978; ALDRIDGE, 1979; VITT, 1983; SEIGEL e FORD, 1987; SHINE et al., 1998; SHINE, 2003). O modo reprodutivo (viviparidade ou oviparidade) também influencia diretamente a periodicidade reprodutiva das serpentes (SHINE, 1985).

O sucesso reprodutivo das fêmeas (fecundidade) pode ser abordado por meio de informações sobre o tamanho da ninhada, tamanho dos filhotes, massa relativa das ninhadas, freqüência de reprodução e as relações das ninhadas com as proporções corporais das fêmeas. Todos esses parâmetros podem variar entre as espécies e dentro de uma mesma espécie, de acordo as alterações climáticas e a disponibilidade de alimento (VITT, 1983; SEIGEL e FORD, 1987). Já o comportamento reprodutivo das serpentes pode ser abordado através das interações, rituais de combate entre machos, comportamento de corte e acasalamento (PIZZATTO; ALMEIDA-SANTOS; MARQUES, 2007).

Reprodução e alimentação são processos estreitamente relacionados, o sucesso reprodutivo é dependente das reservas energéticas obtidas dos alimentos (STEARNS, 
1992), e o recurso alimentar utilizado pode determinar a extensão dos ciclos reprodutivos das serpentes tropicais (VITT, 1983; SEIGEL e FORD, 1987).

Análises da alimentação das serpentes podem incluir estudos de comportamento alimentar e da dieta (WHORLEY, 2000; MARTINS; MARQUES; SAZIMA, 2002; ALFARO, 2003; SHINE, 2003). A dieta pode influenciar no uso do habitat e no período de atividade das serpentes (TOFT, 1985).

As serpentes podem ser generalistas ou especialistas (ZUG, 1993; GREENE, 1997) e alimentam-se de uma ampla gama de presas, como artrópodes, moluscos, peixes, anfíbios, amphisbenídeos, lagartos, serpentes, aves e mamíferos (SEXTON, 1956/1957; VITT, 1983; MUSHINSKY, 1987; SAZIMA,1989,1991,1992; MARQUES e PUORTO, 1994; OLIVEIRA et al., 2001). Pode ocorrer necrofagia comportamental ou ocasional (SAZIMA e STRÜSSMANN, 1990) e ofiofagia em cativeiro em serpentes que não possuem esse hábito no ambiente natural, principalmente por disputa de alimento (CARDOSO JUNIOR et al., 1990).

Variações na dieta são observadas entre machos e fêmeas e entre juvenis e adultos (VANZOLINI, 1948; SAZIMA, 1991, 1992; SHINE, 1991; HOLYCROSS e MACKESSY, 2002). Nas espécies peçonhentas as variações na dieta entre juvenis e adultos podem vir acompanhadas de variações ontogenéticas nas atividades biológicas de seus venenos (FURTADO, 1987; FURTADO et al., 1991; DALTRY; WUSTER; THORPE, 1996; ANDRADE e ABE, 1999; FURTADO; TRAVAGIA-CARDOSO; ROCHA, 2006; ZELANIS; TRAVAGIA-CARDOSO; FURTADO, 2008). Algumas espécies, principalmente aquelas com ampla distribuição geográfica, podem apresentar significativas variações geográficas na dieta (HOLYCROSS e MACKESSY, 2002).

Por meio das análises da dieta podem ser estabelecidas as relações entre presa e predador, a sazonalidade na captura dos itens alimentares e a sobreposição no uso dos mesmos itens por espécies simpátricas (MUSHINSKY, 1987; SAZIMA e MARTINS, 1990; ARNOLD, 1993; RODRIGUEZ-ROBLES, 2002).

Além disso, o dimorfismo sexual, principalmente relacionado às dimensões corporais, pode afetar as estratégias reprodutivas e alimentares das serpentes (SEIGEL e FORD, 1987; SHINE, 1994; FURTADO; TRAVAGIA-CARDOSO; ROCHA, 2006; PIZZATTO; ALMEIDA-SANTOS; MARQUES, 2007). 


\subsubsection{Viperídeos}

A família Viperidae está presente em todos os continentes, exceto na Austrália e no continente Antártico, habitando uma grande diversidade de habitats (GREENE, 1997). É um grupo bem sucedido e bastante diversificado, e apresenta como principais características a dentição solenóglifa, corpo robusto e cabeça destacada do corpo (GREENE, 1997).

No Brasil, a família Viperidae é representada pela subfamília Crotalinae, cuja principal característica é a presença da fosseta loreal, órgão termorreceptor localizado entre o olho e a narina (GREENE, 1997). Após recentes mudanças taxonômicas baseadas em caracteres morfológicos e moleculares, atualmente no Brasil os viperídeos estão representados pelos gêneros: Bothriopsis (duas espécies), gênero Bothrocophias (uma espécie), gênero Bothropoides (onze espécies), gênero Bothrops (oito espécies), gênero Rhinocerophis (quatro espécies), gênero Crotalus (uma espécie) e gênero Lachesis (uma espécie) (FENWICK et al., 2009; Sociedade Brasileira de Herpetologia, 2011).

Neste trabalho, realizado em uma área de altitude da Serra da Mantiqueira, ao sul de Minas Gerais, abordamos a história natural dos viperídeos Bothropoides jararaca, Bothropoides neuwiedi e Crotalus durissus, espécies simpátricas na área de estudo. 


\section{Bothropoides jararaca (Wied, 1824)}

Bothropoides jararaca está distribuída apenas na América do Sul, ocorrendo no Brasil, Paraguai e Argentina. No Brasil sua área de ocorrência vai do sul da Bahia até o Rio Grande do Sul, com distribuição vertical desde o nível do mar até aproximadamente $1.200 \mathrm{~m}$ de altitude (CAMPBELL e LAMAR, 2004).

Serpente abundante no sudeste brasileiro habita toda a extensão do Domínio Tropical Atlântico em diversos tipos de ambientes florestados, áreas abertas associadas a cerrados e áreas perturbadas e com grande influência antrópica, onde sobrevive em pequenas manchas de mata (SAZIMA, 1988; PUORTO; SAZIMA; LAPORTAFERREIRA, 1991; SAZIMA, 1992; CAMPBELL e LAMAR, 2004). Devido à abundância e facilidade de adaptação aos diferentes habitats, B. jararaca é a responsável pela maior parte dos acidentes ofídicos humanos da região sudeste do Brasil, sendo considerada de grande importância epidemiológica (FRANÇA e MÁLAQUE, 2003).

A espécie pode atingir até $1600 \mathrm{~mm}$ de comprimento (CAMPBELL e LAMAR, 2004), mas geralmente fica abaixo dessa medida. Porém, em cativeiro, as fêmeas podem atingir tamanhos superiores aos $2000 \mathrm{~mm}$ (Silvia Cardoso, observação pessoal). Os padrões de coloração são variáveis, com manchas triangulares marrons escuras entremeadas por áreas mais claras, resultando num padrão críptico de coloração, eficaz na camuflagem do animal (GOMES e PUORTO, 1993; CAMPBELL e LAMAR, 2004).

Possuem hábitos crepusculares e noturnos, mas podem ser encontradas durante o dia, principalmente em atividades termoregulatórias (VANZOLINI, 1948; SAZIMA, 1988). Espécie de hábitos predominantemente terrícolas, mas os juvenis utilizam freqüentemente o substrato arbóreo (SAZIMA, 1988; SAZIMA e HADDAD, 1992; MORAES, 2008).

B. jararaca apresenta variação ontogenética na dieta. Os jovens alimentam-se principalmente de pequenos vertebrados como anfíbios anuros e lagartos, e eventualmente de pequenos roedores. Os adultos alimentam-se principalmente de roedores, e ocasionalmente aves e presas ectotérmicas (SAZIMA, 1992; MARQUES; ETEROVIC; SAZIMA, 2001; MARTINS; MARQUES; SAZIMA, 2002; MORAES, 
2008). O comportamento de engodo caudal pode ser utilizado pelos jovens para atrair pequenas presas (SAZIMA, 1991; HARTMANN e ALMEIDA, 2001).

A serpente $B$. jararaca se reproduz por viviparidade, e sua reprodução foi estudada sob diferentes aspectos, quase sempre com animais procedentes do estado de São Paulo (JANEIRO-CINQUINI; LEINZ; ISHIZUKA, 1990; JANEIRO-CINQUINI; LEINZ; FARIAS, 1993 a,b; JANEIRO-CINQUINI; FARIAS; LEINZ, 1995; TRAVAGLIA-CARDOSO, 2001; ALMEIDA-SANTOS e ORSI, 2002; ALMEIDASANTOS, 2005).

O veneno de $B$. jararaca é caracterizado principalmente pelas atividades proteolítica, coagulante e hemorrágica (FRANÇA e MÁLAQUE, 2003), sendo observado um acentuado dimorfismo sexual na quantidade de veneno produzido, assim como nas atividades biológicas e farmacológicas (MENEZES et al., 2006; FURTADO; TRAVAGLIA-CADOSO; ROCHA, 2006).

Devido à sua abundância na região Sudeste do Brasil, a espécie é uma das mais estudadas entre os viperídeos brasileiros.

\section{Bothropoides neuwiedi (Wagler, 1824)}

Há aproximadamente uma década atrás, com base principalmente na coloração e nos padrões de manchas e desenhos do corpo e da cabeça, as Bothrops neuwiedi eram tratadas como parte do "complexo Bothrops neuwiedi", ou seja, Bothrops neuwiedi era classificada como uma espécie com 12 subespécies formalmente reconhecidas: B. n. neuwiedi, B. n. bolivianus, B. n. diporus, B. n. goyazensis, B. n. lutzi, B. n. mattogrossensis, B. n. meridionalis, B. n. paranaensis, B. n. pauloensis, B. $n$. piauhyensis, B. $n$. pubescens e B. $n$. urutu, com distribuição pelas áreas abertas do Brasil, Bolívia, Paraguai, Argentina e Uruguai (PETERS e OREJAS-MIRANDA, 1986; CAMPBELL e LAMAR, 1989). Recentemente, após revisão sistemática de Silva e Rodrigues (2008), passou a ser considerada uma espécie plena, Bothropoides neuwiedi.

Considerado como um grupo taxonomicamente confuso, o complexo B. neuwiedi passou por revisão sistemática onde seis subespécies foram elevadas ao nível de espécie 
(B. neuwiedi, B. diporus, B. lutzi, B. matogrossensis, B. pauloensis, B. pubescens), e as demais entraram na sinonímia destas seis. Além disso, foi descrita uma nova espécie, B. marmoratus (SILVA e RODRIGUES, 2008). Já reconhecida como uma espécie plena, após recentes mudanças taxonômicas, Bothrops neuwiedi passou a Bothropoides neuwiedi (FENWICK et al., 2009).

A espécie Bothropoides neuwiedi ocorre apenas no Brasil, e se distribui pelos estados da Bahia, Goiás, Minas Gerais, Rio de Janeiro, São Paulo, Paraná, Santa Catarina e possivelmente norte do Rio Grande do Sul (CAMPBELL e LAMAR, 2004; SILVA e RODRIGUES, 2008). Distribui-se verticalmente do nível do mar até mais de $1000 \mathrm{~m}$ de altitude (CAMPBELL e LAMAR, 2004), habitando principalmente as regiões cobertas pelo Domínio Tropical Atlântico, geralmente em áreas abertas associadas a regiões rochosas (CAMPBELL e LAMAR, 2004). A espécie possui ampla distribuição e ocorre em diferentes habitats, com populações isoladas na periferia de suas áreas de ocorrência (SILVA e RODRIGUES, 2008). Existe registro da espécie em áreas montanhosas, na Serra do Espinhaço, Minas Gerais (SILVA e RODRIGUES, 2008).

Serpente de hábitos terrícolas possui comprimento médio de $700 \mathrm{~mm}$, porém alguns exemplares podem alcançar por volta de $1000 \mathrm{~mm}$ (CAMPBELL e LAMAR, 2004). Alimentam-se basicamente de pequenos roedores, sem variação ontogenética na dieta (MARTINS; MARQUES; SAZIMA, 2002). São vivíparas, e assim como a maioria dos outros viperídeos apresentam ciclo reprodutivo bienal (ALMEIDASANTOS e SALOMÃO, 2002).

O veneno de B.neuwiedi é caracterizado principalmente pelas atividades proteolítica, coagulante e hemorrágica (FRANÇA e MÁLAQUE, 2003). A espécie é a principal causadora de acidentes ofídicos humanos nas regiões mais altas do sul de Minas Gerais (Silvia Cardoso, observação pessoal).

Informações ecológicas e de biologia reprodutiva e alimentar do grupo ou de outras espécies do grupo B. neuwiedi estão disponíveis (MARTINS; MARQUES; SAZIMA, 2002; ALMEIDA-SANTOS et al, 2004a; HARMANN; MARQUES; ALMEIDA-SANTOS, 2004) porém são poucas as informações sobre a espécie Bothropoides neuwiedi, e nenhum estudo havia sido conduzido em campo. 


\section{Crotalus durissus (Linnaeus, 1758)}

A espécie Crotalus durissus possui distribuição geográfica descontínua da Colômbia até a Argentina. Pode ser encontrada em quase todo o território brasileiro, porém habitando principalmente as áreas abertas (CAMPBELL e LAMAR, 2004). Atualmente, devido à crescente degradação dos habitats florestados, a área de ocorrência da espécie vem aumentando consideravelmente, sendo encontrada em áreas antropizadas, inclusive com registros da espécie em áreas alteradas com presença de mata (BASTOS; ARAUJO; SILVA, 2005).

Serpente terrícola, robusta, de hábito predominantemente noturno, apresenta comprimento médio de $1000 \mathrm{~mm}$, porém alguns exemplares podem chegar a $1600 \mathrm{~mm}$ de comprimento (CAMPBELL e LAMAR, 2004).

Alimentam-se basicamente de roedores e esporadicamente aves e lagartos, e não apresentam variação ontogenética na dieta (SALOMÃO; ALMEIDA-SANTOS; PUORTO, 1995; SANT'ANNA e ABE, 2007). Serpente vivípara, também possui ciclo reprodutivo bienal (ALMEIDA-SANTOS e ORSI, 2002; ALMEIDA-SANTOS et al, 2004b). Os machos apresentam o comportamento de rituais de combate antes do acasalamento (SALOMÃO e ALMEIDA-SANTOS, 2002).

O veneno das $C$. durissus á caracterizado principalmente pelas atividades neurotóxica, miotóxica e coagulante (AZEVEDO-MARQUES; HERING; CUPO, 2003) e, ao contrário de muitas espécies do gênero Bothrops, não apresenta variação ontogenética em suas atividades (FURTADO; TRAVAGLIA-CARDOSO; ROCHA, 2006).

A literatura apresenta importantes informações biológicas sobre a espécie, principalmente referentes à reprodução e dieta (ALMEIDA-SANTOS e SALOMÃO, 2002; VANZOLINI e CALLEFFO, 2002, ALMEIDA-SANTOS e ORSI, 2002; ALMEIDA-SANTOS et al, 2004 a,b, SALOMÃO; ALMEIDA-SANTOS; PUORTO, 1995; SANT' ANNA e ABE, 2007). Porém, com exceção do estudo sobre uso do ambiente, atividade e deslocamento de $C$. durissus (TOZETTI, 2006), são poucas as informações da espécie obtidas no campo. 


\section{Considerações gerais:}

Espécies de serpentes amplamente distribuídas, caso das três espécies aqui analisadas, estão sujeitas a variações geográficas em seus caracteres ecológicos, principalmente os reprodutivos e alimentares, devido a diferentes pressões seletivas em suas áreas de distribuição (MAYR, 1977; SHINE et al, 1998; PIANKA, 2000).

Estudos de comunidades em localidades geograficamente restritas, sujeitas a variáveis climáticas, altitudinais e vegetacionais mais homogêneas, são importantes para o conhecimento da biologia e ecologia das espécies, por submeter às amostras às mesmas condições ambientais (VANZOLINI; RAMOS-COSTA; VITT, 1980; VITT e VANGILDER, 1983). Além disso, padrões relacionados à história natural de serpentes

simpátricas só devem ser interpretados quando as espécies são estudadas ao mesmo tempo e em uma mesma área restrita (VITT e VANGILDER, 1983).

Ainda são escassos no Brasil os trabalhos baseados na observação dos indivíduos em seu habitat natural, talvez devido aos longos períodos de inatividade e aos hábitos secretivos das serpentes (MARQUES; ALMEIDA-SANTOS; RODRIGUES, 2006; TOZETTI, 2006 ).

Este capítulo aborda a historia natural dos viperídeos Bothropoides jararaca, Bothropoides neuwiedi e Crotalus durissus, coletados em uma área delimitada, a Fazenda Santa Elisa, situada na cidade de Munhoz, sul de Minas Gerais, Serra da Mantiqueira. 


\subsection{OBJETIVOS}

\section{Objetivos Gerais:}

Descrever a história natural dos viperídeos Bothropoides jararaca, Bothropoides neuwiedi e Crotalus durissus, simpátricos na região de Munhoz, sul de Minas Gerais, Serra da Mantiqueira.

\section{Objetivos Específicos:}

1) Estudar o ciclo e as estratégias reprodutivas das três espécies de viperídeos.

2) Descrever os padrões de atividade, comportamento e uso do ambiente pelas espécies na área de estudo.

3) Caracterizar e analisar a dieta das três espécies na área de estudo.

4) Analisar a morfometria de adultos e filhotes das três espécies e verificar a ocorrência de dimorfismo sexual. 


\subsection{MATERIAL E MÉTODOS}

\subsubsection{Serpentes}

Todos os exemplares de serpentes são procedentes da Fazenda Santa Elisa (FSE), situada no município de Munhoz, sul de Minas Gerais, parte integrante da Serra da Mantiqueira. Os dados morfológicos, reprodutivos e de dieta utilizados neste trabalho foram obtidos logo após a coleta dos animais, não sendo utilizada nenhuma serpente depositada em coleções. Foram analisados cento e sessenta e quatro exemplares, constituídos por 26 Bothropoides jararaca, 124 Bothropoides neuwiedi e 14 Crotalus durissus.

Detalhes e descrições sobre a área de estudo, métodos de amostragem, armazenamento e destino do material coletado, metodologia utilizada para a coleta de informações no campo (local e horário de coleta, postura do animal, atividade e comportamento no momento do encontro) e composição da fauna de serpentes da localidade são mostrados no Capítulo 1 deste trabalho.

\subsubsection{Morfometrias e massa corporal}

As serpentes foram eutanasiadas por anóxia com gás carbônico, e para todos os indivíduos foram registradas as seguintes variáveis: comprimento rostro-cloacal (CRC, em milímetros); comprimento da cauda ( $\mathrm{CC}$, em milímetros); comprimento total (CT $[\mathrm{CRC}+\mathrm{CC}]$ em milimetros); comprimento da cabeça (CCAB [da escama rostral à articulação quadrato-mandibular] em milímetros); comprimento do tronco (CTRO [CRC - CCA], em milímetros); massa corporal (g) e sexo (observado através da exposição manual do hemipênis).

Para as análises comparativas de morfometria e de massa (entre os sexos e entre as espécies) foram utilizados: comprimento relativo da cauda (CC/CRC); comprimento relativo da cabeça (CCAB/CTRO); robustez (Massa/CT). Porém, nos resultados, nas tabelas em que são mostradas as estatísticas dos testes comparativos da morfometria, na 
amplitude da amostra (A) e na média \pm erro padrão, são apresentados os dados absolutos das medidas corporais das serpentes (comprimento da cauda, comprimento da cabeça e massa) ao invés dos índices utilizados para as análises comparativas.

As medidas de $\mathrm{CRC}$ e $\mathrm{CC}$ foram realizadas por meio de fita métrica com precisão de $1 \mathrm{~mm}$, e as medidas do CCA por meio de paquímetro digital com precisão de $0,1 \mathrm{~mm}$. A medida de massa das serpentes adultas foi feita em balança com precisão de $5 \mathrm{~g}$. A medida de massa dos filhotes em balança com precisão de $1 \mathrm{~g}$.

\subsubsection{Reprodução}

Para todas as fêmeas foram registrados: comprimento $(\mathrm{mm})$ do maior folículo ovariano em vitelogênese primária; número e comprimento $(\mathrm{mm})$ dos folículos ovarianos em vitelogênese secundária; aspecto macroscópico dos ovidutos (liso/pregueado e alargado); número, comprimento $(\mathrm{mm})$ e massa $(\mathrm{g})$ dos ovos; presença / ausência de corpos lúteos nos ovários.

Para os machos, foram registrados: massa (g) dos testículos; comprimento (mm), largura (mm) e espessura $(\mathrm{mm})$ dos testículos; aspecto macroscópico dos ductos deferentes (liso ou convoluto e hipertrofiados na porção distal/ translúcido ou branco opaco).

Para B. neuwiedi, que possibilitou amostragens contínuas ao longo dos meses, foram coletados os testículos e ductos deferentes dos machos, e os ovidutos das fêmeas. Fragmentos do material foram colocados em solução fixadora de paraformaldeído a 4\%, desidratados em etanol a $70 \%$ e incluídos em parafina. Os cortes histológicos foram realizados com espessura de 3 a $5 \mu \mathrm{m}$, e corados com hematoxilina-eosina.

As medidas dos folículos e ovos das fêmeas e dos testículos dos machos foram realizadas como auxílio de paquímetro digital com precisão de $0,1 \mathrm{~mm}$. A medida de massa dos folículos e ovos das fêmeas e dos testículos dos machos foi realizada em balança digital com precisão de $0,1 \mathrm{~g}$.

Análise dos dados de reprodução: 
Machos:

As análises histológicas dos fragmentos dos testículos e ductos deferentes dos machos de $B$. neuwiedi foram utilizadas para verificar a presença de espermatozóides, o principal critério na determinação da maturidade sexual. Foi calculado também o volume testicular. $\mathrm{O}$ volume testícular (VT) pode indicar atividade espermatogênica, e foi calculado através da fórmula para o volume da elipsóide: (VT $=4 / 3 \pi$. a.b.c.), sendo $\mathrm{a}=$ metade do comprimento $; \mathrm{b}=$ metade da largura $; \mathrm{c}=$ metade da espessura (VOLSOE, 1944; ALMEIDA-SANTOS; PIZZATTO; MARQUES, 2006). A diferença entre as médias do volume dos testículos direito e esquerdo não foram significativas, ficando estabelecido o uso dos testículos direito nas análises.

Para os machos de $B$. jararaca e $C$ durissus, foram considerados sexualmente maduros (reprodutivos ou adultos) aqueles que apresentaram testículos túrgidos, com ductos deferentes alargados, enovelados e opacos (SHINE, 1977a; SHINE, 1980a). Machos que não apresentaram nenhuma destas características foram considerados jovens.

Fêmeas:

O ciclo reprodutivo das fêmeas de B. neuwiedi foi caracterizado por meio da distribuição dos folículos ovarianos em vitelogênese secundária, dos ovos e presença de embriões nos ovidutos ao longo do ano. As análises histológicas dos fragmentos do útero posterior (porção do oviduto) de fêmeas coletadas nas diferentes estações do ano foram utilizadas para verificar a estocagem de espermatozóides.

O ciclo reprodutivo das fêmeas de B. jararaca e $C$. durissus foi caracterizado por meio da distribuição dos folículos ovarianos em vitelogênese secundária, dos ovos e presença de embriões nos ovidutos ao longo do ano. Foram consideradas sexualmente maduras (reprodutivas ou adultas) aquelas que possuíam folículos em vitelogênese secundária, ovos nos ovidutos ou presença de corpos lúteos nos ovários (SHINE, 1977b; SHINE, 1978). Fêmeas que não apresentaram nenhuma destas características foram consideradas jovens.

Para evitar possíveis variações entre as espécies, os folículos em vitelogênese secundária não foram determinados pelo tamanho, e sim pela coloração amarelada que adquirem ao iniciar a deposição de vitelo. 
A freqüência reprodutiva foi calculada através da razão entre o número de fêmeas reprodutivas e o número total de fêmeas da amostra a cada estação reprodutiva (SEIGEL e FORD, 1987).

$\mathrm{O}$ índice de dimorfismo sexual de tamanho corporal $(\mathrm{SSD}=$ sexual size dimorphism) nos adultos foi calculado através da fórmula: (CRC médio dos adultos do sexo de maior tamanho / CRC médio dos adultos do sexo de menor tamanho) - 1 . Índices positivos indicam fêmeas maiores do que machos (GIBBONS e LOVICH, 1991; SHINE, 1994).

Ninhadas:

Algumas fêmeas coletadas prenhes foram mantidas em cativeiro até o nascimento dos filhotes. Foram registrados para todas as ninhadas: data do nascimento; número de filhotes vivos, natimortos e malformados; presença de ovos atrésicos (massa endurecida de vitelo, geralmente ovos não fecundados, expelidos na hora do parto); Informações morfométricas (CRC, CC, CT, CCA, CTRO em mm); de massa (g); e sexo dos recém nascidos; massa da mãe antes e depois do parto; massa total da ninhada (massa dos filhotes vivos, e também dos filhotes mortos, malformados e dos ovos atrésicos quando presentes); e massa relativa das ninhadas (MRN), que é a razão da massa da ninhada pela massa da mãe após o parto (SEIGEL e FORD, 1987).

Assim como nos adultos, para as análises morfométricas e de massa comparativas (entre os sexos e entre as espécies) foram utilizados: comprimento relativo da cauda (CC/CRC); comprimento relativo da cabeça (CCAB/CTRO); robustez (Massa/CT). 


\section{Comportamento reprodutivo em cativeiro:}

Foram colocados casais de B. neuwiedi e de B. jararaca (todos procedentes da Fazenda Santa Elisa) para observação de corte e cópulas em cativeiro. Quando nenhum comportamento reprodutivo foi observado, as serpentes foram separadas após 6 horas de permanência juntas. Em algumas tentativas de acasalamento $(\mathrm{N}=4)$ foram colocados juntos dois machos e uma fêmea, para observar possível comportamento agonístico entre os machos.

\subsubsection{Dieta}

Para as análises de dieta foram registradas as seguintes variáveis: presença ou ausência de conteúdo gastrointestinal; número de itens alimentares (quando possível, algumas vezes determinado pelo número de mandíbulas encontradas nas fezes); direção de ingestão da presa (quando possível).

As fezes foram coletadas sempre que presente no intestino dos animais. No caso das serpentes mantidas em cativeiro, foram esperados 15 dias para que defecassem (caso houvesse alimento em seu tubo digestivo) antes de oferecer alimento aos animais. Grande parte das amostras de fezes obtidas foi proveniente das caixas de madeira onde as serpentes eram mantidas após sua captura até serem transportadas para o IB. Após a coleta, as fezes foram lavadas sucessivas vezes em peneiras de pequenos poros. Nesse processo foram separados os pêlos, dentes, ossos, unhas, escamas e penas, evidências que auxiliaram na identificação do item ingerido. Após a separação, o material foi seco em estufa e acondicionado em frascos individualizados.

Conteúdos estomacais quando presentes foram fixados em formol a $10 \%$ e preservados em álcool a 70\% para posterior identificação. Foram retirados diretamente do estômago das serpentes dissecadas; através do regurgitamento forçado; através de regurgitamento espontâneo (não raro, ocorrido durante a captura ou transporte de serpentes recém alimentadas). A maior parte das presas foi identificada ao nível de classe. 


\subsubsection{Análises estatísticas}

As relações entre as proporções corporais e de massa dos adultos e filhotes, e as relações entre as fêmeas e suas ninhadas foram verificadas através de análises de regressão.

O dimorfismo sexual na morfometria e na massa (de adultos e filhotes) foi verificado pelo teste Teste t (de Student). Esse teste também foi utilizado sempre que necessário verificar a significância da diferença entre duas médias.

Testes de proporções foram utilizados para verificar a significância da heterogeneidade entre as amostras.

Em todas as análises estatísticas, foi adotado nível de significância de 0,05\%. Nas Tabelas que mostram resultados estatísticos, os asteriscos significam:

*significante no nível de 5\%

**significante no nível de $1 \%$

***significante no nível de $0,1 \%$

ns. não significante. 


\subsection{RESULTADOS}

\subsubsection{Bothropoides neuwiedi}

Durante o período de estudo foram encontrados e analisados 124 exemplares de B. neuwiedi (42 machos; 82 fêmeas). Esta espécie é a mais abundante na área (ver resultados no capitulo 1 deste trabalho).

\section{Proporções corporais}

As análises de regressão do comprimento da cauda sobre o comprimento rostro-

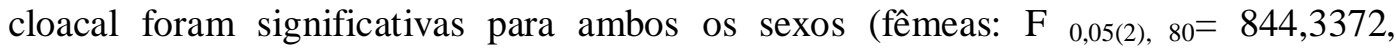
$\mathrm{p}<$ 0,05; machos: $\left.\mathrm{F}_{0,05(2), 40}=296,4376, \mathrm{p}<0,05\right)$ (Figura1). A análise da diferença entre as retas da regressão foi significativa $\left(\mathrm{t}_{0,05}(2), 120=3,6107, \mathrm{p}<0,05\right)$, indicando que machos e fêmeas não apresentam as mesmas relações entre corpo e cauda.

As regressões da massa sobre o comprimento total também foram significativas para machos e fêmeas (fêmeas: $\mathrm{F}_{0,05(2), 80}=382,2087, \mathrm{p}<0$, 05; machos: $\mathrm{F}_{0,05(2), 40}=$ 146,8895, $\mathrm{p}<0,05)$ (Figura 2). A diferença entre as retas foi significativa, indicando que machos e fêmeas não possuem as mesmas relações entre as variáveis massa e comprimento total $\left(\mathrm{t}_{0,05(2), 120}=4,9229, \mathrm{p}<0,05\right)$.

As regressões do comprimento da cabeça sobre o comprimento do tronco foram significativas para ambos os sexos (fêmeas: $\mathrm{F}_{0,05}(2), 76=478,6315, \mathrm{p}<0,05$; machos: $\mathrm{F}_{0,05(2), 39}=211,7273, \mathrm{p}<0,05$ ) (Figura 3). A diferença entre as retas não foi significativa, significando que as relações entre as variáveis são as mesmas nos dois $\operatorname{sexos}\left(\mathrm{t}_{0,05(2), 115}=0,3981, \mathrm{p}>0,05\right)$. 


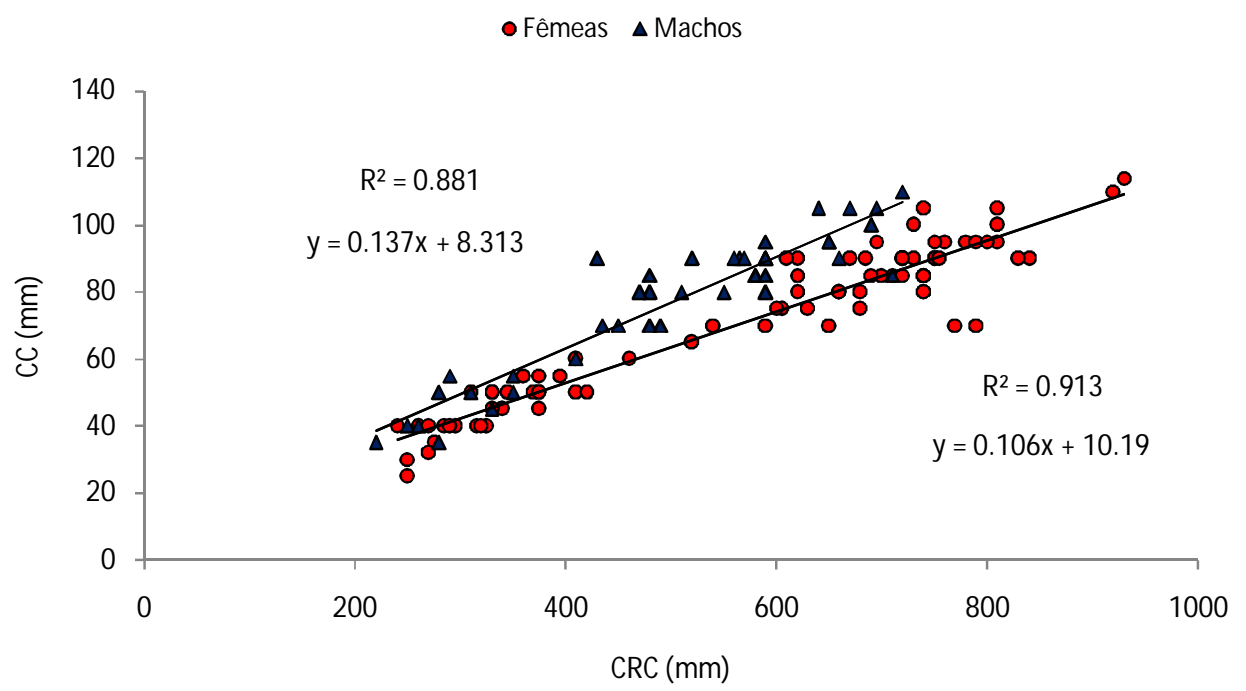

Figura 1: Bothropoides neuwiedi. Regressão do comprimento da cauda (CC) sobre o comprimento do corpo (CRC).

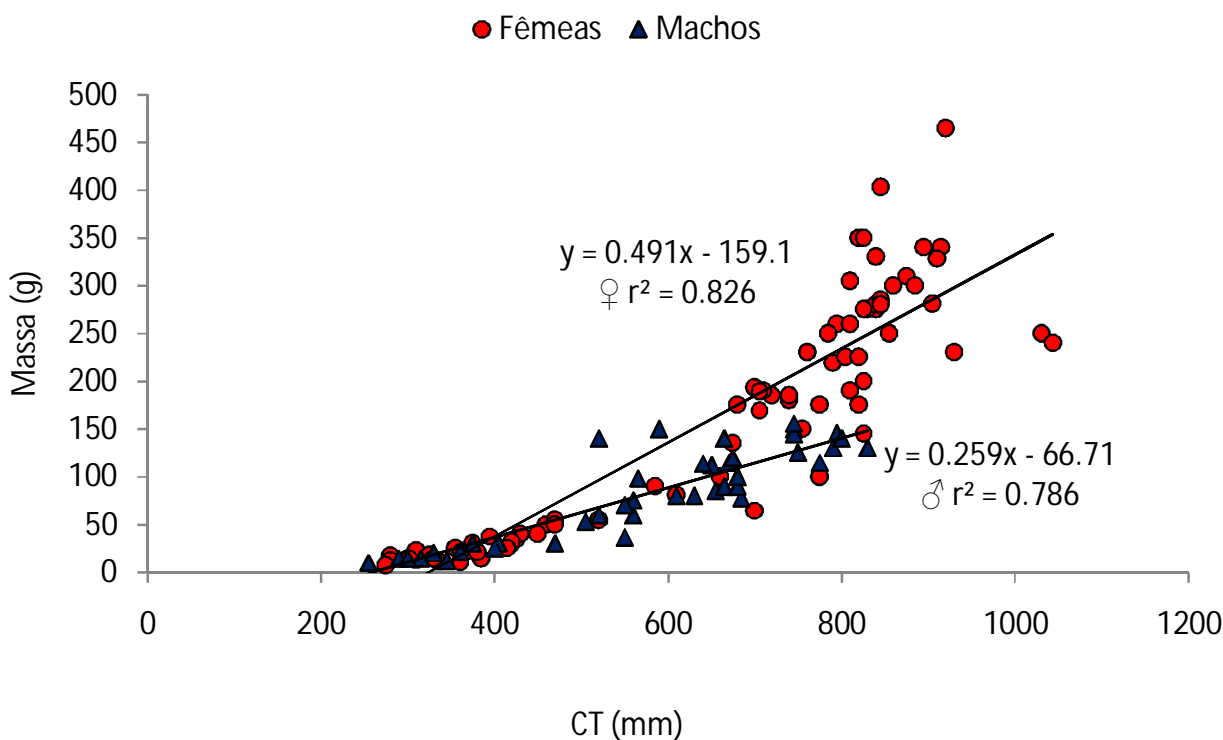

Figura 2: Bothropoides neuwiedi. Regressão da massa sobre o comprimento total (CT). 


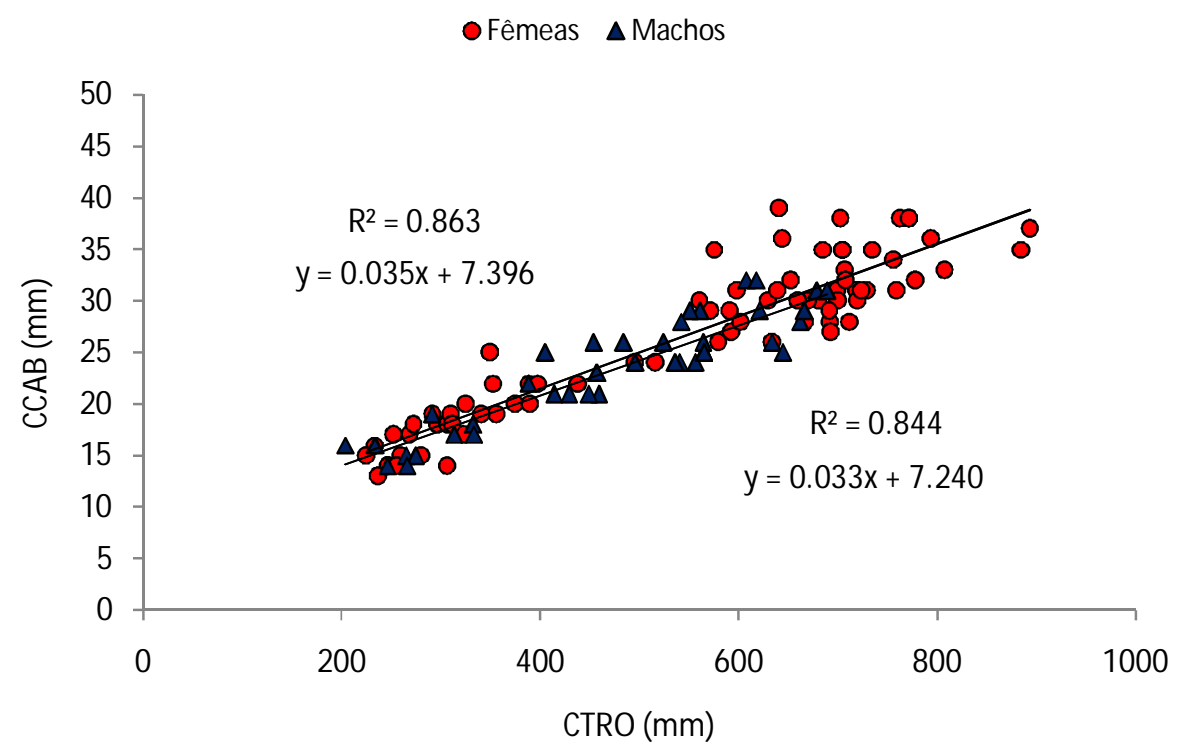

Figura 3: Bothropoides neuwiedi. Regressão do comprimento da cabeça (CCA) sobre o comprimento do tronco (CTRO).

\section{Morfometrias e massa corporal}

O comprimento do corpo das fêmeas adultas de $B$. neuwiedi foi significativamente maior do que os machos adultos ( $\left.\mathrm{t}_{0,05(2), 78}=8,769 ; \mathrm{p}<0,05\right)$. Os machos adultos apresentaram comprimento relativo de cauda maior do que as fêmeas $\left(t_{0,05}(2), 78=10,927 ; \mathrm{p}<0,05\right)$. Não foram encontradas diferenças significativas no comprimento relativo da cabeça de fêmeas e machos $(t=0,05(2), 75=1,549 ; \mathrm{p}>0,05)$. Porém, analisando o comprimento da cabeça com os dados absolutos, fêmeas mostraram cabeça significativamente maior do que machos $(\mathrm{t}=0,05$ (2), $75=7,899$; $\mathrm{p}<0,05)$. Fêmeas adultas são significativamente mais robustas do que machos adultos $\left(\mathrm{t}_{0,05(2), 78}=9,049 ; \mathrm{p}<0,05\right)($ Tabela 1$)$.

O corpo das fêmeas jovens de B. neuwiedi foi significativamente maior do que o corpo dos machos ( $\mathrm{t}_{0,05}(2), 42=2,043 ; \mathrm{p}<0$, 05). Os machos jovens também apresentaram comprimento relativo da cauda maior do que as fêmeas ( $\mathrm{t}_{0,05}(2), 42=$ 3, 905; $\mathrm{p}<0,05)$. O comprimento relativo da cabeça das fêmeas e machos jovens também não apresentou diferenças significativas $(\mathrm{t}=0,05(2), 40=0,4244 ; \mathrm{p}>0,05)$. Machos e fêmeas jovens não diferiram significativamente em relação à robustez $\left(\mathrm{t}_{0,05(2), 42}=1,582 ; \mathrm{p}>0,05\right)($ Tabela 2$)$. 
Tabela 1: Bothropoides neuwiedi. Amplitude, número de observações $(\mathrm{N})$ e média \pm erro padrão dos exemplares adultos coletados durante o período de estudo.

\begin{tabular}{lccccc}
\hline & Sexo & A & N & $\begin{array}{c}\text { Média } \pm \text { erro } \\
\text { padrão }\end{array}$ & t \\
\hline CRC $(\mathrm{mm})$ & Machos & $410-720$ & 32 & $568,3 \pm 87,2$ & $\mathrm{t}_{0,05(2), 78}=8,769 * * *$ \\
CRC $(\mathrm{mm})$ & Fêmeas & $600-920$ & 48 & $728,1 \pm 74,6$ & \\
& & & & & \\
$\mathrm{CC}(\mathrm{mm})$ & Machos & $60-110$ & 32 & $87 \pm 11,5$ & $\mathrm{t}_{0,05(2), 78}=10,927 * * *$ \\
$\mathrm{CC}(\mathrm{mm})$ & Fêmeas & $70-114$ & 48 & $88 \pm 9,8$ & \\
& & & & & \\
$\mathrm{CCAB}(\mathrm{mm})$ & Machos & $21-32$ & 31 & $25,9 \pm 3,2$ & $\mathrm{t}_{0,05(2), 75}=1,549 \mathrm{~ns}$. \\
$\mathrm{CCAB}(\mathrm{mm})$ & Fêmeas & $26-39$ & 46 & $32 \pm 3,5$ & \\
& & & & & \\
Massa $(\mathrm{g})$ & Machos & $30-156$ & 32 & $103,6 \pm 34,9$ & $\mathrm{t}_{0,05(2), 78}=9,049 * * *$ \\
Massa $(\mathrm{g})$ & Fêmeas & $65-465$ & 48 & $244,7 \pm 77,5$ & \\
\hline
\end{tabular}

Tabela 2: Bothropoides neuwiedi. Amplitude, número de observações $(\mathrm{N})$ e média \pm erro padrão dos exemplares jovens coletados durante o período de estudo.

\begin{tabular}{llcccc}
\hline & Sexo & A & N & $\begin{array}{c}\text { Média } \pm \text { erro } \\
\text { padrão }\end{array}$ & t \\
\hline $\mathrm{CRC}(\mathrm{mm})$ & Machos & $220-350$ & 10 & $292 \pm 43,2$ & $\mathrm{t}_{0,05(2), 42}=2,043^{*}$ \\
$\mathrm{CRC}(\mathrm{mm})$ & Fêmeas & $240-590$ & 34 & $348,9 \pm 84,4$ & \\
& & & & & \\
$\mathrm{CC}(\mathrm{mm})$ & Machos & $35-55$ & 10 & $45,5 \pm 7,6$ & $\mathrm{t}_{0,05(2), 42}=3,905^{* * *}$ \\
$\mathrm{CC}(\mathrm{mm})$ & Fêmeas & $25-70$ & 34 & $46,9 \pm 10,5$ & \\
& & & & & \\
$\mathrm{CCAB}(\mathrm{mm})$ & Machos & $14-19$ & 10 & $16,1 \pm 1,7$ & $\mathrm{t}_{0,05(2), 40}=0,4244 \mathrm{~ns}$. \\
$\mathrm{CCAB}(\mathrm{mm})$ & Fêmeas & $13-30$ & 32 & $18,9 \pm 3,9$ & \\
& & & & & \\
Massa $(\mathrm{g})$ & Machos & $10-30$ & 10 & $19,4 \pm 7,2$ & $\mathrm{t}_{0,05(2), 42}=1,582 \mathrm{~ns}$. \\
Massa $(\mathrm{g})$ & Fêmeas & $7-100$ & 34 & $31,7 \pm 22,8$ & \\
\hline
\end{tabular}

Utilizando o grau de dimorfismo sexual de tamanho corporal (SSD), proposto por Shine (1994), verificamos que as fêmeas são maiores do que machos e apresentam um grau de dimorfismo de 0,28 , que é expresso como positivo quando as fêmeas são maiores do que machos. 


\section{Atividade Sazonal}

Tanto fêmeas como machos de B. neuwiedi foram capturados em todos os meses do ano, com exceção dos meses de agosto, quando nenhuma serpente da espécie foi coletada. Fêmeas foram significativamente mais freqüentes na primavera e no verão $\left(\chi^{2}=18,09, \mathrm{p}<0.001\right.$, g.l. $\left.=3\right)$, e machos significativamente mais freqüentes no outono $\left(\chi^{2}=12,28, \mathrm{p}<0.01, \mathrm{~g} .1 .=3\right)$. O número e o percentual de machos e fêmeas encontrados em relação às diferentes épocas do ano são mostrados na Tabela 3.

Tabela 3: Bothropoides neuwiedi. Sazonalidade na captura de machos e fêmeas.

\begin{tabular}{lcc}
\hline & Fêmeas - N (\%) & Machos - N (\%) \\
\hline Primavera & $31(37,8 \%)$ & $10(23,81 \%)$ \\
Verão & $25(30,49 \%)$ & $10(23,81 \%)$ \\
Outono & $21(25,61 \%)$ & $19(45,24 \%)$ \\
Inverno & $5(6,1 \%)$ & $3(7,14 \%)$ \\
\hline Total & $\mathbf{8 2 ( 1 0 0 \% )}$ & $\mathbf{4 2 ( 1 0 0 \% )}$ \\
\hline
\end{tabular}

Levando em consideração a faixa etária das serpentes, machos adultos foram significativamente mais encontrados no outono $\left(\chi^{2}=11,25, \mathrm{p}<0.05\right.$, g.1. $\left.=3\right)$, seguido pela primavera, verão e poucos exemplares no inverno. Machos jovens foram encontrados ao longo do ano, sem diferenças significativas entre as diferentes épocas (Figura 4). 


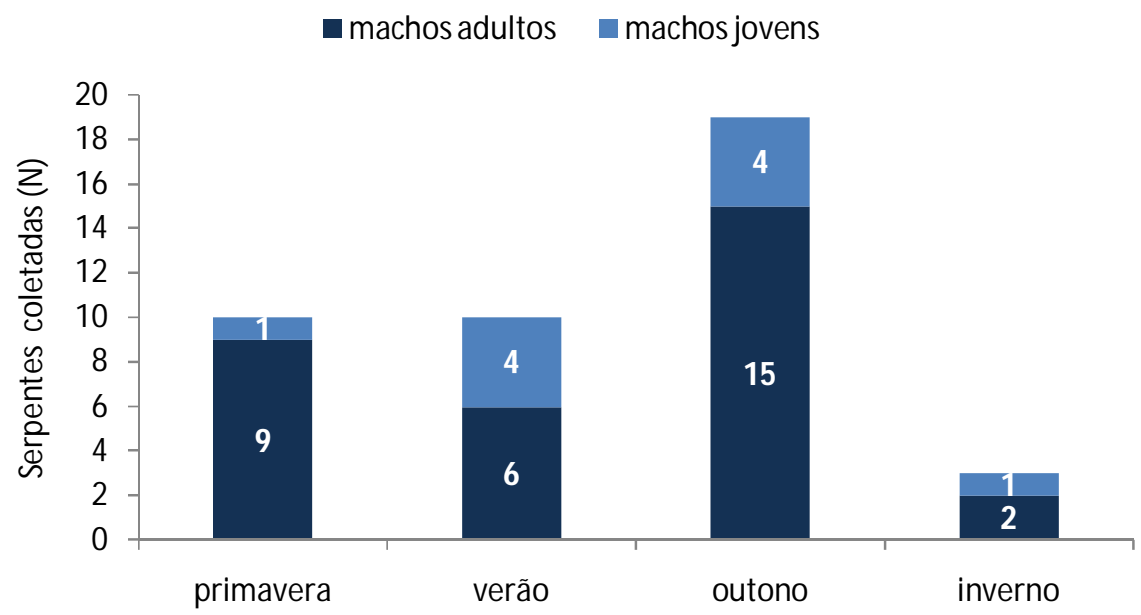

Figura 4: Bothropoides neuwiedi. Machos jovens e adultos coletados nas diferentes épocas do ano.

$\mathrm{Na}$ primavera e no verão o número de encontros de fêmeas adultas foi significativamente maior $\left(\chi^{2}=8,83 \mathrm{p}<0.05\right.$, g.l. $\left.=3\right)$. Das 17 fêmeas adultas coletadas na primavera, 58,8\% estavam reprodutivas. Das 16 adultas encontradas no verão, $75 \%$ estavam reprodutivas. Fêmeas jovens foram significativamente mais amostradas na primavera $\left(\chi^{2}=10,47, \mathrm{p}<0.05\right.$, g.l. $\left.=3\right)$, seguida pelo verão e outono com números similares de captura. No inverno foi encontrado apenas um indivíduo jovem (Figura 5).

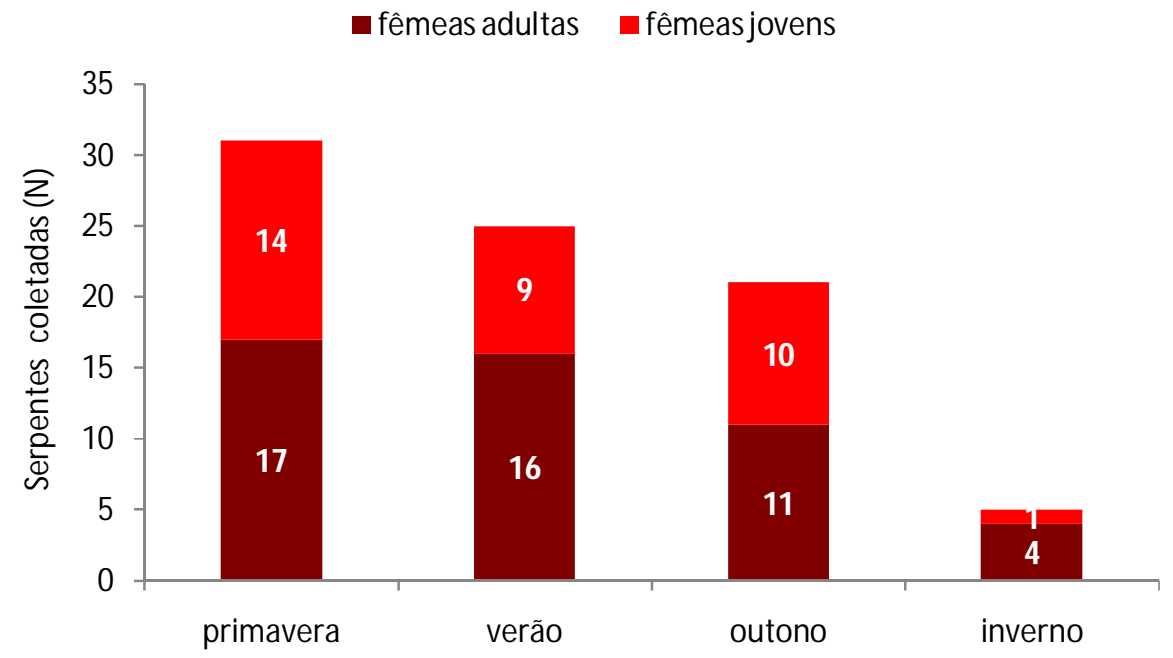

Figura 5: Bothropoides neuwiedi. Fêmeas jovens e adultas coletadas nas diferentes épocas do ano. 


\section{Uso do ambiente}

Para as análises de uso do ambiente, as serpentes foram divididas de acordo com a fisionomia vegetal em que foram coletadas (para detalhes das fisionomias da vegetação e suas subdivisões ver capítulo 1 deste trabalho).

A espécie $B$. neuwiedi foi significativamente mais frequiente nas áreas abertas $\left(\chi^{2}=111,8, \mathrm{p}<0.001\right.$, g.1. $\left.=4\right)$, onde $56,5 \%$ dos espécimes foram encontrados. Nas capoeiras a freqüência de serpentes encontradas também foi alta $(19,4 \%)$, seguida pelas áreas cultivadas $(13,7 \%)$. Menor número de encontros foi observado nas áreas florestadas $(5,6 \%)$ e nas edificações $(4,8 \%)$ (Figura 6$)$.

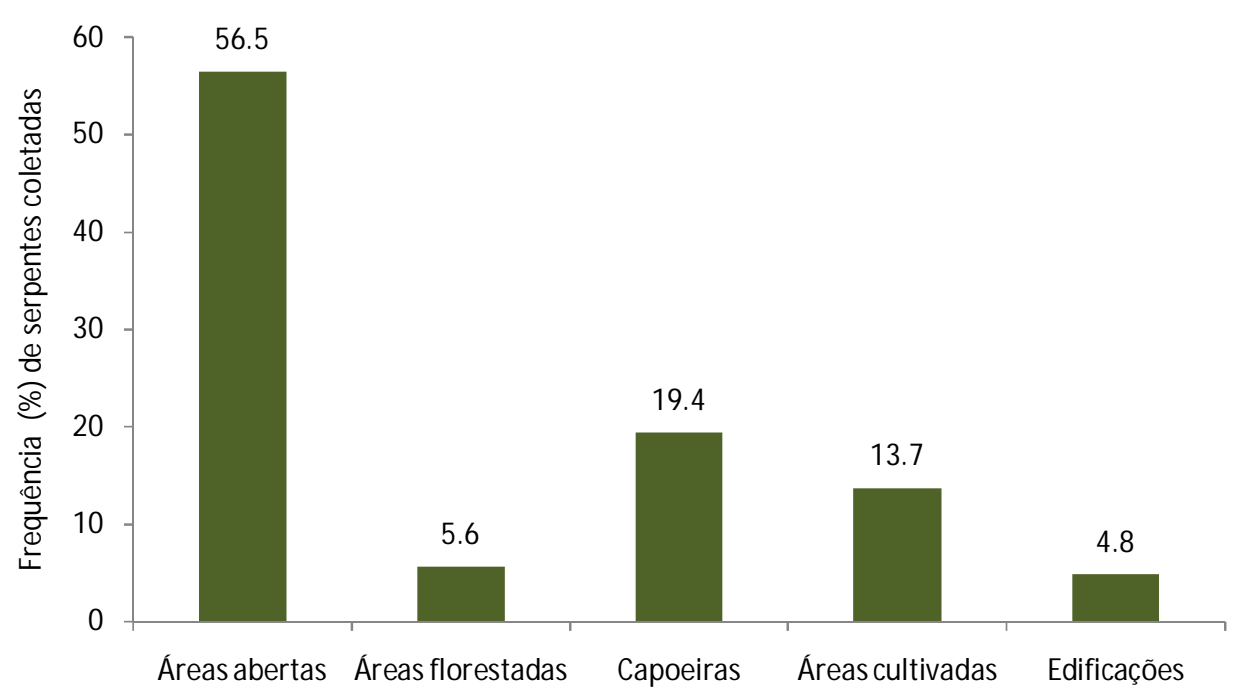

Figura 6: Bothropoides neuwiedi. Freqüência de serpentes capturadas nas diferentes fisionomias vegetais e edificações.

As áreas abertas agrupam os campos de altitude e pastagens. Nos campos de altitude foi encontrada a maior parte dos indivíduos de B. neuwiedi. As capoeiras foram o segundo tipo de ambiente mais freqüentado pelas serpentes. Nas áreas cultivadas os indivíduos estavam quase sempre abrigados sob as folhas. Das 17 serpentes encontradas nas áreas cultivadas, 14 tinham alimento no trato gastrointestinal. 
As áreas florestadas agrupam as regiões de mata, Floresta de Araucárias e reflorestamento. Todas as $B$. neuwiedi coletadas nos ambientes florestados estavam em locais de reflorestamento por Pynus, porém com as árvores ainda pequenas, com aproximadamente $1 \mathrm{~m}$ de altura. Nenhuma $B$. neuwiedi foi amostrada nas áreas de mata nem nas araucárias. A maior parte das serpentes encontradas nas áreas ao redor da sede da Fazenda Santa Elisa (edificações) eram filhotes.

A espécie não mostrou diferenças sexuais acentuadas no uso do ambiente (Figura 7). Detalhes sobre o local e horário de coleta dos indivíduos são mostrados no anexo E.

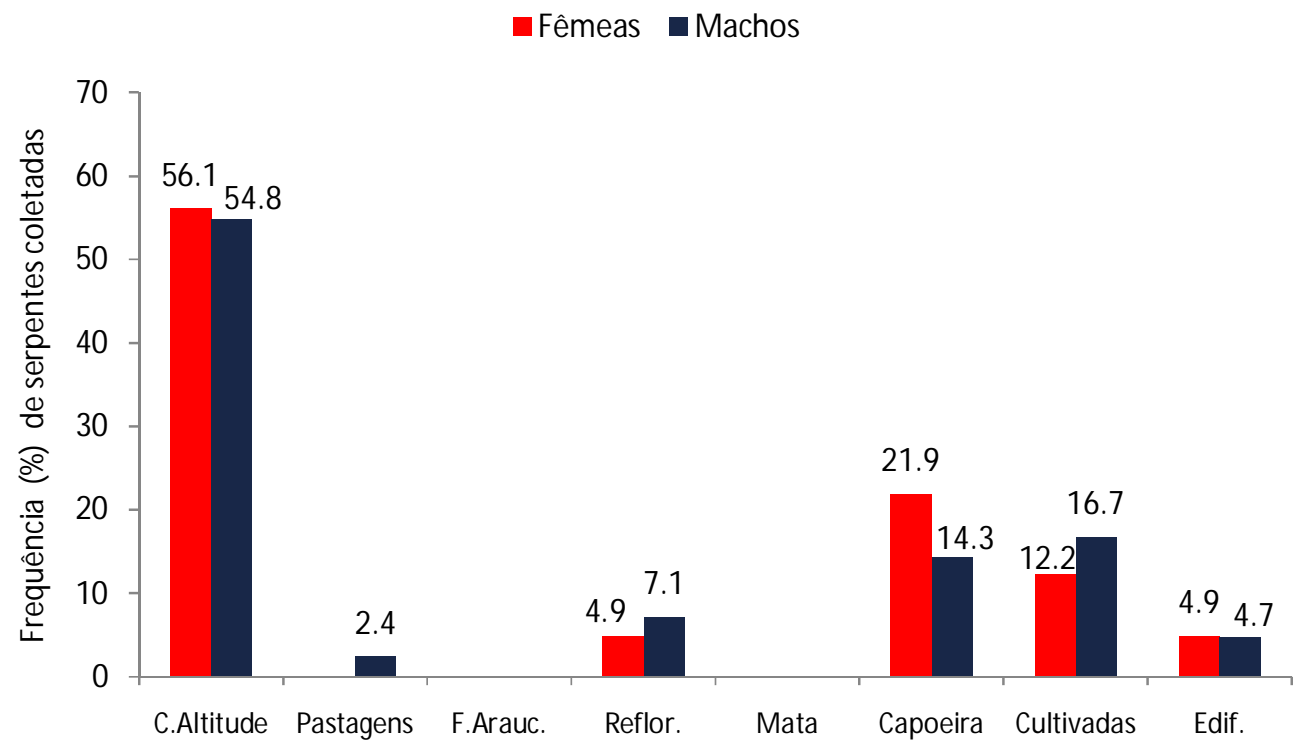

Figura 7: Bothropoides neuwiedi. Freqüência de serpentes capturadas em relação ao local de coleta. 


\section{Atividade no momento do encontro}

Informações completas sobre as serpentes no momento do encontro (com registros do local de coleta e ou atividade humana desenvolvida na hora do encontro, postura do animal, serpente ativa ou em repouso, horário ou período de coleta, ações de defesa e outras observações relevantes) foram obtidas para boa parte dos espécimes coletados. Informações parciais foram obtidas em alguns casos, e em outros apenas o local e o período de coleta.

A maior parte dos exemplares foi coletada no período da tarde (Figura 8). A maioria das serpentes (de ambos os sexos) encontrava-se enrodilhada no momento do encontro (Figura 9). A maior parte estava ativa, atenta a aproximação dos coletores (Figura 10). Como defesa, a maior parte dos exemplares, principalmente as fêmeas, desferiu botes, quase sempre botes sucessivos. Os botes algumas vezes foram precedidos ou seguidos por tentativa de fuga. $\mathrm{O}$ ato de esconder a cabeça sob as voltas do corpo foi observado em algumas oportunidades, comportamento exibido sempre pelas fêmeas. As fêmeas demonstraram maior freqüência de exibição de comportamentos defensivos. $\mathrm{O}$ ato de regurgitar presas recém ingeridas antes de tentar a fuga foi observado em uma fêmea, e um macho largou a presa que estava começando a ingerir. Em sete encontros, as serpentes não esboçaram nenhum comportamento defensivo (Figura 11). Em três oportunidades foi possível observar o comportamento de serpentes prenhes no momento do encontro: duas estavas frouxamente esticadas e aparentemente em repouso; uma enrodilhada, e ativa; todas desferiram bote como defesa; apenas uma (a fêmea que estava ativa) tentou a fuga. Uma síntese da atividade e comportamento no momento do encontro é mostrada no anexo E. Imagens das serpentes no momento do encontro são mostradas no anexo A. 


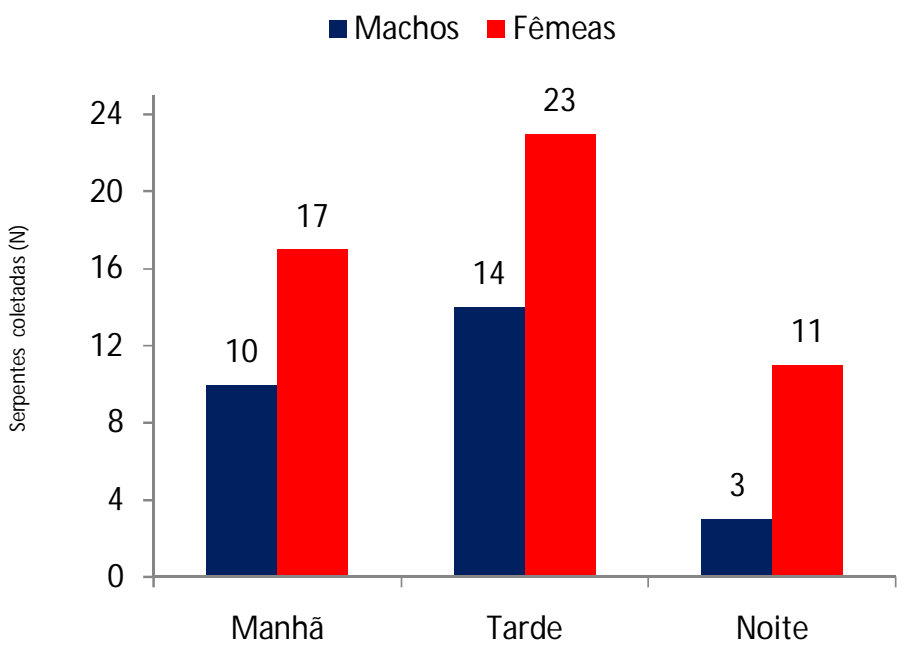

Figura 8: Bothropoides neuwiedi. Período de encontro das serpentes coletadas.

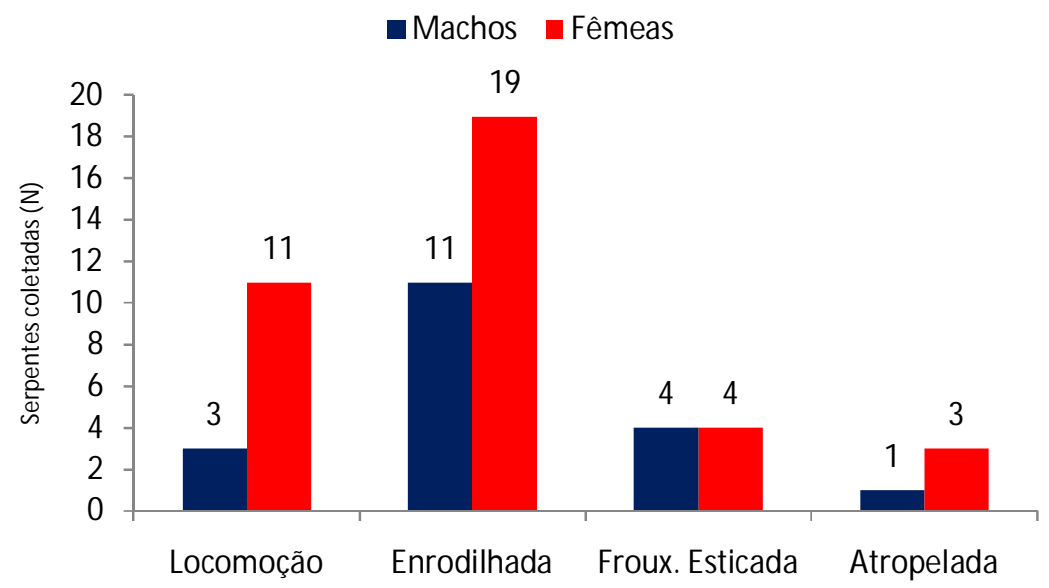

Figura 9: Bothropoides neuwiedi. Postura das serpentes no momento do encontro. 


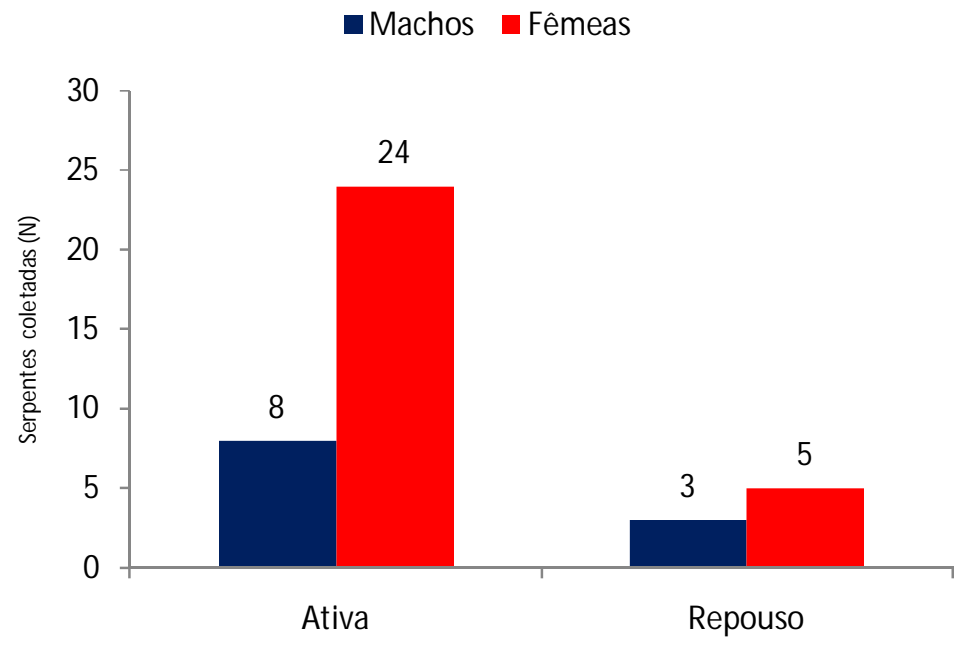

Figura 10: Bothropoides neuwiedi. Estado de atenção das serpentes no momento do encontro.

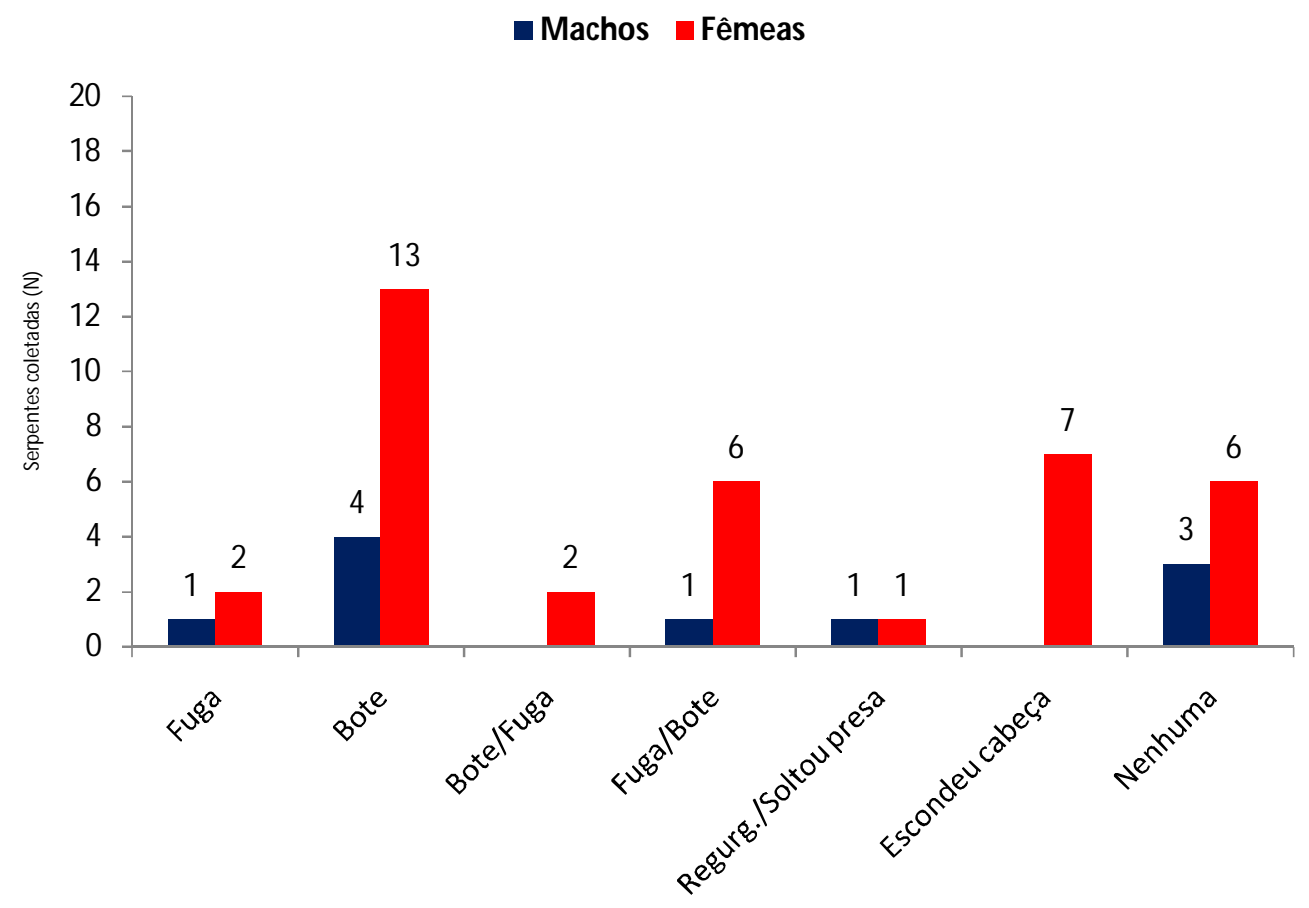

Figura 11: Bothropoides neuwiedi. Defesa utilizada pelas serpentes no momento do encontro. 


\section{Dieta}

Freqüência de serpentes alimentadas, variação sexual e sazonal:

Do total de 124 exemplares capturados, $71(57,3 \%)$ apresentavam alimento no trato gastrointestinal (alimentadas). Das 82 fêmeas capturadas, 46 (56,1\%) estavam alimentadas: $36(78,2 \%)$ apresentaram vestígios de presas no intestino, $9(19,6 \%)$ tinham presas semi digeridas no estômago além de vestígios no intestino, e 1 (2,2\%) fêmea tinha uma presa no estômago. Entre os machos, dos 42 capturados, 25 (59,5\%) haviam ingerido alguma presa: 24 (96\%) possuíam vestígios de presas no intestino, e 1 (4\%) macho apresentou presa semi digerida no estômago.

Serpentes alimentadas foram encontradas em todas as estações climáticas. O número de fêmeas alimentadas foi significativamente maior durante os meses de verão e outono $\left(\chi^{2}=10,17, \mathrm{p}<0.05\right.$, g.l. $\left.=3\right)$, seguido pela primavera e poucos exemplares no inverno. De um total de 20 fêmeas prenhes (ovos com embriões em diferentes estágios de desenvolvimento), 10 (50\%) tinham alimento no trato gastrointestinal. O número de machos com alimento no trato gastrointestinal foi significativamente maior no outono $\left(\chi^{2}=8,11, \mathrm{p}<0.05\right.$, g.1. $\left.=3\right)($ Tabela 4$)$.

Tabela 4: Bothropoides neuwiedi. Serpentes alimentadas nos diferentes períodos do ano.

\begin{tabular}{lcccc}
\hline & \multicolumn{2}{c}{ Fêmeas } & \multicolumn{2}{c}{ Machos } \\
& com alimento & sem alimento & com alimento & sem alimento \\
\hline Primavera & $9(11 \%)$ & $22(26,9 \%)$ & $7(16,7 \%)$ & $3(7,1 \%)$ \\
Verão & $18(21,9 \%)$ & $7(8,5 \%)$ & $6(14,3 \%)$ & $4(9,5 \%)$ \\
Outono & $15(18,3 \%)$ & $6(7,3 \%)$ & $11(26,2 \%)$ & $8(19 \%)$ \\
Inverno & $4(4,9 \%)$ & $1(1,2 \%)$ & $1(2,4 \%)$ & $2(4,8 \%)$ \\
\hline Total (N/\%) & $46(56,1 \%)$ & $38(43,9 \%)$ & $25(59,6 \%)$ & $17(40,4 \%)$ \\
\hline Total (\%) & \multicolumn{2}{c}{$\mathbf{8 2 ( \mathbf { 1 0 0 \% } )}$} \\
\hline
\end{tabular}


Apenas durante os meses de inverno o numero de machos encontrados sem alimento no trato gastrointestinal superou o número de machos alimentados (Figura 12 A). Apenas na primavera o número de fêmeas amostradas sem alimento no sistema gastrointestinal superou o número de fêmeas alimentadas (Figura 12 B ).
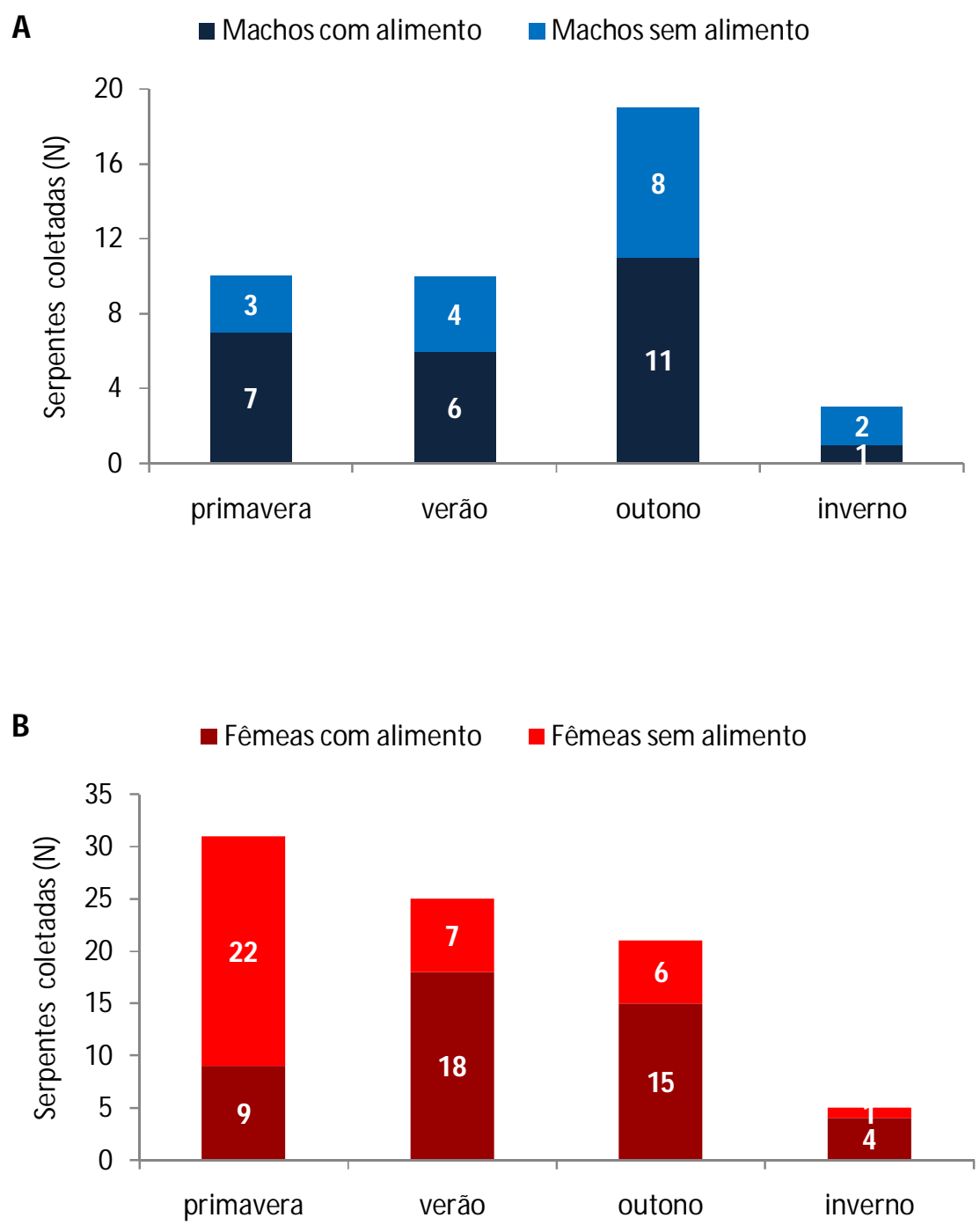

Figuras 12 A e B: Bothropoides neuwiedi. Serpentes alimentadas nas diferentes estações do ano. 
Presas ingeridas e presas múltiplas:

Quase todas as serpentes alimentadas haviam ingerido pequenos mamíferos. Apenas duas fêmeas ingeriram aves adultas (identificadas por especialistas como adultas devido a estrutura das penas), e dois exemplares (1 macho e 1 fêmea) ingeriram lagartos (Figura 13), sendo que um deles foi identificado como pertencente ao gênero Pantodactylus.

Entre as fêmeas, 7 exemplares haviam ingerido mais de uma presa simultaneamente: duas fêmeas que ingeriram aves e pequenos mamíferos, e uma com vestígios de ingestão de lagarto e mamífero. As demais haviam ingerido dois mamíferos. Apenas dois indivíduos machos continham mais de uma presa simultaneamente, um lagarto e um mamífero, e dois mamíferos.

Um macho jovem (CRC $350 \mathrm{~mm}$, massa 30g) foi encontrado quando iniciava a ingestão de um pequeno roedor, e largou a presa ao tentar a fuga (massa da presa 8,9g). Uma fêmea (CRC 685 mm, massa 100g) regurgitou um roedor no momento da captura (massa da presa $8,5 \mathrm{~g}$, porém presa com a cabeça digerida). A maior presa ingerida pelas B. neuwiedi tinha comprimento do corpo de $6,5 \mathrm{~cm}$ (maior presa entre os conteúdos estomacais que possibilitaram a medida do comprimento do corpo). Os conteúdos estomacais $(\mathrm{N}=11)$ permitiram observar que as ingestões das presas iniciaram sempre pela cabeça.

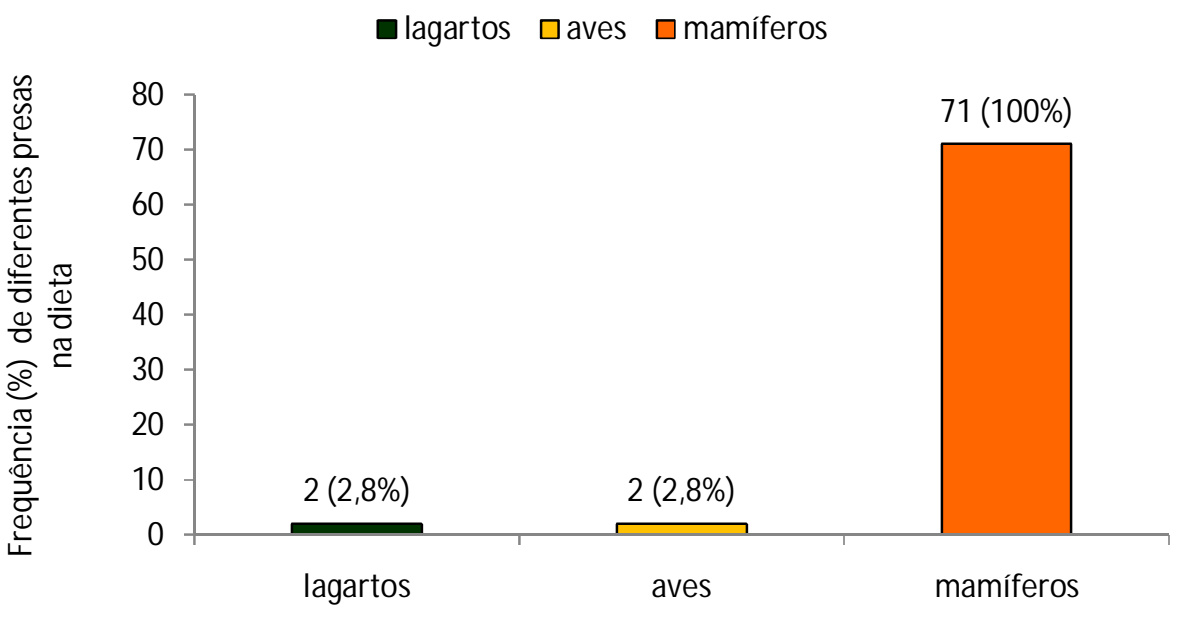

Figura 13: Bothropoides neuwiedi. Número (\%) de presas na dieta em relação ao grupo taxonômico. 
Em ambos os sexos e em todas as faixas etárias foram encontrados mamíferos como presas. Lagartos foram encontrados em machos adultos e fêmeas jovens, e aves apenas em fêmeas adultas (Tabela 5, Figura 14).

Tabela 5: Bothropoides neuwiedi. Número (\%) e tipo de presas ingeridas por jovens e adultos.

\begin{tabular}{|c|c|c|c|c|}
\hline B.neuwiedi & Com alimento (N) & Lagartos & Aves & Mamíferos \\
\hline$\widehat{o}$ jovens $(\mathrm{N}=10)$ & 4 & 0 & 0 & $4(16 \%)$ \\
\hline \multirow[t]{2}{*}{$\widehat{a d u l t o s}(\mathrm{~N}=32)$} & 21 & $1(4 \%)$ & 0 & $21(84 \%)$ \\
\hline & 25 & $1(4 \%) *$ & & $25(100 \%)$ \\
\hline qjovens $(\mathrm{N}=23)$ & 15 & $1(2,2 \%)$ & 0 & $15(32,6 \%)$ \\
\hline qadultos $(\mathrm{N}=48)$ & 31 & 0 & $2(4,4 \%)$ & $31(67,4 \%)$ \\
\hline & 46 & $1(2,2 \%)^{*}$ & $2(4,4)^{*}$ & $46(100 \%)$ \\
\hline
\end{tabular}

* ingestão consecutiva com mamíferos

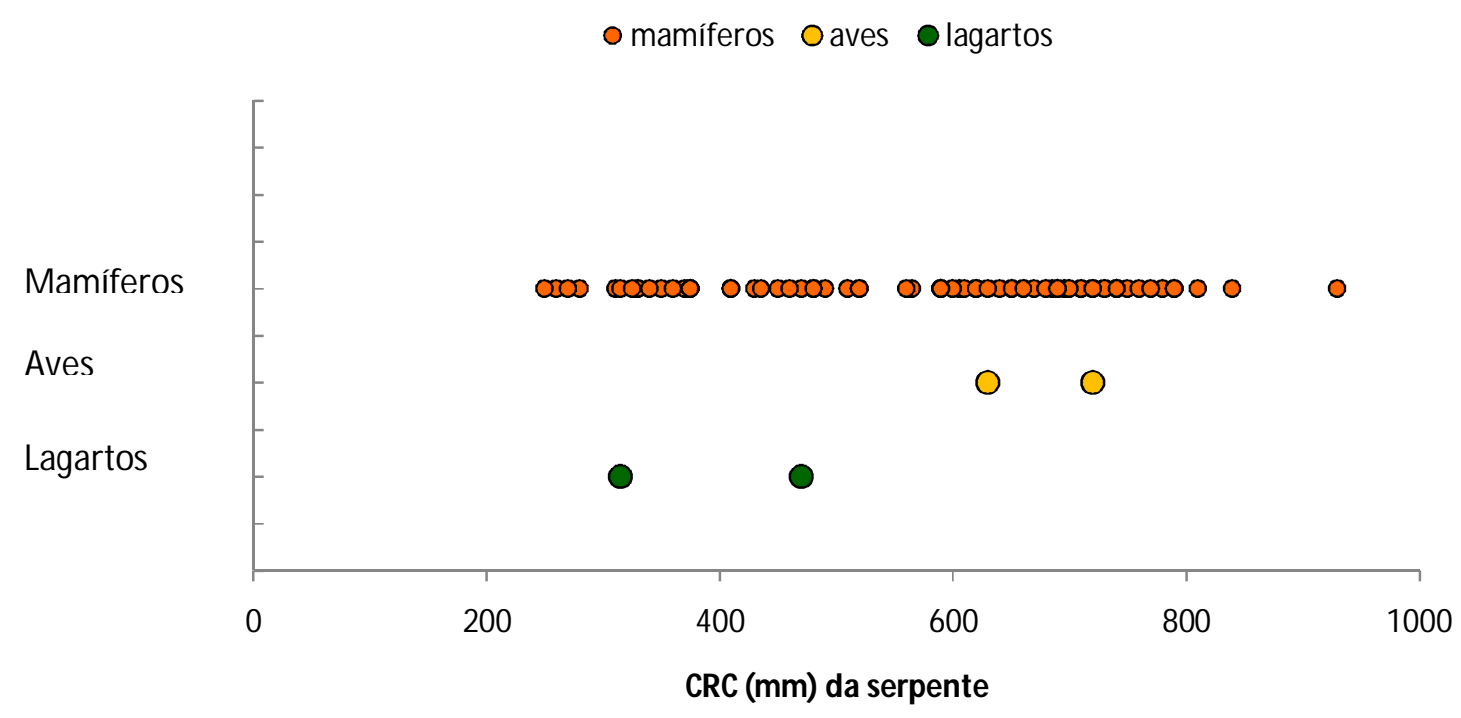

Figura 14: Bothropoides neuwiedi. Tipo de presas ingeridas em relação ao CRC (mm) das serpentes. 


\section{Reprodução}

Ciclo reprodutivo dos machos:

A massa do testículo direito é ligeiramente maior que a do esquerdo, porém a diferença não foi estatisticamente significativa $\left(\mathrm{t}_{0,05(2), 54}=0,562 ; \mathrm{p}>0,05\right)$.

A diferença no volume entre testículos direito e esquerdo não apresentou diferenças significativas ao longo do ano (primavera: $\mathrm{t}_{0,05(2), 10}=0,6859$, $\mathrm{p}>0,05$; verão: $\mathrm{t}_{0,05(2), 12}=0,1969, \mathrm{p}>0,05$; outono: $\mathrm{t}_{0,05(2), 24}=0,31, \mathrm{p}>0,05$; inverno: $0,05(2), 4=$ $1,714, \mathrm{p}>0,05)$. Sendo assim, foi utilizado o volume do testículo direito nas análises de variação do volume testicular.

O volume testicular variou significativamente entre as diferentes estações climáticas $\left(\mathrm{F}_{0,05(3)}=4,6029, \mathrm{p}<0,05\right)$, e o período que contribuiu para a significância do teste foi a primavera $\left(\mathrm{q}_{0,05(3)}=5,2476, \mathrm{p}<0,05\right)$, portanto o pico de volume testicular ocorre durante a primavera e indica maior atividade espermatogênica.

As análises histológicas de fragmentos dos testículos mostraram espermatogênese principalmente na primavera (Figura 15A) (corroborando os resultados do volume testicular). No verão, a atividade espermatogênica é pequena (Figura 15C). As análises histológicas também mostraram estocagem de esperma nos ductos deferentes do final da primavera até o outono (Figura 15B), quando ocorrem os acasalamentos. Ou seja, a produção de espermatozóides é posterior à época de acasalamento, e os machos estocam esperma nos ductos deferentes até a época de cópula. Dessa forma, o ciclo reprodutivo dos machos de B. neuwiedi é do tipo dissociado (ou tipo 1; ou pós nupcial), segundo a classificação de Schuett (1992).

O menor macho sexualmente maduro, identificado através das análises histológicas dos testículos tinha comprimento do corpo de $430 \mathrm{~mm}$. Assim, foi estabelecido que os machos com comprimento do corpo abaixo de $400 \mathrm{~mm}$ fossem considerados jovens. 


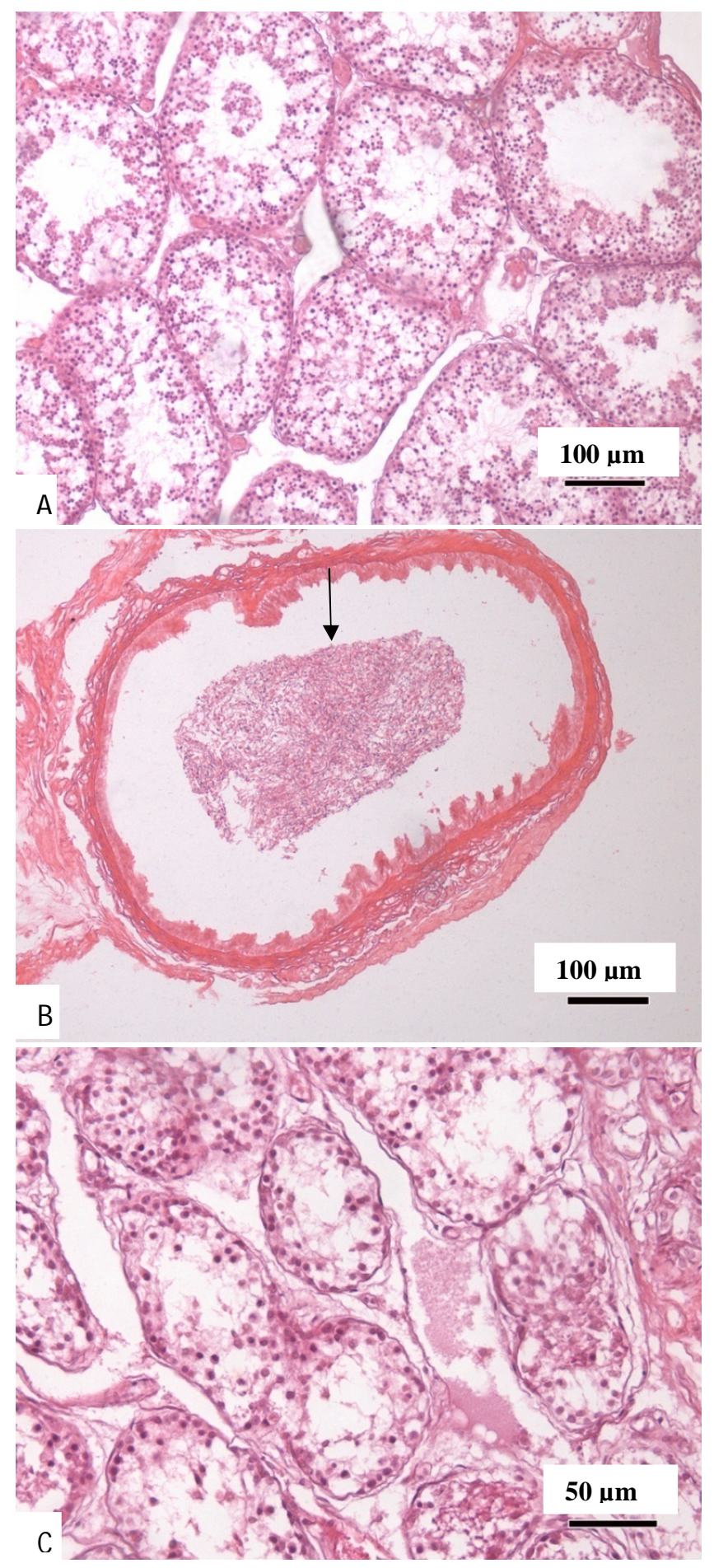

Fig.15: Bothropoides neuwiedi. Cortes transversais. (A): fotomicrografia do testículo de macho coletado na primavera mostrando espermatogênese em fase ativa de produção de espermatozóides. (B): fotomicrografia do ducto deferente de macho coletado no outono, mostrando estocagem de espermatozóides. A seta preta indica a massa de espermatozóides estocados no lúmen. (C): fotomicrografia do testículo de macho coletado no verão, com diminuição da atividade espermatogênica. Objetiva: A 10x; B 10x; C 20x. 
Ciclo reprodutivo das fêmeas:

Folículos em vitelogênese primária foram encontrados ao longo de todo o ano, e o comprimento do maior folículo observado nessa fase foi de 10,4 mm.

Doze fêmeas estavam com folículos em vitelogênese secundária, observada desde o final do verão, quando se inicia a deposição de vitelo, mas concentrada principalmente no outono. $\mathrm{Na}$ maioria das fêmeas $(\mathrm{N}=9)$ o número de folículos em vitelogênese secundária no ovário direito $(\mathrm{N}$ total $=59)$ foi maior do que no esquerdo $(\mathrm{N}$ total $=44)$, diferença estatisticamente significativa $\left(\mathrm{t}_{0,05(2), 22}=2,571 ; \mathrm{p}<0,05\right)$. O menor folículo com início de deposição de vitelo tinha $7,2 \mathrm{~mm}$, e o maior folículo em vitelogênese secundária observado foi de $34 \mathrm{~mm}$.

Quinze fêmeas estavam com ovos nos ovidutos, com embriões em diferentes estágios de desenvolvimento, durante os meses de primavera e verão. Em onze fêmeas foi possível observar o número de ovos em cada oviduto, e o número médio de ovos por fêmea foi de $7,13 \pm 1,06$. Na maioria das fêmeas $(\mathrm{N}=8)$ o número de ovos no oviduto direito $(\mathrm{N}$ total $=52)$ foi maior do que no esquerdo $(\mathrm{N}$ total $=30)$, e essa diferença foi estatisticamente significativa ( $\left.\mathrm{t}_{0,05}(2), 20=5,212, \mathrm{p}<0,05\right)$. O comprimento dos ovos variou de 43,3 a 52,8 mm (Figura16).

As análises histológicas do útero posterior comprovaram que as fêmeas estocam espermatozóides durante o outono e inverno. Os espermatozóides ficam estocados nas pregas formadas pela torção muscular uterina (UMT) (ALMEIDA-SANTOS e SALOMÃO, 2002), e este foi o primeiro relato de observação de UMT e estocagem de esperma em B. neuwiedi. (Figuras 17 A, B e C).

Em síntese, os resultados mostram que as fêmeas de $B$. neuwiedi estão em vitelogênese secundária durante o outono (época de acasalamentos) e inverno, estocam os espermatozóides no útero posterior até a primavera, quando ocorre a ovulação e fecundação, com gestação durante a primavera e verão, e os nascimentos são concentrados principalmente no verão (Figura 18).

O percentual de fêmeas reprodutivas a cada ano (ou estação reprodutiva) variou ao longo do período de coletas. Em seis dos sete anos avaliados, o percentual de fêmeas reprodutivas superou o de não reprodutivas. Porém, o número amostrado de fêmeas anualmente também variou bastante (Figura 19). 
Entre as fêmeas prenhes, $50 \%$ estavam alimentadas, inclusive nos meses de janeiro e fevereiro, fase final da gestação.

A menor fêmea que apresentou folículos em vitelogênese secundária tinha comprimento do corpo de $600 \mathrm{~mm}$, a menor fêmea com ovos tinha comprimento do corpo de $605 \mathrm{~mm}$, e a menor fêmea que pariu filhotes tinha comprimento do corpo de $670 \mathrm{~mm}$. Assim, foi estabelecido que fêmeas com comprimento do corpo abaixo de 600 $\mathrm{mm}$ fossem consideradas jovens.

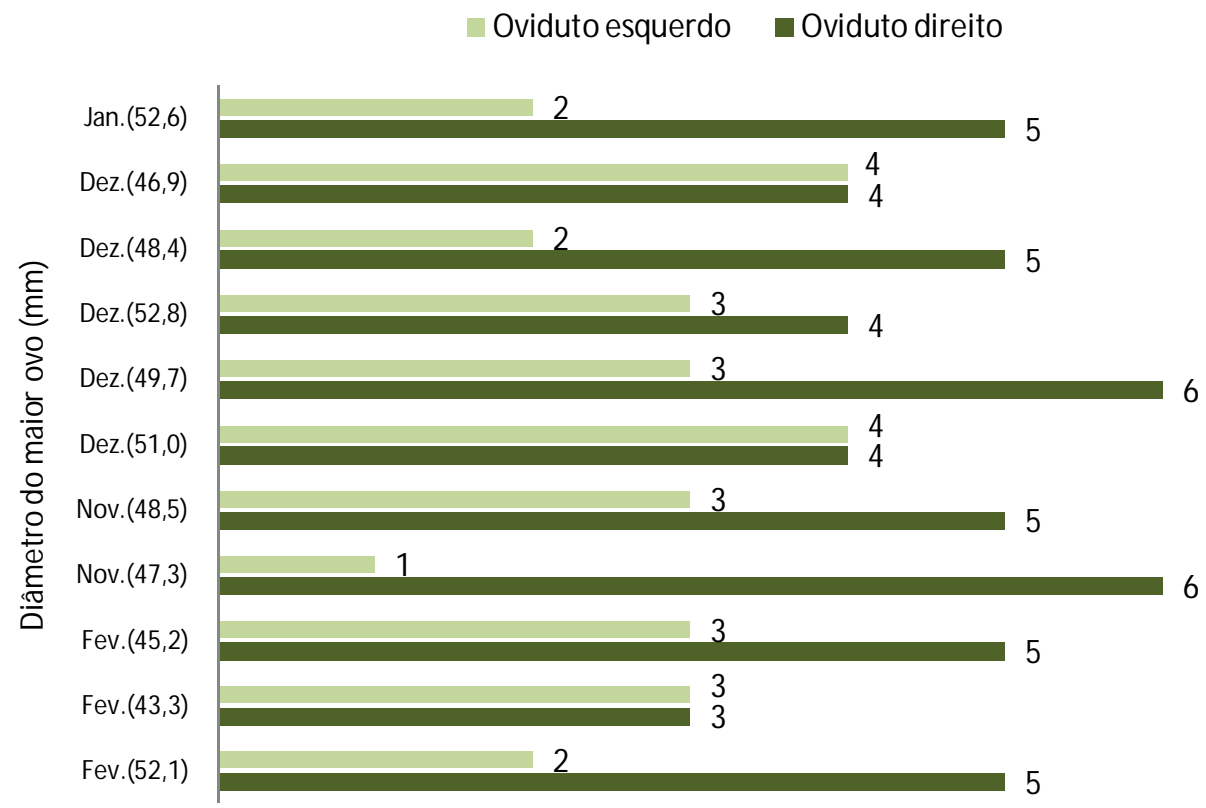

Figura 16: Bothropoides neuwiedi. Número de ovos por oviduto e tamanho do maior ovo de cada fêmea ao longo do ano. 

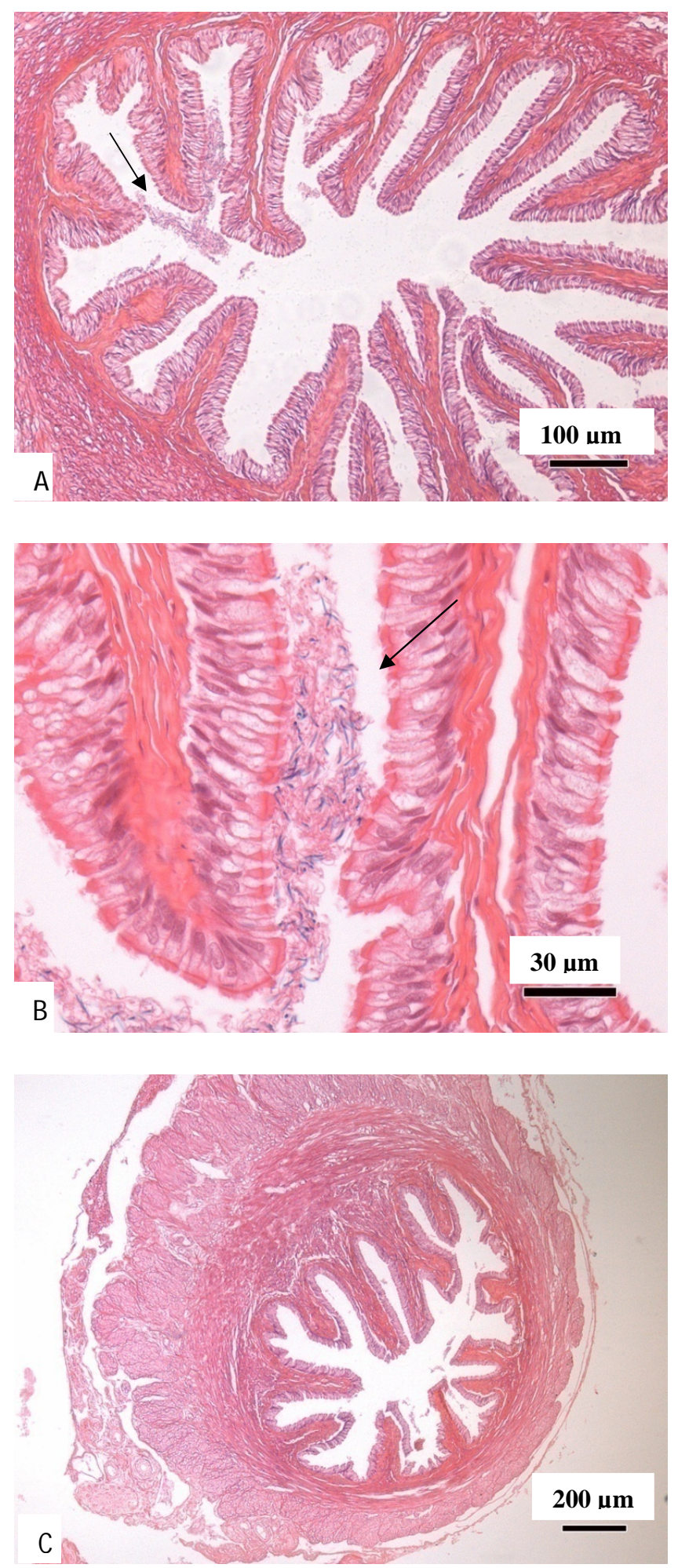

Fig. 17: Bothropoides neuwiedi. Cortes transversais. (A) e (B): fotomicrografias do útero posterior de fêmea coletada na primavera. As setas pretas indicam a massa de espermatozóides estocados nas dobras da UMT. (C): fotomicrografia do útero posterior de fêmea coletada no verão, mostrando visão geral da UMT. Objetiva: A 10x; B 40x; C 4x. 


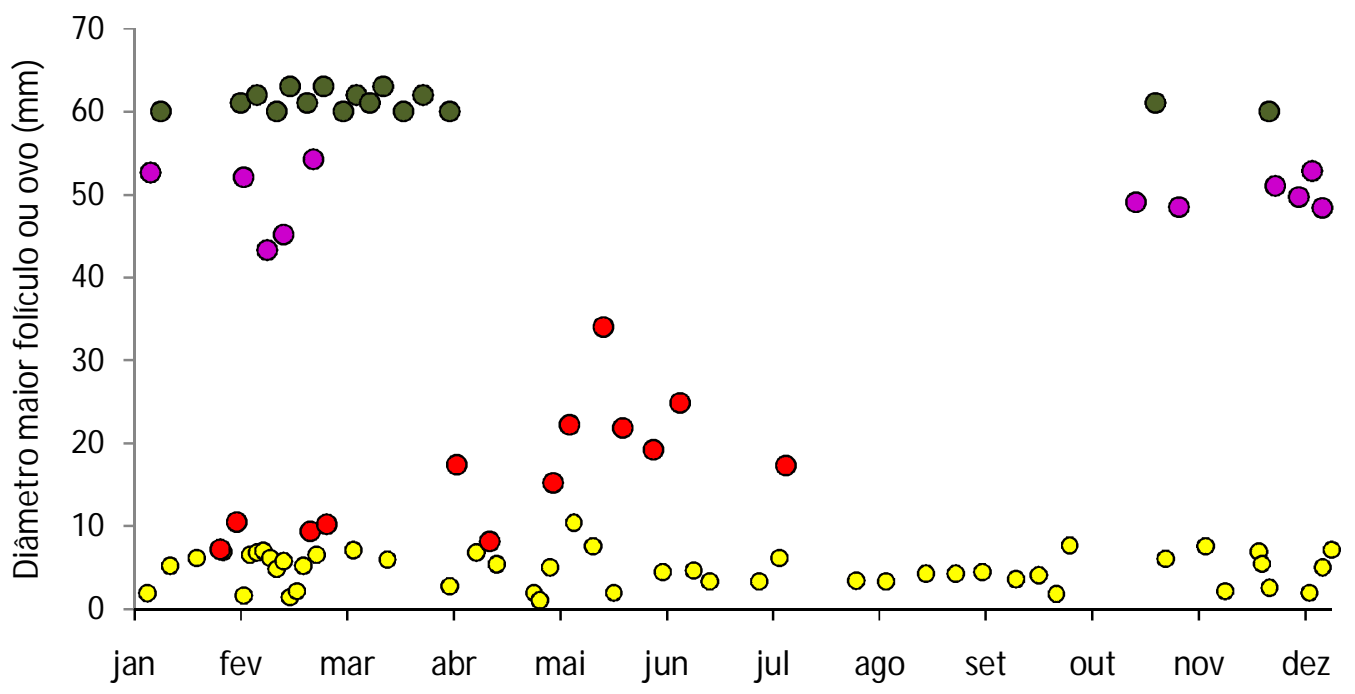

Figura 18: Bothropoides neuwiedi. Variação sazonal no diâmetro do maior folículo ovariano ou ovos nos ovidutos em fêmeas adultas. Círculos amarelos: folículos em vitelogênese primária. Círculos laranja: vitelogênese secundária. Círculos roxos: ovos com embriões em diferentes estágios de desenvolvimento. Círculos verdes: nascimento das ninhadas.

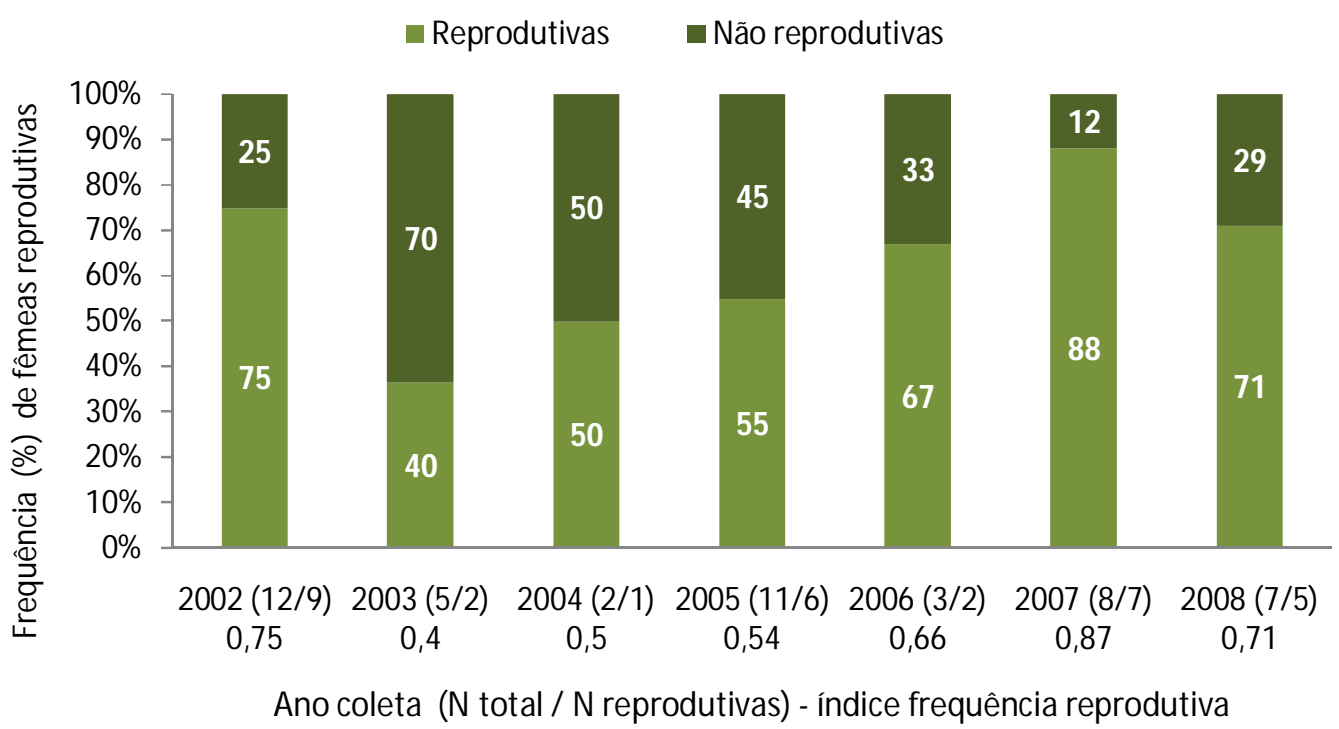

Figura 19: Bothropoides neuwiedi. Freqüência de fêmeas reprodutivas por ano durante o período de estudo. 


\section{Ninhadas}

Foram analisadas quinze ninhadas de B. neuwiedi, que juntas totalizaram 96 filhotes (apenas 1 natimorto e 2 filhotes com malformações). A presença de ovos atrésicos foi constatada em 5 ninhadas (18 ovos atrésicos no total). O número de filhotes por ninhada variou de 3 a 12 (média 6,4 \pm 2,3). Analisando as ninhadas em conjunto registramos o nascimento de 54 filhotes fêmeas $(56,25 \%)$ e 42 machos $(43,75 \%)$.

Os nascimentos ocorreram entre os meses de outubro a abril, com predominância de fevereiro e março. A menor fêmea que pariu filhotes media $670 \mathrm{~mm}$ de comprimento do corpo, e a maior $850 \mathrm{~mm}$.

A massa total das ninhadas variou de 40,2 g a 124,2 g, e a MRN (massa relativa da ninhada) de 0,18 a 0,61. Após o nascimento dos filhotes as fêmeas perderam entre 60,6 g a 290 g de massa corpórea.

Das 15 ninhadas, 11 fêmeas pariram os filhotes nas caixas de manutenção aonde vinham sendo mantidas vivas. Nas outras 4 ocasiões, foi possível observar o número de embriões em cada oviduto, sendo sempre o número de embriões no oviduto direito maior do que no esquerdo (Figura 20).

Três ninhadas são provenientes de cópulas em cativeiro (macho e fêmea coletados na FSE). Uma fêmea pariu logo após ser coletada (abril/2006; CRC 730 mm; 5 filhotes; massa da ninhada de 53g; MRN =0,28). Após dois anos copulou em cativeiro e pariu sua segunda ninhada no ano subseqüente (março/2009; CRC 830 mm; 9 filhotes; massa da ninhada de 92,43g; $\mathrm{MRN}=0,36$ ), copulou novamente em 2010 e pariu sua terceira ninhada (março/2011; CRC $850 \mathrm{~mm}$; 3 filhotes; massa da ninhada de 61,71g; $\mathrm{MRN}=0,19)$

Outra fêmea também pariu logo após ser coletada (março/2006; CRC 670 mm; 6 filhotes; massa da ninhada de $87 \mathrm{~g} ; \mathrm{MRN}=0,61$ ), após 4 anos copulou em cativeiro e no ano subseqüente pariu sua segunda ninhada (março/2011; CRC 845 mm; 6 filhotes; massa da ninhada de 54,68g; MRN =0,18).

Informações sobre as ninhadas e suas mães são mostradas no anexo B. 


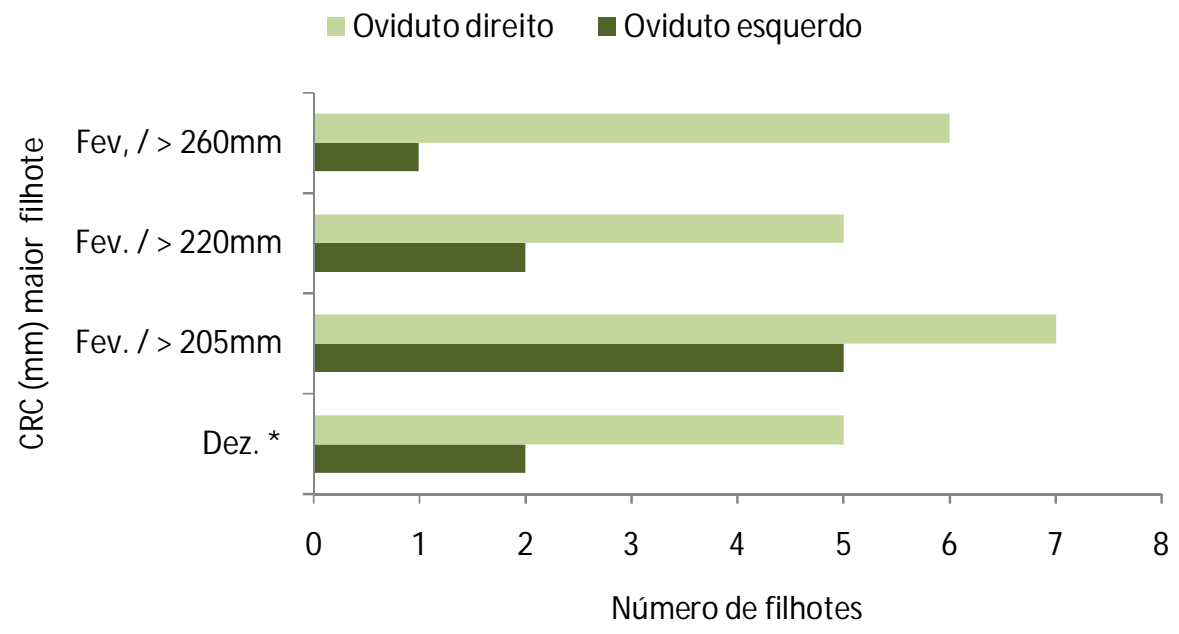

Figura 20: Bothropoides neuwiedi. Número de filhotes em cada oviduto e tamanho do maior filhote de cada fêmea. *filhotes não totalmente formados.

A análise de regressão do número de filhotes sobre o comprimento do corpo das mães não foi significativa $\left(\mathrm{F}_{0,05(2) 15}=0,9313, \mathrm{p}>0,05\right)$ (Figura 21). A análise de regressão da massa total das ninhadas pelo comprimento do corpo das mães não foi significativa $\left(\mathrm{F}_{0,05(2) 14}=1,6622, \mathrm{p}>0,05\right)$ (Figura 22). A análise de regressão do número de filhotes sobre a massa das mães não foi significativa $\left(\mathrm{F}_{0,05(2) 14}=0,0093\right.$, p > 0,05) (Figura 23). A análise de regressão da massa total das ninhadas pela massa das mães não foi significativa $\left(\mathrm{F}_{0,05(2) 14}=0,0061, \mathrm{p}>0,05\right)$ (Figura 24).

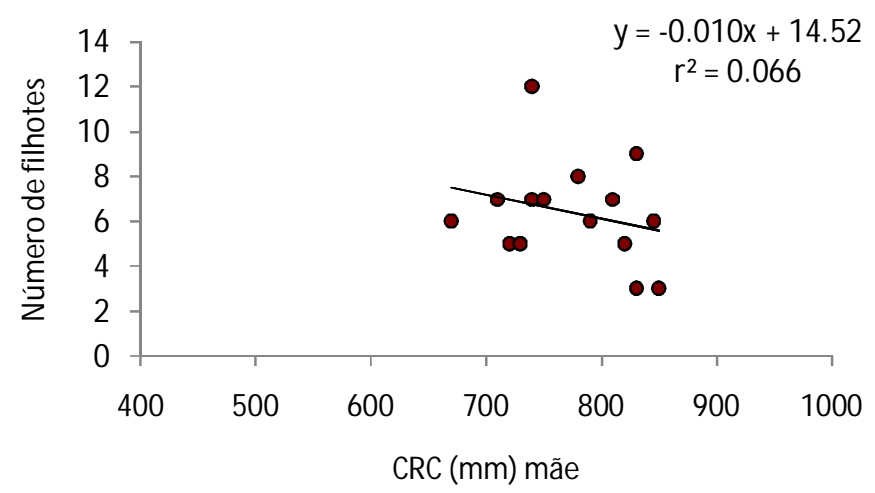

Figura 21: Bothropoides neuwiedi. Regressão do número de filhotes sobre o comprimento do corpo das mães. 


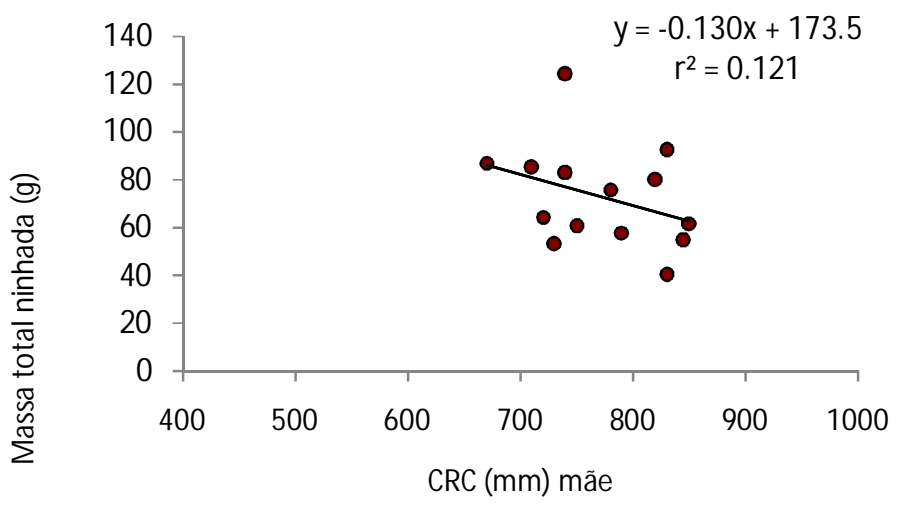

Figura 22: Bothropoides neuwiedi. Regressão da massa total das ninhadas sobre o comprimento do corpo das mães.

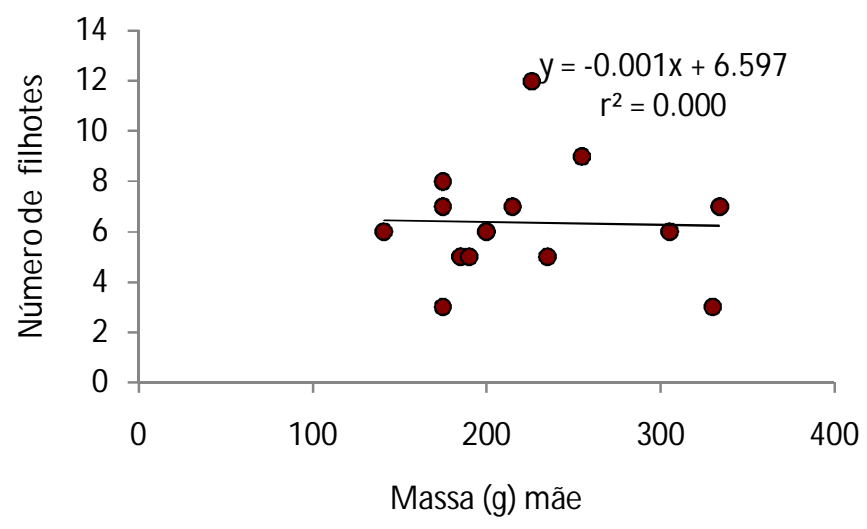

Figura 23: Bothropoides neuwiedi. Regressão do número de filhotes sobre a massa das mães.

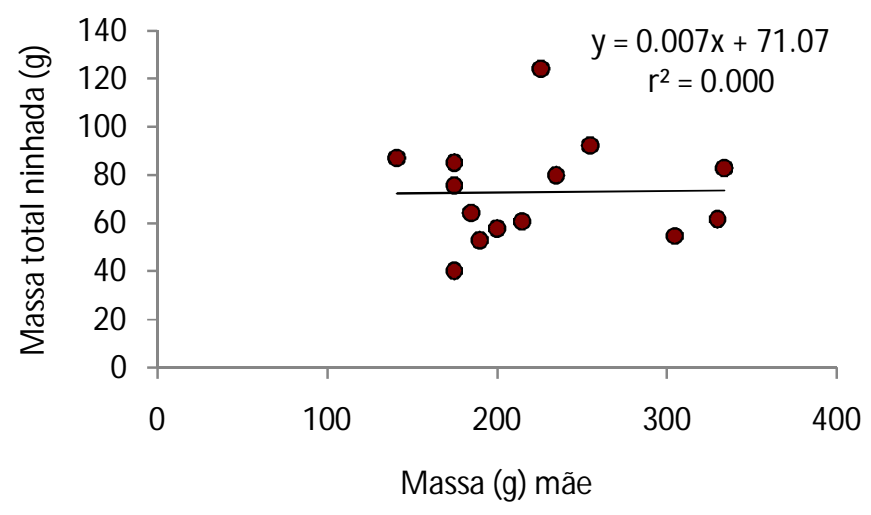

Figura 24: Bothropoides neuwiedi. Regressão da massa total das ninhadas sobre a massa das mães. 


\section{Filhotes}

Morfometrias e massa corporal:

Não foram observadas diferenças significativas no comprimento do corpo dos filhotes machos e fêmeas ( $\mathrm{t}$ 0,05 (2),85 $=0,2559 ; \mathrm{p}>0$, 05). Os filhotes machos apresentaram comprimento relativo de cauda significativamente maior do que as fêmeas $\left(\mathrm{t}_{0,05(2), 85}=3,396 ; \mathrm{p}<0,05\right)$. O comprimento relativo da cabeça de machos e fêmeas não apresentaram diferenças significativas $(t=0,05(2), 76=0,5013 ; \mathrm{p}>0,05)$. Machos e fêmeas filhotes não apresentaram diferenças significativas em relação à robustez $\left(\mathrm{t}_{0,05(2), 85}=1,024 ; \mathrm{p}>0,05\right)($ Tabela 6$)$.

Tabela 6: Bothropoides neuwiedi. Amplitude, número de observações $(\mathrm{N})$ e média \pm erro padrão dos exemplares filhotes.

\begin{tabular}{lccccc}
\hline & Sexo & A & N & $\begin{array}{c}\text { Média } \pm \text { erro } \\
\text { padrão }\end{array}$ & t \\
\hline CRC $(\mathrm{mm})$ & Machos & $175-295$ & 41 & $225,1 \pm 31,1$ & $\mathrm{P}>0,05$ \\
$\mathrm{CRC}(\mathrm{mm})$ & Fêmeas & $190-290$ & 46 & $226,6 \pm 23,8$ & \\
& & & & & \\
$\mathrm{CC}(\mathrm{mm})$ & Machos & $25-45$ & 41 & $34,3 \pm 5,5$ & $\mathrm{P}<0,05^{* * *}$ \\
$\mathrm{CC}(\mathrm{mm})$ & Fêmeas & $17-45$ & 46 & $31,6 \pm 5,4$ & \\
& & & & & \\
$\mathrm{CCAB}(\mathrm{mm})$ & Machos & $10-18$ & 38 & $14,4 \pm 1,5$ & $\mathrm{P}>0,05$ \\
$\mathrm{CCAB}(\mathrm{mm})$ & Fêmeas & $11-17$ & 40 & $14,4 \pm 1,3$ & \\
& & & & & $\mathrm{P}>0,05$ \\
Massa $(\mathrm{g})$ & Machos & $5-16,7$ & 41 & $10,4 \pm 2,5$ & \\
Massa $(\mathrm{g})$ & Fêmeas & $6,1-17,7$ & 46 & $10,6 \pm 2$ & \\
\hline
\end{tabular}

Todos os filhotes nascem com a ponta da cauda amarelada (diferentes tons de amarelo, desde amarelo claro até amarelo escuro), característica que é perdida entre os 18 e 24 meses de idade (observações de cativeiro através da criação dos filhotes nascidos das fêmeas prenhes deste estudo). A primeira ecdise, em todos os filhotes, ocorreu em até 48 horas de vida. 


\section{Comportamento de corte e cópula em cativeiro}

Foram realizadas tentativas de acasalamento em cativeiro das serpentes coletadas na área de estudo. O período escolhido para essas tentativas foi restrito ao outono e inicio do inverno, baseado no período de vitelogênese secundária observado para a espécie (ver resultados dos ciclos reprodutivos).

No total foram realizadas 17 tentativas de acasalamento, sendo que 5 resultaram em cópula (Tabela 8). As tentativas de acasalamento mal sucedidas ocorreram nos meses de maio $(\mathrm{N}=3)$, junho $(\mathrm{N}=6)$ e julho $(\mathrm{N}=3)$.

$\mathrm{Na}$ espécie não é observado comportamento de ritual de combate entre os machos. Mesmo quando colocados dois machos e uma fêmea juntos, os machos não mostraram comportamento agressivo. Em alguns casos, ambos cortejaram a fêmea, porém sem demonstrações de rivalidade. Vale ressaltar que quando foi colocado mais de um macho para as tentativas de acasalamento $(\mathrm{N}=4)$, apesar do comportamento de corte realizado por um ou pelos dois machos, não ocorreu a cópula.

O comportamento de corte ocorreu em todas as cópulas observadas, porém com duração variando entre 10 a 130 minutos. Sempre o macho iniciava o comportamento de corte, aproximando-se da fêmea com movimentos curtos e bruscos da região anterior do corpo. Durante a corte o macho sobe sobre o dorso do corpo da fêmea, realizando movimentos ondulatórios (ondas caudo-cefálicas) com tremores do corpo. O dardejar de língua por parte dos machos é intermitente por todo o corpo das fêmeas, com atenção especial as áreas da cabeça e região cloacal das fêmeas. A agitação da cauda também é freqüente, muitas vezes bem próximo à cauda da fêmea. Os movimentos dos machos às vezes são cessados para breves períodos de descanso. A corte termina com a aceitação da cópula por parte da fêmea, que levanta a cauda e relaxa a musculatura cloacal, permitindo que o macho enlace sua cauda com a dele, alinhe sua cloaca a dela e faça a introdução do hemipênis.

As fêmeas geralmente são passivas durante a corte. Quando não ocorreu cópula, em apenas um casal foi observado comportamento agressivo por parte da fêmea, se movimentando bastante e desferindo botes para afastar o macho. As demais permaneceram enrodilhadas ignorando os movimentos do macho. Nesses casos, quando 
mesmo após várias tentativas, a fêmea permaneceu enrodilhada e não aceitou a corte, o macho também se enrodilhou em um dos cantos da gaiola.

A duração das cópulas observadas variou de no mínimo 6 horas e 52 minutos a no mínimo 9 horas e 12 minutos. Não foi possível determinar a duração exata dos acasalamentos, pois sempre continuavam durante a noite. O comportamento de cópula foi similar entre todos os casais. Em alguns casos os dois permaneciam bastante próximos, com parte com corpos entrelaçados, e em outros permaneciam cada um a um canto da gaiola, apenas unidos pelas cloacas. São freqüentes discretos movimentos de cabeça, tremores no corpo e agitação da cauda dos machos. Em alguns momentos são percebidas ondas caudo-cefálicas percorrendo o corpo do macho, algumas vezes acompanhadas por esperma escorrendo pela cloaca das fêmeas (observado ao microscópio sempre apresentava espermatozóides vivos). Em uma das cópulas observadas a fêmea (geralmente passiva também durante os acasalamentos) se movimentou muito durante as duas primeiras horas de cópula, tentando sair da gaiola e arrastando o corpo do macho enquanto se movimentava. Após o término do acasalamento, cada um permanecia enrodilhado em um canto do terrário.

Foi observado que fêmeas que haviam copulado, nos dois dias posteriores rejeitavam nova cópula com outros machos, apesar destes cortejarem insistentemente as fêmeas, que permaneciam imóveis e enrodilhadas em um canto da gaiola. Machos que haviam copulado, nos dois dias seguintes ao da cópula também não mostravam nenhum interesse por outras fêmeas. Permaneciam enrodilhados em um canto, indiferentes à presença da fêmea.

Quando os casais que copularam foram colocados juntos novamente no dia seguinte ao da cópula, não houve interesse por parte do macho de iniciar novo comportamento reprodutivo. Tanto os machos quanto as fêmeas permaneciam enrodilhados. Passado um período de 10 dias após os acasalamentos, as fêmeas que haviam copulado continuaram rejeitando o mesmo ou diferentes machos. Já os machos copularam com outras fêmeas. 
Das 5 cópulas observadas e registradas, 3 resultaram em ninhadas. O tempo transcorrido desde a cópula até o nascimento dos filhotes foi de 207 a 286 dias (Tabela 7). Nenhuma das fêmeas que estava prenhe deixou de se alimentar durante a gestação, aceitando a quantidade habitual de alimento. Imagens do comportamento de corte e dos acasalamentos são mostradas no anexo D.

Tabela 7: Bothropoides neuwiedi. Cópulas registradas em cativeiro.

\begin{tabular}{cccccc}
\hline Mês & Início corte & Tempo corte & Tempo cópula * & Ninhadas & Cópula/Nasc. ** \\
\hline maio & imediato & $10 \mathrm{~min}$ & $7 \mathrm{~h} 20 \mathrm{~min}$ & - & \\
junho & após $20 \mathrm{~min}$. & $29 \mathrm{~min}$. & $8 \mathrm{~h} 40 \mathrm{~min}$ & 9 filhotes & $251 \mathrm{dias}$ \\
maio & imediato & $130 \mathrm{~min}$. & $8 \mathrm{~h} 05 \mathrm{~min}$ & - & \\
maio & imediato & $58 \mathrm{~min}$. & $9 \mathrm{~h} 12 \mathrm{~min}$ & 3 filhotes & 286 dias \\
julho & após $46 \mathrm{~min}$. & $22 \mathrm{~min}$. & $6 \mathrm{~h} 52 \mathrm{~min}$ & 6 filhotes & 207 dias \\
\hline
\end{tabular}

* Tempo mínimo de duração da cópula: período computado desde o início da cópula até às $18 \mathrm{~h}$ (em alguns casos) ou em até $19 \mathrm{~h}$. Cópulas continuavam durante a noite. Às $8 \mathrm{hs} \mathrm{do}$ dia seguinte todas haviam terminado.

**Cópula/Nasc. $=$ período computado desde o dia da cópula até o nascimento dos filhotes. 


\subsection{Bothropoides jararaca}

\section{Proporções corporais}

Foram coletados 26 exemplares de B. jararaca (8 machos, 18 fêmeas). As análises de regressão do comprimento da cauda sobre o comprimento rostro-cloacal foram significativas para ambos os sexos (fêmeas: $\mathrm{F}_{0,05(2), 16}=97,8553, \mathrm{p}<0,05$; machos: $\mathrm{Fv}_{0,05(2), 6}=60,9925, \mathrm{p}<0,05$ ) (Figura 25). A análise da diferença entre as retas da regressão foi significativa $\left(\mathrm{t}_{0,05}(2), 22=2,2885, \mathrm{p}<0,05\right)$, indicando que machos $\mathrm{e}$ fêmeas não possuem as mesmas relações entre as variáveis corpo e cauda.

As regressões da massa sobre o comprimento total também foram significativas para machos e fêmeas (fêmeas: $\mathrm{F}_{0,05(2), 16}=47,1579, \mathrm{p}<0,05$; machos: $\mathrm{F}_{0,05(2), 6}=$ 25,2397, $\mathrm{p}<0,05)$ (Figura 26). A diferença entre as retas foi significativa, indicando que machos e fêmeas não possuem as mesmas relações entre as variáveis massa e comprimento total $\left(\mathrm{t}_{0,05(2), 22}=2,8317, \mathrm{p}<0,05\right)$.

As regressões do comprimento da cabeça sobre o comprimento do tronco foram significativas apenas para as fêmeas (fêmeas: $\mathrm{F}_{0,05(2), 16}=96,0355, \mathrm{p}<0,05$; machos: $\left.\mathrm{F}_{0,05(2), 6}=1,7117, \mathrm{p}>0,05\right)$ (Figura 27).

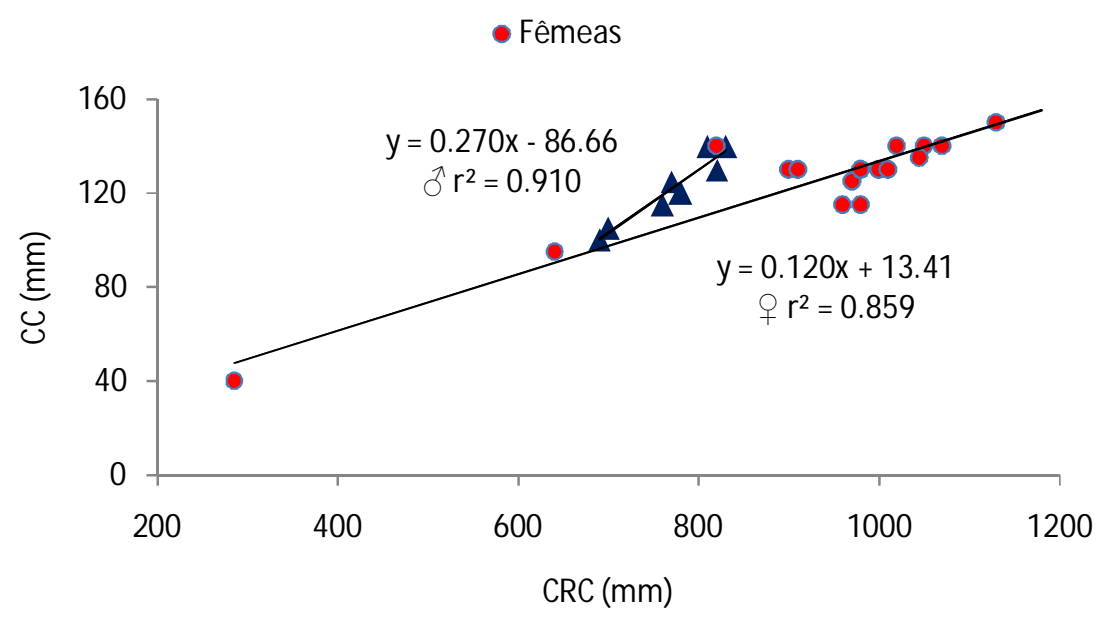

Figura 25: Bothropoides jararaca. Regressão do comprimento da cauda (CC) sobre o comprimento do corpo (CRC). 


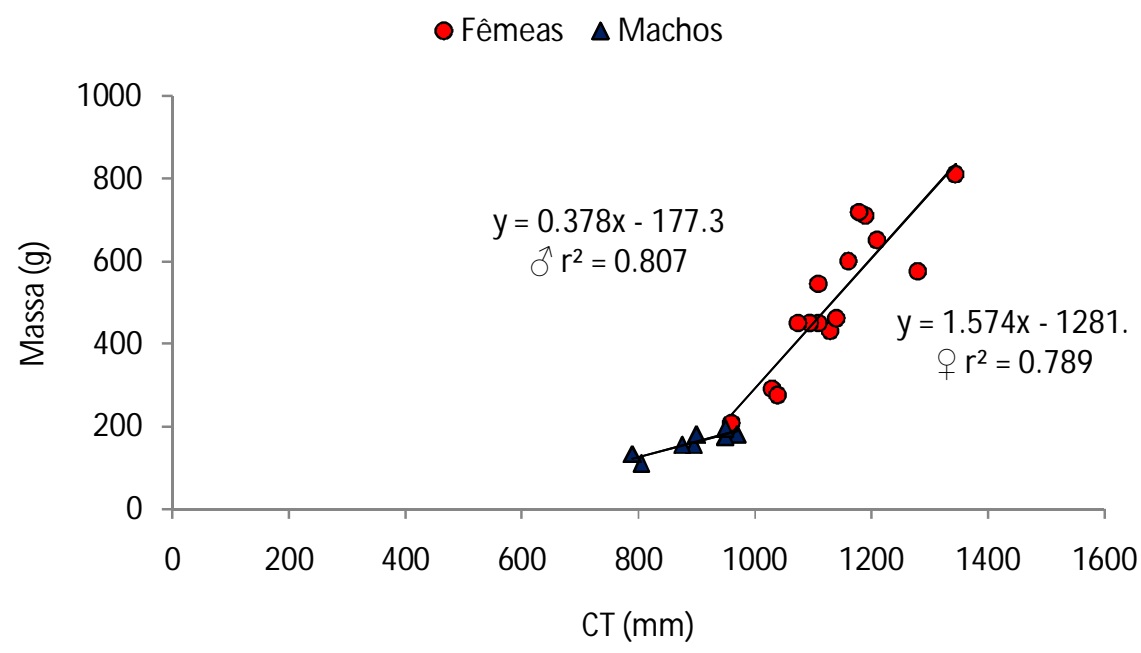

Figura 26: Bothropoides jararaca. Regressão da massa sobre o comprimento total (CT).

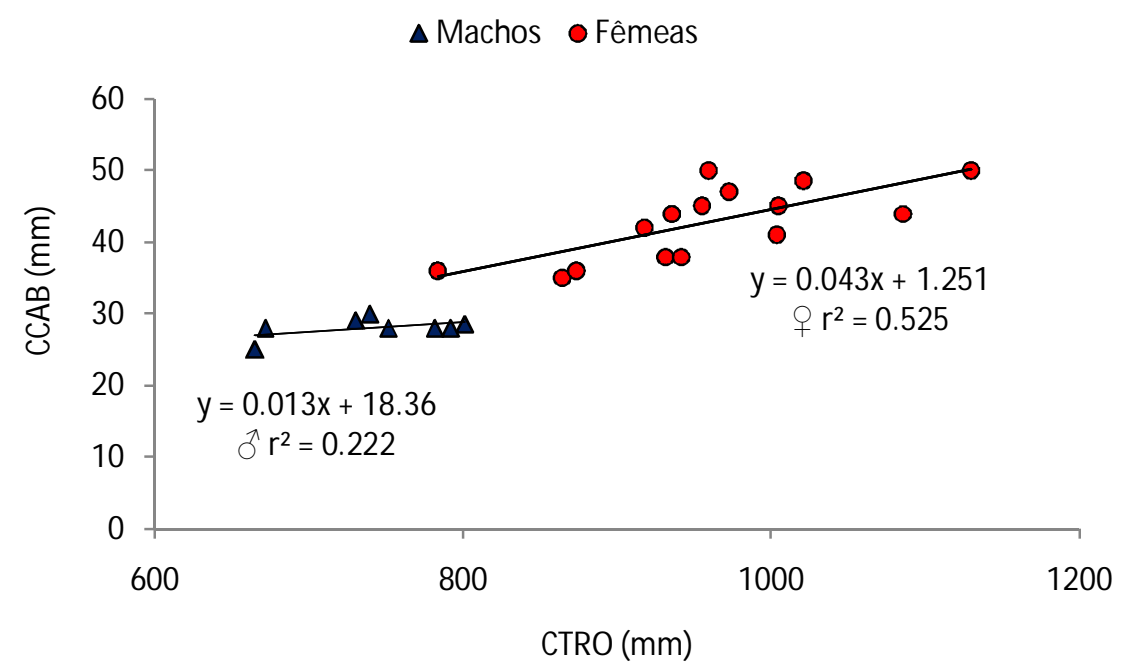

Figura 27: Bothropoides jararaca. Regressão do comprimento da cabeça (CCA) sobre o comprimento do tronco (CTRO). 


\section{Morfometrias e massa corporal}

O comprimento do corpo das fêmeas adultas de $B$. jararaca foi significativamente maior do que os machos adultos ( $\mathrm{t}_{0,05}$ (2) $22=6,851 ; \mathrm{p}<0$, 05). Os machos adultos apresentaram comprimento relativo de cauda significativamente maior do que as fêmeas ( $\mathrm{t}_{0,05}$ (2) $\left.22=4,886 ; \mathrm{p}<0,05\right)$. O comprimento relativo da cabeça das fêmeas foi significativamente maior do que os machos ( $\mathrm{t}_{0,05}$ (2) $22=5$, 684; $\mathrm{p}<0$, 05). Fêmeas adultas são significativamente mais robustas do que machos adultos $\left(\mathrm{t}_{0,05}\right.$ (2) $22=5,684$; $\mathrm{p}<0,05)($ Tabela 8).

Tabela 8: Bothropoides jararaca. Amplitude, número de observações $(\mathrm{N})$ e média \pm erro padrão dos exemplares adultos coletados durante o período de estudo.

\begin{tabular}{lccccc}
\hline & Sexo & A & N & $\begin{array}{c}\text { Média } \pm \text { erro } \\
\text { padrão }\end{array}$ & t \\
\hline CRC $(\mathrm{mm})$ & Machos & $690-830$ & 8 & $770 \pm 52,4$ & $\mathrm{t}_{0,05(2) 22}=6,851^{* * *}$ \\
$\mathrm{CRC}(\mathrm{mm})$ & Fêmeas & $820-1180$ & 16 & $1000,3 \pm 86,9$ & \\
& & & & & \\
$\mathrm{CC}(\mathrm{mm})$ & Machos & $100-140$ & 8 & $121,9 \pm 14,8$ & $\mathrm{t}_{0,05(2) 22}=4,886^{* * *}$ \\
$\mathrm{CC}(\mathrm{mm})$ & Fêmeas & $115-165$ & 16 & $134 \pm 12,3$ & \\
& & & & & \\
$\mathrm{CCAB}(\mathrm{mm})$ & Machos & $25-30$ & 8 & $28,1 \pm 1,4$ & $\mathrm{t}_{0,05(2) 22}=5,684^{* * *}$ \\
$\mathrm{CCAB}(\mathrm{mm})$ & Fêmeas & $35-50$ & 16 & $42,7 \pm 4,9$ & \\
& & & & & \\
Massa $(\mathrm{g})$ & Machos & $133-195$ & 8 & $160,4 \pm 28,1$ & $\mathrm{t}_{0,05(2) 22}=5,684^{* * *}$ \\
Massa $(\mathrm{g})$ & Fêmeas & $209-810$ & 16 & $504,6 \pm 169,4$ & \\
\hline
\end{tabular}

Utilizando o grau de dimorfismo sexual de tamanho corporal (SSD), proposto por Shine (1994), verificamos que as fêmeas são maiores do que machos e apresentam um grau de dimorfismo de 0,29 , que é expresso como positivo quando as fêmeas são maiores do que machos. 


\section{Atividade sazonal}

Os machos de Bothropoides jararaca foram capturados apenas nos meses de verão. As fêmeas foram mais amostradas na primavera e no verão, porém as diferenças em relação aos outros períodos do ano não foram significativas (Tabela 9). Apenas duas fêmeas jovens foram amostradas, uma na primavera e uma no verão (Figura 28).

Tabela 9: Bothropoides jararaca. Sazonalidade na captura de machos e fêmeas.

\begin{tabular}{lcc}
\hline & Fêmeas - N (\%) & Machos - N (\%) \\
\hline Primavera & $7(38,9 \%)$ & 0 \\
Verão & $6(33,3 \%)$ & $8(100 \%)$ \\
Outono & $2(11,1 \%)$ & 0 \\
Inverno & $3(16,7 \%)$ & 0 \\
\hline Total & $\mathbf{1 8 ( 1 0 0 \% )}$ & $\mathbf{8 ( 1 0 0 \% )}$ \\
\hline
\end{tabular}

- fêmeas adultas — fêmeasjovens

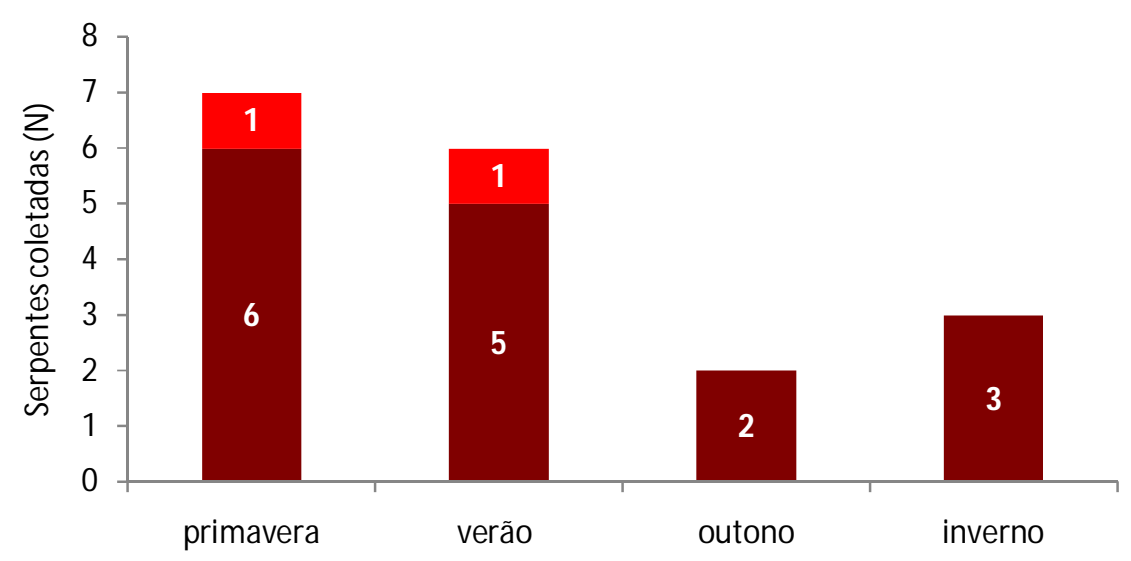

Figura 28: Bothropoides jararaca. Fêmeas jovens e adultas coletadas nas diferentes épocas do ano. 


\section{Uso do ambiente}

A espécie B. jararaca foi significativamente mais freqüente nas capoeiras e nas áreas abertas $\left(\chi^{2}=11,30 \mathrm{p}<0.005\right.$, g.l. $\left.=4\right)$, com percentual de coleta de $38,5 \% \mathrm{e}$ $30,8 \%$, respectivamente. Um número significativo foi encontrado nas áreas florestadas $(19,2 \%)$, e poucos indivíduos nas áreas cultivadas $(7,7 \%)$ e edificações $(3,8 \%)$ (Figura 29).

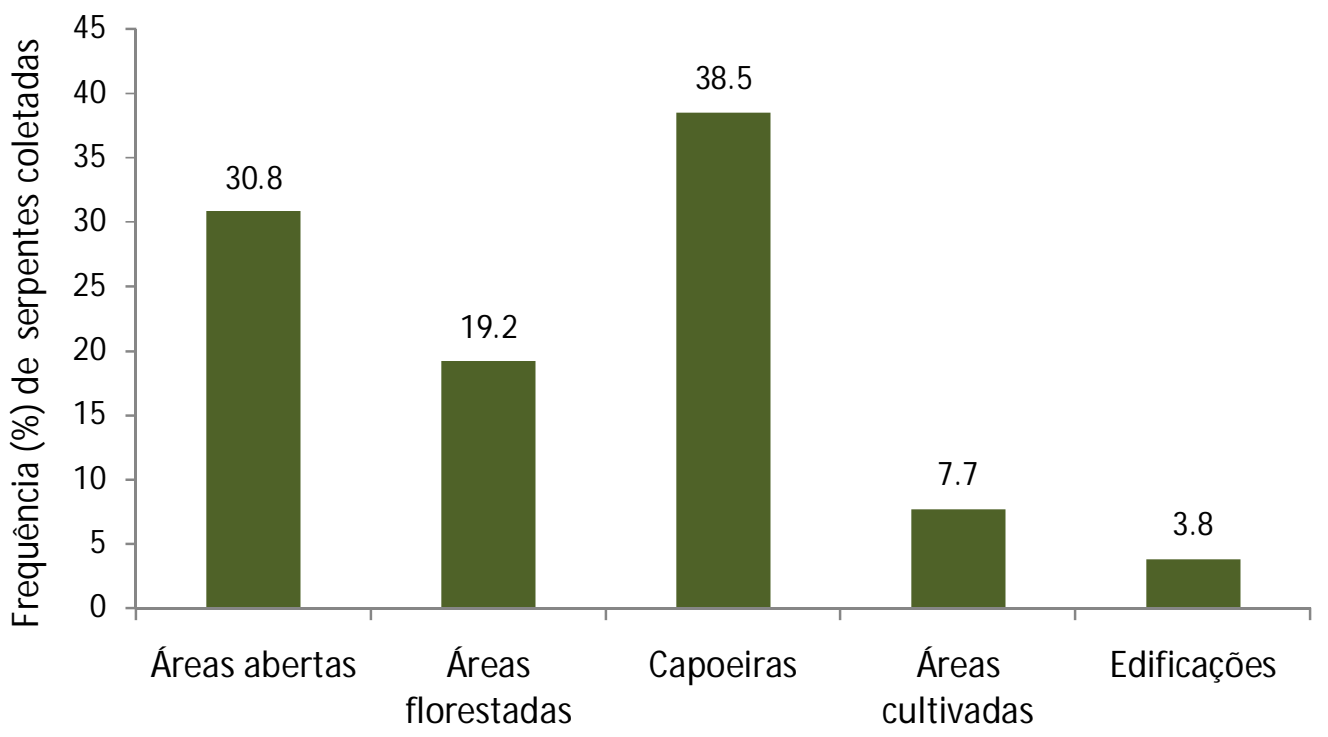

Figura 29: Bothropoides jararaca. Freqüência de serpentes capturadas nas diferentes fisionomias vegetais e edificações.

Levando em conta a subdivisão das fisionomias vegetais, exemplares machos foram encontrados apenas nas capoeiras e nas áreas de Campos de Altitude. As fêmeas foram observadas em todos os tipos de ambientes, porém com maior número de coleta nos Campos de Altitude e nas capoeiras. Em menor número, as fêmeas foram encontradas em todos os ambientes florestados (mata, áreas de reflorestamento e Floresta de Araucárias), nas áreas cultivadas, nas pastagens e nas edificações (Figura 30). Detalhes do local e horário de coleta dos indivíduos são mostrados no anexo F. 


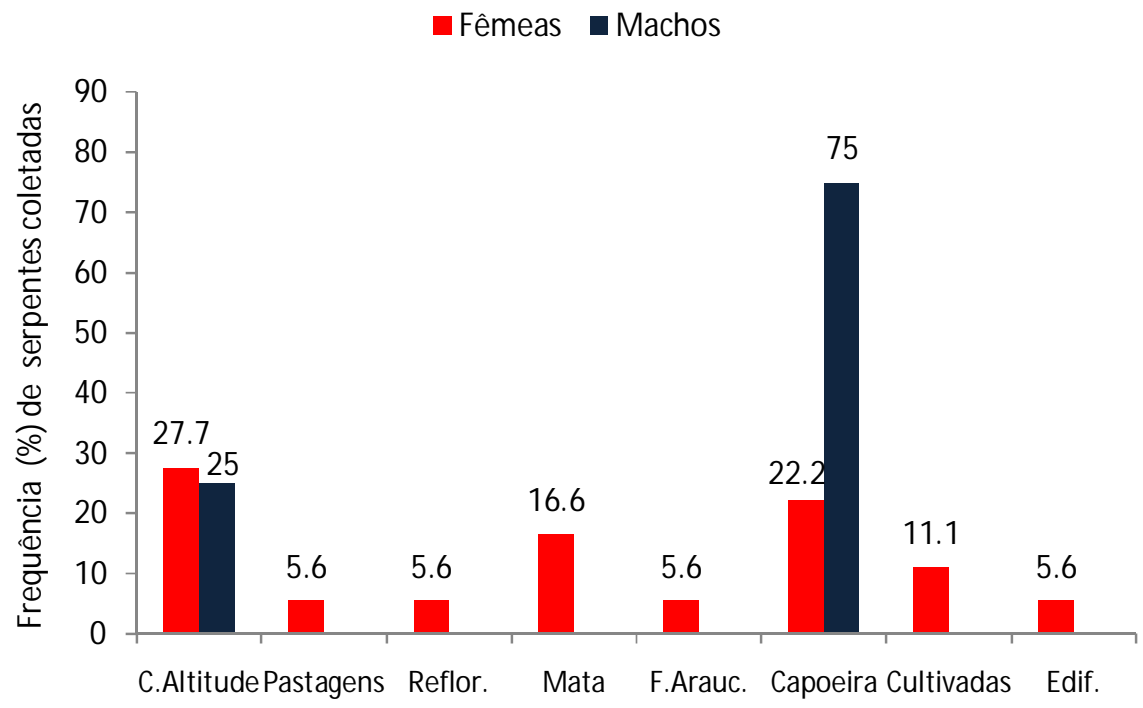

Figura 30: Bothropoides jararaca. Freqüência de serpentes capturadas em relação ao local de coleta.

\section{Atividade no momento do encontro}

Nos períodos da manhã e tarde foi coletada a maioria dos indivíduos (Figura 31). A maior parte das serpentes estava enrodilhada (Figura 32). A maior parte mostrou-se ativa quando da aproximação das pessoas (Figura 33), e o comportamento defensivo mais utilizado foi o bote, seguido ou precedido por tentativa de fuga (Figura 34). Apenas uma fêmea prenhe foi observada, tentando a fuga como defesa. Uma síntese da atividade e comportamento no momento do encontro é mostrada no anexo F. Imagens das serpentes no momento do encontro são mostradas no anexo A. 


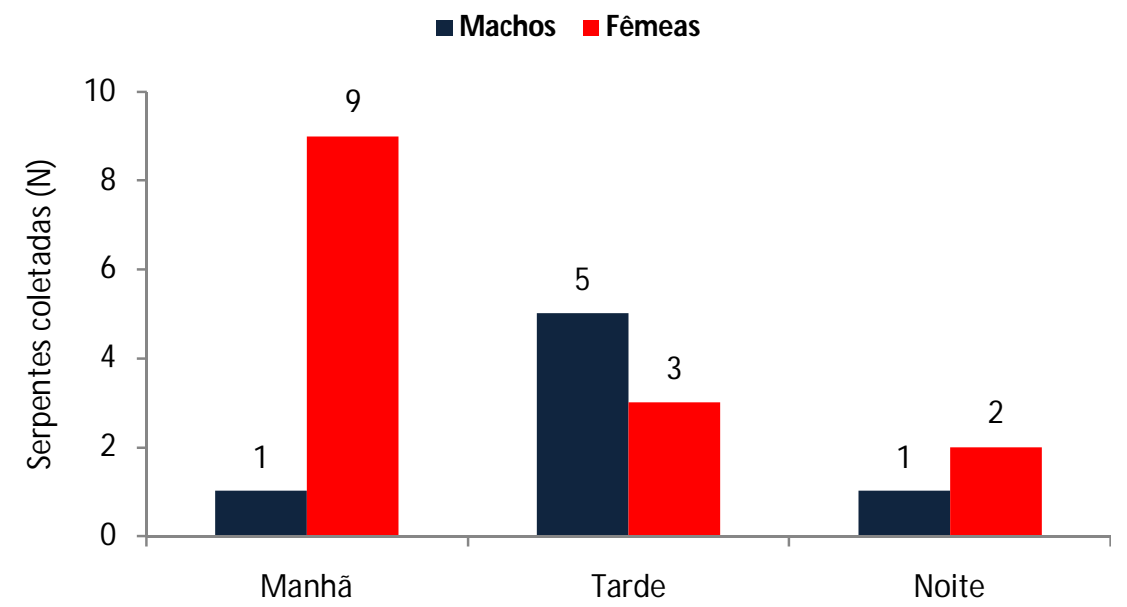

Figura 31: Bothropoides jararaca. Período de encontro das serpentes coletadas.

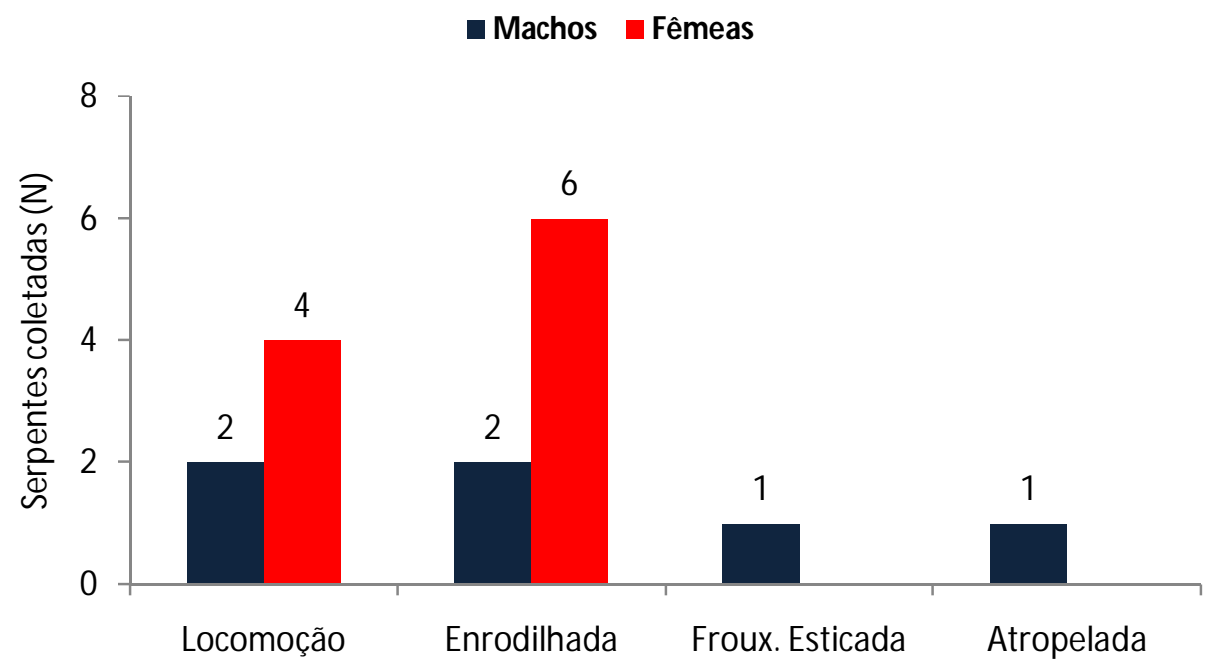

Figura 32: Bothropoides jararaca. Postura das serpentes no momento do encontro. 


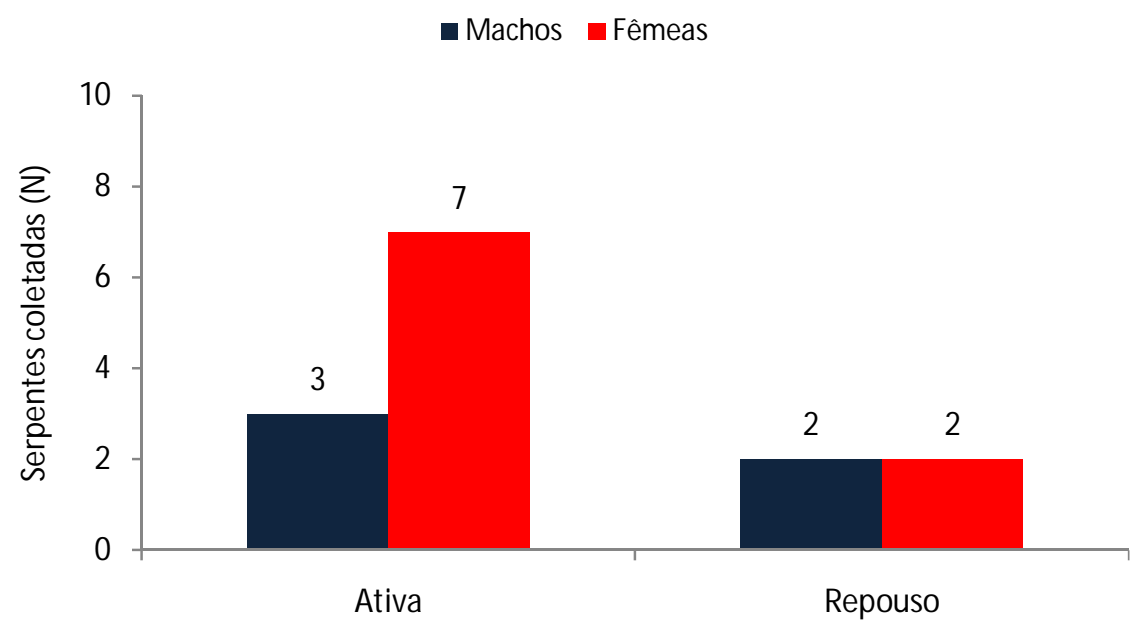

Figura 33: Bothropoides jararaca. Estado de atenção das serpentes no momento do encontro.

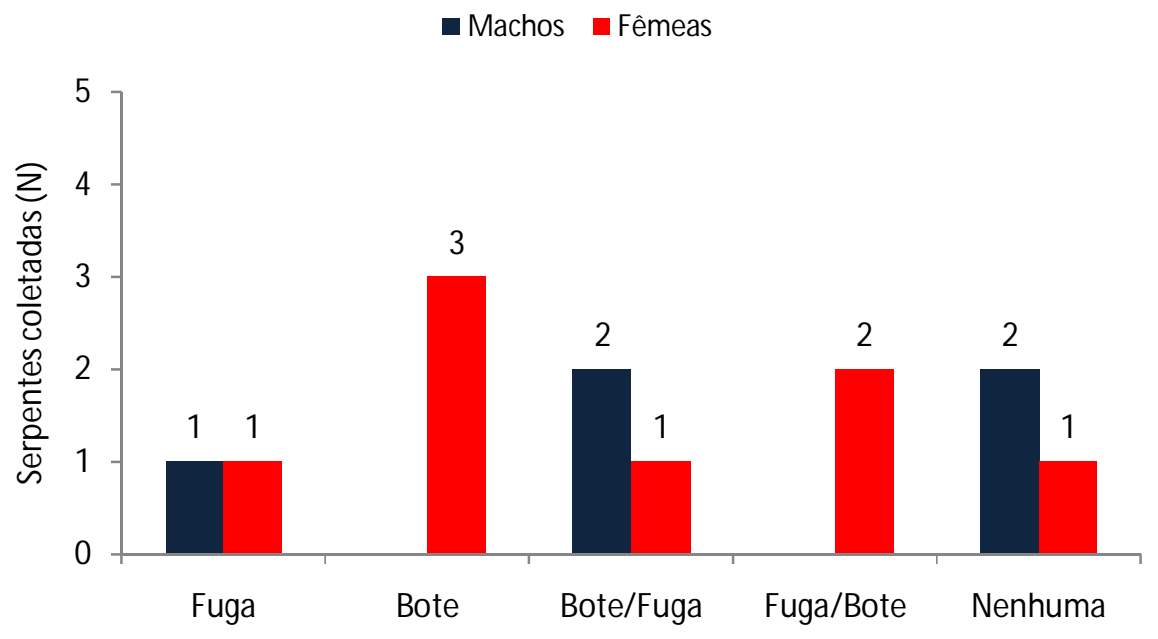

Figura 34: Bothropoides jararaca. Defesa utilizada pelas serpentes no momento do encontro. 


\section{Dieta}

Freqüência de serpentes alimentadas, variação sexual e sazonal:

Do total de 26 exemplares capturados, $13(50 \%)$ apresentavam alimento no trato gastrointestinal (alimentadas). Das 18 fêmeas capturadas, 9 (50\%) apresentavam alimento no tubo digestivo: 7 (77,8\%) apresentaram vestígios de presas no intestino,1 $(11,1 \%)$ tinha presas semi digeridas no estômago além de vestígios no intestino, e 1 $(11,1 \%)$ fêmea tinha uma presa no estômago. Dos 8 machos coletados, 4 (50\%) apresentaram vestígios de presas no intestino.

Fêmeas com alimento no trato gastrointestinal foram encontradas ao longo de todo o ano, e as diferenças na freqüência de alimentação nas diferentes épocas não foram significativas. Machos apresentaram alimento em seus tubos digestivos (e foram coletados) apenas no verão (Tabela 10). Do total de 7 serpentes prenhes (ovos nos ovidutos em diferentes estágios de desenvolvimento do embrião), 55\% apresentavam alimento no trato gastrointestinal.

Tabela 10: Bothropoides jararaca. Serpentes alimentadas nos diferentes períodos do ano.

\begin{tabular}{|c|c|c|c|c|}
\hline & \multicolumn{2}{|c|}{ Fêmeas } & \multicolumn{2}{|c|}{ Machos } \\
\hline & com alimento & sem alimento & com alimento & sem alimento \\
\hline Primavera & $3(16,7 \%)$ & $4(22,2 \%)$ & 0 & 0 \\
\hline Verão & $3(16,7 \%)$ & $3(16,7 \%)$ & $4(50 \%)$ & $4(50 \%)$ \\
\hline Outono & $2(11,1 \%)$ & 0 & 0 & 0 \\
\hline Inverno & $1(5,5 \%)$ & $2(11,1 \%)$ & 0 & 0 \\
\hline Total (N) & $9(50 \%)$ & $9(50 \%)$ & $4(50 \%)$ & $4(50 \%)$ \\
\hline Total (\%) & \multicolumn{2}{|c|}{$8(100 \%)$} & \multicolumn{2}{|c|}{$8(100 \%)$} \\
\hline
\end{tabular}


Tipos de presas ingeridas e presas múltiplas:

Todas as serpentes alimentadas haviam ingerido mamíferos. Uma fêmea com ovos nos ovidutos (CRC $1050 \mathrm{~mm}$, massa 710g) apresentou três mamíferos (2 praticamente inteiros) em seu estômago: 1 marsupial (massa 70,9g, comprimento do corpo $13 \mathrm{~cm}$, a maior presa ingerida por uma $B$. jararaca), um roedor (massa 63,5g) e um roedor já bastante digerido (massa presa semi digerida 22g). A massa das presas no momento da captura da serpente representava $22 \%$ do peso corporal do animal. Nenhum jovem apresentou presa no trato gastrointestinal (Tabela 11).

Tabela 11: Bothropoides jararaca. Número (\%) e tipo de presas ingeridas por jovens e adultos.

\begin{tabular}{ccccc}
\hline B.jararaca & Alimentados $(\mathbf{N})$ & Lagartos & Aves & Mamíferos \\
\hline 0 jovens $(\mathrm{N}=0)$ & 0 & 0 & 0 & 0 \\
$\sigma_{\text {adultos }}(\mathrm{N}=8)$ & 4 & 0 & 0 & $4(100 \%)$ \\
\hline & $\mathbf{4}$ & & & $\mathbf{1 0 0 \%}$ \\
क jovens $(\mathrm{N}=2)$ & 0 & 0 & 0 & 0 \\
+ adultos $(\mathrm{N}=16)$ & 9 & 0 & 0 & $9(100 \%)$ \\
\hline & $\mathbf{9}$ & & & $\mathbf{1 0 0 \%}$ \\
\hline
\end{tabular}

\section{Reprodução}

Ciclo reprodutivo dos machos:

Todos os machos apresentaram evidências de atividade reprodutiva, com os testículos desenvolvidos e túrgidos, e os ductos deferentes enovelados e de coloração opaca. As variações de massa e do volume testicular ao longo do ano não foram analisadas, em razão de todos machos terem sido coletados no verão. Os testículos da espécie também não foram analisados histologicamente.

O menor macho da amostra com características de reprodutivo tinha comprimento do corpo de $690 \mathrm{~mm}$. 
Ciclo reprodutivo das fềmeas:

Quase todas as fêmeas coletadas eram sexualmente maduras. Apenas duas foram classificadas como jovens.

Fêmeas com folículos em vitelogênese primária foram encontradas ao longo de todo o ano, e o comprimento do maior folículo observado nessa fase foi de $8,9 \mathrm{~mm}$.

Folículos em vitelogênese secundária foram observados desde o final do verão, quando se inicia a deposição de vitelo, e também durante o outono e inverno. Em todas as fêmeas o número de folículos em vitelogênese secundária no ovário direito $(\mathrm{N}$ total $=$ 46) foi maior do que no esquerdo ( $\mathrm{N}$ total $=33$ ), diferença estatisticamente significativa $\left(\mathrm{t}_{0,05}(2), 10=2,891 ; \mathrm{p}<0,05\right)$. Folículos a partir de 10,2 mm apresentavam início de deposição do vitelo, e o tamanho do maior folículo observado foi de $30 \mathrm{~mm}$.

Ovos estavam presentes em 6 fêmeas, durante a primavera. O número de ovos não variou entre oviduto direito e esquerdo, e o número médio de ovos por fêmea foi de $7,1 \pm 1,1$. O comprimento dos ovos variou de 45 a 52,4 $\mathrm{mm}$.

Os resultados mostram que as fêmeas estão em vitelogênese secundária durante o outono (época de acasalamentos) e inverno, na primavera ocorre a ovulação e fecundação, com gestação durante a primavera e verão, e nascimentos concentrados no final do verão (neste estudo, mais precisamente no mês de março) (Figura 35).

A amostra é pequena para calcular o percentual de fêmeas reprodutivas a cada ano. Entre as fêmeas que estavam com ovos nos ovidutos, 55,5\% apresentavam alimento no trato gastrointestinal.

A menor fêmea considerada reprodutiva da amostra tinha comprimento de corpo de $820 \mathrm{~mm}$, e apresentava ovos nos ovidutos. 


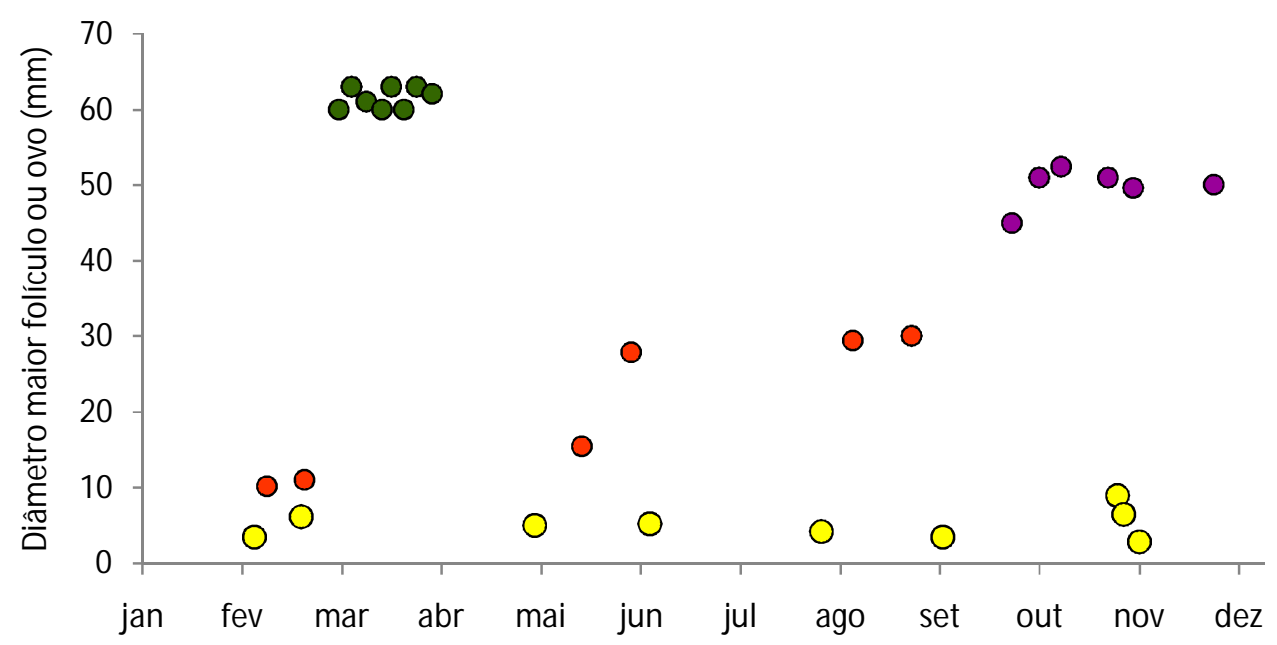

Figura 35. B. jararaca. Variação sazonal no diâmetro do maior folículo ovariano ou ovos nos ovidutos em fêmeas adultas. Círculos amarelos: folículos em vitelogênese primária. Círculos laranja: vitelogênese secundária. Círculos roxos: ovos com embriões em diferentes estágios de desenvolvimento. Círculos verdes: nascimentos das ninhadas.

\section{Ninhadas}

Foram obtidas 8 ninhadas de $B$. jararaca, totalizando 70 filhotes: 52 vivos e 18 natimortos. Malformações foram observadas em 8 filhotes (11,4\%). Ovos atrésicos foram registrados em 5 ninhadas, totalizando 16 ovos. Ao todo, nasceram 31 filhotes machos $(44,3 \%)$ e 39 fêmeas $(55,7 \%)$.

O número de filhotes por ninhada variou de 2 a 16 (média 8,7 $\pm 4,4$ ). Excetuando da análise uma ninhada onde nasceram apenas 2 filhotes com tamanho e peso fora dos padrões da espécie (vide anexo C), o numero de filhotes por ninhada variou de 5 a 16 (média 9,7 $\pm 3,8$ ).

Todos os nascimentos ocorreram nos meses de março. A menor fêmea que pariu filhotes tinha CRC de $970 \mathrm{~mm}$, e a maior $1150 \mathrm{~mm}$. A MRN (massa relativa da ninhada) variou de 0,04 a 0,67 ; a massa total das ninhadas de $17,9 \mathrm{~g}$ a $153,66 \mathrm{~g}$; e a massa perdida pelas fêmeas após o parto de $55 \mathrm{~g}$ a $315 \mathrm{~g}$. Novamente, excetuando a ninhada que produziu apenas 2 filhotes,o MRN variou de variou de 0,15 a 0,67 ; a massa total das ninhadas de $66,7 \mathrm{~g}$ a $153,6 \mathrm{~g}$; e a massa perdida pelas fêmeas de $120 \mathrm{~g}$ a $315 \mathrm{~g}$. 
Sete fêmeas pariram os filhotes nas caixas de manutenção aonde vinham sendo mantidas vivas. Em uma das ninhadas o intervalo até o nascimento de todos os filhotes foi de 6 dias. Uma das ninhadas analisadas é proveniente de cópula ocorrida em cativeiro.

Assim como em B. neuwiedi, todos os filhotes nascem com a ponta da cauda amarelada, característica que é perdida entre os 18 e 24 meses de idade (observações de cativeiro através da criação dos filhotes nascidos deste estudo). A primeira ecdise, em todos os filhotes, ocorreu em até 48 horas de vida. Informações sobre as ninhadas e suas mães podem ser observadas no anexo $\mathrm{C}$.

A análise de regressão do número de filhotes sobre o comprimento do corpo das mães não foi significativa $\left(\mathrm{F}_{0,05(2) 7}=0,5580 ; \mathrm{p}>0,05\right)$ (Figura 36). A análise de regressão da massa total das ninhadas pelo comprimento do corpo das mães não foi significativa $\left(\mathrm{F}_{0,05(2) 7}=0,2758 ; \mathrm{p}>0,05\right)$ (Figura 37). A análise de regressão do número de filhotes sobre a massa das mães não foi significativa $\left(\mathrm{F}_{0,05(2) 7}=0,5629, \mathrm{p}>0,05\right)$ (Figura 38). A análise de regressão da massa total das ninhadas pela massa das mães não foi significativa $\left(\mathrm{F}_{0,05(2) 7}=0,0916, \mathrm{p}>0,05\right)$ (Figura 39).

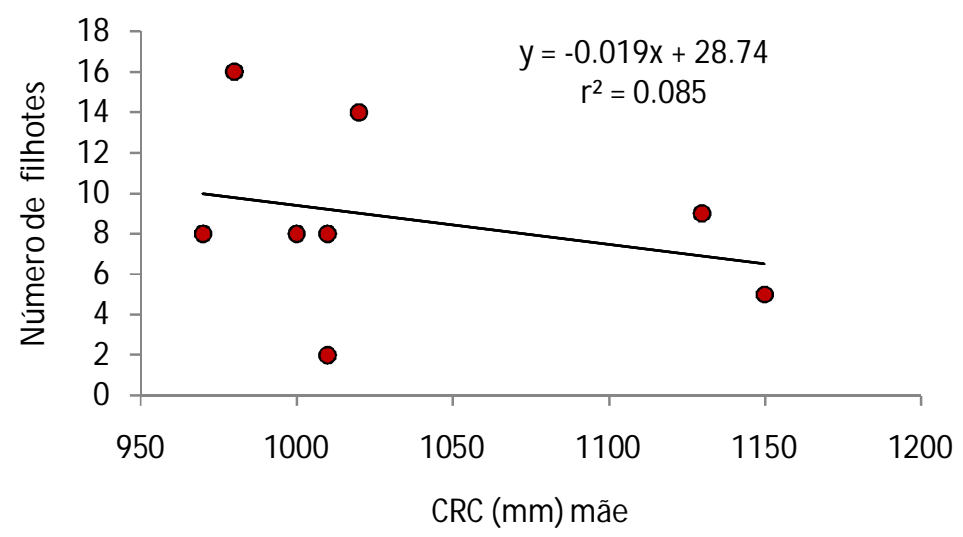

Figura 36: Bothropoides jararaca. Regressão do número de filhotes sobre o comprimento do corpo das mães. 


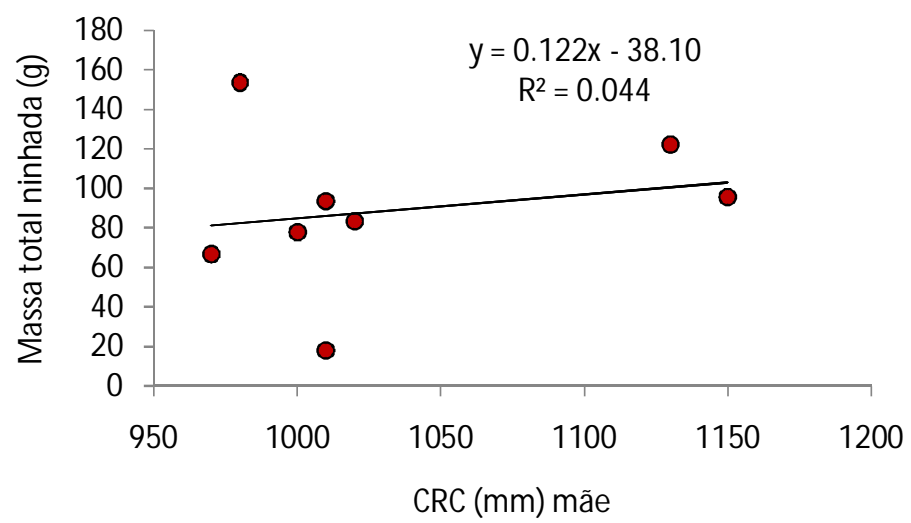

Figura 37: Bothropoides jararaca. Regressão da massa total das ninhadas sobre o comprimento do corpo das mães.

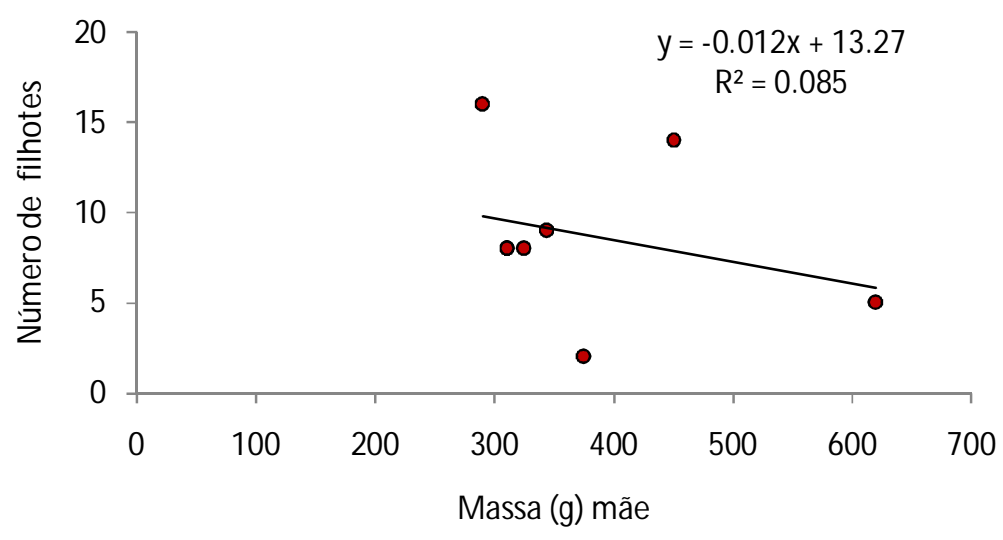

Figura 38: Bothropoides jararaca. Regressão do número de filhotes sobre a massa das mães.

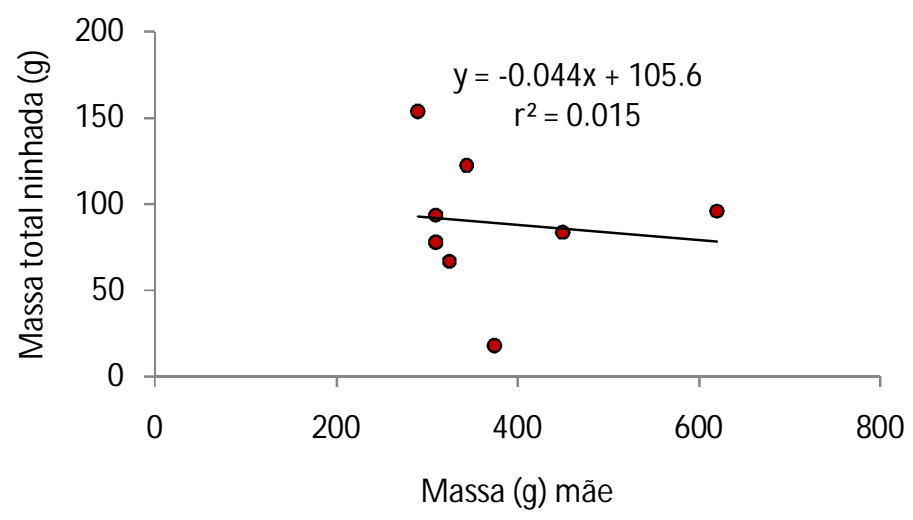

Figura 39: Bothropoides jararaca. Regressão da massa total das ninhadas sobre a massa das mães. 


\section{Filhotes}

Morfometrias e massa corporal:

Não foram observadas diferenças significativas no comprimento do corpo de machos e fêmeas $\left(\mathrm{t}_{0,05(2), 59}=0,0138 ; \mathrm{p}>0,05\right)$. $\mathrm{O}$ comprimento relativo da cauda de machos e fêmeas não apresentou diferenças significativas ( $\mathrm{t}_{0,05}(2), 59=0,0492$; $\mathrm{p}>0,05)$. O comprimento relativo da cabeça de machos e fêmeas não apresentou diferenças significativas $(\mathrm{t}=0,05(2), 59=0,1810 ; \mathrm{p}>0,05)$. Machos e fêmeas filhotes não apresentaram diferenças significativas em relação à robustez $\left(\mathrm{t}_{0,05}(2), 59=0,7800\right.$; $\mathrm{p}>0,05)$ (Tabela 12).

Tabela 12: Bothropoides jararaca. Amplitude, número de observações $(\mathrm{N})$ e média \pm erro padrão dos exemplares filhotes.

\begin{tabular}{lccccc}
\hline & Sexo & A & N & $\begin{array}{c}\text { Média } \pm \text { erro } \\
\text { padrão }\end{array}$ & t \\
\hline CRC $(\mathrm{mm})$ & Machos & $190-260$ & 27 & $225,4 \pm 19,9$ & P > 0,05 ns. \\
CRC $(\mathrm{mm})$ & Fêmeas & $175-260$ & 34 & $225,3 \pm 24,1$ & \\
& & & & & \\
$\mathrm{CC}(\mathrm{mm})$ & Machos & $30-45$ & 27 & $38 \pm 3,8$ & $\mathrm{P}>0,05 \mathrm{~ns}$. \\
$\mathrm{CC}(\mathrm{mm})$ & Fêmeas & $30-50$ & 34 & $37,9 \pm 4,6$ & \\
& & & & & \\
$\mathrm{CCAB}(\mathrm{mm})$ & Machos & $14-18,6$ & 27 & $15,3 \pm 1,2$ & $\mathrm{P}>0,05 \mathrm{~ns}$. \\
$\mathrm{CCAB}(\mathrm{mm})$ & Fêmeas & $13-18,2$ & 34 & $15,3 \pm 1,1$ & \\
& & & & & $\mathrm{P}>0,05 \mathrm{~ns}$. \\
Massa $(\mathrm{g})$ & Machos & $4,8-15,4$ & 27 & $9,6 \pm 3$ & \\
Massa $(\mathrm{g})$ & Fêmeas & $4,1-16$ & 34 & $9,2 \pm 2,7$ & \\
\hline
\end{tabular}




\section{Comportamento reprodutivo em cativeiro:}

Foram observadas duas cópulas de B. jararaca em cativeiro. Nas cópulas observadas (22/08/2008 e 24/07/2008), os comportamentos de corte tiveram duração de 64 e 87 minutos, respectivamente. As cópulas duraram no mínimo 7h 50 min. (também não foi possível registrar a duração exata das cópulas). Após 248 dias (contados da data da cópula até o nascimento) uma fêmea pariu uma ninhada com 5 filhotes vivos.

Nos dois dias subseqüentes à cópula, foram realizadas outras tentativas de acasalamento. Os machos não cortejaram outras fêmeas (2 tentativas) e as fêmea não copularam com outros machos (2 tentativas), apesar de serem cortejadas por mais de 30 minutos em ambas as tentativas. Também não foi observado comportamento agonístico entre os machos.

\subsubsection{Crotalus durissus}

\section{Proporções corporais}

Foram encontrados 14 exemplares de C. durissus (8 machos, 6 fêmeas), única espécie onde o número de captura de machos superou o de fêmeas.

As análises de regressão do comprimento da cauda sobre o comprimento rostrocloacal foram significativas para ambos os sexos (fêmeas: $F_{0,05(2), 4}=28,9097, p<0,05$; machos: $\mathrm{F}_{0,05(2), 6}=80,0900, \mathrm{p}<0,05$ ) (Figura 40). A análise da diferença entre as retas da regressão não foi significativa $\left(\mathrm{t}_{0,05(2), 10}=0,3054, \mathrm{p}>0,05\right)$, indicando que machos e fêmeas apresentam as mesmas relações entre corpo e cauda.

As regressões da massa sobre o comprimento total também foram significativas para machos e fêmeas (fêmeas: $\mathrm{F}_{0,05(2), 4}=229,3798, \mathrm{p}<0,05$; machos: $\mathrm{F}_{0,05}(2), 6=$ 19,4885, p < 0,05) (Figura 41). A diferença entre as retas não foi significativa, indicando que machos e fêmeas apresentam as mesmas relações entre as variáveis massa e comprimento total $\left(\mathrm{t}_{0,05(2), 10}=1,3459, \mathrm{p}>0,05\right)$ 
As regressões do comprimento da cabeça sobre o comprimento do tronco foram significativas para machos e fêmeas (fêmeas: $\mathrm{F}_{0,05(2), 4}=201,0781, \mathrm{p}<0,05$; machos: $\left.\mathrm{F}_{0,05(2), 6}=27,9779, \mathrm{p}<0,05\right)$. A análise da diferença entre as retas da regressão não foi significativa $\left(\mathrm{t}_{0,05(2), 10}=0,1834, \mathrm{p}>0,05\right)$, indicando que machos e fêmeas apresentam as mesmas relações entre comprimento da cabeça e comprimento do tronco (Figura 42).

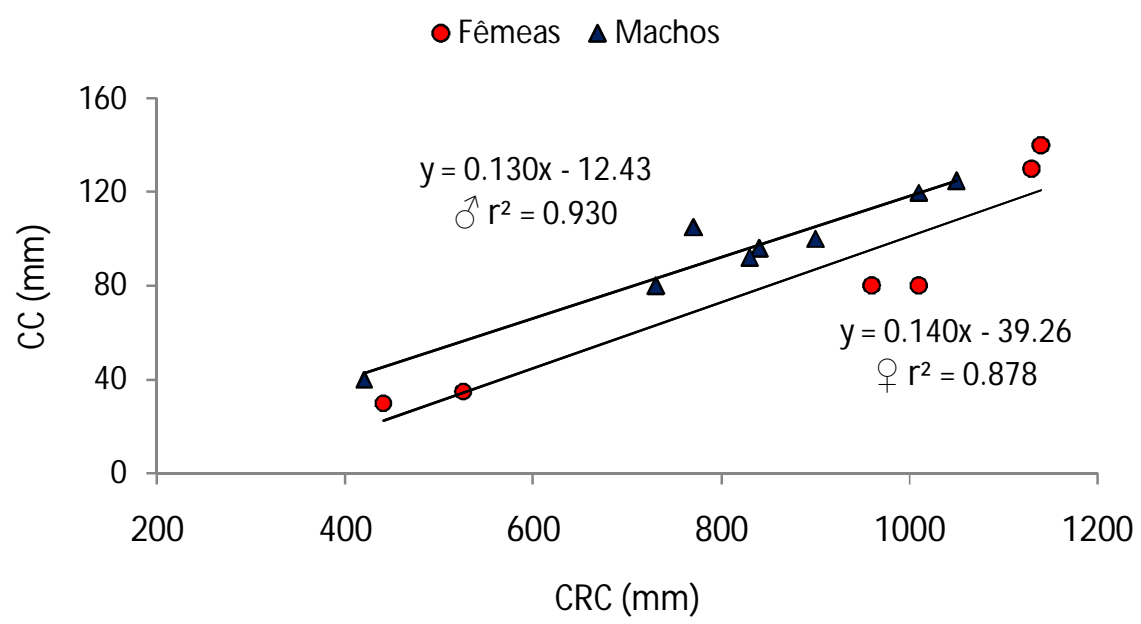

Figura 40: Crotalus durissus. Regressão do comprimento da cauda (CC) sobre o comprimento do corpo (CRC).

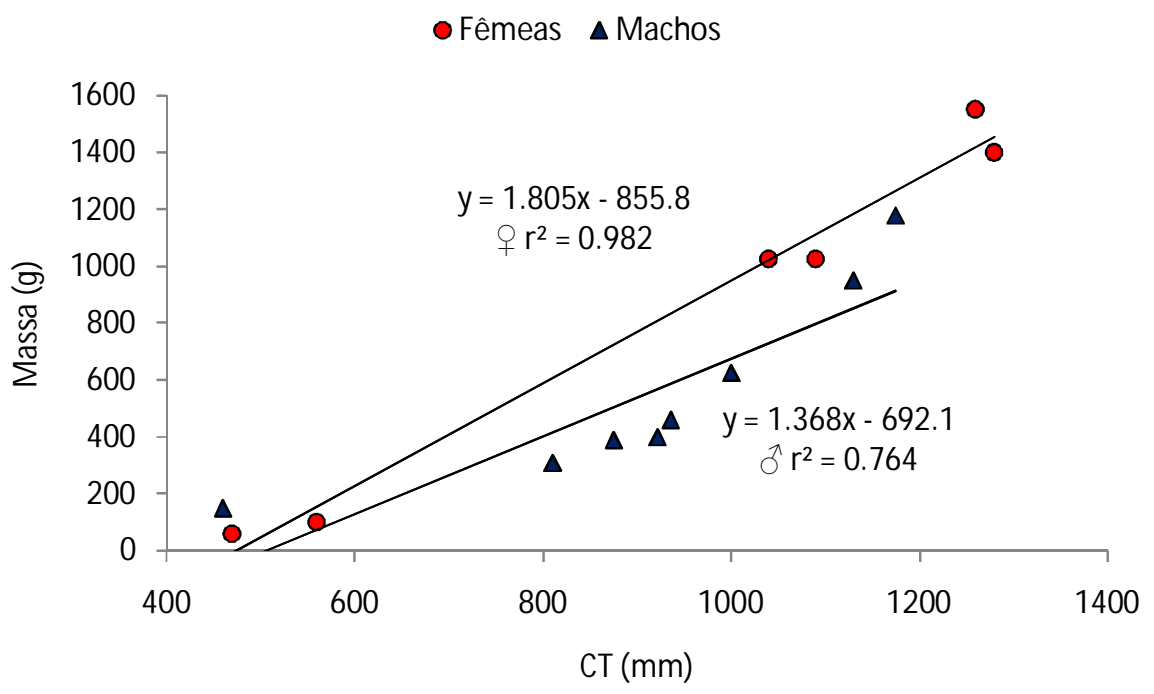

Figura 41: Crotalus durissus. Regressão da massa sobre o comprimento total (CT). 


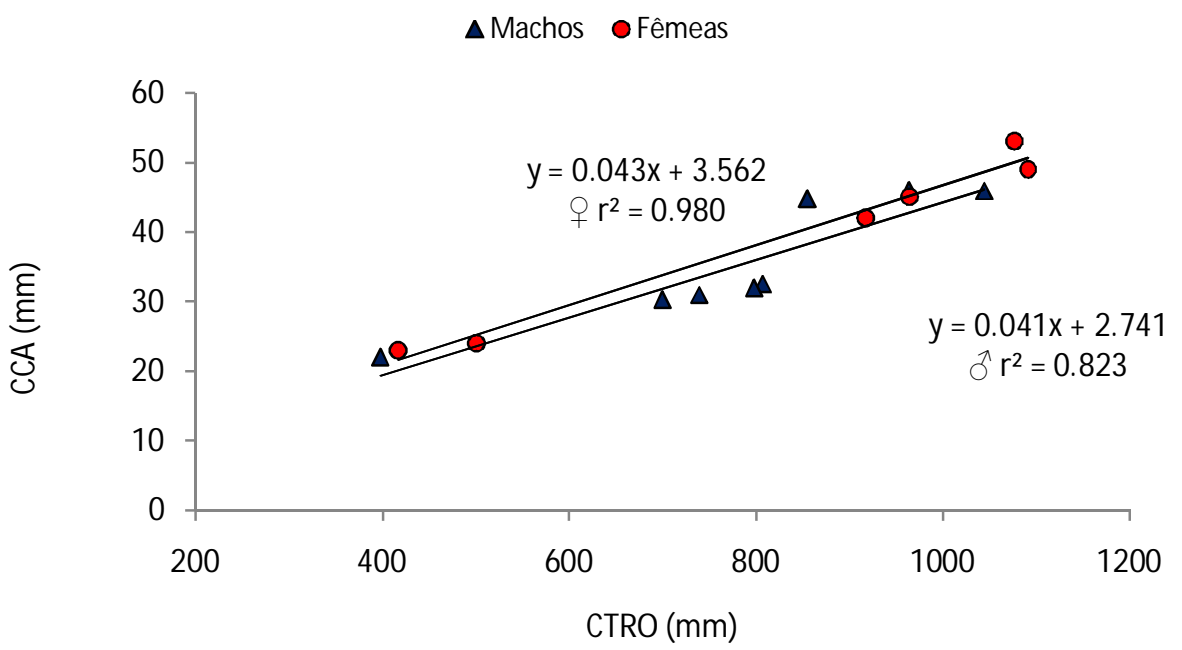

Figura 42: Crotalus durissus. Regressão do comprimento da cabeça (CCA) sobre o comprimento do tronco (CTRO).

\section{Morfometrias}

O comprimento do corpo das fêmeas adultas de $C$. durissus foi significativamente maior do que os machos adultos $\left(\mathrm{t}_{0,05(2), 9}=2,677\right.$; $\left.\mathrm{p}<0,05\right)$. Machos e fêmeas adultos não apresentaram diferenças significativas no comprimento relativo da cauda $\left(\mathrm{t}_{0,05(2), 9}=2,116 ; \mathrm{p}>0,05\right)$. O comprimento relativo da cabeça não apresentou diferenças significativas entre machos e fêmeas $\left(\mathrm{t}_{0,05(2), 9}=1,155 ; \mathrm{p}>0,05\right)$. Fêmeas adultas são significativamente mais robustas do que os machos adultos $\left(\mathrm{t}_{0,05(2), 9}=3\right.$, 586; $\mathrm{p}<0,05)$ (Tabela 13).

O índice de dimorfismo sexual no tamanho corporal (SSD) foi de 0,21 , fêmeas maiores do que machos. 
Tabela 13: Crotalus durissus. Amplitude, número de observações $(\mathrm{N})$ e média \pm erro padrão dos exemplares adultos coletados durante o período de estudo.

\begin{tabular}{lccccc}
\hline & Sexo & A & N & $\begin{array}{c}\text { Média } \pm \text { erro } \\
\text { padrão }\end{array}$ & t \\
\hline CRC $(\mathrm{mm})$ & Machos & $730-1050$ & 7 & $875,7 \pm 119$ & $\mathrm{t}_{0,05(2), 9}=2,677^{*}$ \\
$\mathrm{CRC}(\mathrm{mm})$ & Fêmeas & $960-1140$ & 4 & $1060 \pm 89$ & \\
& & & & & \\
$\mathrm{CC}(\mathrm{mm})$ & Machos & $80-130$ & 7 & $104,42 \pm 16,9$ & $\mathrm{t}_{0,05(2), 9}=2,116 \mathrm{~ns}$. \\
$\mathrm{CC}(\mathrm{mm})$ & Fêmeas & $80-140$ & 4 & $107,5 \pm 32$ & \\
& & & & & \\
$\mathrm{CCAB}(\mathrm{mm})$ & Machos & $30,3-46$ & 7 & $37,5 \pm 7,6$ & $\mathrm{t}_{0,05(2), 9}=1,155 \mathrm{~ns}$. \\
$\mathrm{CCAB}(\mathrm{mm})$ & Fêmeas & $42-53$ & 4 & $47,3 \pm 4,8$ & \\
& & & & & \\
Massa $(\mathrm{g})$ & Machos & $310-1180$ & 7 & $616,4 \pm 328$ & $\mathrm{t}_{0,05(2), 9}=3,586^{*}$ \\
Massa $(\mathrm{g})$ & Fêmeas & $1025-1550$ & 4 & $1250 \pm 266$ & \\
\hline
\end{tabular}

\section{Atividade sazonal}

As fêmeas de $C$. durissus foram capturadas durante todo o ano, e machos não foram capturados apenas no inverno (Tabela 14). Apenas um macho jovem foi coletado, no verão. Fêmeas adultas não foram coletadas na primavera, e fêmeas jovens foram encontradas apenas na primavera.

Tabela 14: Crotalus durissus. Sazonalidade na captura de machos e fêmeas.

\begin{tabular}{lcc}
\hline & Fêmeas - N (\%) & Machos - N (\%) \\
\hline Primavera & $2(33,3 \%)$ & $1(12,5 \%)$ \\
Verão & $1(16,7 \%)$ & $4(50 \%)$ \\
Outono & $2(33,3 \%)$ & $3(37,5 \%)$ \\
Inverno & $1(16,7 \%)$ & 0 \\
\hline Total & $\mathbf{6 ( 1 0 0 \% )}$ & $\mathbf{8 ( 1 0 0 \% )}$ \\
\hline
\end{tabular}




\section{Uso do ambiente}

Todos os exemplares de C. durissus foram capturados nas áreas abertas, mais precisamente nos campos de altitude. Com relação à distribuição altitudinal, nenhum exemplar foi encontrado acima de $1400 \mathrm{~m}$.

A espécie C. durissus parece utilizar bastante os abrigos naturais oferecidos pelo ambiente, pois dos 14 exemplares capturados, cinco $(35,7 \%)$ foram encontrados dentro de cupinzeiros: 1 macho adulto (verão; CRC $840 \mathrm{~mm}$ ); 1 macho imaturo (verão; CRC 420mm); 2 fêmeas sexualmente imaturas encontradas juntas dentro de outro cupinzeiro

(primavera; CRC 525 e $440 \mathrm{~mm}$ ); e uma fêmea adulta prenhe capturada em janeiro (verão; CRC 1010 mm) e que pariu sua ninhada em cativeiro menos de um mês após a coleta.

\section{Atividade no momento do encontro}

Devido à maioria dos exemplares da espécie ter sido encontrado por trabalhadores rurais, foram poucas as informações obtidas relativas ao momento do encontro.

Dos 14 exemplares de $C$. durissus, 13 foram encontrados durante a preparação de áreas de campos de altitude para a plantação de Pinus, tanto no período da manhã quanto no da tarde. Apenas um macho foi capturado pela equipe de coletores em um final de tarde, enrodilhado dentro de um buraco sob uma árvore, na beira de uma estrada secundária que corta uma grande área de campo de altitude. O único comportamento de defesa registrado para $C$. durissus foi desferir botes. A imagem da serpente no momento do encontro é mostrada no anexo A. 


\section{Dieta}

Freqüência de serpentes alimentadas, variação sexual e sazonal:

Dos 14 exemplares capturados, $8(57,1 \%)$ apresentavam alimento no sistema gastrointestinal. Das 6 fêmeas $5(83,3 \%)$ estavam alimentadas: uma apresentava uma presa no estômago além de vestígios de presa no intestino, e as demais apresentavam vestígios de presas apenas no intestino. Dos 8 machos capturados 3 (37,5\%) haviam ingerido alimento, e todos possuíam vestígios de presas apenas no intestino.

Foram encontradas serpentes alimentadas em todas as estações climáticas, exceto machos que não foram coletados no inverno (Tabela 15).

Tabela 15: Crotalus durissus. Serpentes alimentadas nas diferentes épocas do ano.

\begin{tabular}{lcccc}
\hline & \multicolumn{2}{c}{ Fêmeas } & \multicolumn{2}{c}{ Machos } \\
& com alimento & sem alimento & com alimento & sem alimento \\
\hline Primavera & $1(16,7 \%)$ & $1(16,7 \%)$ & $1(12,5 \%)$ & \\
Verão & $1(16,7 \%)$ & & $1(12,5 \%)$ & $3(37,5 \%)$ \\
Outono & $2(33,2 \%)$ & $1(12,5 \%)$ & $2(25 \%)$ \\
Inverno & $1(16,7 \%)$ & & \\
\hline Total (N/\%) & $5(83,3 \%)$ & $1(16,7 \%)$ & $3(37,5 \%)$ & $5(62,5 \%)$ \\
\hline Total (\%) & \multicolumn{6}{c}{$\mathbf{6 ( 1 0 0 \% )}$} & $\mathbf{8 ( 1 0 0 \% )}$ \\
\hline
\end{tabular}

Tipos de presas ingeridas e presas múltiplas:

Tanto jovens como adultos foram encontrados com vestígios de ingestão de presas (Tabela 16). Todas as serpentes alimentadas haviam ingerido mamíferos. Em um macho foi encontrado vestígios da ingestão simultânea de 2 presas. Em uma fêmea com CRC $960 \mathrm{~mm}$ foi constatada a ingestão simultânea de 4 presas, sendo 1 marsupial e 3 pequenos roedores. 
Tabela 16: Crotalus durissus. Número (\%) e tipo de presas ingeridas por jovens e adultos.

\begin{tabular}{|c|c|c|c|c|}
\hline C. durissus & Alimentados (N) & Lagartos & Aves & Mamíferos \\
\hline$\widehat{\partial}$ jovens $(\mathrm{N}=1)$ & 1 & 0 & 0 & $1(66,7 \%)$ \\
\hline$\delta$ adultos $(\mathrm{N}=7)$ & 2 & 0 & 0 & $2(33,3 \%)$ \\
\hline & 3 & & & $100 \%$ \\
\hline q jovens $(\mathrm{N}=2)$ & 1 & 0 & 0 & $1(20 \%)$ \\
\hline o adultos $(\mathrm{N}=4)$ & 4 & 0 & 0 & $4(80 \%)$ \\
\hline
\end{tabular}

\section{Reprodução}

Ciclo reprodutivo dos machos:

Dos oito machos capturados, sete apresentaram características de sexualmente maduro, com testículos túrgidos e ductos deferentes enovelados e de coloração opaca. $\mathrm{O}$ menor macho com essas características tinha comprimento do corpo de $730 \mathrm{~mm}$.

Ciclo reprodutivo das fêmeas:

Das seis fêmeas amostradas, quatro foram consideradas sexualmente maduras. Três apresentavam folículos em vitelogênese secundária no final no outono e no inverno. A outra foi mantida viva e pariu os filhotes no mês de janeiro. A menor fêmea reprodutiva tinha comprimento do corpo de $960 \mathrm{~mm}$. A fêmea coletada prenhe apresentava vestígios de presa no intestino. 
Ninhadas:

Foi obtida uma ninhada, nascida em fevereiro, com 11 filhotes ( 7 filhotes vivos e 4 mortos) (Tabela 17). A mãe tinha CRC 1010 mm, e massa de 670g após o parto. Foi coletada dentro de um cupinzeiro no mês de janeiro (menos de um mês antes de parir).

Tabela 17: Crotalus durissus. Informações da ninhada e sua mãe.

\begin{tabular}{lccccccc}
\hline NASC & CRA क & N.FIL. & F. VIVOS & F. MORT. & M. T. N. (g) & MRN & M. P. + (g) \\
\hline Fev. & 1010 & $11(6 \mathrm{~F}-5 \mathrm{M})$ & 7 & 4 & 198,9 & 0,296 & 355 \\
\hline
\end{tabular}

N.FIL. $=$ número de filhotes; F. VIVOS= número de filhotes vivos; F. MORT.$=$ número de filhotes mortos; M.T.N.= massa total da ninhada (filhotes + ovos atrésicos); MRN= massa relativa da ninhada; M.P..$=$ massa perdida pela fêmea após parir.

\section{Filhotes}

Morfometrias e massa corporal:

Filhotes machos apresentaram comprimento do corpo significativamente maior do que fêmeas $\left(\mathrm{t}_{0,05(2), 9}=2,451 ; \mathrm{p}<0,05\right)$. Machos e fêmeas filhotes não apresentaram diferenças significativas no comprimento relativo da cauda $\left(t_{0,05}(2), 9=2,116\right.$; $\mathrm{p}>0$, 05). O comprimento relativo da cabeça de machos e fêmeas não apresentou diferenças significativas $(\mathrm{t}=0,05(2), 9=2,000 ; \mathrm{p}>0,05)$. Machos e fêmeas filhotes não apresentaram diferenças significativas em relação à robustez $\left(\mathrm{t}_{0,05}(2), 9=1,523\right.$; $\mathrm{p}>0,05)$ (Tabela 18). 
Tabela 18: Crotalus durissus. Amplitude, número de observações $(\mathrm{N})$ e média \pm erro padrão dos exemplares filhotes.

\begin{tabular}{lccccc}
\hline & Sexo & A & N & $\begin{array}{c}\text { Média } \pm \text { erro } \\
\text { padrão }\end{array}$ & t \\
\hline CRC $(\mathrm{mm})$ & Machos & $290-310$ & 5 & $302 \pm 8,4$ & $\mathrm{P}<0,05^{*}$ \\
$\mathrm{CRC}(\mathrm{mm})$ & Fêmeas & $245-310$ & 6 & $275 \pm 23,2$ & \\
& & & & & \\
$\mathrm{CC}(\mathrm{mm})$ & Machos & $29-31$ & 5 & $30,2 \pm 0,8$ & $\mathrm{P}>0,05 \mathrm{~ns}$. \\
$\mathrm{CC}(\mathrm{mm})$ & Fêmeas & $20-25$ & 6 & $22 \pm 2,1$ & \\
& & & & & \\
$\mathrm{CCAB}(\mathrm{mm})$ & Machos & $16-18,2$ & 5 & $17,3 \pm 0,8$ & $\mathrm{P}>0,05 \mathrm{~ns}$. \\
$\mathrm{CCAB}(\mathrm{mm})$ & Fêmeas & $14-18,9$ & 6 & $16,8 \pm 1,7$ & \\
& & & & & $\mathrm{P}>0,05 \mathrm{~ns}$. \\
Massa $(\mathrm{g})$ & Machos & $14,1-25$ & 5 & $20,6 \pm 4,3$ & \\
Massa $(\mathrm{g})$ & Fêmeas & $12,7-20$ & 6 & $15,9 \pm 3$ & \\
\hline
\end{tabular}

\subsubsection{Bothropides neuwiedi e Bothropoides jararaca - análises comparativas}

\section{Morfometrias - Adultos}

O comprimento do corpo dos machos adultos de $B$. jararaca foi significativamente maior do que os machos adultos $B$. neuwiedi $\left(\mathrm{t}_{0,05(2), 38}=6,231\right.$; $\mathrm{p}<0,05)$. O comprimento relativo da cauda de machos adultos de B. neuwiedi e de B. jararaca não apresentou diferenças significativas ( $\left.\mathrm{t}_{0,05}(2), 38=0,7183 ; \mathrm{p}>0,05\right)$. Machos adultos das duas espécies não apresentaram diferenças significativas em relação à robustez $\left(\mathrm{t}_{0,05}(2), 78=1,549 ; \mathrm{p}>0,05\right)$ (Tabela 19). 
Tabela 19: Bothropoides neuwiedi (Bn) e Bothropoides jararaca (Bj). Amplitude, número de observações $(\mathrm{N})$ e média \pm erro padrão dos machos adultos coletados durante o período de estudo.

\begin{tabular}{|c|c|c|c|c|c|}
\hline & Sexo & $\mathbf{A}$ & $\mathbf{N}$ & $\begin{array}{c}\text { Média } \pm \text { erro } \\
\text { padrão }\end{array}$ & $\mathbf{t}$ \\
\hline CRC (mm) & Machos Bn & $410-720$ & 32 & $568,3 \pm 87,2$ & $\mathrm{t}_{0,05(2), 38}=6,231 ; \mathrm{p}<0,05 * * *$ \\
\hline $\mathrm{CRC}(\mathrm{mm})$ & Machos Bj & $690-830$ & 8 & $770 \pm 52,4$ & \\
\hline $\mathrm{CC}(\mathrm{mm})$ & Machos Bn & $60-110$ & 32 & $87 \pm 11,5$ & $\mathrm{t}_{0,05(2), 38}=0,7183 ; \mathrm{p}>0,05 \mathrm{~ns}$ \\
\hline $\mathrm{CC}(\mathrm{mm})$ & Machos $\mathrm{Bj}$ & $100-140$ & 8 & $121,8 \pm 14,8$ & \\
\hline Massa (g) & Machos Bn & $30-156$ & 32 & $103,5 \pm 34,9$ & $\mathrm{t}_{0,05(2), 38}=1,549 ; \mathrm{p}>0,05 \mathrm{~ns}$ \\
\hline Massa (g) & Machos Bj & $133-195$ & 8 & $160,4 \pm 28$ & \\
\hline
\end{tabular}

O comprimento do corpo das fêmeas adultas de $B$. jararaca foi significativamente maior do que as fêmeas adultas de $B$. neuwiedi (t $0,05(2), 38=12,126 ; \mathrm{p}<0,05$ ). O comprimento relativo da cauda das fêmeas adultas de $B$. jararaca foi significativamente maior do que as fêmeas adultas de B. neuwiedi $\left(\mathrm{t}_{0,05(2), 38}=4,063 ; \mathrm{p}<0,05\right)$. Fêmeas adultas de $B$. jararaca foram significativamente mais robustas do que as fêmeas adultas de B. neuwiedi $\left(\mathrm{t}_{0,05(2), 78}=5,353 ; \mathrm{p}>0,05\right)$ (Tabela 20).

Tabela 20: Bothropoides neuwiedi (Bn) e Bothropoides jararaca (Bj). Amplitude, número de observações $(\mathrm{N})$ e média \pm erro padrão das fêmeas adultas coletadas durante o período de estudo.

\begin{tabular}{lccccc}
\hline & Sexo & A & N & $\begin{array}{c}\text { Média } \pm \text { erro } \\
\text { padrão }\end{array}$ & t \\
\hline CRC $(\mathrm{mm})$ & Fêmeas Bn & $600-920$ & 48 & $728,1 \pm 74,58$ & $\mathrm{t}_{0,05(2), 62}=12,126 ; \mathrm{p}<0,05^{* * *}$ \\
$\mathrm{CRC}(\mathrm{mm})$ & FêmeasBj & $820-1180$ & 16 & $1000,3 \pm 86,9$ & \\
& & & & & \\
$\mathrm{CC}(\mathrm{mm})$ & FêmeasBn & $70-114$ & 48 & $88 \pm 9,8$ & $\mathrm{t}_{0,05(2), 62}=4,063 ; \mathrm{p}<0,05^{* * *}$ \\
$\mathrm{CC}(\mathrm{mm})$ & FêmeasBj & $115-165$ & 16 & $134,1 \pm 12,3$ & \\
& & & & & \\
Massa $(\mathrm{g})$ & Fêmeas Bn & $65-465$ & 48 & $244,7 \pm 77,5$ & $\mathrm{t}_{0,05(2), 62}=5,353 ; \mathrm{p}>0,05^{* * *}$ \\
Massa $(\mathrm{g})$ & Fêmeas Bj & $209-810$ & 16 & $504,6 \pm 169,4$ & \\
\hline
\end{tabular}




\section{Morfometrias - Filhotes}

Não foram observadas diferenças significativas no comprimento do corpo dos machos filhotes de $B$. jararaca e de $B$. neuwiedi $\left(\mathrm{t}_{0,05(2), 38}=0,037 ; \mathrm{p}>0,05\right)$. Machos filhotes de $B$. jararaca apresentaram comprimento relativo da cauda significativamente maior do que machos filhotes de $B$. neuwiedi ( $\mathrm{t}_{0,05(2), 38}=4,064 ; \mathrm{p}<0,05$ ). Machos filhotes das duas espécies não apresentaram diferenças significativas na robustez $\left(t_{0,05}\right.$ (2), $78=1,549 ; \mathrm{p}>0,05) \quad($ Tabela 21$)$.

Tabela 21: Bothropoides neuwiedi (Bn) e Bothropoides jararaca (Bj). Amplitude, número de observações $(\mathrm{N})$ e média \pm erro padrão dos filhotes machos.

\begin{tabular}{lccccc}
\hline & Sexo & A & N & $\begin{array}{c}\text { Média } \pm \text { erro } \\
\text { padrão }\end{array}$ & t \\
\hline CRC $(\mathrm{mm})$ & Machos Bn & $175-295$ & 41 & $225,1 \pm 31$ & $\mathrm{t}_{0,05(2), 66}=0,037 ; \mathrm{p}>0,05 \mathrm{~ns}$. \\
$\mathrm{CRC}(\mathrm{mm})$ & Machos Bj & $190-260$ & 27 & $225,4 \pm 19,9$ & \\
& & & & & \\
$\mathrm{CC}(\mathrm{mm})$ & Machos Bn & $25-45$ & 41 & $34,4 \pm 5,5$ & $\mathrm{t}_{0,05(2), 66}=4,064 ; \mathrm{p}<0,05 * * *$ \\
$\mathrm{CC}(\mathrm{mm})$ & Machos Bj & $30-45$ & 27 & $38,1 \pm 3,8$ & \\
& & & & & \\
Massa $(\mathrm{g})$ & Machos Bn & $5-16,7$ & 41 & $10,4 \pm 2,5$ & $\mathrm{t}_{0,05(2), 66}=1,764 ; \mathrm{p}>0,05 \mathrm{~ns}$. \\
Massa (g) & Machos Bj & $4,8-15,4$ & 27 & $9,6 \pm 3,1$ & \\
\hline
\end{tabular}

Não foram observadas diferenças significativas no comprimento do corpo dos

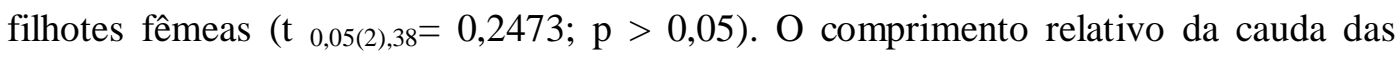
fêmeas de $B$. jararaca foi significativamente maior do que as fêmeas de $B$. neuwiedi $\left(\mathrm{t}_{0,05(2), 38}=7,060 ; \mathrm{p}<0,05\right)$. Fêmeas filhotes de $B$. neuwiedi foram significativamente mais robustas do que as fêmeas filhotes de B. jararaca $\left(\mathrm{t}_{0,05}(2), 78=4,667 ; \mathrm{p}<0,05\right)$ (Tabela 22). 
Tabela 22: Bothropoides neuwiedi (Bn) e Bothropoides jararaca (Bj). Amplitude, número de observações $(\mathrm{N})$ e média \pm erro padrão dos filhotes fêmeas.

\begin{tabular}{lccccc}
\hline & Sexo & A & N & $\begin{array}{c}\text { Média } \pm \text { erro } \\
\text { padrão }\end{array}$ & t \\
\hline CRC (mm) & Fêmeas Bn & $190-290$ & 46 & $226,6 \pm 23,8$ & $\mathrm{t}_{0,05(2), 78}=0,2473 ; \mathrm{p}>0,05 \mathrm{~ns}$. \\
$\mathrm{CRC}(\mathrm{mm})$ & Fêmeas Bj & $175-260$ & 34 & $225,3 \pm 24,2$ & \\
& & & & & \\
$\mathrm{CC}(\mathrm{mm})$ & Fêmeas Bn & $17-45$ & 46 & $31,6 \pm 5,4$ & $\mathrm{t}_{0,05(2), 78}=7,060 ; \mathrm{p}<0,05^{* * *}$ \\
$\mathrm{CC}(\mathrm{mm})$ & Fêmeas Bj & $30-50$ & 34 & $37,9 \pm 4,6$ & \\
& & & & & \\
Massa (g) & Fêmeas Bn & $6,1-17,7$ & 46 & $10,6 \pm 2$ & $\mathrm{t}_{0,05(2), 78}=4,667 ; \mathrm{p}<0,05^{* * *}$ \\
Massa $(\mathrm{g})$ & Fêmeas Bj & $4-16$ & 34 & $9,2 \pm 2,7$ & \\
\hline
\end{tabular}

\section{Reprodução - Ninhadas}

Os filhotes de B. neuwiedi nasceram ao longo dos meses de verão. Apenas uma ninhada nasceu prematuramente, no inicio da primavera (outubro), porém com filhotes normais e ausência de natimortos e ovos atrésicos. Outra ninhada nasceu no início do outono (abril). Na espécie B. jararaca, todas as ninhadas nasceram no final do verão (março).

O número de filhotes por ninhada variou significativamente entre as duas espécies, $B$. jararaca produziu ninhadas maiores $\left(\mathrm{t}_{0,05(2) 20}=2,610 ; \mathrm{p}<0,05\right)$. A massa total da ninhada também foi significativamente maior em B. jararaca $\left(\mathrm{t}_{0,05(2)} 19=2,334\right.$; $\mathrm{p}<0,05)$, assim como a perda de peso da fêmeas após os nascimentos, que foi mais significativa em $B$. jararaca $\left(\mathrm{t}_{0,05(2)} 18=2,130 ; \mathrm{p}<0,05\right)$. Mas a MRN não apresentou diferença significativa entre as espécies $\left(\mathrm{t}_{0,05}(2)\right.$ 19 $\left.=0,6387 ; \mathrm{p}>0,05\right)$. 


\subsection{DISCUSSÃO}

\section{Morfometrias - Serpentes Adultas}

Tanto em B. neuwiedi quanto em B. jararaca as análises de regressão mostraram dimorfismo sexual nas relações entre corpo e cauda, ou seja, acréscimos de comprimento no corpo não são acompanhados por acréscimos no comprimento da cauda da mesma maneira nos dois sexos. Isso pode ser explicado pelo maior crescimento da cauda dos machos durante a ontogenia. Também foi observado dimorfismo sexual nas relações entre massa corporal e comprimento total, machos e fêmeas não mostraram as mesmas relações entre essas variáveis. Em algumas espécies de viperídeos, durante o desenvolvimento as fêmeas passam a ganhar mais peso do que os machos (FURTADO; TRAVAGLIA-CARDOSO; ROCHA, 2006; TRAVAGLIACARDOSO; ZELANIS; FURTADO, 2010) devido ao custo reprodutivo, que é maior nas fêmeas (SHINE et al., 1998). Não foi significante o dimorfismo sexual nas relações entre comprimento da cabeça e comprimento do tronco para B. neuwiedi, machos e fêmeas apresentam as mesmas relações entre essas variáveis.

Em C. durissus não foi significante o dimorfismo sexual entre as retas das regressões, machos e fêmeas possuem as mesmas relações entre todas as variáveis analisadas.

\section{Comprimento do corpo}

Tanto em $B$. neuwiedi quanto em $B$. jararaca as fêmeas adultas mostraram comprimento do corpo maior do que os machos.

Em C. durissus foi observado o mesmo dimorfismo sexual, porém o número de serpentes analisadas foi pequeno, o que pode não refletir os padrões locais para a espécie. Machos com comprimento do corpo maior do que fêmeas foi relatado para a espécie no sudeste do Brasil, porém as diferenças não foram significativas (ALMEIDASANTOS, 2005), e ausência de dimorfismo sexual nesses caracteres já foi relatada (SANT'ANNA e ABE, 2007). 
Entre as serpentes, o dimorfismo sexual nas proporções corporais é comum (VANZOLINI, 1991; SHINE, 1993), e as diferenças no tamanho do corpo podem estar relacionadas às diferenças no custo reprodutivo entre os sexos (MADSEN e SHINE, 1993). A seleção natural tende a favorecer fêmeas maiores, pois um corpo maior e mais volumoso pode ser vantajoso em relação à fecundidade, permitindo que as fêmeas produzam e mantenham mais ovos ou embriões em seus ovidutos (FITCH, 1970; SHINE, 1994; SHINE et al, 1998). Na maioria dos viperídeos brasileiros, as fêmeas possuem o corpo maior e mais pesado do que os machos (VANZOLINI, 1991; VALDUJO; NOGUEIRA; MARTINS, 2002; NOGUEIRA; SAWAYA; MARTINS; HARMANN; MARQUES; ALMEIDA-SANTOS, 2004; ALMEIDA-SANTOS, 2005; FURTADO; TRAVAGLIA-CARDOSO; ROCHA, 2006; MONTEIRO et al, 2006; MORAES, 2008).

Porém, esse dimorfismo poderia beneficiar os machos de outras maneiras. Um corpo menor pode facilitar os deslocamentos durante o período reprodutivo, quando estão à procura de fêmeas para acasalamento, além de diminuir os riscos relacionados à predação, devido à maior agilidade na fuga (PEARSON; SHINE; WILLIAMS, 2002, ANDERSSON, 1994). Algumas observações feitas durante este estudo vêm de encontro a essa afirmação, pois além de terem sido coletados em menor número, dois indivíduos machos (identificados visualmente como machos) conseguiram escapar do coletor, todos em áreas de Campos de Altitude, deslocando-se rapidamente em meio à vegetação. Além disso, um corpo menor permite que os machos se alimentem de presas menores (PEARSON; SHINE; WILLIAMS, 2002).

Ainda em relação ao tamanho do corpo, é relatado que o combate entre machos é geralmente ausente nas espécies em que as fêmeas são maiores (SHINE, 1978; SHINE, 1994). Essa afirmação não se confirma para os viperídeos brasileiros, onde, por exemplo, as espécies B. atrox, B. leucurus e B. moojeni apresentam o ritual de combate entre machos, e as fêmeas são maiores e mais pesadas (LELOUP, 1975; TRAVAGLIACARDOSO et al, 1993; SANT'ANNA et al, 2007).

Fêmeas mostraram tamanho corporal maior nas três espécies estudadas. Em B. jararaca, quando o dimorfismo sexual é comparado em relação ao SSD (grau de dimorfismo sexual, proposto por Shine, 1994), foi observada variação entre diferentes populações da espécie. O SSD obtido no presente estudo $(0,29)$ foi menor do que o 
verificado em outras populações de B. jararaca (ALMEIDA-SANTOS, 2005; MORAES, 2008). Variações no SSD podem estar relacionadas à taxa de crescimento diferenciada em um dos sexos devido ao consumo de presas mais calóricas (MADSEN e SHINE, 1993; KRAUSE; BURGHARDT; GILLINGHAM, 2003; MORAES, 2008) ou a diferentes pressões seletivas para diferentes tamanhos corporais entre os sexos (KRAUSE; BURGHARDT; GILLINGHAM, 2003; MORAES, 2008). Na população estudada o tamanho corporal das B. jararaca de ambos os sexos é menor do que o observado em outras populações (ALMEIDA-SANTOS, 2005; MORAES, 2008), portanto as divergências ocorrem tanto em machos como em fêmeas, e possivelmente estão relacionadas aos fatores ambientais de sua área de ocorrência, evidenciando possível variação geográfica no grau de dimorfismo sexual, o que pode indicar variação geográfica no tamanho corporal entre diferentes populações da mesma espécie. Variações geográficas nas proporções corporais já foram relatadas para outras espécies de serpentes (SHINE, 1991; MADSEN e SHINE, 1993; KING et al, 1999).

A literatura não apresenta outros estudos para discutir possíveis variações no SSD de $B$. neuwiedi, e para $C$. durissus a amostra foi pequena para permitir comparações.

\section{Comprimento relativo da cauda}

Nas duas espécies de Bothropoides, os machos apresentaram maior comprimento relativo da cauda do que as fêmeas. Em C. durissus não foram observadas diferenças significativas entre os sexos, talvez devido ao pequeno número de serpentes encontradas.

Dimorfismo sexual no tamanho relativo da cauda também é freqüente entre as serpentes, e machos geralmente apresentam comprimento relativo de cauda maior do que as fêmeas (KING, 1989; SHINE, 1993). Uma cauda maior pode ser mais vantajosa para melhor acomodação do hemipênis e de seus músculos retratores (KING, 1989), e talvez possa auxiliar na disputa pela fêmea em agregações reprodutivas, afastando outros machos ou auxiliando na retenção das fêmeas (KING, 1989; ALMEIDASANTOS et al, 1999). Em serpentes do grupo Bothrops (no presente trabalho fazendo referência aos gêneros Bothrops e Bothropoides), a função da cauda dos machos parece ser mais importante durante a corte e início da cópula, quando estes entrelaçam a cauda 
das fêmeas. Após a penetração do hemipênis, a cauda dos machos parece relaxar e não se observa entrelaçamento de caudas (observações pessoais feitas durante os acasalamentos deste e de outros estudos).

Entre os viperídeos brasileiros, cauda mais longa em machos já foi relatada para várias espécies (VANZOLINI, 1991; VALDUJO; NOGUEIRA; MARTINS, 2002; NOGUEIRA; SAWAYA; MARTINS, 2003, ALMEIDA-SANTOS, 2005; MONTEIRO et al, 2006). Em serpentes arborícolas, caudas mais longas, em ambos os sexos, podem facilitar a locomoção sobre a vegetação e ajudar a manter o equilíbrio (LILLYWHITE e HENDERSON, 1993).

\section{Comprimento relativo da cabeça}

As diferenças sexuais no tamanho da cabeça geralmente estão associadas à divergências na dieta (Shine, 1991), e o tamanho máximo da presa que pode ser ingerida é limitado pela abertura da boca da serpente (GREENE, 1997). Maior tamanho de cabeça favorece a ingestão de presas maiores e potencialmente mais perigosas, além de permitir o consumo de um maior número de itens alimentares (SHINE, 1986; SHINE e CREWS, 1988; FORSMAN, 1994).

As fêmeas adultas de B. jararaca têm o comprimento relativo da cabeça maior do que os machos. Esse dimorfismo pode estar relacionado a divergências na composição da dieta entre machos e fêmeas, pois as fêmeas geralmente predam ítens mais volumosos do que os machos (SAZIMA, 1992; SAZIMA e HADDAD, 1992; MARTINS ; MARQUES; SAZIMA, 2002; MORAES, 2008).

Já em B. neuwiedi não houve significância no dimorfismo sexual no comprimento relativo da cabeça. Porém, quando o comprimento da cabeça foi comparado entre os sexos com os dados absolutos (sem a utilização de índices), as fêmeas possuem a cabeça significativamente maior.

A espécie não apresenta variação ontogenética na dieta, desde filhotes alimentamse principalmente de pequenos roedores (MARTINS; MARQUES; SAZIMA, 2002). E, mesmo quando adultos, ingerem principalmente presas de pequeno porte (observações obtidas durante este estudo). Talvez devido a esses fatores o dimorfismo sexual no 
comprimento da cabeça seja pequeno e não tenha sido encontrado em relação ao comprimento relativo. Em outra espécie, Bothrops pauloensis (uma das espécies do grupo B. neuwiedi), o dimorfismo sexual no comprimento relativo da cabeça também não foi relatado (VALDUJO; NOGUEIRA; MARTINS, 2002).

Em C. durissus também não foram encontradas diferenças sexuais no comprimento relativo da cabeça. A ausência de dimorfismo sexual no comprimento da cabeça já foi relatada para a espécie (SANT'ANNA, 1999), que também não apresenta variação ontogenética na dieta (SALOMÃO; ALMEIDA-SANTOS; PUORTO, 1995; SANT'ANNA e ABE, 2007).

Fêmeas com a cabeça maior do que os machos é um fato comum entre os viperídeos brasileiros (NOGUEIRA; SAWAYA; MARTINS, 2003; MONTEIRO et al, 2006; TRAVAGLIA-CARDOSO; ZELANIS; FURTADO, 2010), fato geralmente relacionado a ingestão de presas maiores.

\section{Robustez}

Nas três espécies estudadas as fêmeas são mais robustas do que os machos. Um corpo mais volumoso pode trazer vantagens relacionadas à fecundidade, aumentando o sucesso reprodutivo, além de permitir o armazenamento de gordura, essencial para o processo de vitelogênese (DERICKSON, 1976; STEARNS, 1992; SHINE, 1993; SHINE, 2003). Além disso, serpentes mais robustas podem ingerir itens alimentares mais volumosos sem prejudicar suas diversas funções fisiológicas e sofrer menor limitação de movimentos (POUGH e GROOVES, 1983). Esse dimorfismo é bastante comum entre as serpentes em geral e também entre os viperídeos (ALMEIDASANTOS,2005; VALDUJO; NOGUEIRA; MARTINS, 2002; NOGUEIRA; SAWAYA; MARTINS, 2003; HARMANN; MARQUES; ALMEIDA-SANTOS, 2004; ALMEIDA-SANTOS, 2005; FURTADO; TRAVAGLIA-CARDOSO; ROCHA, 2006; MONTEIRO et al, 2006).

Sintetizando as observações referentes às morfometrias e a massa corporal, nas duas espécies de Bothropoides as fêmeas adultas são mais pesadas e maiores do que os machos em relação ao comprimento do corpo, e machos apresentam maior comprimento relativo da cauda. Dimorfismo sexual no comprimento relativo da cabeça foi encontrado 
apenas em B. jararaca. Na espécie $C$. durissus as fêmeas mostraram-se maiores e mais pesadas do que os machos, e não foi encontrado dimorfismo sexual no tamanho relativo da cauda e da cabeça. Porém devido ao pequeno tamanho da amostra, talvez este não seja o padrão para a espécie na localidade.

\section{Morfometrias - Filhotes}

Nem sempre o dimorfismo sexual nos caracteres morfométricos e de massa observado entre os adultos está presente nos filhotes (KING et al, 1999). O dimorfismo sexual entre adultos é bem relatado para as serpentes, porém são poucos os estudos que abordam esse dimorfismo em recém nascidos (KING et al, 1999).

Não foi encontrado dimorfismo sexual entre os filhotes de $B$. neuwiedi no comprimento do corpo, comprimento relativo da cabeça e robustez. Dimorfismo sexual foi encontrado apenas no comprimento relativo da cauda, filhotes machos nascem com a cauda maior do que as fêmeas. Esse dimorfismo no comprimento da cauda também foi observado para filhotes do complexo Bothrops neuwiedi (SILVA, 2002), e para filhotes do grupo B. neuwiedi procedentes de várias regiões do Rio Grande do Sul (ARAUJO et al., 1998). Assim, os resultados indicam variação ontogenética para os caracteres comprimento do corpo e robustez, já que entre os adultos esse dimorfismo é encontrado. Comprimento relativo da cauda maior em machos, e ausência de dimorfismo sexual no comprimento relativo da cabeça ocorre em filhotes e permanece nas serpentes adultas.

Entre os filhotes de $B$. jararaca não foi encontrado dimorfismo sexual significativo em nenhum dos caracteres analisados. Porém quando adultos, o dimorfismo sexual ocorre e é bastante acentuado (ALMEIDA-SANTOS, 2005; FURTADO; TRAVAGLIA-CARDOSO; ROCHA, 2006), indicando variação ontogenética para todos os caracteres.

Para filhotes de $C$. durissus foi observado maior comprimento do corpo nos machos, e nos demais caracteres nenhum dimorfismo foi observado. Porém vale lembrar que foi obtida apenas uma ninhada da espécie, e os resultados podem não refletir a realidade. 
As variações ontogenéticas nos caracteres morfométricos são relatadas para várias espécies de serpentes, e algumas espécies podem mostrar variações geográficas nas proporções corporais (SHINE, 1991; MADSEN e SHINE, 1993; KING et al, 1999).

Geralmente, os filhotes de serpentes do grupo Bothrops que ocorrem no Brasil não apresentam dimorfismo sexual no peso e no comprimento corporal (ARAUJO et al., 1998; ALVES; ARAUJO; WITT, 2000; SILVA, 2002; FURTADO; TRAVAGLIACARDOSO; ROCHA, 2006), porém durante a ontogenia o dimorfismo sexual passa a ser observado. Em algumas espécies, após os 12 meses de idade as curvas de crescimento de machos e fêmeas começam a divergir, e após os 18 meses essa divergência é muito acentuada, sendo as fêmeas significativamente maiores e mais pesadas do que os machos (FURTADO; TRAVAGLIA-CARDOSO; ROCHA, 2006; TRAVAGLIA-CARDOSO; ZELANIS; FURTADO, 2010).

\section{Morfometrias - adultos - Bothropoides neuwiedi e Bothropoides jararaca}

Machos e fêmeas adultos de B. jararaca possuem comprimento relativo do corpo maior do que B. neuwiedi, podendo ser considerada uma espécie de maior porte.

O comprimento relativo da cauda não mostrou diferenças significativas entre os machos das duas espécies. Mas as fêmeas de $B$. jararaca possuem cauda mais longa do que as fêmeas de $B$. neuwiedi. Ambas as espécies possuem hábitos predominantemente terrícolas (SAZIMA, 1992, CAMPBELL e LAMAR, 2004), porém B. jararaca pode ser esporadicamente encontrada sobre a vegetação (SAZIMA, 1992; SAZIMA e HADDAD, 1992), enquanto que para $B$. neuwiedi não há relatos de encontros no substrato arbóreo. Talvez essa possa ser uma explicação para maior comprimento da cauda em B. jararaca, lembrando que uma cauda maior auxilia no equilíbrio e locomoção sobre a vegetação (LILLYWHITE e HENDERSON, 1993).

Os machos das duas espécies não mostraram diferenças relacionadas à robustez, porém fêmeas de $B$. jararaca são mais robustas do que fêmeas de $B$. neuwiedi. Isso pode estar relacionado à fecundidade, pois neste estudo as fêmeas de $B$. jararaca mostraram investir mais na reprodução do que as fêmeas de B. neuwiedi (ver resultados em "estratégias reprodutivas" neste trabalho). 


\section{Morfometrias - filhotes - Bothropoides neuwiedi e Bothropoides jararaca}

Os filhotes das duas espécies, de ambos os sexos, nascem com comprimento do corpo de tamanho similar.

Porém, machos e fêmeas de $B$. jararaca nascem com a cauda mais longa do que os filhotes de B. neuwiedi. Talvez esse fato esteja relacionado aos hábitos das espécies, pois B. neuwiedi possui hábitos terrícolas desde filhotes, mas em B. jararaca os juvenis exploram freqüentemente a vegetação (SAZIMA, 1992; HARMANN; HARTMANN; GIASSON, 2003), e um maior comprimento de cauda torna-se vantajoso. Além disso, filhotes de $B$. jararaca (espécie com variação ontogenética na dieta) alimentam-se com freqüência de presas ectotérmicas, e uma cauda mais longa seria vantajosa na realização do comportamento de engodo caudal, utilizado para atrair presas como anfíbios e pequenos lagartos (SAZIMA, 1991; HARMANN e ALMEIDA, 2001). Com a maturidade a ponta da cauda adquire a mesma coloração do resto do corpo, sugerindo variação ontogenética na dieta das serpentes que se utilizam do engodo caudal (SAZIMA, 1991). Em B. atrox, outra espécie que apresenta variação ontogenética na dieta, jovens também são mais observados no substrato arbóreo do que adultos (OLIVEIRA e MARTINS, 2001).

Em relação à robustez, não foi encontrada diferença entre os filhotes machos das duas espécies, porém fêmeas de B. neuwiedi nascem mais robustas do que B. jararaca.

\section{Padrões de Atividade das serpentes}

A sazonalidade na captura pode refletir os padrões de atividade das serpentes, e a atividade pode estar relacionada à reprodução (MARQUES; ETEROVICK; ENDO, 2000; MARQUES; ALMEIDA-SANTOS; RODRIGUES, 2006; PIZZATTO; ALMEIDA-SANTOS; MARQUES, 2007).

Estabelecer os padrões de atividade para cada espécie de serpente seria o ideal, mas são muitas as dificuldades. Seriam necessárias coletas por longos períodos, onde fossem obtidas grandes amostras de cada uma das espécies (MARQUES; ETEROVICK; ENDO, 2000). Diferenças sazonais no esforço de coleta poderiam afetar o número de serpentes coletadas, e inviabilizar as análises de atividade das serpentes ao 
longo do ano (HENDERSON; DIXON; SOINI, 1978). No caso especifico deste estudo a maior parte das serpentes foi coletada por terceiros (ver resultados cap. 1), muitos residentes na Fazenda Santa Elisa. Apesar da rotina de trabalho nas áreas cultivadas exigir mais tempo em determinadas épocas do ano (plantio, colheita), os trabalhos com o gado, os cavalos, com os açudes e com as áreas de reflorestamento (dispersas pela área total da fazenda) não variam ao longo do ano, exigindo deslocamento contínuo e diário dos trabalhadores. Devido a esses fatores, podemos utilizar as informações obtidas para discutir a atividade das serpentes ao longo do ano.

O número de exemplares de $B$. neuwiedi permitiu uma análise mais criteriosa relacionada à sazonalidade na captura. Machos adultos de B. neuwiedi foram capturados em maior número no outono, o que pode refletir a época de acasalamentos, quando os machos estão mais ativos, à procura das fêmeas (ALMEIDA-SANTOS e SALOMÃO, 2002; HARMANN; MARQUES; ALMEIDA-SANTOS, 2004). A coleta de machos também pode aumentar durante o período de espermatogênese, principalmente nas áreas temperadas, quando os machos necessitam termorregular por períodos mais prolongados (DUVALL; ARNOLD; SCHUETT, 1992). Essa afirmação se confirma no presente estudo, pois a primavera foi o segundo período com maior número de coletas de machos, justamente a época de maior atividade espermatogênica observada nos machos de B. neuwiedi.

O número representativo de fêmeas adultas de $B$. neuwiedi coletadas na primavera e no verão provavelmente reflete o período final da vitelogênese e o período de gestação, quando as fêmeas ficam mais expostas devido às atividades de termorregulação, além de perderem a agilidade devido ao aumento da massa corporal, tornando-se mais vulneráveis a captura (SHINE 1980 a,b; MARQUES, 1996 a,b; HARMANN; MARQUES; ALMEIDA-SANTOS, 2004). No presente estudo, a maioria das fêmeas adultas encontradas durante os meses de primavera $(58,8 \%)$ e verão $(75 \%)$ estava reprodutiva, resultado que corrobora as observações de maior vulnerabilidade à captura.

Fêmeas jovens também foram mais coletadas durante a primavera, porém no verão e outono também foram bem amostradas. A maioria das fêmeas jovens coletadas no verão apresentava CRC similar ao dos filhotes da espécie nascidos em cativeiro. Provavelmente haviam sido recrutados na mesma estação em que foram coletados. 
No inverno foi pequeno o número de indivíduos capturados (de ambos os sexos), o que pode estar relacionado às restrições das baixas temperaturas na área de estudo. Baixa atividade das serpentes durante os meses mais frios é comum (SAZIMA, 1992; ALMEIDA-SANTOS, 1995). Porém, apesar dos poucos indivíduos coletados no inverno, pouco mais da metade apresentava alimento no sistema gastrointestinal, o que significa que apesar de diminuírem as atividades, talvez não percam oportunidades de se alimentar.

Machos de B. jararaca foram encontrados apenas no verão. Esse fato pode ser apenas um problema amostral, ocorrido ao acaso, ou pode também refletir uma menor adaptação da espécie as temperaturas mais baixas na região, com os machos se locomovendo mais apenas durante os meses mais quentes. As fêmeas de B. jararaca foram mais amostradas no verão e na primavera, provavelmente pelas mesmas razões descritas para $B$. neuwiedi.

O pequeno número de $C$. durissus não permite discorrer sobre os padrões de atividade sazonal da espécie na região de estudo. Mas os machos da espécie mostram pico de atividade durante o outono, e as fêmeas maior atividade da primavera até o outono (SALOMÃO; ALMEIDA-SANTOS; PUORTO, 1995; ALMEIDA-SANTOS, 2005). Apenas nesta espécie o número de machos encontrados foi maior que o de fêmeas, fato também observado para $C$. durissus em área de cerrado (TOZETTI E MARTINS, 2008).

Entre todas as serpentes encontradas durante o período de coletas (incluindo os indivíduos da família Dipsadidae, comentados no capítulo 1) apenas uma fêmea de B. jararaca foi coletada nos meses de agosto. Na região da Fazenda Santa Elisa, os meses de agosto geralmente registram as temperaturas mais baixas, com ocorrência constante de geadas nos últimos anos (Celso Nomura, comunicação pessoal ${ }^{1}$ )

\footnotetext{
${ }^{1}$ Nomura, C., São Paulo, 2011
} 


\section{Uso do ambiente}

A preferência por determinados habitats pode estar associada aos aspectos climáticos, abundância de presas e disponibilidade de abrigos (DUVALL; KING; GUTZWILLER, 1985; GIBBONS e SEMLITSCH, 1987).

A maior parte das B. neuwiedi foi encontrada nas áreas abertas, mais especificamente nos Campos de Altitude, corroborando com as informações da literatura sobre habitar preferencialmente áreas abertas (CAMPBELL e LAMAR, 2004; SILVA e RODRIGUES, 2008

Alguns indivíduos foram encontrados nas capoeiras, que dependendo do grau de regeneração pode apresentar vegetação esparsa e clareiras. Nas capoeiras, a maioria dos indivíduos estava ativa, alguns foram encontrados em locomoção na periferia da vegetação, e outros atravessando a estrada. As serpentes atropeladas quase sempre foram encontradas em estradas de terra que cortam as áreas de capoeira.

A espécie também mostrou freqüentar as áreas cultivadas, principalmente as plantações de batata e mandioquinha, sendo sempre encontradas abrigadas sob as folhas. Quase a totalidade das B. neuwiedi amostradas nas áreas cultivadas tinham alimento no trato gastrointestinal. As áreas de cultivo podem atrair roedores consumidores de frutos e sementes (CHRISTOFF; LIMA; JUNG, 2009), e talvez os corredores de terreno limpo ao redor das plantas facilite a captura dos mesmos.

As poucas serpentes amostradas nas áreas florestadas estavam em locais de reflorestamento, com as mudas de Pinus ainda pequenas, fato que confirma a preferência da espécie pelas áreas abertas. Machos e fêmeas parecem não divergir em relação ao uso do ambiente.

A espécie B. jararaca, apesar de mais abundante nas capoeiras e nas áreas abertas, mostra maior plasticidade em relação ao uso do ambiente, pois foi encontrada em todas as fisionomias da vegetação. Talvez não tenha sido mais amostrada nas áreas florestadas devido à coloração críptica dificultar sua visualização nesse ambiente (SAZIMA, 1988, 1992). Ainda Sazima (1992) observa que a espécie é ocasionalmente encontrada nas áreas abertas. No presente estudo os Campos de Altitude (áreas abertas) foi o segundo ambiente mais freqüentado por B. jararaca. Machos foram encontrados 
apenas nas capoeiras e nos Campos de Altitude, já as fêmeas mostraram freqüentar todos os ambientes.

Como era esperado, todas as $C$. durissus estavam nas áreas abertas, mais precisamente nos Campos de Altitude. Espécie associada a áreas abertas (CAMPBELL e LAMAR, 2004), atualmente vem colonizando ambientes antes florestados, agora fragmentados e degradados pela ação antrópica (BASTOS; ARAUJO; SILVA, 2005). Cinco indivíduos de $C$. durissus foram encontrados dentro de cupinzeiros abandonados. Os cupinzeiros são abundantes na área de estudo, principalmente nos Campos de Altitude, são extremamente duros e removidos apenas com o auxílio de tratores. Os cinco exemplares foram encontrados durante o desmatamento de pequenas áreas para preparação do terreno para plantio.

As C. durissus podem selecionar, pela temperatura oferecida, diferentes microhabitats, que variam entre os períodos do dia, e entre as diferentes épocas do ano (TOZETTI e MARTINS, 2008). Habitando as áreas abertas, com menor oferta de abrigos do que as áreas florestadas, a espécie parece utilizar freqüentemente os cupinzeiros, que oferecem temperatura e umidade constantes, além de possibilitar abrigo contra predadores. Para Crotalus durissus, o uso de cupinzeiros por fêmeas prenhes ou fêmeas com ninhadas recém nascidas já foi documentado (TRAVAGLIACARDOSO e ALMEIDA-SANTOS, 2007), assim como o uso de tocas na agregação de filhotes de Crotalus cerastes (REISERER; SCHUETT; EARLEY, 2008).

Outras espécies também utilizam os cupinzeiros na área de estudo como abrigo ou como local de ovipostura (TRAVAGLIA-CARDOSO, 2007). O uso de ninhos naturais (cupinzeiros, formigueiros, tocas, buracos) por espécies ovíparas como local escolhido para fazer suas posturas, inclusive posturas comunitárias, já foi relatado para espécies de ocorrência no Brasil (ALBUQUERQUE e FERRAREZI, 2004; BRAZ: FRANCO; ALMEIDA-SANTOS, 2008; BRAZ e MANÇO, 2011). 


\section{Postura e comportamento no momento do encontro}

O encontro com serpentes na natureza pode ser considerado um evento fortuito (STRÜSSMANN e SAZIMA, 1993; MARTINS e OLIVEIRA, 1999). Poucas informações comportamentais foram obtidas das serpentes encontradas nos Campos de Altitude, pois boa parte foi coletada por trabalhadores rurais. Os registros mais completos são dos animais encontradas nas áreas de capoeira, de reflorestamento e nas áreas próximas à sede da FSE, onde a maior parte dos exemplares foi encontrada pela equipe de coletores, possibilitando informações mais precisas.

Apesar dos viperídeos aqui estudados apresentarem hábito predominantemente crepuscular e noturno, foi baixo o número de indivíduos coletados no período noturno. Uma explicação seria o menor esforço de coleta, pois as atividades de rotina da Fazenda Santa Elisa acontecem durante o dia, e o clima frio (principalmente durante o outono e o inverno) muitas vezes restringiu o trabalho noturno também por parte da equipe de coletores. Além disso, pode ser que as baixas temperaturas durante a noite limitem em alguns períodos do ano a atividade das serpentes. Mas, apesar das baixas temperaturas, uma fêmea adulta de $B$. jararaca foi coletada em locomoção (mês de julho) às $20 \mathrm{~h} 30 \mathrm{~min}$, com temperatura de $7^{\circ} \mathrm{C}$, vento e garoa forte.

Todas as observações descritas abaixo se referem a $B$. neuwiedi e a $B$. jararaca. A maior parte das serpentes estava enrodilhada no momento em que foram avistadas (algumas ativas, outras em repouso, ver metodologia cap.1). Geralmente os indivíduos encontrados em locomoção ou estavam cruzando estradas e trilhas ou se locomovendo na borda da vegetação.

A maioria das serpentes estava ativa, atentas à aproximação das pessoas. A imobilidade foi relatada por Sazima (1988) como sendo a primeira fase das ações defensivas em $B$. jararaca, pois sua coloração críptica favorece a camuflagem. Caso a ameaça permaneça, a segunda fase é a fuga. Esse fato foi observado nas serpentes B. neuwiedi e B. jararaca, cuja primeira reação ao perceber a aproximação foi a imobilidade. Persistindo a ameaça, outros comportamentos defensivos procederam a essa imobilidade.

Desferir botes foi a defesa mais utilizada por ambas as espécies, principalmente pelas fêmeas, que exibiram comportamentos defensivos mais freqüentemente do que os 
machos, se mostrando mais agressivas. Algumas fêmeas de B. neuwiedi escondem a cabeça sob as voltas do corpo quando molestadas, alterando visivelmente a frequiência respiratória e exibindo tremores pelo corpo. Esse comportamento é comum para fêmeas da espécie em cativeiro, que também se mostram mais agressivas do que os machos (observação pessoal).

Fêmeas prenhes de $B$. neuwiedi também desferiram botes. Uma B. jararaca prenhe tentou a fuga, porém sua mobilidade estava comprometida. Sazima (1988) observou em $B$. jararaca que a maioria das fêmeas prenhes não tentava a fuga e não desferiam botes como defesa, devido à mobilidade limitada. Talvez a espécie B. neuwiedi seja mais agressiva do que B. jararaca.

Um B. neuwiedi macho largou a presa que estava começando a ingerir, e uma fêmea regurgitou uma presa, provavelmente para conseguir maior mobilidade nas tentativas de fuga. Em ambas as espécies, alguns indivíduos não exibiram comportamento de defesa, sendo facilmente capturados. A maioria dos indivíduos que não exibiu comportamento de defesa estava enrodilhada e em repouso. Não foi observada possível relação entre a ausência de comportamento defensivo e o período do dia e ou época do ano da captura da serpente. Para $C$. durissus o único registro de comportamento de defesa foi um bote.

Os modos de defesa exibidos pelas serpentes podem variar de acordo com a intensidade e os riscos do ataque, de acordo com as circunstâncias em que ocorrem e suas possibilidades de fuga e também de acordo com a temperatura ambiente (DUVALL; KING; GUTZWILLER, 1985; SAZIMA, 1988). Mas é grande a variabilidade individual e a diversidade de circunstâncias, e informações comportamentais devem ser observadas com cautela (SAZIMA, 1988). As informações aqui apresentadas foram observadas em campo, sob determinadas circunstâncias, e não pretendem estabelecer padrões comportamentais para as espécies estudadas. 


\section{Dieta}

Apesar de o forrageamento ativo estar presente principalmente em B. jararaca, os três viperídeos que freqüentam a área de estudo caçam principalmente por espreita e matam suas presas por envenenamento (SAZIMA, 1992).

Nas serpentes, a dieta pode influenciar no uso do hábitat e no período de atividade das espécies (TOFT, 1985). Espécies que apresentam ampla distribuição geográfica podem também apresentar heterogeneidade nos hábitos alimentares, devido à disponibilidade de presas, que também pode variar entre as diferentes regiões (LUISELLI e AGRIMI, 1991; SHINE et al, 1998; HOLYCROSS e MACKESSI, 2002; HARTMANN; HARTMANN; GIASSON, 2003).

B. neuwiedi possui dieta especializada em mamíferos, e não apresenta variação ontogenética na dieta, se alimentando preferencialmente de pequenos mamíferos desde filhotes (MARTINS; MARQUES; SAZIMA, 2002). Os resultados obtidos corroboram essa observação, pois todas as serpentes com alimento no trato gastrointestinal haviam ingerido mamíferos. Simultaneamente com mamíferos, dois indivíduos haviam ingerido lagartos, e outros dois indivíduos ingerido aves. Portanto, outros itens alimentares são pouco freqüentes na dieta da espécie.

Apenas mamíferos foram encontrados como presas em B. jararaca. A espécie apresenta variação ontogenética na dieta, os jovens ingerem principalmente anuros e lagartos, e os adultos principalmente mamíferos e ocasionalmente aves e lagartos (SAZIMA, 1992; SAZIMA e HADDAD, 1992; MARQUES; ETEROVIC; SAZIMA, 2001; MARTINS; MARQUES; SAZIMA, 2002, MORAES, 2008). A captura quase que somente de indivíduos adultos pode explicar apenas mamíferos terem sido predados. Além disso, os mamíferos são abundantes na área de estudo (CHRISTOFF; LIMA; JUNG, 2009), e a dieta de muitas espécies pode simplesmente refletir a disponibilidade e abundância de suas presas nos hábitats onde vivem (MUSHINSKY, 1987).

Diferenças geográficas na dieta de jovens já foram relatadas para B. jararaca, onde indivíduos que habitam áreas litorâneas mostraram ingerir maior proporção de presas ectotérmicas, enquanto que jovens de áreas mais elevadas, presas endotérmicas. Essas diferenças podem ser atribuídas às condições climáticas, que nas regiões 
litorâneas favorecem maior disponibilidade de presas ectotérmicas por um período mais prolongado do ano, o que não ocorre em regiões mais altas, onde a sazonalidade climática é mais acentuada (MORAES, 2008).

Para a espécie $C$. durissus também foram encontrados apenas mamíferos na dieta. A espécie é especialista em mamíferos, consumindo esporadicamente aves e lagartos (SALOMÃO; ALMEIDA-SANTOS; PUORTO, 1995; SANT’ANNA e ABE, 2007).

A dieta das três espécies de viperídeos estudadas foi composta quase que totalmente por mamíferos, apesar de anfíbios anuros e lagartos serem freqüentemente encontrados na área de estudo (observação pessoal). Segundo Christoff, et al. (2009), nos ambientes de Floresta com Araucária, a araucária contribui na produção sazonal de sementes, de grande importância como recurso alimentar para as comunidades de roedores que habitam essa floresta e as áreas adjacentes, o que pode refletir no aumento da densidade populacional de roedores. Além disso, talvez as baixas temperaturas da região levem as serpentes a preferir presas que fornecem mais energia, no caso, as presas endotérmicas (ARNOLD, 1993).

Em relação à variação sazonal na dieta, o maior número de fêmeas de B.neuwiedi com alimento no trato gastrointestinal nos meses de verão e outono pode estar relacionado a alguns fatores: temperaturas mais elevadas no verão, época de maior atividade das serpentes; período final de gestação, e os resultados mostraram que metade das fêmeas encontradas com ovos nos ovidutos tinha alimento no trato digestório (discussão mais adiante), portanto elas não cessam a alimentação; e o grande número de fêmeas alimentadas no outono pode refletir a necessidade de reposição energética por parte das serpentes que produziram ninhadas no verão. O maior número de machos com alimento no trato gastrointestinal durante o outono reflete o período de acasalamento, quando os machos estão mais ativos, à procura de parceiras.

As baixas temperaturas reduzem a taxa metabólica das serpentes, causando redução nas suas atividades durante os meses mais frios, incluindo diminuição na frequiência de alimentação, e diminuindo a eficiência digestiva durante esse período (LILLYWHITE, 1987; SAZIMA, 1992; MORAES, 2008). Durante os meses de inverno foi baixo o número de serpentes amostradas. Entre as poucas $B$. jararaca encontradas nesse período $(\mathrm{N}=3)$, apenas uma estava alimentada. Já entre as $B$. neuwiedi, apesar do 
pequeno número de encontros no inverno, a maioria apresentava alguma presa no trato gastrointestinal.

Diferenças sexuais na dieta podem estar relacionadas ao tamanho do corpo e da cabeça (SHINE, 1991; SHINE, 1994; FORSMANN, 1994), e em espécies peçonhentas essa variação na dieta pode vir acompanhada de variação nas atividades biológicas de seus venenos (FURTADO; TRAVAGLIA-CARDOSO; ROCHA, 2006; ZELANIS; TRAVAGLIA-CARDOSO; FURTADO, 2008). Em algumas espécies as divergências sexuais na dieta podem diminuir a competição por recursos entre os sexos de uma mesma espécie (SHINE, 1991). Em B.neuwiedi lagartos foram ingeridos apenas por indivíduos jovens, e as aves por fêmeas adultas, em conformidade com a literatura que afirma que presas ectotérmicas são ingeridas principalmente por serpentes jovens, e presas endotérmicas, de maior porte, por indivíduos adultos (SAZIMA, 1992; MARTINS; MARQUES; SAZIMA, 2002; MORAES, 2008). As fêmeas de B. neuwiedi são mais robustas e possuem corpo maior do que os machos. E, embora não tenha sido encontrado dimorfismo sexual no comprimento relativo da cabeça, as fêmeas possuem o corpo maior, são mais robustas, e conseqüentemente possuem comprimento da cabeça maior do que os machos (dados absolutos), portanto aptas a ingestão de presas mais volumosas, como aves.

A maioria das serpentes se alimenta com pouca frequiência, e não é comum o encontro de itens alimentares múltiplos no sistema digestório (GREENE, 1997; NOGUEIRA; SAWAYA; MARTINS, 2003; HARMANN et al, 2005). Mas talvez algumas espécies não desperdicem oportunidades de alimentação. Nove indivíduos de B. neuwiedi $(12,7 \%)$ apresentaram evidências da ingestão simultânea de duas presas; uma fêmea de B. jararaca havia ingerido dois roedores e um marsupial; e duas C. durissus apresentaram evidências de ingestão múltipla de presas, sendo que uma fêmea havia ingerido quatro presas (1 marsupial e 3 pequenos roedores).

Devido ao baixo benefício energético, algumas serpentes adultas podem deixar de consumir presas ectotérmicas ou presas endotérmicas de pequeno porte (ARNOLD, 1993). Neste estudo as presas não foram identificadas ao nível de gênero ou espécie, o que traria informações mais precisas sobre o tamanho das presas ingeridas e as relações presa-predador. Porém as evidências (tamanho dos conteúdos estomacais, tamanho da cauda de presas semi digeridas, tamanho das mandíbulas, dos dentes e das unhas) 
permitem inferir que: as $B$. neuwiedi, em ambos os sexos e em todas as fases de vida, alimentaram-se de roedores pequenos (espécies de pequeno porte ou jovens de espécies maiores); os machos de $B$. jararaca também ingeriram presas de pequeno porte (ou jovens), já as fêmeas ingeriram presas maiores; as $C$. durissus ingeriram presas maiores. Mas é clara a necessidade de um maior número de amostras de B. jararaca e C. durissus para informações mais precisas.

Grande parte das fêmeas prenhes (inclusive no final da gestação) apresentou alimento no trato gastrointestinal. Muitas espécies de serpentes reduzem a alimentação durante a gestação (SHINE, 1980a), mas isso parece não ocorrer na área de estudo. Uma fêmea de $B$. jararaca com ovos nos ovidutos havia ingerido três presas relativamente grandes (ver resultados dieta), que ocupavam praticamente toda cavidade abdominal do animal. É possível que na natureza as fêmeas prenhes tenham maior dificuldade em capturar suas presas devido à baixa mobilidade. No caso deste estudo, provavelmente as fêmeas prenhes não perderam oportunidades de alimentação, Além disso, os viperídeos caçam principalmente por espreita, o que não exige muita rapidez de locomoção.

Todas as serpentes iniciaram a ingestão de suas presas pela cabeça (quando foi possível observar), o modo de ingestão mais utilizado pelas serpentes, pois diminui o tempo de ingestão (e conseqüentemente o gasto energético) e os riscos de predação (GREENE, 1997).

Em síntese, as três espécies ingeriram mamíferos, e o número representativo de indivíduos com alimento no trato gastrointestinal pode ser explicado pela abundância de mamíferos na área. Parece ocorrer partilha de recursos entre as espécies de viperídeos. Devido à heterogeneidade ambiental, nas áreas de ecótono da Floresta de Araucárias, com os Campos de Altitude e a Mata Atlântica, a mastofauna é extremamente rica, e ocorrem roedores associados a diferentes habitats (CHRISTOFF; LIMA; JUNG, 2009). 


\section{Reprodução}

\section{Maturidade sexual:}

Os machos de B. jararaca e $B$. neuwiedi atingem a maturidade sexual com tamanho menor do que as fêmeas. Esse padrão é relativamente comum entre as serpentes (PARKER e PLUMMER, 1987), e pode ser observado em outras espécies de viperídeos que ocorrem no Brasil (HARTMANN; MARQUES; ALMEIDA-SANTOS, 2004; MONTEIRO et al., 2006; KASPEROVICZUS, 2009). O custo reprodutivo é maior nas fêmeas do que nos machos, portanto para as fêmeas é vantajoso atingir a maturidade com maior tamanho de corpo, o que pode acarretar em aumento na fecundidade (SEIGEL e FORD, 1987; SHINE, 1978).

Machos e fêmeas de $B$. neuwiedi atingem a maturidade com tamanho do corpo menor do que B. jararaca, o que é atribuído às diferenças de tamanho entre as espécies. Para C. durissus o mesmo padrão foi observado, mas a amostra é pequena para chegar a conclusões.

\section{Ciclos reprodutivos dos machos}

Os machos podem apresentar ciclos reprodutivos onde a produção de espermatozóides é contínua, ou ciclos sazonais, onde essa produção é interrompida durante algum período do ano, sendo a temperatura um dos fatores climáticos que mais influencia na periodicidade da espermatogênese (ALDRIDGE, 1975; SAINT- GIRONS, 1982; LICHT, 1984, SEIGEL e FORD, 1987; SCHUETT, 1992).

Os ciclos sazonais podem ser classificados como associado (ou pré-nupcial) onde a produção de espermatozóides precede ou coincide com a época de acasalamentos; ou como dissociado (ou pós-nupcial), onde a produção de gametas é posterior a época de cópula e os machos estocam esses espermatozóides nos ductos deferentes até a época de acasalamentos (SAINT- GIRONS, 1982; SEIGEL e FORD, 1987; SCHUETT, 1992). O período de espermatogênese dos machos pode ser determinado pelo aumento da massa dos testículos (VOLSOE, 1944), e também pelo aumento do diâmetro dos ductos 
deferentes, que reflete estocagem de esperma (ALMEIDA - SANTOS et al, 2004 b; ALMEIDA - SANTOS; PIZZATTO; MARQUES, 2006).

Em B. neuwiedi a variação do volume testicular mostrada ao longo do ano indicou a primavera como o período de maior atividade espermatogênica. Corroborando o resultado do volume testicular, as análises histológicas dos testículos também mostraram a primavera como o período de maior atividade espermatogênica, e indicaram estocagem de esperma nos ductos deferentes principalmente durante o outono. Dessa forma, o ciclo reprodutivo dos machos da espécie foi caracterizado como do tipo dissociado, com espermatogênese principalmente na primavera, e estocagem de esperma nos ductos deferentes até o outono, quando ocorrem os acasalamentos.

Em B. jararaca todos os machos foram considerados reprodutivos pelas características morfológicas dos testículos e ductos deferentes (SHINE, 1977a; SHINE, 1980a). Todos os machos foram coletados durante o verão, portanto não foi possível analisar as variações ao longo do ano. Porém, foi registrada a época de acasalamentos da espécie (corroborada pelos resultados de cativeiro), o período de vitelogênese das fêmeas, e a época de nascimento das ninhadas. Essas informações, aliadas ao ciclo reprodutivo descrito para a espécie em outras localidades, evidenciam o ciclo reprodutivo dos machos também como dissociado, com estocagem de esperma nos ductos deferentes até o período de acasalamentos. Assim, o ciclo reprodutivo de machos de $B$. jararaca na área de estudo mostrou-se similar ao descrito para a espécie em populações procedentes de localidades com diferentes características climáticas (JANEIRO-CINQUINI; LEINZ; FARIAS, 1993b; ALMEIDA-SANTOS e ORSI, 2002; ALMEIDA-SANTOS e SALOMÃO, 2002).

Em C. durissus quase todos os machos foram considerados adultos pelas características morfológicas dos testículos e ductos deferentes (SHINE, 1977a; SHINE, 1980a). O período de vitelogênese secundária observado para as fêmeas, a época de nascimento da ninhada, além do ciclo reprodutivo determinado para a espécie em outras localidades, permitiu evidenciar o ciclo reprodutivo dos machos como dissociado, com estocagem de espermatozóides até o outono, época de cópula da espécie. Dessa forma, o ciclo reprodutivo dos machos de $C$. durissus observado também é similar ao descrito para a espécie em outras localidades (ALMEIDA-SANTOS e ORSI, 2002). 


\section{Ciclos reprodutivos das fêmeas}

As fêmeas de serpentes tropicais podem apresentar ciclo reprodutivo restrito a um período do ano, ou ciclos mais longos, porém com um pico reprodutivo (PIZZATTO; ALMEIDA-SANTOS; MARQUES, 2007). Mas, mesmo nos ciclos mais longos, a reprodução das fêmeas obedece a certa sazonalidade, e essas diferenças na extensão dos ciclos reprodutivos podem estar associadas às variações sazonais dos recursos e custo reprodutivo (FITCH, 1982; ALMEIDA-SANTOS e SALOMÃO, 2002). Além disso, as variações sazonais nas condições climáticas podem afetar a extensão e o período reprodutivo das serpentes tropicais, fazendo com que os ciclos reprodutivos de uma mesma espécie possam variar em relação à área de ocorrência das diferentes populações, mostrando maior sazonalidade em ambientes onde a sazonalidade climática é mais acentuada (SEIGEL e FORD, 1987; PIZZATTO; JORDÃO; MARQUES, 2008).

A vitelogênese secundária pode se restringir a um determinado período do ano, chamada de reprodução não continua, ou pode ocorrer em qualquer época, chamada também de reprodução contínua (PIZZATTO; ALMEIDA-SANTOS; MARQUES, 2007). Durante a vitelogênese secundária ocorre a deposição de vitelo sobre os folículos, que adquirem coloração amarelada e aumentam bastante de volume. Tanto em B. neuwiedi quanto em B. jararaca a deposição de vitelo teve inicio no final do verão, porém foi durante o outono que o maior número de folículos em vitelogênese secundária foi encontrado. Os folículos de $B$. neuwiedi iniciam a deposição de vitelo com tamanho menor do que B. jararaca, provavelmente devido às variações no tamanho corporal das espécies. Apesar de ambas as espécies apresentarem o mesmo padrão, os resultados sugerem vitelogênese secundária iniciando um pouco mais cedo em B. neuwiedi.

Tanto em B. neuwiedi quanto em B. jararaca, ovos nos ovidutos (com embriões em diferentes estágios de desenvolvimento) começam a ser encontrados na primavera, quando tem inicio o desenvolvimento embrionário. Os nascimentos de B. neuwiedi se distribuíram durante todo o verão, então o período de gestação foi estimado entre 4 a 5 meses. Já os nascimentos de B. jararaca ocorreram todos no final do verão, e seu período de gestação parece ser um pouco mais longo, de 5 a 6 meses. O número médio e o tamanho dos ovos não variaram entre as duas espécies de Bothropoides. 
As análises histológicas permitiram comprovar que em B. neuwiedi há estocagem de esperma durante o outono e inverno. Como as cópulas acontecem no outono, e a fertilização na primavera, as fêmeas necessariamente devem fazer estocagem de esperma no útero posterior, da cópula até a época de ovulação e fertilização. Este foi o primeiro relato de estocagem de esperma para a espécie.

Nos viperídeos, a estocagem de esperma nos ovidutos permite o lapso entre a cópula (no outono) e a fertilização (na primavera), com os nascimentos acontecendo no verão, uma época mais propícia devido às temperaturas mais elevadas e maior disponibilidade de alimento para os filhotes (SCHUETT, 1992, ALMEIDA-SANTOS e SALOMÃO, 1997). Mas a estocagem de esperma pode também favorecer as fêmeas aumentando o período reprodutivo, possibilitando a paternidade múltipla na mesma ninhada e permitindo a fertilização de mais de uma série de folículos, independente de quando ela tenha copulado (SCHUETT, 1992; BIRKHEAD e MOLLER, 1993).

Nas fêmeas que apresentam estocagem de esperma, observa-se uma torção do útero posterior, denominada "uterine muscular twist" (UMT) (ALMEIDA-SANTOS e SALOMÃO, 1997, 2002). O útero posterior apresenta-se de forma espiralada, causada por contrações da musculatura que alteram sua morfologia, resultando em uma obstrução que impede a passagem dos espermatozóides para o útero anterior até o momento da ovulação. Na primavera as torções uterinas relaxam, e os espermatozóides movimentam-se em direção ao infundíbulo, onde ocorre a fertilização. Todo esse processo é modulado por hormônios (ALMEIDA-SANTOS e SALOMÃO, 1997; ALMEIDA-SANTOS e SALOMÃO, 2002; mas ver detalhes de todo o processo em ALMEIDA-SANTOS et al, 2004a). A estocagem de esperma ocorre em boa parte das espécies de serpentes, porém o tempo que os espermatozóides podem permanecer viáveis no trato reprodutivo das fêmeas ainda permanece desconhecido (ver ALMEIDA-SANTOS, 2005).

Em resumo, os ciclos reprodutivos das fêmeas de $B$. neuwiedi e de $B$. jararaca foram determinados com observações de corte e cópula acontecendo principalmente no outono, com estocagem de esperma até a primavera. A vitelogênese secundária inicia no outono (em alguns indivíduos no final do verão) e se estende até a primavera quando ocorre a ovulação e a fertilização. Ovos nos ovidutos foram observados do início da primavera até o verão. Os nascimentos ocorrem principalmente do meio para o final do 
verão, com um registro no final da primavera e um no início do outono (para B. neuwiedi).

O número de fêmeas de $C$. durissus foi pequeno. Mas, a julgar pelas características reprodutivas observadas (vitelogênese secundária no outono, nascimento no verão) e padrão de atividade, foi possível inferir que o ciclo reprodutivo na região de estudo é semelhante ao ciclo já descrito para a espécie (ALMEIDA-SANTOS e ORSI, 2002).

O período de acasalamento, associado ao período de espermatogênese, vitelogênese e estocagem de esperma determinam o sucesso reprodutivo das serpentes (ALDRIDGE e DUVALL, 2002; ALMEIDA-SANTOS e SALOMÃO, 2002). Em uma mesma espécie, em uma mesma população, a época de produção dos gametas pode diferir entre os sexos (MARQUES, 1996b; ALMEIDA-SANTOS; PIZZATTO; MARQUES, 2006), fazendo com que ocorra a estocagem de esperma nos ductos deferentes dos machos até a cópula ou no útero posterior das fêmeas até a época de vitelogênese (ALMEIDA-SANTOS e SALOMÃO, 1997). Sendo assim, nesses casos a estocagem de esperma é essencial para sincronizar os ciclos reprodutivos quando a produção de gametas é assincrônica.

Os ciclos reprodutivos das fêmeas estão sujeitos a variações decorrentes das condições ambientais, principalmente a temperatura, e da disponibilidade de presas, pois o gasto energético despendido para a reprodução é grande e dependente das reservas de lipídios do corpo das fêmeas (DERICKSON, 1976, STEARNS, 1992). Para os viperídeos vivíparos, considerando-se o período de nascimento dos filhotes (verão), e o início do período de vitelogênese secundária (outono e inverno) o período disponível para as fêmeas conseguirem o depósito de energia necessário para iniciar o processo de desenvolvimento folicular é curto. Isso faz com que, na natureza, as fêmeas vivíparas que habitam regiões tropicais apresentem ciclos reprodutivos bienais (DERICKSON, 1976; SHINE, 1986, ALMEIDA-SANTOS e SALOMÃO, 2002). Em regiões temperadas alguns viperídeos podem apresentar ciclos reprodutivos a cada três ou até quatro anos (BROWN, 1991; GOLDBERG, 2000). A bienalidade reprodutiva parece ser o padrão em viperídeos neotropicais (ALMEIDA-SANTOS e SALOMÃO, 2002).

Para B. jararaca e C. durissus a bienalidade dos ciclos reprodutivos foi proposta em uma série de trabalhos que abordaram aspectos ecológicos e ou hormonais dessas 
espécies (SAZIMA, 1992; ALMEIDA-SANTOS e ORSI, 2002; ALMEIDA-SANTOS e SALOMÃO, 2002; ALMEIDA-SANTOS et at., 2004a; ALMEIDA-SANTOS, 2005).

A freqüência de reprodução (porcentagem de fêmeas prenhes durante o período reprodutivo) é dependente das condições nutricionais das fêmeas (STEARNS, 1992), sendo também influenciada pelo modo reprodutivo (PIZZATTO e MARQUES, 2002; MADSEN e SHINE, 1996). É um aspecto da reprodução difícil de ser analisado devido às variações geográficas na proporção de fêmeas reprodutivas, além da diferença comportamental entre fêmeas reprodutivas e não reprodutivas, que pode influenciar no número de serpentes capturadas (SHINE, 1994).

O número de fêmeas reprodutivas de B.neuwiedi variou a cada ciclo durante o período de estudo, mas geralmente foi maior que o de fêmeas não reprodutivas. Porém, o número de fêmeas coletadas anualmente também variou, e a hipótese de que talvez as fêmeas prenhes sejam mais vulneráveis à captura não pode ser descartada. Dessa forma, não seria possível inferir a freqüência reprodutiva da espécie, mas baseado nos ciclos reprodutivos das fêmeas podemos dizer que o ciclo é bienal, assim como na maioria dos viperídeos (ALMEIDA-SANTOS e SALOMÃO, 2002; ALMEIDA-SANTOS, 2005).

Resultados obtidos com viperideos em cativeiro mostram quanto às reservas energéticas influenciam na bienalidade dos ciclos reprodutivos das fêmeas. Em programa de reprodução em cativeiro de Bothropoides insularis (Laboratório de Herpetologia, Instituto Butantan) a mesma fêmea pariu filhotes em três anos sucessivos (2009, 2010 e 2011), com um número crescente de filhotes por ninhada. Fica evidente o gasto energético despendido pela fêmea e sua quase "prostração" logo após os partos. Porém, o fornecimento constante de alimento faz com que a fêmea logo se recupere, passe a ganhar peso e a estocar lipídios novamente, iniciando novo ciclo reprodutivo no mesmo ano em que pariu os filhotes (Silvia Cardoso, dados não publicados). Esse padrão provavelmente não é o observado na espécie $B$. insularis em ambiente natural, onde a reprodução acontecendo a cada dois ou mais anos é resultado do tempo necessário para a aquisição de reservas de gordura (KASPEROVICZUS, 2009).

Em algumas espécies de serpentes, as fêmeas prenhes ou no final da vitelogênese secundária param ou raramente se alimentam, devido à diminuição do espaço na cavidade corporal, a redução da agilidade nessas fases do ciclo reprodutivo e conseqüentemente maior risco de predação (GREGORY e STEWART, 1975; SHINE, 
1977b; SHINE, 1980a). Porém metade das B. neuwiedi e pouco mais da metade das B. jararaca coletadas prenhes (com ovos nos ovidutos) apresentavam alimento no trato gastrointestinal, mesmo nos estágios mais avançados da gestação. Resultado semelhante foi encontrado em fêmeas de Nerodia sipedon, onde mais de $50 \%$ das fêmeas prenhes estava com conteúdo alimentar (ALDRIDGE e BUFALINO, 2003). Estudando Hydropsini, Scartozzoni (2009) encontrou fêmeas reprodutivas com alimento no estômago. Por outro lado, em Tropidodryas serra e Tropidodryas striaticeps, a maioria das fêmeas com ovos não apresentou conteúdo no trato digestório (OLIVEIRA, 2008).

Alguns autores concluem que talvez a ocorrência de conteúdos estomacais em fêmeas prenhes seja mais comum em espécies que se alimentam de presas pequenas e de fácil digestão (BERNARDE e ABE, 2010), o que não se aplica aos viperídeos deste estudo. Em cativeiro, a maioria das fêmeas prenhes continua se alimentando normalmente durante toda a gestação (observação pessoal). Na natureza, talvez o fator "diminuição de agilidade" interfira mais do que o fator "restrição de espaço na cavidade abdominal" nas espécies que deixam de se alimentar durante o período em que estão reprodutivas.

A menor fêmea de B. neuwiedi considerada reprodutiva tinha comprimento do corpo de $600 \mathrm{~mm}$ e apresentava folículos em vitelogênese secundária. A menor fêmea reprodutiva de $B$. jararaca tinha comprimento do corpo de $820 \mathrm{~mm}$, e possuía ovos nos ovidutos. Novamente essas variações podem ser decorrentes da diferença de tamanho entre as fêmeas adultas das duas espécies.

Concluindo, as três espécies de viperídeos analisadas possuem ciclo reprodutivo sazonal e bienal. O ciclo reprodutivo das fêmeas de viperídeos tem-se mostrado sazonal na maioria das espécies em que foi analisado, independentemente da área de ocorrência e suas sazonalidades climáticas (ALMEIDA-SANTOS e SALOMÃO, 2002; VALDUJO; NOGUEIRA;MARTINS, 2002; NOGUEIRA; SAWAYA; MARTINS, 2003; MORAES, 2008). 


\section{Estratégias reprodutivas}

\section{Ninhadas}

As ninhadas de $B$. neuwiedi nasceram ao longo do verão, enquanto que os nascimentos de $B$. jararaca se restringiram ao final do verão. A única ninhada de C. durissus nasceu no verão. A época de nascimento dos filhotes de B. jararaca e C. durissus coincide com os registros da literatura para as espécies em outras localidades (JANEIRO-CINQUINI; LEINZ; ISHIZUKA, 1990; TRAVAGLIACARDOSO, 2001; ALMEIDA-SANTOS e SALOMÃO, 2002; MORAES, 2008). Para B. neuwiedi não foram encontrados outros registros. Porém o verão é a época de nascimento dos filhotes da maioria dos viperídeos que ocorrem no Brasil (ALMEIDASANTOS e SALOMÃO, 2002; VALDUJO; NOGUEIRA; MARTINS, 2002; HARTMANN; MARQUES; ALMEIDA-SANTOS, 2004).

A razão sexual dos filhotes não variou entre $B$. neuwiedi e $B$. jararaca, assim como o percentual de atresia folicular. O número de filhotes nascidos mortos ou com malformações foi mais representativo em B. jararaca. Os filhotes das duas espécies nascem com coloração amarelada na ponta da cauda. Em B. jararaca essa coloração pode estar associada à atração de pequenas presas por meio do engodo caudal, já relatado para a espécie (SAZIMA, 1991; HARMANN e ALMEIDA, 2001).

\section{Fecundidade}

Em serpentes, a fecundidade (ou esforço reprodutivo) das espécies pode ser estimada através de informações sobre o número de ovos ou filhotes, tamanho dos filhotes, massa relativa da ninhada (MRN) e as relações de todas essas características com a massa corporal e tamanho das mães (SEIGEL e FORD, 1987).

A fecundidade é dependente principalmente do tamanho do corpo, porém outros custos reprodutivos podem estar associados a variações na fecundidade (SEIGEL e FORD, 1987). Um aspecto importante da fecundidade das serpentes, a MRN (massa relativa da ninhada), pode variar em relação ao modo reprodutivo (SEIGEL e FITCH, 1984) e também em relação ao uso do ambiente. Serpentes arborícolas, de corpo 
delgado e que necessitam de agilidade na locomoção tendem a possuir menor fecundidade do que espécies terrícolas (PIZZATTO; ALMEIDA-SANTOS; SHINE, 2007).

Portanto, no presente estudo, a fecundidade das espécies B. jararaca e B. neuwiedi é apresentada de forma comparativa, sendo que as duas espécies pertencem ao mesmo gênero, são vivíparas, possuem hábitos principalmente terrícolas e habitam a mesma localidade, o que torna plausível as comparações. Além disso, foi obtida apenas uma ninhada de $C$. durissus, o que inviabilizaria quaisquer comparações com as outras espécies.

Uma ninhada de B. jararaca produziu apenas dois filhotes, com tamanho e peso fora dos padrões da espécie. A fêmea, debilitada e com pneumonia, morreu logo após o nascimento dos filhotes. Dessa forma, essa ninhada foi excluída das informações discutidas abaixo.

A serpente B. jararaca produziu ninhadas maiores e ninhadas mais pesadas (maior massa total das ninhadas), porém a MRN (massa relativa das ninhadas) não apresentou diferenças significativas entre as espécies. Sendo assim, as duas espécies de Bothropoides apresentam fecundidade similar, apesar do maior tamanho corporal de B. jararaca. A menor fêmea de B. neuwiedi que pariu filhotes tinha comprimento do corpo de $670 \mathrm{~mm}$, e a menor B. jararaca, $970 \mathrm{~mm}$.

Devido ao alimento utilizado pelos filhotes das duas espécies, seria esperado que os filhotes de B. neuwiedi, que ingerem roedores, fossem maiores e mais robustos que os de B. jararaca, já que serpentes especialistas em mamíferos podem investir em menor numero de filhotes e filhotes mais pesados (MARTINS; MARQUES; SAZIMA, 2002). As fêmeas recém nascidas de B. neuwiedi apresentaram maior robustez que as de B. jararaca. Entre os filhotes machos esse dimorfismo não foi encontrado.

A fecundidade está relacionada ao tamanho do corpo das mães, sendo comum a relação entre o comprimento da fêmea e o tamanho de suas ninhadas (SEIGEL e FORD, 1987; SHINE, 1994). Porém, essas relações podem variar entre as espécies, e também na mesma espécie em populações geograficamente distintas (FITCH, 1970). Tanto em B. neuwiedi quanto em $B$. jararaca não foram encontradas relações significativas entre as ninhadas e suas mães. Essas relações foram relatadas em outras populações de 
B. jararaca (JANEIRO-CINQUINI; LEINZ; ISHIZUKA, 1990; ALMEIDA-SANTOS, 2005), e em cascavéis (ALMEIDA-SANTOS, 2005).

Portanto, na amostragem analisada, a diferença de tamanho corporal entre as diferentes espécies não proporciona maior fecundidade à espécie de maior porte. Dentro da mesma espécie, essa relação também não foi encontrada.

Em B. jararaca, na população estudada, o número de filhotes por ninhada variou de 5 a 16 (média 9,7 $\pm 3,8$ ). Esse número pode ser considerado baixo quando comparado a outros estudos realizados com a espécie. A literatura registra 9 a 31, com média de 21 filhotes (TRAVAGLIA-CARDOSO, 2001); 17,75 \pm 6 (ALMEIDASANTOS, 2005); 14,3 filhotes (JANEIRO-CINQUINI; LEINZ; ISHIZUKA, 1990); 16,3 $\pm 2,2$ (BRENO et al, 1990) (todos os estudos se referem a ninhadas de mães procedentes quase que exclusivamente da cidade de São Paulo).

A fecundidade pode variar em uma mesma espécie dentro de sua área de ocorrência, provavelmente por fatores relacionados ao clima e à disponibilidade de alimento (VITT, 1983). Estudando 53 ninhadas de B. jararaca, todas procedentes do Rio Grande do Sul, o número médio de filhotes por ninhada foi de 8,04 (ALVES; ARAUJO; WITT, 2000), semelhante ao obtido neste estudo. Talvez a espécie em regiões mais frias tenha sua fecundidade reduzida.

Apesar das B. jararaca da área de estudo produzirem ninhadas menores do que outras populações da espécie, o tamanho dos filhotes é similar. Porém, a massa dos filhotes também é menor. Pode ser que o fator clima esteja envolvido no menor tamanho das ninhadas de B. jararaca deste estudo. Esse fato, adicionado ao maior número de filhotes malformados $(11,4 \%)$, talvez possa estar relacionado a problemas de adaptação ao clima da região. 


\section{Reprodução em cativeiro}

Os combates rituais entre machos durante o período de acasalamento é freqüente em muitas espécies, e pode ser considerado conservativo em alguns grupos (SHINE, 1994). Esses rituais de combate foram observados e descritos para alguns viperídeos brasileiros, como B. moojeni (LELOUP, 1973), B. atrox (TRAVAGLIA-CARDOSO et al, 1993), B. leucurus (SANT'ANNA et al, 2007) e $C$. durissus (ALMEIDA-SANTOS; LAPORTA-FERREIRA; PUORTO, 1990).

Apesar da ausência do comportamento de rituais de combate entre os machos de B. neuwiedi e de B. jararaca (CHAVES et al, 1993 ; ALVES; ARAUJO; CABERLON, 1998; ALVES; ARAUJO; WITT, 2000; ALMEIDA-SANTOS e SALOMÃO, 2002), os experimentos realizados, além de corroborar essa afirmação, mostram que mesmo acontecendo o comportamento de corte, onde um ou ambos os machos cortejaram a mesma fêmea, nenhum comportamento agonístico em relação ao outro macho foi registrado.

No período de acasalamento, os machos localizam possíveis parceiras dispersas pelo ambiente através dos feromônios liberados pelas fêmeas, que no caso das serpentes são substâncias derivadas da vitelogenina (GARSTKA e CREWS, 1981). Após a localização da fêmea tem início o comportamento de corte, que é também bastante conservativo (ver GUILLINGHAM, 1987). São raras as observações de comportamentos reprodutivos na natureza. O comportamento reprodutivo observado em cativeiro, tanto o de corte quanto o de cópula, foi semelhante ao descrito na literatura para as espécies do grupo B. neuwiedi (CHAVES et al, 1993; ALVES; ARAUJO; CABERLON, 1998), e para B. jararaca (ALVES; ARAUJO; WITT, 2000 ).

O período de cópula registrado para as $B$. neuwiedi deste trabalho foi o mesmo registrado para B. neuwiedi no Rio Grande do Sul (ALVES; ARAUJO; CABERLON, 1998) e para B. neuwiedi procedentes de diversas regiões do estado de São Paulo (CHAVES et al, 1993).

Os machos que copularam (de ambas as espécies) não mostraram interesse por outras fêmeas (nem pelas mesmas) nos dois dias seguintes ao acasalamento. Talvez isso ocorra por cansaço físico, devido à longa duração dos acasalamentos. Porém, no Laboratório de Herpetologia do IB, um macho de B. neuwiedi copulou com duas fêmeas 
em seqüência (W. Fernandes, comunicação pessoal ${ }^{1}$ ). As fêmeas que haviam recém copulado também rejeitaram outros machos nos dois dias subseqüentes, apesar de bastante cortejadas.

Sabe-se que o sucesso reprodutivo dos machos depende do número de cópulas, e o das fêmeas depende do número e da qualidade de seus filhotes. Copular com mais de um macho pode garantir maior variabilidade genética, resultando em melhor qualidade de seus filhotes (MADSEN et al, 1992). Casos de múltipla paternidade já foram registrados em algumas espécies de serpentes (SCHUETT e GUILLINGHAM, 1986; SCHWARTZ; McCRACKEN; BURGHARDT, 1989), mas ainda nada foi registrado para viperídeos brasileiros.

Fernandes, Wilson. São Paulo, 2011. 


\section{6 CONCLUSÕES}

1. Bothropoides neuwiedi ocorre principalmente nas áreas abertas, mais precisamente nos Campos de Altitude. Bothropoides jararaca apresenta maior plasticidade, ocupando todas as fisionomias da vegetação, porém mostrando preferência pelas capoeiras e áreas abertas. Crotalus durissus ocorre apenas nas áreas abertas.

2. Nas três espécies de viperídeos estudadas, as fêmeas são maiores e mais robustas do que os machos, e machos possuem a cauda mais longa. Nas duas espécies de Bothropoides, o dimorfismo sexual nas morfometrias é ausente nos filhotes, com exceção de tamanho da cauda em filhotes de B. neuwiedi.

3. As três espécies alimentam-se quase que exclusivamente de pequenos mamíferos, principalmente roedores, abundantes na área de estudo. As fêmeas não param de se alimentar durante o período de gestação.

4. B. jararaca é uma espécie de maior porte do que B. neuwiedi, e produziu ninhadas maiores e mais pesadas, porém a massa relativa das ninhadas foi similar nas duas espécies. Foi observada variação geográfica na fecundidade de B. jararaca.

5. O ciclo reprodutivo das fêmeas de B. neuwiedi foi classificado como sazonal e bienal. Cópulas no outono e estocagem de espermatozóides no útero posterior até a ovulação. Vitelogênese secundária do final do verão até a primavera, quando ocorre a ovulação e fertilização. Os nascimentos ocorrem ao longo de todo o verão. Fêmeas atingem a maturação sexual com tamanho corporal maior do que os machos.

6. O ciclo reprodutivo dos machos de B. neuwiedi foi classificado como dissociado, com produção de gametas na primavera e estocagem de esperma nos ductos deferentes até o período de cópula, no outono e início do inverno. 
7. Os machos apresentaram pico de atividade no outono e na primavera, refletindo os períodos de acasalamento e espermatogênese. Fêmeas apresentaram pico de atividade na primavera e no verão, correspondente ao final da vitelogênese e período de gestação.

8. Independente das características climáticas e altitudinais da área de estudo, que podem estar influenciando em outros aspectos da reprodução, o ciclo reprodutivo das serpentes foi similar ao descrito para as espécies em outras localidades. Dessa forma, os resultados evidenciam que o ciclo reprodutivo é conservativo entre os viperídeos. 


\section{REFERÊNCIAS}

ALBUQUERQUE, C. E.; FERRAREZI, H. A case of communal nesting in the neotropical snake Sibynomorphus mikanii (Serpentes, Colubridae). Phyllomedusa, v. 3, n. 1, p. 73-77, 2004.

ALDRIDGE, R. D. Environmental control of spermatogenesis in the rattlesnake Crotalus viridis.Copeia, v. 1975, n. 3, p. 493-496, 1975.

ALDRIDGE, R. D. Female reproductive cycles of the snakes Arizona elegans and Crotalus viridis. Herpetologica, v. 35, n. 3, p. 256-261, 1979.

ALDRIDGE, R. D.; DUVALL, D. Evolution of the mating season in the pitvipers of North America. Herpetol. Monog., v.16, p.1-25, 2002.

ALDRIDGE, R. D.; BUFALINO, A. P. Reproductive female common water snakes (Nerodia sipedon sipedon) are not anorexic in the wild. J. Herpetol., vol. 37, n. 2, p. 416-419, 2003.

ALFARO, M. E. Sweeping and striking: a kinematic study of the trunk during prey capture in three thamnophiine snakes. J. Exp. Biol., v. 206, n. 14, p. 2381-2392, 2003.

ALMEIDA-SANTOS, S.M. Modelos reprodutivos em serpentes: estocagem de esperma e placentação em Crotalus durissus e Bothrops jararaca (Serpentes: Viperidae) 204f. Tese (doutorado) - Faculdade de Medicina Veterinária e Zootecnia, Universidade de São Paulo, 2005.

ALMEIDA-SANTOS, S. M.; SALOMÃO, M. G. Long-term sperm storage in the female neotropical rattlesnake Crotalus durissus terrificus (Viperidae: Crotalinae). Jpn. J. Herpetol., v. 17, n. 2, p. 46-52, 1997.

ALMEIDA-SANTOS, S. M.; ORSI, A. M. Ciclo reprodutivo de Crotalus durissus e Bothrops jararaca (Serpentes, Viperidae): morfologia e função do oviduto. Rev. Bras. Reprod. Anim., v. 26, n. 2, p. 109-112, 2002. 
ALMEIDA-SANTOS, S. M; SALOMÃO, M. G. Reproduction in neotropical pitvipers, with emphasis on species of the genus Bothrops. In: SCHUETT, G. W.; HÖGGREN, M.; DOUGLAS, M. E.; GREENE, H. W. (Ed.). Biology of the vipers. Utah: Eagle Mountain Publishing, p. $445-462$.

ALMEIDA-SANTOS, S. M.; ORSI, A. M. Ciclo reprodutivo de Crotalus durissus e Bothrops jararaca (Serpentes, Viperidae): morfologia e função do oviduto. Rev. Bras. Reprod. Anim., v. 26, n. 2, p. 109-112, 2002.

ALMEIDA-SANTOS, S. M.; LAPORTA-FERREIRA, I. L.; PUORTO, G. Ritual de combate em Crotalus durissus. An. Acad. Bras. Cienc., v. 62, n. 4, p. 418, 1990.

ALMEIDA-SANTOS, S. M.; PIZZATTO, L.; MARQUES, O. A. V. Intra-sex synchrony and intersex coordination in the reproductive timing of the coral snake Micrurus corallinus (Elapidae). Herpetol.J., v. 16, n. 4, p. 371-376, 2006.

ALMEIDA-SANTOS, S. M; SALOMÃO, M. G.; PENETI, E. A.; SENA, P. S.; GUIMARÃES, E. S. Predatory combat and tail wrestling in hierarchical contests of the neotropical rattlesnake Crotalus durissus terrificus (Serpentes: Viperidae). Short notes. Amphib-reptil., v. 20, n. 1, p. 88-96, 1999.

ALMEIDA-SANTOS, S. M; ABDALLA, F. M. F.; SILVEIRA, P. F.; YAMANOUYE, N.; BRENO, M. C.; SALOMÃO, M. G. Reproductive cycle of the neotropical Crotalus durissus terrificus. I. Seasonal levels and interplay between steroid hormones and vasotocinase. Gen. Comp. Endocrinol., v. 139, n. 2, p. 143-150, 2004a.

ALMEIDA-SANTOS, S. M; LAPORTA-FERREIRA, I. L.; ANTONIAZZI, M. M.; JARED, C. Sperm storage in males of the snake Crotalus durissus terrificus (Crotalinae: Viperidae) in southeastern Brazil. Comp. Biochem. Physiol.A Mol. Integr.Physiol., v. 139, n. 2, p. 169-174, 2004b.

ALVES, M. L. M.; LEITÃO-DE-ARAÚJO, M.; CABERLON, E. Atividade reprodutiva de Bothrops neuwiedi em cativeiro (Serpentes,Viperidae). Iheringia Ser. Zool., n. 84, p. 185-191, 1998. 
ALVES, M.L. M.; LEITÃO-DE-ARAÚJO, M.; WITT, A. A.. Aspectos da biologia reprodutiva de Bothrops jararaca em cativeiro (Serpentes, Viperidae). Iheringia Ser. Zool., n. 89, p. $187-192,2000$

ANDERSSON, M. Sexual selection. New Jersey: Princeton University Press, 1994. 599p.

ANDRADE, D. V.; ABE, A. S. Relationship of venom ontogeny and diet in Bothrops. Herpetologica, v. 55, n. 2, p. 200-204, 1999.

ARAÚJO, M. L.; ALVES, M. L. M.; BALESTRIN, R. L.; AGUIAR, L. F. S. Nascimento e desenvolvimento de Bothrops neuwiedi em cativeiro (Serpentes, Viperidae). Iheringia Ser. Zool., v. 85, p. 3-10, 1998.

ARNOLD, S. J. Foraging theory and prey-size-predator-size relations in snakes.In: SEIGEL, R. A.; COLLINS, J. T. (Ed.). Snakes: ecology and behavior. New York:McGraw-Hill Inc., 1993. p. 87-115.

AZEVEDO-MARQUES, M. M.; HERING, S. E.; CUPO, P. Acidente crotálico. In: CARDOSO,

J. L. C.; FRANÇA, F. O. S.; WEN, F. H.; MÁLAQUE, C. M. S.; HADDAH JÚNIOR, V. Animais Peçonhentos no Brasil. biologia, clínica e terapêutica dos acidentes. São Paulo: Sarvier - FAPESP, 2003. p. 91-98.

BASTOS, E. G. M.; ARAÚJO, A. F. B.; SILVA, H. R. Records of the rattlesnakes Crotalus durissus terrificus (Laurenti) (Serpentes, Viperidae) in the state of Rio de Janeiro, Brazil: a possible case of invasion facilitated by deforestation. Rev. Bras.Zool., v. 22, n. 3, p. 812-815, 2005.

BERNARDE, P. S. Composição faunística, ecologia e história natural de serpentes de uma região no sudeste da Amazônia, Rondônia, Brasil. 139 f. Tese (Doutorado em Zoologia) Instituto de Ciências Biológicas, Universidade Estadual Paulista, Rio Claro, 2004.

BERNARDE, P. S.; ABE, A. S. Hábitos alimentares de serpentes em Espigão do Oeste, Rondônia, Brasil. Biota Neotrop.,v. 10, n. 1, p. 167-173, 2010. 
BIRKHEAD, T. R.; MOLLER, A. P. Sexual selection and the temporal separation of reproductive events: sperm storage data from reptiles, bird and mammals. Biol. J. Linn. Soc., v. 50, n. 4, p. 295-311, 1993.

BRAZ, H. B. P.; FRANCO, F. L.; ALMEIDA-SANTOS, S. M. Communal egg-laying and nestsites of the Goo-eater snake, Sibynomorphus mikanii (Dipsadidae, Dipsadinae) in southeastern Brazil. Herpetol.Bull., n. 106, p. 26-30, 2008.

BRAZ, H. B. P.; MANÇO, D. D. G. Natural nests of the false-coral snake Oxyrhopus guibei in southeastern Brazil.Herpetol.Notes, v. 4, p. 187-189, 2011.

BRENO, M. C.; YAMANOUYE, N.; PREZOTTO, B. C.; LAZARI, M. F. M.; TOFFOLETTO, O.; PICARELLI, Z. P. Maintenance the snake Bothrops jararaca (Wied, 1824) in captivity. Snake, v. 22, p. 126-130, 1990.

BROWN, W. S. Female reproductive ecology in a northern population of the timber rattlesnake, Crotalu shorridus.Herpetologica, v. 47, n. 1, p.101-115, 1991.

CAMPBELL, J. A.; LAMAR, W. W.The venomous reptiles of Latin America.Ithaca, NY. Comstock Publishing, Cornell University Press, 1989. 425p.

CAMPBELL, J. A.; LAMAR, W. W. The venomous reptiles of the western hemisphere. Ithaca, NY. Comstock Publishing, Cornell University Press, 2004. 870p.

CARDOSO JÚNIOR, R. P.; LULA, L. A. B. M.; IWASAKI, M.; OLIVEIRA, S. M. Análise radiológica na ofiofagia de filhote de serpente Bothrops alternatus(Viperidae: Crotalinae). Mem. Inst. Butantan, v. 52, n. 2, p. 63-68, 1990.

CARVALHO, C. M.; VILAR, J. C.; OLIVEIRA, F. F. Répteis e anfíbios. In: CARVALHO, C. M.; VILAR, J. C. (Ed.). Parque Nacional Serra de Itabaiana: levantamento da biota. Aracaju: Ibama, 2005. p. 39-61.

CHAVES, M. M. G.; FERNANDES, W.; MIYAJI, C. K.; TRAVAGLIA-CARDOSO, S. R.; SANT'ANNA, S. S.; LULA, L. A. B. M. Observações em cativeiro da reprodução de Bothrops neuwiedi (Serpentes, Viperidae). Livro de Resumos. III Congresso Latino Americano de Herpetologia, Campinas, 1993. p. 66. 
CHRISTOFF, A. U.; LIMA, J.; JUNG, D. M. H. Mamíferos não-voadores da floresta com araucária e áreas adjacentes no Rio Grande do Sul: ênfase em roedores e suas adaptações ao habitat. In: FONSECA, C. R.; SOUZA, A. F.; LEAL-ZANCHET, A. M.; DUTRA, T. L.; BACKES, A.; GANADE, G. (Ed.). Floresta com araucária: ecologia, conservação e desenvolvimento sustentável. Ribeirão Preto: Holos Editora, 2009. p. 171-184.

DALTRY, J. C.; WUSTER, W.; THORPE, R. S. Diet and snake venom evolution. Nature, v. 379, n. 6565 , p. 537-540, 1996.

DEIQUES, C. H. Répteis da floresta com araucária. In: FONSECA, C. R.; SOUZA, A. F.; LEAL-ZANCHET, A. M.; DUTRA, T. L.; BACKES, A.; GANADE, G. (Ed.). Floresta com araucária: ecologia, conservação e desenvolvimento sustentável. RibeirãoPreto: HolosEditora, 2009. p. 185-190.

DERICKSON W. K. Lipid storage and utilization in reptiles. Am. Zool., v. 16, n. 4, p. 711-723, 1976.

DI-BERNARDO, M. História natural de uma comunidade de serpentes da borda oriental do planalto das araucárias, Rio Grande do Sul, Brasil. $123 \mathrm{f}$. Tese (Doutorado em Zoologia) - Instituto de Biociências, Universidade Estadual Paulista, Rio Claro, 1998.

DUARTE, M. R. Microhabitat e relações térmicas da jararaca ilhoa, Bothrops insularis (Serpentes, Viperidae). 43 f. Dissertação (Mestrado em Zoologia) - Instituto de Biociências, Universidade Estadual Paulista, Botucatu, 1999.

DUELLMAN, W. E. The biology of an equatorial herpetofauna in Amazonian Ecuador. Misc. Publ. Mus. Nat. Hist., n. 65, p. 1-352, 1978.

DUNHAM, A. E.; MILES, D. B. Patterns of covariation in life history traits of squamate reptiles: the effects of size and phylogeny reconsidered. Am. Nat., v. 126, n. 2, p. 231-257, 1985.

DUVALL, D.; KING, M. B.; GUTZWILLER, K. J. Behavioral ecology and ethology of the prairie rattlesnake. Natl. Geogr. Res., v. 1, n. 1, p. 80-111, 1985. 
DUVALL, D.; ARNOLD, S.J.; SCHUETT, G.W. Pit viper mating systems: ecological potential, sexual selection and microevolution. In: CAMPBELL, J. A.; BRODIE JR, E. D. (Ed.).Biology of the pitvipers. Arlington: Selva Publ., 1992. p. 321-336.

FENWICK, A. M.; GUTBERLET JUNIOR, R. L.; EVANS, J. A.; PARKINSON, C. L. Morphological and molecular evidence for phylogeny and classification of South American pitvipers, genera Bothrops, Bothriopsis, and Bothrocophias (Serpentes: Viperidae). Zool. J. Linn. Soc., v. 156, n. 3, p. 617-640, 2009.

FITCH, H. S. Reproductive cycles in lizards and snakes. Publ. Mus. Nat. Hist., n. 52, p. 1-247, 1970.

FITCH, H. S. Reproductive cycles in tropical reptiles. Sci. Pap. Nat. Hist. Mus., n. 96, p. 1$53,1982$.

FORSMAN, A. Growth rate and survival in relation to relative head size in Vipera berus. J. Herpetol., v. 28, n. 2, 231-238, 1994.

FRANÇA, F. O. S.; MÁlAQUE, C. M. S. Acidente botrópico. In: CARDOSO, J. L. C.; FRANÇA, F. O. S.; WEN, F. H.; MÁLAQUE, C. M. S.; HADDAH JÚNIOR, V. Animais Peçonhentos no Brasil. biologia, clínica e terapêutica dos acidentes. São Paulo: Sarvier, 2003. p. 72-86.

FURTADO, M. F. D. Contribuição ao estudo do veneno de Bothrops moojeni (Hoge, 1965) (Serpentes, Viperidae, Crotalinae) em função da idade das serpentes. $118 \mathrm{f}$. Tese (Doutorado em Fisiologia Geral) - Instituto de Biociências, Universidade de São Paulo, São Paulo, 1987.

FURTADO, M. F. D.; MARUYAMA, M.; KAMIGUTI, A. S.; ANTONIO, L. C. Comparative study of nine Bothrops snake venoms from adult female snakes and their offspring. Toxicon, v. 29, n. 2, p. 219-226, 1991.

FURTADO, M. F. D.; TRAVAGLiA-CARDOSO, S. R.; ROCHA, M. M. T. Sexual dimorphism in venom of Bothrops jararaca (Serpentes: Viperidae). Toxicon, v. 48, n. 4, p. 401-410, 2006.

GARSTKA, W. R.; CREWS, D. Female sex pheromone in the skin and circulation of a garter snake. Science, v. 214, n. 4521, p. 681-683, 1981. 
GIBBONS, J. W.; SEMLITSCH, R. D. Activity patterns. In: SEIGEL, R. A.; COLLINS, J. T.; NOVAK, S. S. (Ed.). Snakes: ecology and evolutionary biology. New York: MacMillan Publ. Co., 1987. p. 396-421.

GIBBONS, J.W.; LOVICH, J.E. Sexual dimorphism in turtles with emphasis on the slider turtle (Trachemys scripta). Herpetol. Monogr., v. 4, p. 1-29, 1991.

GILlingHAM, J. C. Social behavior. In: SEIGEL, R. A.; COLlinS, J. T.; NOVAK, S. S. (Ed.). Snakes: ecology and evolutionary biology. New York: Mac Millan Publ. Co., 1987. p. 184-209.

GOLDBERG, S. R. Reproduction in the twin-spotted rattlesnake, Crotalus pricei (Serpentes: Viperidae).West. N. Am. Nat.,v. 60, n. 1, p. 98-100, 2000.

GOMES, N.; PUORTO, G. Atlas anatômico de Bothrops jararaca Wied, 1824 (Serpentes: Viperidae). Mem. Inst. Butantan, v. 55, supl.1, p. 69-100, 1993.

GREENE, H. W. Snakes: the evolution of mystery in nature. Berkeley: University of California Press., 1997. 351p.

GREGORY, P.T.; STEWART, K.W. Long-distance dispersal and feeding strategy of red-sided garter snake (Thamnophis sirtalis parietalis) in the Interlake of Manitoba. Can. J. Zool. v. 53, p. $238-245$.

HARTMANN, P. A.; ALMEIDA, M. T. Bothrops jararaca (Jararaca Pitviper). Caudal luring. Herpetol. Rev., v. 32, n. 1, p. 45, 2001.

HARTMANN, P. A.; HARTMANN, M. T.; GIASSON, L. O. M. Uso do hábitat e alimentação em juvenis de Bothrops jararaca (Serpentes, Viperidae) na Mata Atlântica do Sudeste do Brasil. Phyllomedusa, v. 2, n. 1, p. 35-41, 2003.

HARTMANN, M. T.; MARQUES, O. A. V.; ALMEIDA-SANTOS, S. M. Reproductive biology of the southern Brazilian pitviperBothrops neuwiedi pubescens (Serpentes, Viperidae). Amphib-reptil., v. 25, n. 1, p. 77-85, 2004.

HARTMANN, P. A.; HARTMANN, M. T.; MARTINS, M. Ecologia e história natural de uma taxocenose de serpentes do Núcleo Santa Virgínia do Parque estadual da Serra do Mar, no Sudeste do Brasil. Biota Neotrop., v. 9, n. 3, p. 173-184, 2009. 
HARTMANN, M. T.; HARTMANN, P. A.; CECHIN, S. Z.; MARTINS, M. Feeding habits and habitat use in Bothrops pubescens (Viperidae, Crotalinae) from southern Brazil. J. Herpetol., v. 39, n. 4, p. 664-667, 2005.

HENDERSON, R. W.; MICUCCI, T. W.; PUORTO, G.; BOURGEOIS, R. W. Ecological correlates and patterns in the distribution of neotropical boines (Serpentes: Boidae): a preliminary assessment. Herp.Nat. Hist., v. 3, p. 15-27, 1995.

HOLYCROSS, A. T.; MACKESSY, S. P. Variation in the diet of Sistrurus catenatus (Massasauga), with emphasis on Sistrurus catenatus edwardsii (Desert Massasauga).J. Herpetol., v. 36, n. 3, p. 454-464, 2002.

JANEIRO-CINQUINI, T. R. F; LEINZ, F. F.; ISHIZUKA, M. M. Body size-litter size relationships and some characteristics in Bothrops jararaca.Bull. Chicago Herp. Soc., v. 25 , $\mathrm{n}$. 5, p. 84-85, 1990.

JANEIRO-CINQUINI, T. R. F; LEINZ, F. F.; FARIAS, E. C. Ovarian cycle of the snake Bothrops jararaca.Mem.Inst. Butantan, v. 55, n. 1, p. 33-36, 1993 a.

JANEIRO-CINQUINI, T. R. F; LEINZ, F. F.; FARIAS, E. C.Seasonal variation in weight and length of the testicles and the quantity of abdominal fat of the snake Bothrops jararaca. Mem.Inst. Butantan, v. 55, n. 1, p. 15-19, 1993b.

JANEIRO-CINQUINI, T. R. F; FARIAS, E. C.; LEINZ, F. F. Relation between the quantity of abdominal fat and the reproductive state of the snake Bothrops jararaca. Snake, v. 27 , $\mathrm{n}$. 1 , p. 21-24, 1995.

KASPEROVICSUS, K.N. Biologia reprodutiva da jararaca ilhoa, Bothrops insularis (Serpentes, Viperidae) da Ilha da Queimada Grande, São Paulo.124f. Dissertação (Mestrado em Biotecnologia) - Instituto de Ciências Biomédicas, Universidade de São Paulo, São Paulo, 2009.

KING, R.B. Sexual dimorphism in snake tail length: sexual selection, natural selection, or morphological constraint? Biol. J. Linn. Soc., v. 38, p. 133-154, 1989. 
KING, R. B.; BITTNER, T. D.; QUERAL-REGIL, A.; CLINE, J. H. Sexual dimorphism in neonate and adult snakes. J. Zool. , v. 247, n. 1, p. 19-28, 1999.

KRAUSE, M. A.; BURGHARDT, G. M.; GILLINGHAM, J. C. Body size plasticity and local variation of relative head and body size sexual dimorphism in garter snake (Thamnophis sirtalis). J. Zool. , v. 261, n. 4, p. 399-407, 2003.

LELOUP, P. Essais de rationalisation dans le maintien d'un serpentarium à but industriel. Acta Trop., v. 30, n. 4, p. 281-311, 1973.

LICHT, P. Environmental physiology of reptilian breeding cycles: role of temperature. Gen. Comp. Endocrinol., v. 3, suppl. 1, p. 477-488, 1972.

LICHT, P. Reptiles. In: LAMMING, G. E. (Ed.). Marshall's physiology of reproduction. Edinburg: Churchill-Livingstone, v. 1, 1984. p. 206-282.

LILLYWHITE, H. B. Circulatory adaptations of snakes to gravity. Am. Zool., v. 27, n. 1, p. 81-95, 1987.

LILLYWHITE, H. B.; HENDERSON, R. W. Behavioral and functional ecology of arboreal snakes. In: SEIGEL, R. A.; COLLINS, J. T. (Ed.). Snakes: ecology and behavior. New York: McGraw-Hill Inc., 1993. p. 1-48.

LUISELLI, L. M.; AGRIMI, U. Composition and variation of diet of Vipera aspis francisciredi in relation to age and reproductive stage. Amphib-reptil., v. 12, n. 2, p. 137-144, 1991.

MADSEN, T.; SHINE, R. Phenotypic plasticity in body sizes and sexual dimorphism in european grass snakes. Evolution, v. 47, n. 1, p. 321-325, 1993.

MADSEN, T.; SHINE, R. Determinants of reproductive output in female water pythons (Liasis fuscus: Pythonidae). Herpetologica, v. 52, n. 2, p. 146-159, 1996.

MADSEN, T.; SHINE, R.; LOMAN, J.; HAKANSSON, T. Why do female adders copulate so frequently? Nature, v. 355, n. 6359, p. 440-441, 1992. 
MARQUES, O. A. V. Reproduction, seasonal activity and growth of the coral snake, Micrurus corallinus (Elapidae), in the southeastern Atlantic forest in Brazil. Amphib-reptil., v. 17, n. 3, p. 277-285, 1996a.

MARQUES, O. A. V. Biologia reprodutiva da cobra-coral Erythrolamprus aesculapii Linnaeus (Colubridae), no sudeste do Brasil. Rev. Bras. Zool., v. 13 n. 3, p. 747-753, 1996 b.

MARQUES, O. A. V. Composição faunística, história natural e ecologia de serpentes da Mata Atlântica, na região da estação ecológica Juréia-Itatins, São Paulo, SP. 135 f. Tese (Doutorado em Zoologia) - Instituto de Biociências, Universidade de São Paulo, São Paulo, 1998.

MARQUES, O.A.V.; PUORTO, G. Dieta e comportamento alimentar de Erythrolamprus aesculapii, uma serpente ofiófaga. Rev. Bras. Biol., v. 54, n. 2, p. 253-259, 1994.

MARQUeS, O. A. V.; ETEROVIC, A.; SAZIMA, I. Serpentes da Mata Atlântica: guia ilustrado para a Serra do Mar. Ribeirão Preto: Holos Editora, 2001. 184p.

MARQUES, O. A. V.; ALMEIDA-SANTOS, S. M.; RODRIGUES, M. G. Activitypatterns in coral snakes, genus Micrurus (Elapidae), in south and southeastern Brazil. SouthAm. J. Herpetol., v. 1, n. 2, p. 99-105, 2006.

MARTINS, M. História natural e ecologia de uma taxocenose de serpentes de mata na região de Manaus, Amazônia Central, Brasil. 98 f. Tese (Doutorado em Ecologia) - Instituto de Biologia, Universidade Estadual de Campinas, Campinas, 1994.

MARTINS, M.; OLIVEIRA, M. E. Natural history of snakes in forests of the Manaus region, Central Amazonia, Brazil. Herpetol. Nat. Hist., v. 6, n. 2, p. 78-150, 1999.

MARTINS, M.; MARQUES, O. A. V.; SAZIMA, I. Ecological and phylogenetic correlates of feeding habits in neotropicalpitvipers of the genus Bothrops. In: SCHUETT, G. W.; HÖGGREN, M.; DOUGLAS, M. E.; GREENE, H. W. (Ed.). Biology of the vipers. Utah: Eagle Mountain Publishing, 2002. p. 307-328. 
MAYR, E. Populações, espécies e evolução.Tradução Hans Reichardt. São Paulo: Editora da Universidade de São Paulo, 1977. 485p.

MENEZES, M. C.; FURTADO, M. F. D.; TRAVAGLIA-CARDOSO, S. R.; CAMARGO, A. C. M.;SERRANO,S.M.T. Sex-based individual variation of snake venom proteome among eighteen Bothrops jararaca siblings. Toxicon, v. 47, n. 3, p. 304-312, 2006.

MONTEIRO, C.; MONTGOMERY, C. E.; SPINA, F.; SAWAYA, R. J.; MARTINS, M. Feeding, reproduction, and morphology of Bothrops mattogrossensis (Serpentes, Viperidae, Crotalinae) in the Brazilian pantanal. J. Herpetol., v. 40, n. 3, p. 408-413, 2006.

MORATO, S. A. A. Padrões de distribuição da fauna de serpentes da floresta de araucária e ecossistemas associados na região Sul do Brasil. 122 f. Dissertação (Mestrado em Zoologia) - Departamento de Zoologia, Universidade Federal do Paraná, Curitiba, 1995.

MORAES, R. A. Variações em caracteres morfológicos e ecológicos em populações de Bothrops jararaca (Serpentes: Viperidae) no estado de São Paulo. 146 f. Dissertação (Mestrado em Ecologia) - Instituto de Biociências, Universidade de São Paulo, São Paulo, 2008.

MUSHINSKY, H. R. Foraging ecology.In: SEIGEL, R. A.; COLLINS, J. T.; NOVAK, S. S. (Ed.). Snakes: ecology and evolutionary biology. New York: MacMillan Publ. Co., 1987. p. 302-334.

NOGUEIRA, C. C. Ecologia histórica de Bothrops spp. (Serpentes: Viperidae: Crotalinae) simpátricas no Cerrado. 69 f. Dissertação (Mestrado em Ecologia) - Instituto de Biociências, Universidade de São Paulo, São Paulo, 2001.

NOGUEIRA, C.; SAWAYA, R. J.; MARTINS, M. Ecology of the pitviper, Bothrops moojeni, in the Brazilian cerrado. J. Herpetol., v. 37, n. 4, p, 653-659, 2003.

OLIVEIRA, F.S. Ecologia alimentar e reprodutiva de duas espécies de Tropidodryas (Serpentes, Colubridae) da Mata Atlântica. 113p. Dissertação (Mestrado em Ecologia) Instituto de Biociências, Universidade de São Paulo, São Paulo, 2008. 
OLIVEIRA, M. E.; MARTINS, M. When and where to find a pitviper: activity patterns and habitat use of the lancehead, Bothrops atrox, in central Amazonia, Brazil. Herpetol. Nat. Hist., v. 8, n. 2, p. 101-110, 2001.

OLIVEIRA, R. B.; DI-BERNARDO, M.; PONTES, G. M. F. MACIEL, A. P.; KRAUSE, L. Dieta e comportamento alimentar da cobra-nariguda Lystrophis dorbignyi (Duméril, Bibron \& Duméril, 1854), no litoral Norte do Rio Grande do Sul, Brasil. Cuad. Herpetol., v. 14, n. 2, p. 117-122, 2001.

PARKER, W. S.; PLUMMER, M. V.Population ecology.In: SEIGEL, R. A.; COLLINS, J. T.; NOVAK, S. S. (Ed.). Snakes: ecology and evolutionary biology. New York: MacMillan Publ. Co., 1987. p. 253-301.

PEARSON, D. J.; SHINE, R.; WILLIAMS, A. Geographic variation in sexual size dimorphism within a single snake species (Morelia spilota, Pythonidae). Oecologia, v. 131, n. 3, p. 418-426, 2002.

PETERS, J. A.; OREJAS-MIRANDA, B. Catalogue of the Neotropical Squamata: Part I, Snakes. revised edition (originally published 1970), addenda and corrigenda by Vanzolini, P. E. Washington, D.C.: Smithsonian Institution, 1986. 347p.

PIANKA, E. R. Evolutionary ecology. 6. ed. San Francisco: Benjamin-Cummings, AddisonWesley-Longman., 2000. 512 p.

PIZZATO, L; MARQUES, O.A.V. Reproductive biology of the false coral snake Oxyrhopus guibei (Colubridae) from southeastern Brazil. Amphib-Reptilia, v. 23, p. 495-504, 2002.

PIZZATTO, L.; ALMEIDA-SANTOS, S. M.; MARQUES, O. A. V. Biologia reprodutiva de serpentes brasileiras. In. NASCIMENTO, L. B.; OLIVEIRA, M. E. (Ed.). Herpetologia no BrasilII. Belo Horizonte: Sociedade Brasileira de Herpetologia, 2007. p. 201-221.

PIZZATTO, L.; ALMEIDA-SANTOS, S. M.; SHINE, R. Life-history adaptations to arboreality in snakes. Ecology.v.88, p. 359-366, 2007. 
PIZZATTO, L.; JORDÃO, R.; MARQUES, O.A.V. Overview of reproductive strategies in Xenodontini (Serpentes: Colubridae: Xenodontinae) with new data for Xenodon neuwiedi and Waglerophis merremii. J. Herpetol. v. 42, p. 153-162, 2008.

POUGH, F. H.; GROOVES, J. D. Specialization of the body form and food habits of snakes. Am. Zool., v. 23, n. 2, p. 443-454, 1983.

POUGH, F. H.; ANDREWS, R. M.; CADLE, J. E.; CRUMP, M. L.; SAVITZKY, A. H.; WELLS, K. D. Herpetology. New Jersey: Prentice-Hall Inc., 2001. 612p.

PUORTO, G.; SAZIMA, I.; LAPORTA-FERREIRA, I. L. Serpentes na selva de pedra. Ciência Hoje, v. 13, n. 76, p. 66-67, 1991.

QUINN, H. R. Reproduction and growth of the Texas coral snake (Micrurus fulvius tenere). Copeia, v. 1979, n. 3, p. 453-463, 1979.

REISERER, R.S.; SCHUETT, G.W.; EARLEY, R.L. Dynamic aggregations of newborn sibling rattlesnakes exhibit stable thermoregulatory properties. J. Zool., v. 274, p. 277-283, 2008.

RODRIGUEZ-ROBLES, J. A. Feeding ecology of North American gopher snakes (Pituophis catenifer, Colubridae). Biol. J. Linn. Soc. Lond., v. 77, n. 2, p. 165-183, 2002.

SAINT-GIRONS, H. Spermatogènese et évolution cyclique des caractères sexuels secondaires chez les squamata. Ann. Sci. Nat. Zool. Biol. Anim., v.5, p. 461-478, 1963.

SAINT-GIRONS, H. Reproductive cycles of male snake and their relationships with climate and female reproductive cycles. Herpetologica, v. 38, n. 1, p. 5-16, 1982.

SALOMÃO, M. G.; ALMEIDA-SANTOS, S. M.; PUORTO, G. Activity pattern of Crotalus durissus (Viperidae, Crotalinae): feeding, reproduction and snakebite. Stud. Neotrop.FaunaEnviron., v. 30, n. 2, p. 101-106, 1995.

SALOMÃO, M. G.; ALMEIDA-SANTOS, S. M. The reproductive cycle in male neotropical rattlesnake (Crotalus durissus terrificus). In: CAMPBELL, J. A.; BRODIE JR, E. D. (Ed.).Biology of the pitvipers. Arlington: Selva Publ., Univ. Texas, 1992. p. 506-514. 
SANT'ANNA, S. S. Hábito alimentar da cascavel, Crotalus durissus no sudeste brasileiro (Serpentes, Viperidae). 64f. Dissertação (Mestrado em Zoologia). Instituto de Biociências, Universidade Estadual Paulista, Rio Claro, 1999.

SANT'ANNA, S. S.; ABE, A. S. Diet of rattlesnake Crotalus durissus in southeastern Brazil (Serpentes, Viperidae).Stud. Neotrop.FaunaEnviron., v. 42, n. 3, p. 169-174, 2007.

SANT'ANNA, S. S.; NICOLETI, A. F.; BETKOWSKY, S. E.; GREGO, K. F.; FERNANDES, W. Reproductive aspects of Bothrops leucurus (Serpentes, Viperidae): male combat, mating and litters. Resumos,. IX Reunião Científica Anual do Instituto Butantan, São Paulo, 2007.1 CDROM.

SAWAYA, R. J. História natural e ecologia das serpentes de cerrado da região de Itirapina, SP. 145 f. Tese (Doutorado em Ecologia) - Instituto de Biologia, Universidade Estadual de Campinas, Campinas, 2004.

SAZIMA, I. Um estudo de biologia comportamental da jararaca, Bothrops jararaca, com uso de marcas naturais. Mem.Inst. Butantan, v. 50, n. 3, p. 83-99, 1988.

SAZIMA, I. Feeding behavior of the snail-eating snake Dipsas indica.J. Herpetol., v. 23, n. 4, p. 464-468, 1989.

SAZIMA, I. Caudal luring in two neotropical pitvipers, Bothrops jararaca and B. jararacussu. Copeia, v. 1991, n. 1, p. 245-248, 1991.

SAZIMA, I. Natural history of the jararaca pitviper, Bothrops jararaca, in southeastern Brazil. In: CAMPBELL, J. A.; BRODIE JR, E. D. (Ed.).Biology of the pitvipers. Arlington: Selva Publ., 1992. p. 199-216.

SAZIMA, I,; MARTINS,M. Presas grandes e serpentes jovens: quando os olhos são maiores que a boca. Mem.Inst.Butantan, v.52, p. 73-39.

SAZIMA, I.; STRÜSSMANN, C. Necrofagia em serpentes brasileiras: exemplos e previsões. Rev. Bras. Biol., v. 50, n. 2, p. 463-468, 1990. 
SAZIMA, I.; HADDAD, C. F. B. Répteis da Serra do Japi: notas sobre história natural. In: MORELLATO, L. P. C. (Ed.). História natural da Serra do Japi: ecologia e preservação de uma área florestal no sudeste do Brasil. Campinas: Ed. UNICAMP, 1992. p. 212-236.

SCARTOZZONI, R.R. Estratégias reprodutivas e ecología alimentar de serpentes aquáticas da tribo Hydropsini (Dipsadidae, Xenodontonae).160p.Tese (Doutorado em Biotecnologia) - Instituto de Ciências Biomédicas, Universidade de São Paulo, São Paulo, 2009.

SCHUETT, G. W. Is long-term sperm storage an important component of the reproductive biology of temperate pitvipers? In: CAMPBELL, J. A.; BRODIE JR, E. D. (Ed.).Biology of the pitvipers. Arlington: Selva Publ., Univ. Texas, 1992. p. 169-184.

SCHUETT, G. W.; GILlingHAM, J. C. Sperm storage and multiple paternity in the copperhead, Agkistrodon contortrix. Copeia, v. 1986, n. 3, p. 807-811, 1986.

SCHWARTZ, J. M.; McCRACKEN, G. F.; BURGHARDT, G. M. Multiple paternity in wild populations of the garter snake, Thamnophis sirtalis. Behav.Ecol. Sociobiol., v. 25, n. 4, p. 269-273, 1989.

SEIGEL, R. A.; FITCH, H. S. Ecological patterns of relative clutch mass in snakes. Oecologia, v. 61, n. 3, p. 293-301, 1984.

SEIGEL, R. A.; FORD, N. B. Reproductive ecology. In: SEIGEL, R. A.; COLLINS, J. T.; NOVAK, S. S. (Ed.). Snakes: ecology and evolutionary biology. New York: MacMillan Publ. Co., 1987. p. 210-252.

SEIGEL, R. A.; FITCH, H. S.; FORD, N. B. Variation in relative clutch mass in snakes among and within species. Herpetologica, v. 42, n. 2, p. 179-185, 1986.

SEXTON, O. The distribution of Bothrops atrox in relation to food supply.Bol. Mus. Cienc. Nat, v. 2, p. 47-54, 1956/1957.

SHINE, R. Reproduction in Australian Elapid snakes. I. Testicular cycles and mating seasons. Aust. J. Zool., v. 25, n. 4, p. 647-653, 1977a. 
SHINE, R. Reproduction in Australian Elapid snakes. II. Female reproductive cycles. Aust. J. Zool., v. 25, n. 4, p. 655-666, 1977b.

SHINE, R. Grow rates and sexual maturation in six species of Australian elapid snakes. Herpetologica, v. 34, n. 1, p. 73-79, 1978.

SHINE, R. "Costs" of reproduction in reptiles. Oecologia, v. 46, n. 1, p. 92-100, 1980a.

SHINE, R. Comparative ecology of three Australian snake species of the genus Cacophis (Serpentes: Elapidae). Copeia, v. 1980b, n. 4, p. 831-838, 1980 b.

SHINE, R. The evolution of viviparity in reptiles: an ecological analysis. In: GANS, C.; BILLETT, F. (Ed.). Biology of the reptilia. NY: John Wiley, 1985. v.15, p. 605-694.

SHINE, R. Ecology of a low-energy specialist: food habits and reproductive biology of the arafura filesnake (Acrochordidae). Copeia, v. 1986, n. 2, p. 424-437, 1986.

SHINE, R. Constraints on reproductive investment: a comparison between aquatic and terrestrial snakes. Evolution, v. 42, n. 1, p. 17-27, 1988.

SHINE, R. Intersexual dietary divergence and the evolution of sexual dimorphism in snakes. Am. Nat., v. 138, n. 1, p. 103-122, 1991.

SHINE, R. Sexual dimorphism in snakes. In: SEIGEL, R. A.; COLLINS, J. T. (Ed.). Snakes: ecology and behavior. New York: McGraw-Hill Inc., 1993. p. 49-86.

SHINE, R. Sexual size dimorphism in snakes revisited. Copeia, v. 1994, n. 2, p. 326-346, 1994.

SHINE, R. Reproductive strategies in snakes. Proc. R. Soc. Lond. B Biol. Sci., v. 270, p. $995-1004,2003$.

SHINE, R.; CREWS, D. Why male garter snake have small heads: the evolution and endocrine control of sexual dimorphism. Evolution, v.42, n. 5, p. 1105-1110, 1988. 
SHINE, R.; BRANCH, W. R.; HARLOW, P. S.; WEBB, J. K. Reproductive biology and food habits of horned adders, Bitis caudalis (Viperidae), from southern Africa. Copeia, v. 1998, n. 2, p. 391-401, 1998.

SILVA, V. X. Variação entre filhotes de representantes do complexo Bothrops neuwiedi (Serpentes, Viperidae, Crotalinae). Phyllomedusa, v. 1, n. 1, p. 11-30, 2002.

SILVA, V. X.; RODRIGUES, M. T. Taxonomic revision of the Bothrops neuwiedi complex (Serpentes, Viperidae) with description of a new species. Phyllomedusa, v. 7, n. 1, p. 45-90, 2008.

SOCIEDADE BRASILEIRA DE HERPETOLOGIA (SBH). Lista brasileira de anfíbios e répteis. In: BÉRNILS, R. S. (Org.), 2010. Brazilian reptiles: list of species. Sociedade Brasileira de Herpetologia. Disponível em: <http://sbherpetologia.org.br/checklist/checklist_brasil.asp.> Acesso em: 20 fev. 2011.

STEARNS, S. C. A new view of life-history evolution.Oikos, v. 35, n. 2, p. 266-281, 1980.

STEARNS, S. C. The evolution of life histories. New York: Oxford Univ. Press, 1992. 248 p.

STRÜSSMANN, C.; SAZIMA, I. The snake assemblage of the Pantanal at Poconé, western Brazil: faunal composition and ecological summary. Stud. Neotrop. Fauna Environ., v. 28, n. 3, p. 157-168, 1993.

TOFT, C. A. Resource partitioning in amphibians and reptiles.Copeia, v. 1985, n. 1, p. 1-21, 1985.

TOZETTI, A. M. Uso do ambiente e ecologia alimentar da cascavel (Crotalus durissus) em área de cerrado na região de Itirapina, SP. 93 f. Tese (Doutorado em Ecologia) - Instituto de Biociências, Universidade de São Paulo, São Paulo, 2006.

TOZETTI, A. M.; MARTINS, M. Habitat use by the South-American rattlesnake (Crotalus durissus) in south-eastern Brazil.J. Nat. Hist., v. 42, n. 19-20, p. 1435-1444, 2008. 
TRAVAGLIA-CARDOSO, S. R. Estratégias reprodutivas de Bothrops jararaca (Serpentes, Viperidae). 89 f. Dissertação (Mestrado em Zoologia) - Instituto de Biociências, Universidade de São Paulo, São Paulo, 2001.

TRAVAGLIA-CARDOSO, S. R. Waglerophis merremii (Boipeva). Reproduction. Herpetol.Rev., v. 38, n. 4, p. 471, 2007.

TRAVAGLIA-CARDOSO, S. R.; ALMEIDA-SANTOS, S. M. Termites nests as brood-laying sites in Crotalus durissus. Resumos, Biologia Animal. IX Reunião Científica Anual do Instituto Butantan, São Paulo, 2007. 1 CD-ROM.

TRAVAGLIA-CARDOSO, S. R.; ZELANIS, A. P. P.; FURTADO, M. F. D. Sexual dimorphism in development and venom production of the insular threatened pitviper Bothrops insularis (Serpentes: Viperidae) of Queimada Grande Island, Brazil. J. Threat. Taxa, v. 2, n. 10 ,

p. $1177-1184,2010$.

TRAVAGLIA-CARDOSO, S. R.; CHAVES, M. M. G.; MIYAJI, C. K.; SANT'ANNA, S. S.; LULA, L. A. B. M.; FERNANDES, W. Descrição da dança combate entre machos de Bothrops atrox durante a corte (Serpentes, Viperidae). Livro de Resumos. III Congresso Latino Americano de Herpetologia, Campinas, 1993. p. 66.

VALDUJO, P. H.; NOGUEIRA, C. C.; MARTINS, M. Ecology of Bothrops neuwiedi pauloensis (Serpentes: Viperidae: Crotalinae) in the Brazilian cerrado. J. Herpetol., v. 36, n. 2, p. 169-176, 2002.

VANZOLINI, P. E. Notas sobre os ofídios e lagartos da Cachoeira de Emas, no município de Pirassununga, Estado de São Paulo. Rev. Bras. Biol., v. 8, n. 3, p. 377-400, 1948.

VANZOLINI, P. E. A biometrical note on Bothrops moojeni Hoge, 1966 (Serpentes: Viperidae). An. Acad. Bras. Cienc., v. 63, n. 4, p. 389-401, 1991.

VANZOLINI, P. E.; CALLEFFO, M. E. V. On some aspects of reproductive biology of Brazilian Crotalus (Serpentes: Viperidae). Biol. Geral Exper., v. 3, n. 1, p. 3-37, 2002. 
VANZOLINI, P. E.; RAMOS-COSTA, A. M. M.; VITT, L. J. Répteis das caatingas. Rio de Janeiro: Academia Brasileira de Ciências, 1980. 161p.

VITT, L. J. Ecology of an anuran eating guild of terrestrial tropical snakes. Herpetologica, v. 39, n. 1, p. 52-66, 1983.

VITT, L.J.; VANGILDER, L.D. Ecology of snake community in the northeastern Brazil. Amphib.Reptil.v.4, p. 273-296, 1983.

VOLSOE, H. Structure and seasonal variation of the male reproductive organs of Vipera berus (L.). Spolia Zool. Mus. Hauniensis, v. 5, p. 1-157, 1944.

WHORLEY, J. R. Keys to partial mammals: a method for identifying prey items from snakes. Herp.Rev., v. 31, n. 4, p. 227-229, 2000.

ZELANIS, A.; TRAVAGLIA-CARDOSO, S. R.; FURTADO, M. F. D. Ontogenetic changes in the venom of Bothrops insularis (Serpentes, Viperidae) and its biological implication. South Am. J. Herpetol., v. 3, n. 1, p. 43-50, 2008.

ZUG, G. R. Herpetology: an introductory biology of amphibians and reptiles. New York: Academic Press Inc., 1993. 527p. 


\section{Anexo A - Viperídeos coletados na Fazenda Santa Elisa, Munhoz, Minas Gerais.}

Fig. A 1 - B. neuwiedi (fêmea jovem). Momento do encontro. Coletada nas edificações da Fazenda Santa Elisa, exposto ao sol sobre uma floreira (15horas).

Fig. A 2 - B. neuwiedi (macho jovem). Momento do encontro. Em repouso, sob pedra (18h12min).

Fig. A 3 - B. neuwiedi (fêmea adulta). Momento do encontro. Enrodilhada na beira da estrada (período da tarde).

Fig. A 4 - B. neuwiedi (fêmea adulta). Momento do encontro. Enrodilhada sobre tronco de árvore caído. Exibindo comportamento de esconder a cabeça, que precedeu bote (17h43min).

Fig. A 5a, 5b e 5c - B. neuwiedi (fêmea adulta) Momento do encontro. Encontrada em locomoção na borda de área de capoeira. Ao sentir a aproximação se enrodilhou, depois tentou a fuga, persistindo a ameaça, desferiu o bote (aproximadamente às 18 horas).

Fig. A $6-B$. neuwiedi. Ninhada de fêmea recém capturada, nascida na caixa de transporte.

Fig. A 7 - B. jararaca (fêmea adulta). Momento do encontro. Enrodilhada, parcialmente exposta ao sol, encostada em tronco de araucária (período da tarde).

Fig. A 8 - B. jararaca (fêmea adulta).

Fig. A 9 - B. jararaca (fêmea adulta).

Fig. A 10 - Crotalus durissus (macho adulto). Momento do encontro. Enrodilhado dentro de um buraco sob uma árvore, na beira da estrada (aproximadamente 17 horas).

Fig. A $11-B$. neuwiedi (filhote).

Fig. A $12-B$. neuwiedi (filhote).

Fig. A $13-B$. neuwiedi (filhote).

Fig. A $14-B$. neuwiedi (filhote). 


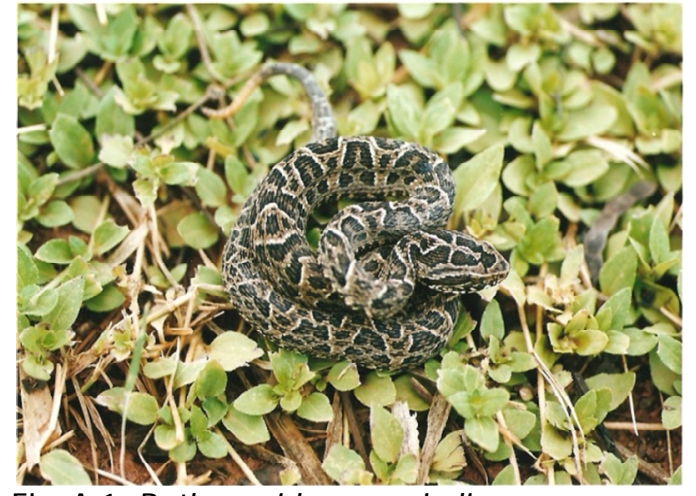

Fig. A 1: Bothropoides neuw iedi.

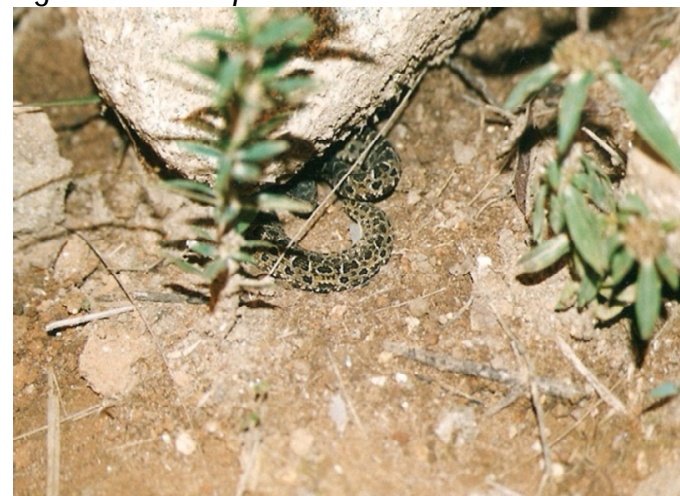

Fig. A 2: Bothropoides neuw iedi.

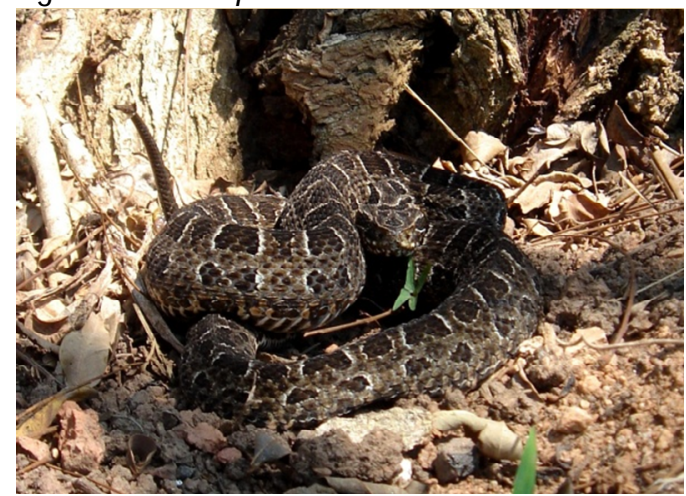

Fig. A 3: Bothropoides neuwiedi.

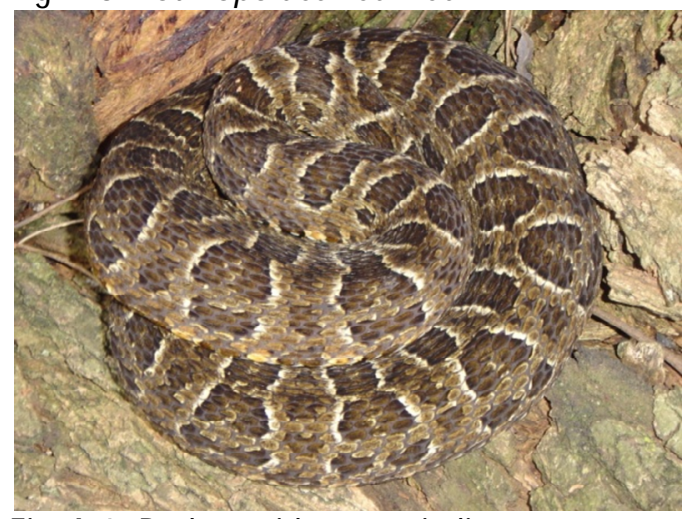

Fig. A 4: Bothropoides neuw iedi.

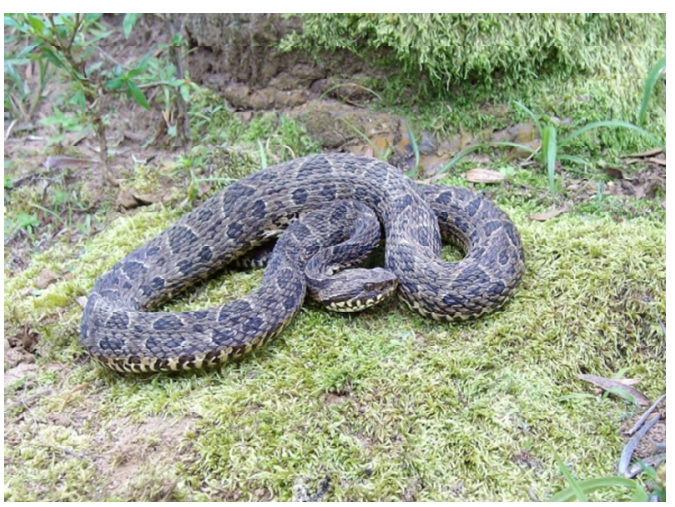

Fig.A 5a : Bothropoides neuwiedi.

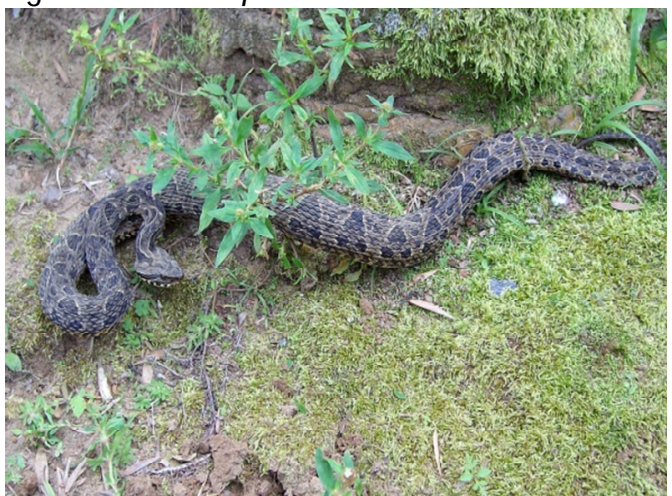

Fig. A 5b: Bothropoides neuwiedi.

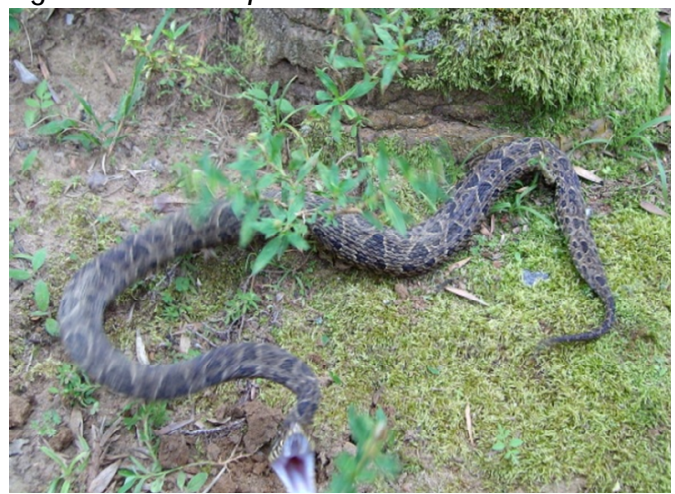

Fig. A 5c: Bothropoides neuwiedi.

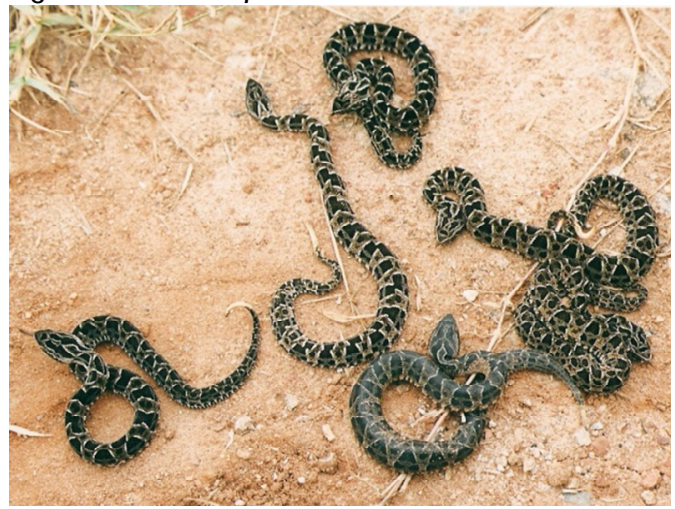

Fig. A 6: Bothropoides neuwiedi (ninhada). 
Anexo D - Comportamento de corte e acasalamento em cativeiro. Serpentes coletadas na Fazenda Santa Elisa, Munhoz, Minas Gerais.

Fig. D 1 - B. jararaca. Início do comportamento de corte com aproximação do macho.

Fig. D 2 - B. jararaca. Cópula.

Fig.D 3 - B. neuwiedi. Comportamento de corte. Macho sobre dorso da fêmea.

Fig.D 4 - B. neuwiedi. Comportamento de corte. Observar relaxamento da cloaca da fêmea.

Fig.D 5 - B. neuwiedi. Cópula.

Fig.D 6a, 6b e 6c - B. neuwiedi. Sequência do mesmo casal: comportamento de corte com macho sobre dorso da fêmea (6a), macho enlaça a cauda da fêmea e alinha as cloacas (6b) e após introdução do hemipênis (6c). 


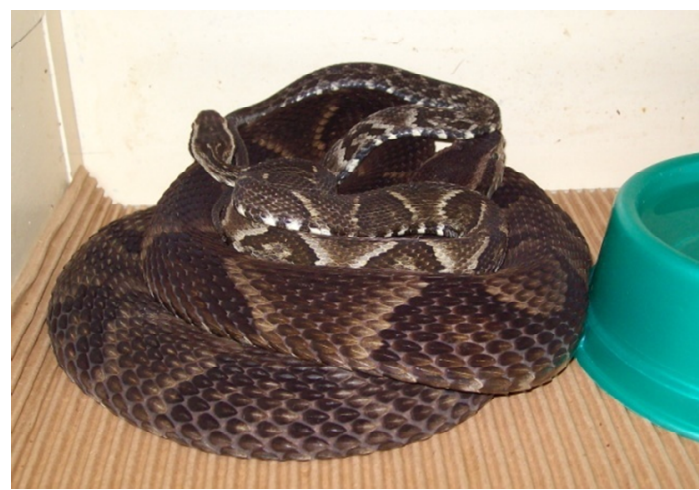

Fig. D1: B. jararaca. Corte

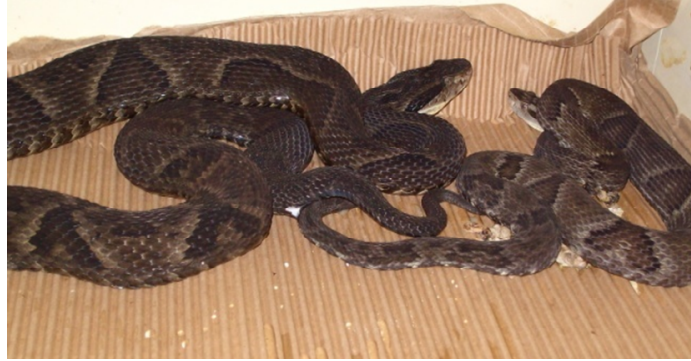

Fig. D 2: B. jararaca. Cópula.

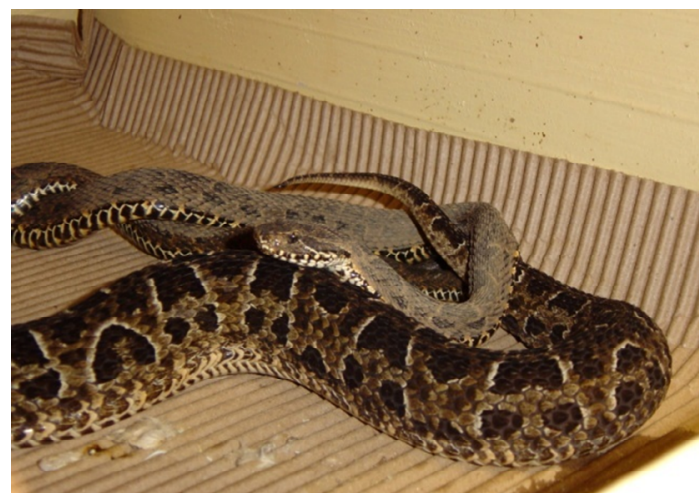

Fig. D 3: B. neuwiedi. Corte.

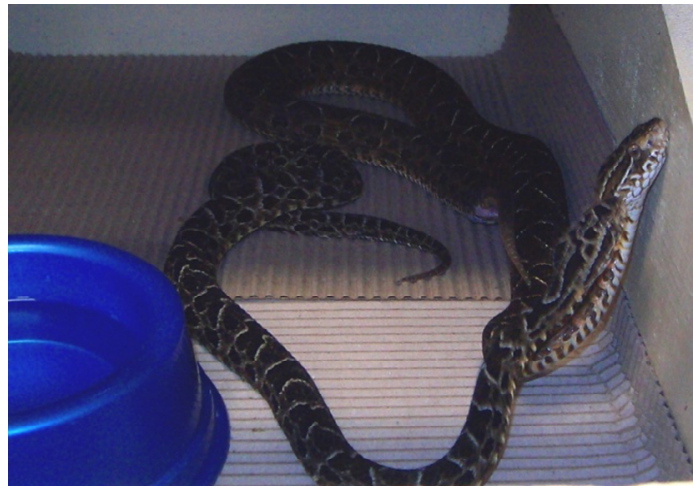

Fig. D 4: B. neuwiedi. Corte. Observar relaxamento cloacal da fêmea.

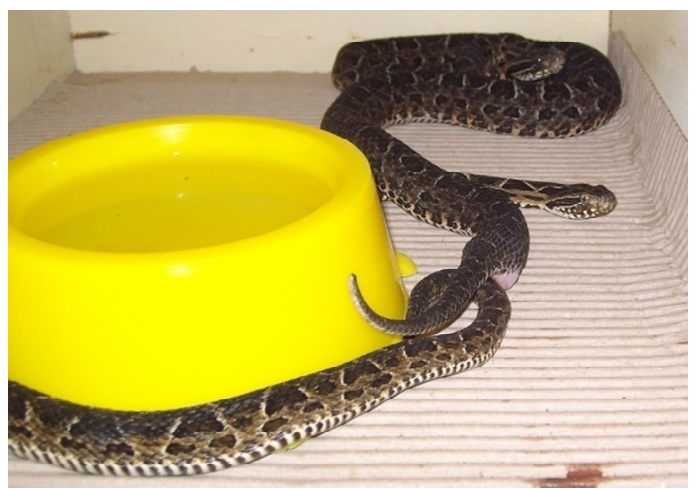

Fig. D 5: B.neuwiedi. Cópula.

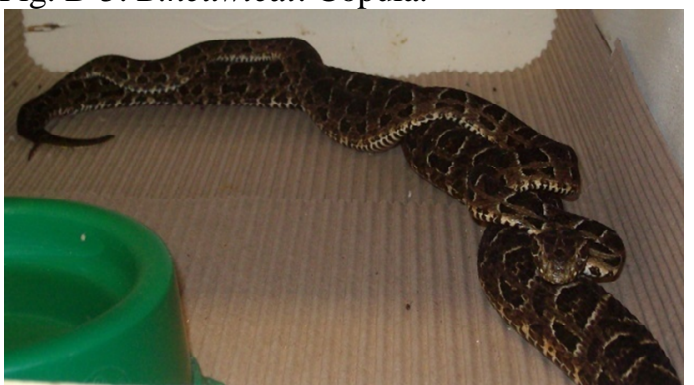

Fig. D 6a: B.neuwiedi. Corte.

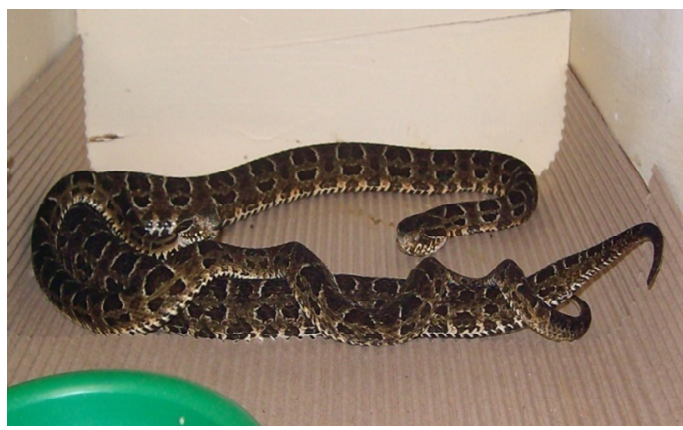

Fig. D 6b: B. neuwiedi. Alinhando cloacas.

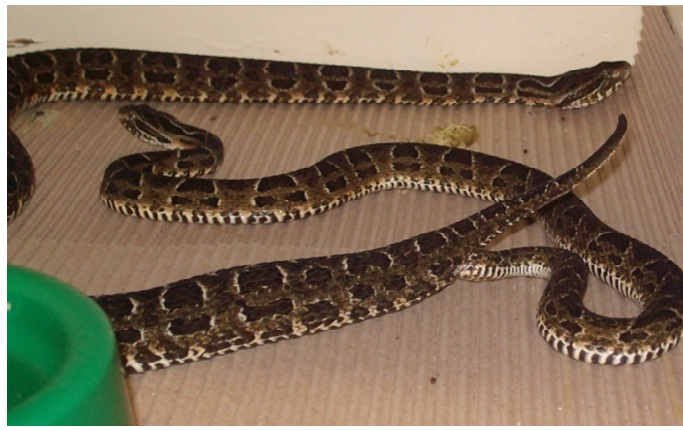

Fig. D 6c: B. neuwiedi. Cópula 
